Zweiter Beratungsgegenstand:

\title{
Eigentum, Sozialbindung und Enteignung bei der Nutzung von Boden und Umwelt
}

1. Bericht von Prof. Dr. Heinz Peter Rill, Wien

\section{Inhalt}

I. Die Rechtsquellen $\ldots \ldots \ldots \ldots \ldots \ldots \ldots \ldots \ldots \ldots \ldots$

II. Schutzobjekt der Eigentumsgarantie ............ 179

A. Die Eigentumsgarantie schützt die vermögenswerten

Privatrechte .................... 179

B. Schützt die Eigentumsgarantie auch das Vermögen als solches? ........................... 184

C. Schützt die Eigentumsgarantie auch öffentlich-rechtliche vermögenswerte Ansprüche? . . . . . . . . . . 185

D. Die Liegenschaftsverkehrsfreiheit (Art.6 StGG) schützt den rechtsgeschäftlichen Verkehr mit Grundstücken $\ldots \ldots \ldots \ldots \ldots \ldots \ldots \ldots \ldots \ldots \ldots$

III. Sozialbindung und Enteignung $\ldots \ldots \ldots \ldots \ldots \ldots \ldots 189$

A. Systematik der Eigentumseingriffe . . . . . . . . 189

B. Eigentumsbeschränkungen ............... 193

1. Eigentumsbeschränkungen nach Art.5 StGG und Art. 1 Zusatzprotokoll zur Menschenrechtskonvention ....................... 193

2. Eigentumsbeschränkungen, die den Liegenschaftsverkehr betreffen ................. 200

C. Enteignungen .................... 201

IV. Schlußbemerkung . . . . . . . . . . . . . . . . . . 204 


\section{Die Rechtsquellen}

Die verfassungsrechtliche Garantie des Eigentums in Österreich geht - wie die meisten unserer Grundrechte - auf das Jahr 1867 zurück. Der Art. 5 des Staatsgrundgesetzes über die allgemeinen Rechte der Staatsbürger der im Reichsrathe vertretenen Königreiche und Länder (StGG), das 1920 Teil der Bundesverfassung der Republik Österreich wurde ${ }^{1}$, lautet: „Das Eigentum ist unverletzlich. Eine Enteignung gegen den Willen des Eigentümers kann nur in den Fällen und in der Art eintreten, welche das Gesetz bestimmt." Als lex specialis garantiert Art. 6 des Staatsgrundgesetzes allen Staatsangehörigen, daß sie Liegenschaften aller Art erwerben und über diese frei verfügen dürfen. Einen ausdrücklichen Gesetzesvorbehalt enthält dieses Grundrecht nur für Beschränkungen für bestimmte kirchliche Einrichtungen. 1964 trat als Bestimmung im Bundesverfassungsrang der Art. 1 des (ersten) Zusatzprotokolls zur Menschenrechtskonvention (ZP) hinzu ${ }^{2}$, der den Rechtsunterworfenen nach dem derzeitigen Stand der Straßburger Rechtsprechung keine günstigere Position als die beiden aus monarchischer Zeit stammenden Grundrechte gewährt.

Als boden- und umweltpolitische Entscheidungen, die eine bundesverfassungsrechtliche Verankerung gefunden haben, besitzen zwei kompetenzrechtliche Anordnungen und das Bekenntnis zum Umweltschutz für die Auslegung der Eigentumsgrundrechte nicht zuletzt im Blickwinkel unseres Themas Relevanz. Die Bundesverfassung ermächtigt die Landesgesetzgeber, den Verkehr mit land- und forstwirtschaftlichen Grundstücken ${ }^{3}$ und den Liegenschaftserwerb durch Ausländer ${ }^{4}$ verwaltungsbehördlichen Beschränkungen zu unterwerfen, was das Grundrecht auf freien Liegenschaftsverkehr - jedenfalls explicite - nicht zuläßt. 1984 wurde das Bundesverfassungsgesetz über den umfassenden Umweltschutz erlassen ${ }^{5}$. Seinen normativen Gehalt muß man in der Legaldefinition dieses Schutzes ${ }^{6}$ und in dem

1 Art. 149 Abs. 1 B-VG.

2 Art. II Z7 BVG BGBl. 1964/59.

${ }^{3}$ Rechtssatz des Kompetenzfeststellungserk. des VfGH (Slg. 2658/1954): „Die Regelung des Verkehrs mit land- und forstwirtschaftlichen Grundstücken ... steht ... gemäß Art. 15 Abs. 1 B-VG in Gesetzgebung und Vollziehung den Ländern zu." Der Rechtssatz hat nach h. A. Bundesverfassungsrang.

${ }^{4}$ Art. 10 Abs. 1 Z6 B-VG.

5 BGBl. 1984/491.

6 $\$ 1$ Abs. 2: „Umfassender Umweltschutz ist die Bewahrung der natürlichen Umwelt als Lebensgrundlage des Menschen vor schädlichen Einwirkungen. Der umfassende Umweltschutz besteht insbesondere in Maßnahmen zur Reinhaltung der Luft, des Wassers und des Bodens sowie zur Vermeidung von Störungen durch Lärm." 
Satz suchen: „Die Republik Österreich (Bund, Länder und Gemeinden) bekennt sich zum umfassenden Umweltschutz. "7 Dem sogenannten Konrad-Lorenz-Volksbegehren, das etwa 353000 Wahlberechtigte unterstützt haben ${ }^{8}$ und das auf die Schaffung eines Grundrechts auf umfassenden Umweltschutz gerichtet war', blieb ein Erfolg versagt.

Welchen Schutz die Eigentumsgrundrechte und die erwähnten boden- und umweltschutzrechtlichen Regelungen im Gesamtzusammenhang der Bundesverfassung dem Eigentum gewähren und welchen Aktionsradius sie dem einfachen Gesetzgeber bei der Bewältigung der aktuellen boden- und umweltpolitischen Probleme eröffnen, möchte ich nun unter Orientierung an jenen Schwerpunkten darlegen, die unserem Vorstand und den Berichterstattern wesentlich erschienen.

\section{Schutzobjekt der Eigentumsgarantie}

\section{A. Die Eigentumsgarantie schützt die vermögenswerten Privatrechte}

Art. 5 des Staatsgrundgesetzes und Art. 1 des Zusatzprotokolls zur Menschenrechtskonvention schützen - darin sind sich Lehre ${ }^{10}$ und Rechtsprechung ${ }^{11}$ einig - alle vermögenswerten Privatrechte. Ob sich der Schutz darin erschöpft, lasse ich vorerst offen. Der Grundrechtsgesetzgeber von 1867 hat sich bei der Verwendung des Begriffs Eigentum am ABGB orientiert. Eine andere Orientierung ist durch nichts indiziert. Art. 5 stellt das Eigentum, wie es $\$ 353$ ABGB abgrenzt, unter Schutz ${ }^{12}$. $\$ 353$ lautet: „Alles, was jemandem zugehört, alle seine körperlichen und unkörperlichen Sachen, heißen sein

$7 \$ 1$ Abs. 1.

8 ABl. zur WrZtg. vom 22.3.1985.

9 Text des Begehrens in 607 d. Blg. z.d. StenProt. d. Nationalrats XVI. GP.

$10 \mathrm{Vgl}$. die Nachweise bei Aicher, Grundfragen der Staatshaftung bei rechtmäßigen hoheitlichen Eigentumsbeeinträchtigungen (1978) 302 Fn.228, Adamovich/ Funk, Österreichisches Verfassungsrecht ${ }^{3}$ (1985) 421; Walter/Mayer, Grundriß des Verfassungsrechts ${ }^{6}$ (1988) Rdn. 1370 und Ermacora, Grundriß der Menschenrechte in Österreich (1988) Rdn. 993.

11 Vgl. die Nachweise bei Aicher (Fn. 10) 302 Fn. 229 und bei Öblinger, Eigentum und Gesetzgebung in Österreich, EuGRZ 1984, 557 (560f.) sowie aus jüngster Zeit VfSlg. 11689/1988.

12 Das ABGB kennt in $\$ 354$ auch einen engeren Eigentumsbegriff (Eigentum an körperlichen Sachen). Für eine Beschränkung der Eigentumsgarantie auf das Sacheigentum läßt sich ein einsichtiger Grund nicht finden. So auch Aicher (Fn. 10) $305 \mathrm{ff}$. 
Eigentum." und definiert damit Eigentum als Inbegriff der vermögenswerten Privatrechte ${ }^{13}$. Eben diese Rechte sind auch unter den Eigentumsbegriff des Art. 1 des Zusatzprotokolls subsumierbar ${ }^{14}$, der nach herrschender Auffassung im Sinne des Völkergewohnheitsrechts $\mathrm{zu}$ interpretieren ${ }^{15}$ ist.

Welche vermögenswerten Privatrechte den Rechtsunterworfenen zukommen, hängt von der zivilen Vermögensrechtsordnung ab, deren Gestaltung der Gesetzgebung obliegt. Anders gewendet, der Inhalt des Eigentums wird durch die Gesetze bestimmt. Dies gilt - wenngleich nicht ausdrücklich normiert wie in Art. 14 des Bonner GG auch in Österreich ${ }^{16}$. Ebensowenig wie in der BRD $^{17}$ steht aber deshalb der Umfang des verfassungsrechtlichen Eigentumsschutzes zur unumschränkten Disposition des einfachen Gesetzgebers ${ }^{18}$. Vielmehr hat er sich bei der Bestimmung des Inhalts des Eigentums innerhalb nicht allzu weit gesteckter Schranken zu bewegen.

Was den Art. 5 StGG anbelangt, sind diese Schranken in den wesentlichen Elementen der präkonstitutionellen Bestimmung des Inhalts des Eigentums zu sehen ${ }^{19}$. Das Prädikat "wesentlich" verdienen jene Elemente, auf die die prägenden Grundgedanken dieser präkonstitutionellen Ordnung hinweisen und die im Lichte des Telos der Eigentumsgarantie des Art. 5 Bedeutung haben, wie es sich vor

${ }^{13} \mathrm{Vgl}$. die Definition von körperlichen und unkörperlichen Sachen in $\$ 292$ ABGB.

${ }^{14}$ Böckstiegel, Die allgemeinen Grundsätze des Völkerrechts über die Eigentumsentziehung (1963) 26ff.; Frowein/Peukert, EMRK-Kommentar (1985) Rdn. 5-7 zu Art. 1 des 1.ZP; Dolzer, Eigentum, Enteignung und Entschädigung im geltenden Völkerrecht (1985) 170.

15 Böckstiegel (Fn. 14) 22 ff.; Frowein/Peukert (Fn. 14) Rdn. 4 zu Art. 1 des 1.ZP; Dolzer (Fn. 14) $170 \mathrm{f}$.

${ }_{16}$ Dies ergibt sich jedoch nicht - wie Aicher (Fn. 10) 93 meint - mangels einer ausdrücklichen Regelung, wie sie Art. 14 Abs. 1 Satz 2 GG enthält, „aus einem ,denknorwendig' angenommenen Gesetzesvorbehalt“, sondern daraus, daß der Eigentumsbegriff des $₫ 353 \mathrm{ABGB}$, an dem sich Art. 5 StGG orientiert, ein Verweisungsbegriff ist. Zur deutschen Rechtslage vgl. insbesondere Rudolf Wendt, Eigentum und Gesetzgebung (1985) $33 \mathrm{ff}$. und Rüdiger Breuer, Die Bodennutzung im Konflikt zwischen Städtebau und Eigentumsgarantie (1976) $19 \mathrm{ff}$.

17 Papier in Maunz/Dürig et al., Grundgesetz. Kommentar (Loseblatt $1958 \mathrm{ff}$.), Rdn. 252-278 zu Art. 14; Brewer (Fn. 16) 19 ff.; Wendt (Fn. 16) $144 \mathrm{ff}$.

18 Aicher (Fn. 10) 86ff.; Öblinger (Fn.11) EuGRZ 1984, 557 (569f.); Karl Korinek, Zur Lage des Eigentumsschutzes in Österreich, Wirtschaftspolitische Blätter (WipolBl.) 1982, 125 (127f.)

19 Aicher (Fn. 10) 93 spricht in diesem Zusammenhang vom Leitbild eines durch einfachgesetzliche Normierung auszugestaltenden Sozialbezuges. 
dem historischen Hintergrund von 1867 und auf Grund des Zusammenhangs der Eigentumsgarantie mit den anderen Grundrechten des Wirtschaftslebens darstellt. Danach ist die Eigentumsgarantie - wie vor allem Karl Korinek ${ }^{20}$ zutreffend herausgearbeitet hat - darauf gerichtet, eine grundsätzlich marktwirtschaftliche Ordnung zu gewährleisten. Art. 5 ist ein Kind des Liberalismus, ohne daß aber wie in Österreich seit jeher unbestritten ist - diese Abkunft zur verfassungsrechtlichen Verankerung einer liberalistischen Wirtschaftsordnung geführt hätte ${ }^{21}$. Die Schranken für die einfachgesetzliche Bestimmung des Inhalts des Eigentums nach Art. 1 des Zusatzprotokolls sind aus dem Völkerrecht zu gewinnen.

Schließlich unterliegen Änderungen der Inhaltsbestimmung des Eigentums zu Lasten des Eigentümers, also Inhaltsbestimmungen, die zugleich Schrankenbestimmungen $\operatorname{sind}^{22}$, dem aus der Grundrechtsordnung abzuleitenden Gebot, daß Eigentumseingriffe dem Verhältnismäßigkeitsgrundsatz zu entsprechen haben ${ }^{23}$.

Lassen Sie mich nun einige Aussagen zu dieser Schrankenziehung machen, die für unser Thema relevant sind. $\mathrm{Da}$ ist zunächst einmal festzuhalten: Die Eigentumsgarantie beschränkt sich angesichts ihrer dargelegten Zielsetzung nicht auf das sogenannte persönliche Eigentum, sondern umfaßt auch das Eigentum an den Produktionsmitteln Boden und Kapital, welcher Größenordnung immer ${ }^{24}$.

${ }^{20}$ Karl Korinek, Verfassungsrechtlicher Eigentumsschutz und Raumplanung (1977) 15, Ermacora (Fn. 10) Rdn. 992; Karl Wenger, Grundriß des österreichischen Wirtschaftsrechts I (1989) Rdn. 176 f.; Pernthaler, Raumordnung und Verfassung III (1990) 400.

${ }^{21}$ Entgegen Öblinger (Fn. 11) 562 ist eine liberalistische Deutung des Art.5 nicht deshalb verfehlt, weil man „auch das Rezeptionsdatum“ der Übernahme des StGG ins republikanische Bundesverfassungsrecht im Jahre 1920 „in Betracht ziehen muß“. Denn eine Festschreibung des liberalistischen Wirtschaftskonzepts hat nicht stattgefunden. Die Gesetzesvorbehalte sind vom Vertrauen in die Gesetzgebung getragen und eröffnen ein weites Feld von Gestaltungsmöglichkeiten. Es ist daher entgegen Öblinger (ebenda) nicht erforderlich, „jene (einfach-)gesetzlichen Gestaltungsmöglichkeiten, die unter der Verfassung der Monarchie ... als verfassungsrechtlich möglich und zulässig angesehen wurden“, (= „dem Wandel des Eigentums, wie er in der Gesetzgebung nach 1867 zum Ausdruck kommt“) bei der Interpretation des Art. 5 zu berücksichtigen, um eine Deutung des Art. 5 i.S. der Vorstellungswelt des Liberalismus zu vermeiden.

22 Zur Notwendigkeit und Möglichkeit der Unterscheidung zwischen Inhaltsbestimmung und Schrankenziehung siehe Wendt (Fn. 16) $147 \mathrm{ff}$.

${ }^{23}$ Papier (Fn. 17) Rdn. 258 zu Art. 14; Wendt (Fn. 16) 280 ff.; Breuer (Fn. 16) $33 \mathrm{ff}$.

${ }^{24}$ Korinek (Fn. 20) $11 \mathrm{ff}$. 
Ferner sind Grund und Boden ohne Einschränkung eigentumsfähig. Der einfache Gesetzgeber verletzte die Verfassung, wenn er zum Beispiel, einem Vorschlag Hans Christoph Binswangers ${ }^{25}$ folgend, „kulturell wertvolle Gebäude ... aus dem Komplex möglicher privater Eigentumsinhalte“ ausschlösse.

Das Sacheigentum ist in der präkonstitutionellen Ordnung als ein grundsätzlich volles Herrschaftsrecht gestaltet ${ }^{26}$. Exemtionen aus diesem umfassenden Recht müssen in der präkonstitutionellen Eigentumsordnung angelegt sein, um im Rahmen einfachgesetzlicher Inhaltsbestimmung verfügt werden zu dürfen.

So ist im Hinblick auf das Bergregal, das der Grundrechtsgesetzgeber vorfand ${ }^{27}$, davon auszugehen, daß die bergbauliche Nutzung der Bodensubstanz dem Grundeigentümer nicht zur Gänze verfassungsrechtlich vorbehalten ist. Aus der Konzeption dieses Regals ist abzuleiten, daß der einfache Gesetzgeber Mineralien wegen ihres nutzbaren Gehalts und der damit verbundenen volkswirtschaftlichen Bedeutung der Nutzungsbefugnis des Grundeigentümers vorenthalten und sich selbst oder einem tauglichen Bewerber vorbehalten darf ${ }^{28}$. Die mit den Bewilligungen bzw. durch Vereinbarung mit dem Staat erworbenen Bergbauberechtigungen sind vermögenswerte Privatrechte ${ }^{29}$. Sie machen den Bergbauberechtigten zum vertikalen Nachbar des Grundeigentümers ${ }^{30,31}$. Die erwähnten bergrechtlichen Gestaltungsmöglichkeiten haben auch vor dem völkerrechtlichen Eigentumsbegriff des Art. 1 des Zusatzprotokolls Bestand.

Beim Grundwasser und bei dem auf einem Grundstück zutage tretenden Wasser liegen die Dinge anders, soweit es sich nicht um die dem Bergrecht unterworfenen Gewässer handelt. Nach der präkonsti-

25 Eigentum und Eigentumspolitik (1978) 66.

${ }^{26}$ Aicher (Fn. 10) $26 \mathrm{ff}$.

$27 \$ 3$ Allgemeines BergG ÖRGBl. 1854/146.

28 Es ist daher nicht verfassungswidrig, wenn in Österreich heute Kohlenwasserstoffe und Uran bundeseigene mineralische Rohstoffe sind und viele andere mineralische Rohstoffe als "bergfreie“ Mineralien mit behördlicher Bewilligung von jedem erschlossen und gewonnen werden dürfen, der bestimmte Voraussetzungen erfüllt.

${ }^{29}$ Schurfbewilligungen sind gem. $\$ 22$ BergG privatrechtlich übertragbar. Bergbauberechtigungen sind gem. $\$ 49$ leg. cit. unbewegliche Sachen. Über die bundeseigenen Mineralien verfügt der Bund gem. $\$ 77$ BergG als Träger von Privatrechten.

${ }^{30}$ Zum Ausdruck vertikaler Nachbar: Leisner, Bestandsgarantie des Eigentums - vom Bergrecht unterminiert? DVBl. 1988, 555 (559).

${ }^{31}$ Bei der sog. Zugangsenteignung ist daher das Vorliegen eines öffentlichen Interesses nach Enteignungsgrundsätzen nicht erforderlich; vgl. Leisner (Fn. 30). 
tutionellen Eigentumsordnung war die Nutzung des Grundwassers und des Quellwassers dem Grundeigentümer vorbehalten, und zwar nicht nur als Nebenfolge einer Bodennutzung ${ }^{32}$. Im Hinblick auf das Telos der Eigentumsgarantie und weil es zur Sicherung einer funktionsfähigen Wasserwirtschaft nicht notwendig ist, die Nutzung der genannten Gewässer einer öffentlich-rechtlichen dem Eigentumsschutz entzogenen Benutzungsordnung zu unterstellen, erachte ich die in Rede stehende Nutzungsbefugnis als vom verfassungsfesten Inhalt des Eigentums erfaßt ${ }^{33}$.

Aus den gleichen Gründen ist auch die Nutzung des Umweltmediums Luft zum Kernbestand des Eigentums zu zählen ${ }^{34}$.

Während die Grundwasser- und Luftproblematik in Österreich eigentumsgrundrechtlich bisher überhaupt nicht thematisiert wurden, läßt sich hinsichtlich der Frage, ob die Befugnis zur baulichen Nutzung aus dem Grundeigentum erfließe, eine beinahe einhellige Zustimmung des Schrifttums ${ }^{35}$ zur ständigen Rechtsprechung des Verfassungsgerichtshofs ${ }^{36}$ feststellen, daß die bauliche Nutzung zum Inhalt des Grundeigentums gehört. Diese zutreffende Auffassung ist dahin zu verstehen, daß die Verknüpfung von Grundeigentum und Befugnis zur baulichen Nutzung verfassungsrechtlich festgeschrieben ist.

Zuletzt sei dem Recht am sogenannten eingerichteten und ausgeübten Gewerbebetrieb ${ }^{37}$ Aufmerksamkeit geschenkt. Ist das Recht am

32 Waren nach dem ReichwasserrechtsG 1869 ÖRGBI. 1869/93 die Eigentumsverhältnisse am Grundwasser in vielerlei Hinsicht umstritten, so war doch klar, daß dieses letztlich dem Grundeigentümer vorbehalten ist (vgl. dazu Klang in Klang II 151 m.w. N.). Seit Erlassung des WasserrechtsG 1934 BGBl. 1934 II 316 "gehört“ das Grundwasser als Privatgewässer kraft ausdrücklicher Normierung dem Grundeigentümer, hat dieser also ein vermögenswertes Privatrecht auf Nutzung des Grundwassers.

${ }^{33}$ Ebenso für Deutschland: Papier (Fn. 17) Rdn. 371 a-371 c, Wendt (Fn. 16) $211 \mathrm{ff}$; a. M. z. B. Kloepfer, Umweltrecht (1989) 609.

${ }^{34}$ Die einfachgesetzlichen Regelungen über Emissionsbegrenzungen und Immissionsschutz lassen sich nicht als eine öffentlich-rechtliche Benutzungsordnung deuten, nach der die Benutzung des Umweltmediums Luft auf hoheitlicher Zuteilung beruhte. Vgl. Stephan Schwarzer, Die Betriebsanlage im Spannungsfeld zwischen Wirtschaftssicherung und Umweltschutz (1991) $218 \mathrm{f}$.

${ }^{35}$ Aicher (Fn. 10) $367 \mathrm{ff}$; Krzizek, System des österreichischen Baurechts I (1971) 82f. A. M. nur Fröbler/Oberndorfer, Positivplanung und Eigentumsrecht (1979) $47 \mathrm{ff}$., dieselben, Österreichisches Raumordnungsrecht I (1975) $159 \mathrm{f}$.

36 VfSlg. 4500/1963, 7108/1973, 8281/1978, 8603/1979.

37 Das Recht am eingerichteten und ausgeübten Gewerbebetrieb umfaßt nicht nur das Sacheigentum und die Förderungsrechte, sondern „alles das, was in seiner Gesamtheit den wirtschaftlichen Wert des konkreten Betriebes ausmacht" (BGHZ $23,157)$. 
Unternehmen in Österreich ein auf Gesetz oder sogenanntem Richterrecht basierendes vermögenswertes Privatrecht, das der Disposition des den Inhalt des Eigentums bestimmenden einfachen Gesetzgebers entzogen ist? Die Antwort lautet nein. Die österreichische Zivilistik leugnet, daß es ein absolutes Recht am Unternehmen gibt, das gegen nicht sozialadäquate Beeinträchtigungen deliktischen Schutz gewährt ${ }^{38}$. Auch durch richterliche Rechtsfortbildung trat ein solches Recht bei uns nicht ans Licht. Es fehlt ja auch in der Bundesrepublik Deutschland nicht an Stimmen, die das Bestehen eines solchen absoluten Rechts leugnen. Es wurde z.B. von Peter Badura daraus die einleuchtende Konsequenz gezogen, daß das genannte Recht nur unmittelbar durch die verfassungsrechtliche Eigentumsgarantie geschützt sein kann ${ }^{39}$. Es stellt sich daher die Frage, ob die österreichische Eigentumsgarantie Vermögen als solches schützt ${ }^{40}$.

\section{B. Schützt die Eigentumsgarantie auch das Vermögen als solches?}

Die herrschende Lehre ${ }^{41}$ und der Verfassungsgerichtshof ${ }^{42}$ leugnen, daß Art. 5 Staatsgrundgesetz solchen Schutz gewährt, sofern nicht die allerdings nur von der Lehre anerkannte Entschädigungspflicht bei gravierenden Eigentumseingriffen in Frage steht. Ich teile diese Auffassung. Was nach verbal-historischer Interpretation kaum zweifelhaft ist, nämlich, daß Art. 5 mit Eigentum nur das Eigentum im Sinne des

${ }_{38}$ Bydlinski, Der Ausgleich von Schadensfolgen der Durchführung öffentlicher Projekte, in: Bundeskammer der gewerblichen Wirtschaft (Hrsg.), Rechtsprobleme der Planungsfolgen (1971) 27 (28); Koziol, Österreichisches Haftpflichtrecht II (1975) 33; Aicher (Fn. 10) 341.

${ }^{39}$ Peter Badura, Der Eigentumsschutz des eingerichteten und ausgeübten Gewerbebetriebes, AÖR 98 (1973) 153 (163).

${ }^{40}$ Dem von Bydlinski (Fn. 38) 40 f. und Aicher (Fn. 10) $338 \mathrm{ff}$. unternommenen Versuch, das Recht am Unternehmen als ein im ABGB, nämlich im schon erwähnten weiten Eigentumsbegriff des $\$ 353$ verankerten Anspruch auszugeben, kann indes nicht gefolgt werden, weil nach der insoweit klaren Terminologie des ABGB (vgl. $\$ 353$ i.V.m. $\$ 292$ ABGB) das Eigentum nur als Inbegriff von Sacheigentum und Forderungsrechten definiert ist. Vgl. auch die Ablehnung der Meinung Bydlinskis und Aichers durch Rummel, in: Rummel/Schlager, Enteignungsentschädigung (1981) $39 \mathrm{f}$.

41 Aicher (Fn. 10) 338 ff.; Korinek (Fn. 20) 50 ff.; Pernthaler, Raumordnung und Verfassung II (1978) 299f.; Holzinger, Buchbesprechung ZfV 1976, 32; a.M. Fröbler/Oberndorfer (Fn. 35 Raumordnungsrecht) 172ff.; Rummel (Fn. 40) $39 \mathrm{ff}$;; Potacs, Devisenbewirtschaftung (1991) $325 \mathrm{ff}$.

42 VfSlg. 9570/1982, 9876/1983. 
ABGB und somit nur Rechtspositionen meint, ist auch teleologisch wohl begründet. Der Zielsetzung des Art. 5, eine grundsätzlich marktwirtschaftliche Ordnung zu gewährleisten, entspricht es, das Risiko von Vermögenswertänderungen dem Eigentümer zu belassen ${ }^{43}$.

Ebensowenig wie Art. 5 gewährt Art. $1 \mathrm{ZP}$ also einen Schutz des Vermögens als solchen. Jedenfalls ist mir eine unzweifelhaft widersprechende Entscheidung einer Straßburger Instanz nicht bekannt ${ }^{44}$. Auch der Eigentumsschutz nach Völkergewohnheitsrecht gibt meines Erachtens keine hinreichende Basis, um Art. 1 als primäre Vermögenswertgarantie ${ }^{45} \mathrm{zu}$ verstehen ${ }^{46}$.

\section{Schützt die Eigentumsgarantie auch öffentlich-rechtliche vermögenswerte Ansprüche?}

Meines Erachtens ist nicht nur die Erstreckung der Eigentumsgarantie auf einen primären Vermögensschutz abzulehnen, es ist auch ein Schutz von öffentlich-rechtlichen Ansprüchen als solchen de constitutione lata nicht begründet ${ }^{47}$. Was subjektive vermögenswerte

${ }^{43}$ Nicht zu Unrecht hat Korinek (Fn. 20) 38 f. die Frage aufgeworfen, ob jene inzwischen aufgehobene Raumordnungsvorschrift des Landes Steiermark, die für jede Minderung des Verkehrswertes des Grundstücks durch Widmung oder Widmungsänderung eine Entschädigung zusprach, nicht verfassungswidrig war, weil sie jegliches raumordnungsrechtliche Risiko sozialisieren wollte. - Diese Regelung bewirkte im übrigen, daß die Gemeinden keine Flächenwidmungspläne erließen, um nicht entschädigungspflichtig zu werden.

${ }_{44}$ Der vom EGMR entschiedene Fall Van Marle (EuGRZ 1988, 35) bietet entgegen der Meinung von Potacs (Fn. 41) 330 Fn. 73 - keinen Ansatzpunkt für einen Schutz des Vermögenswertes des Eigentums. Die Passage des Erkenntnisses, auf die sich Potacs beruft, bringt m. E. zum Ausdruck, daß ein auf eigener Arbeit beruhender öffentlich-rechtlicher Anspruch als Eigentum i.S. des Art. 1 ZP verstanden werden kann.

${ }^{45}$ Im Gegensatz zum subsidiären Vermögensschutz durch die Enteignungsentschädigungspflicht: Papier (Fn. 17) Art. 14 Rdn. 154.

46 Ich kann in den Fällen Oscar Chinn (PCIJ Series A/B, Nr. 63 [1934]) und Jablonski (Annual Digest 1935-1937, No.42, $138 \mathrm{ff}$.) keine hinreichende Basis für die Annahme eines solchen Schutzes erblicken. Vgl. Böckstiegel (Fn. 14) 28, der unter Berufung auf den Oscar-Chinn-Fall einen Schutz des goodwill leugnet, a.M. aber Dolzer (Fn. 14) 180 ff. A. M. als hier aber Böckstiegel (Fn. 14) 30, wenn er unter Berufung auf den Jablonski-Fall einen völkergewohnheitsrechtlichen Schutz des Rechts am eingerichteten und ausgeübten Gewerbebetrieb annimmt.

${ }^{47}$ D. h. indes nicht, daß sozialversicherungsrechtliche Ansprüche, Gehaltsansprüche der Beamten und ähnliche öffentlich-rechtliche Entgeltansprüche überhaupt keinen verfassungsrechtlichen Schutz genießen. Der VfGH gewährt solchen 
Ansprüche im Rahmen des Systems der sozialen Sicherheit anbelangt, widerspricht ihre Einbeziehung in den Eigentumsschutz entgegen der Meinung der meisten meiner österreichischen Kollegen ${ }^{48}$, wohl aber - im Ergebnis - in Übereinstimmung mit dem VfGH ${ }^{49}$ der Zielsetzung der Eigentumsgarantie, soweit nicht der Schutz der eigenen Beitragsleistung in Frage steht. Telos der Eigentumsgarantie ist, wie gesagt, die Gewährleistung einer grundsätzlich marktwirtschaftlichen Ordnung. Das System sozialer Sicherheit beruht aber gerade nicht auf diesem Mechanismus der Selbstregulierung. Liberale Grundrechte, wie sie Art. 5 Staatsgrundgesetz und Art. 1 des Zusatzprotokolls darstellen, in soziale umzudeuten, ist verfehlt ${ }^{50,51}$.

Indes ist diese Problematik im Rahmen unseres Beratungsgegenstandes nicht weiter zu vertiefen. Vielmehr ist die von mir vertretene Beschränkung des Eigentumsschutzes auf vermögenswerte Privatrechte gegen den angesichts der Rechtsprechung des Verfassungsgerichtshofs naheliegenden Einwand zu verteidigen, eine so verstandene Eigentumsgarantie verfehle gerade hinsichtlich der Nutzung von Boden und Umwelt ihre Schutzfunktion. Der Verfassungsgerichtshof kommt in der Tat von der Prämisse, nur vermögenswerte Privatrechte seien geschützt, zu nicht beifallswürdigen Ergebnissen. So qualifiziert er Nachbarrechte auf Grund des Baurechts oder des gewerblichen Betriebsanlagenrechts als öffentlich-rechtliche und

öffentlich-rechtlichen Ansprüchen durch seine auf den Gleichheitsgrundsatz gegründete Vertrauensschutzrechtsprechung verfassungsrechtliche Protektion (VfSlg. 11309, 11310/1987, 11665/1988).

48 Pernthaler in Ermacora/Klecatsky/Marcic (Hrsg.), FS 100 Jahre Verfassungsgerichtsbarkeit, 50 Jahre VfGH (1968) 201; Groiss/Schantl/Welan, ÖJZ 1975, 367; Korinek, WipolBl. 1982, 128; Rummel (Fn. 40) 37; Ermacora (Fn. 10) Rdn.993; kritisch Wenger (Fn. 20) Rdn.183. Für eine Einbeziehung öffentlich-rechtlicher Ansprüche im Wege der Verfassungsreform Oblinger, in Adamovich/Pernthaler (Hrsg.), Auf dem Weg zur Menschenwürde und Gerechtigkeit - Klecatsky-FS (1980) 699 (700 ff.).

${ }^{49}$ Der VfGH (VfSlg. 1827/1949, 2119/1951, 2437/1952, 2869/1955, 5370/1966, $5684 / 1968,7267 / 1974$ ) stützt sich zur Begründung allerdings offenbar nur auf eine Wortsinninterpretation des Begriffs Eigentum in Art. 5 StGG.

50 Im wesentlichen auch dieser Meinung Morscher, 9. ÖJT (1985) II/1, 3.

${ }^{51}$ M.E. sind auch Beamtengehaltsansprüche und ähnliche öffentlich-rechtliche Entgeltansprüche nicht durch die Eigentumsgarantie geschützt, weil im Hinblick auf die Sonderstellung der Beamten (VfSlg. 5341/1966, 11665/1988) oder sonstiger öffentlich-rechtlich in Dienst Genommener die Entgeltansprüche dieser Personen nicht funktionsgleich mit privatrechtlichen Entlohnungsansprüchen sind, auch wenn die Sonderstellung der Beamten in Österreich keine dem Art. 33 GG entsprechende bundesverfassungsrechtliche Verankerung gefunden hat. 
daher eigentumsgrundrechtlich nicht geschützte Ansprüche ${ }^{52}$. Keinen Eigentumsschutz gewährte der Gerichtshof in einem älteren, heute allerdings nicht mehr verallgemeinerungsfähigen Erkenntnis einem Betriebsinhaber, der neue Maschinen in seinem Betrieb aufstellen wollte, weil gewerbebehördliche Verfügungen dieser Art dem öffentlichen Recht angehörten ${ }^{53}$. Wasserbenutzungsrechte an öffentlichen Gewässern sind nach unbestrittener Auffassung öffentlich-rechtlicher Natur und könnten im Sinne der Verfassungsgerichtshofrechtsprechung folglich keinen Eigentumsschutz genießen ${ }^{54}$.

Solche Folgerungen aus der Beschränkung der Eigentumsgarantie auf den Schutz vermögenswerter Privatrechte sind meines Erachtens verfehlt. Die erwähnten Nachbarrechte sind - ich verweise auf Jürgen Schwabe ${ }^{55}$ - nur als Ansprüche gegenüber der Behörde, die nachbarschützenden Normen korrekt anzuwenden, öffentlich-rechtlicher Natur, als Ansprüche gegen den Nachbarn sind sie, auch wenn sie in Österreich nur im Verwaltungswege geltend gemacht werden können, subjektive Privatrechte ${ }^{56}$.

Was die anlagenrechtlichen Verfügungen betreffend die Aufstellung neuer Maschinen anbelangt, so weicht der Verfassungsgerichtshof in diesem älteren Erkenntnis von der Linie ab, daß Anordnungen, welche die aus dem Eigentum erfließenden Nutzungsbefugnisse

52 VfSlg. 2943/1955, 3309/1958, 5334/1966, 9195/1981, 10106/1984.

${ }^{53}$ VfSlg. 5416/1966.

54 Walter/Mayer, Grundriß des Besonderen Verwaltungsrechts (1987) $285 \mathrm{f}$.

55 Nachbarschützende Baurechtsnormen und Art. 14 GG, NJW 1971, 913; ders., Letztmals: Zur Enteignungsfähigkeit subjektiver öffentlicher Nachbarrechte des Baurechts, NJW 1971, 1835. A. M. Horst Joachim Müller, Zum enteignungsrechtlichen Bestandsschutz subjektiver öffentlicher Nachbarrechte des Baurechts, NJW 1971, 81 ff., ders., Nochmals: Zur Enteignungsfähigkeit subjektiver öffentlicher Nachbarrechte des Baurechts, NJW 1971, 1302.

56 Die traditionelle Qualifikation (Krzizek, Das öffentliche Nachbarrecht [1959] 12 ff.; Wolfgang Hauer, Der Nachbar im Baurecht ${ }^{2}$ [1986] 21. Zur Rsp. siehe Fn. 52.) als öffentlich-rechtliche Ansprüche beruht offensichtlich allein darauf, daß diese Ansprüche nur im Verwaltungswege geltendzumachen sind und die einschlägigen nachbarrechtlichen Bestimmungen zwischen öffentlich-rechtlichen (= nur im Verwaltungsweg geltendzumachen) und privatrechtlichen (= nur im ordentlichen Rechtsweg geltendzumachen) Nachbarrechten unterscheiden. Diese Qualifikation in einfachen Gesetzen hindert jedoch nicht, sie im Sinne des Art. 5 als vermögenswerte Privatrechte zu qualifizieren. Gerade im Lichte einer Unterscheidung nach der Interessentheorie (eingehend dazu Rill, Zur Abgrenzung des öffentlichen vom privaten Recht, ZöR 11 [1961], 457 [466 ff.]) erscheint diese Qualifikation wohlbegründet. 
betreffen, ins Eigentum eingreifen ${ }^{57}$ und demnach die verfassungsrechtlichen Grenzen zulässiger Sozialbindung des Eigentums nicht überschreiten dürfen.

Soweit es sich wie bei den Wasserbenutzungsrechten an öffentlichen Gewässern um hoheitlich verliehene Nutzungsbefugnisse handelt, ist nach deutscher Lehre ${ }^{58}$ - und nichts anderes kann meines Erachtens für Österreich gelten - ein Eigentumsschutz dann gegeben, wenn auf Grund der öffentlich-rechtlichen Verleihungen Investitionen getätigt wurden. Nicht die öffentlich-rechtlichen Befugnisse als solche stehen unter dem Schutz, wohl aber die Verfügungs- und Nutzungsbefugnisse des Eigentümers, die er sich dank der öffentlichrechtlichen Befugnisverleihung durch seine Investitionen erworben hat. Denn diesfalls handelt es sich um eine Position, die ganz ähnlich der Position eines Grundeigentümers ist, der eine Betriebsanlage mit behördlichem Konsens betreibt, der die Ausübung einer Grundeignerbefugnis erlaubt und nicht eine Nutzungsbefugnis zuteilt. Soviel zum Schutzobjekt der allgemeinen Eigentumsgrundrechte.

\section{Die Liegenschaftsverkebrsfreibeit (Art. 6 StGG) schützt den rechtsgeschäftlichen Verkebr mit Grundstücken}

Die Frage nach dem Schutzobjekt der österreichischen Eigentumsgarantie wäre unvollständig erörtert, wollte man in diesem Zusammenhang nicht auch den Blick auf Art. 6 StGG werfen. Ich darf daran erinnern, daß dieser Artikel allen Staatsangehörigen garantiert, daß sie Liegenschaften aller Art erwerben und über dieselben frei verfügen dürfen. Schutzobjekt dieses Grundrechts ist der rechtsgeschäftliche Verkehr mit Grundstücken ${ }^{59}$, und zwar argumento lege non distinguente unter Einschluß erbrechtlicher Dispositionen.

${ }^{77}$ VfSlg. 7125/1973, 7362/1974, 8281/1978, 8603/1979, 9306/1981.

${ }^{58}$ So hinsichtlich aller Genehmigungen außer der Baugenehmigung Stettner, Der Schutz privater Investitionen gegen nachträgliche verschärfende Gesetzgebung, BayVBl. 1991, 550 (556f.) und Friauf, Zum gegenwärtigen Stand der Bestandsschutzproblematik, WiVerw. 1986, 87 (98f.). Ebenso Breuer (Fn. 16) $209 \mathrm{f}$. hinsichtlich der Baubewilligung, die seiner Meinung nach eine öffentlich-rechtliche Nutzungsbefugnis zuteilt.

59 A. M. nur Morscher, Die Niederlassungsfreiheit und die Freiheit des Liegenschaftsverkehrs in Österreich, EuGRZ 1983, 515 (521 f.), und Wenger (Fn. 20) Rdn. 345, die durch dieses Grundrecht auch die freie Nutzung der Grundstücke garantiert sehen. Zur h. M. Walter/Mayer (Fn. 10) Rdn. 1384 m.w. N. 


\section{Sozialbindung und Enteignung}

\section{A. Systematik der Eigentumseingriffe}

Um den Gestaltungsspielraum zu umreißen, den die Eigentumsgarantie dem einfachen Gesetzgeber bei Verfolgung boden- oder umweltpolitischer Ziele beläßt, empfiehlt es sich, die zulässigen Eingriffe begrifflich zu ordnen.

Art. 5 StGG erwähnt als zulässigen Eigentumseingriff nur die Enteignung. Von Eigentumsbeschränkungen ist ausdrücklich nicht die Rede, was Lehre und Rechtsprechung nicht wenig verwirrt hat ${ }^{60}$. Eine

60 Der VfGH hat in seiner Rsp. eine klare dogmatische Einordnung der Eigentumsbeschränkungen nach Art. $5 \mathrm{StGG}$ nicht vorgenommen. Einerseits führt er in älteren Erkenntnissen (VfSlg. 2685/1954, 4486/1963, 6264/1970) unter Hinweis auf $\$ 364$ Abs. 1 ABGB aus, Eigentumsbeschränkungen und deren Zulässigkeit aus Gründen des öffentlichen Wohls seien dem Begriff des Eigentums inhärent. Andererseits betont er in zahlreichen Erkenntnissen, Art. 5 Satz 2 StGG enthalte einen Gesetzesvorbehalt sowohl für Enteignungen als auch für Eigentumsbeschränkungen. Anders als bei Enteignungen sieht er jedoch die verfassungsrechtlichen Schranken für eine gesetzliche Eigentumsbeschränkung lediglich im Wesensgehalt des Grundrechts und in sonstigen Verfassungsgrundsätzen. Die Eingriffsvoraussetzung des allgemeinen Wohls wird entweder nicht erwähnt (VfSlg. 5208/1966, 6780/ $1972,7306 / 1974,8759 / 1980,9173 / 1981$ ) oder es wird gar ausgeführt, daß sich bei Eigentumsbeschränkungen die Frage nicht stellt, „ob die Maßnahmen durch das öffentliche Wohl geboren war" (VfSlg. 8212/1977). Vgl. zu dieser Rsp. auch Berchtold, Eigentumsbeschränkungen und allgemeines Interesse, ZfV 1983, $123 \mathrm{ff}$.

Stolzlechner, Abgabengesetze und Eigentumsgarantie, ÖZW 1975, 31 (37 ff.), sieht durch die Rsp. des VfGH zum Gesetzesvorbehalt in Art. 5 Satz 2 StGG ,alle Zweifel über den Inhalt des Enteignungsbegriffs ausgeräumt“. Der grundrechtliche Enteignungsbegriff erfasse auch Beschränkungen des Eigentums. Auch Schantl, Berufsfreiheit, Eigentumsfreiheit und Vertragsfreiheit als die wichtigsten Grundrechte der Wirtschaft, in: Franz Korinek-FS (1972) 129 (149) versteht unter dem Begriff Enteignung jede Beschränkung des Eigentums. Ohne rechtsdogmatische Begründung unternimmt es die h. L. (Aicher, Enteignung durch Raumplanung, JBl. 1975, $393 \mathrm{ff}$, ders. [Fn. 10] $235 \mathrm{ff}$, ders., Verfassungsrechtlicher Eigentumsschutz und Enteignung, 9. ÖJT I/1, $17 \mathrm{ff}$; Pernthaler II [Fn. 41] 304 f.; Korinek [Fn. 20] 34 ff.; Stolzlechner, ÖZW 1975, 331 f.), der klassischen Enteignung eine „materielle Enteignung" zur Seite zu stellen und diese unter den Enteignungsbegriff des Art. 5 Satz 2 StGG zu subsumieren. Dieser Versuch beruht zwar auf der zutreffenden teleologischen Erwägung, daß die Eigentumsgarantie nicht nur für klassische Enteignungen, sondern auch für andere schwere Eigentumseingriffe eine Entschädigung verlangt. Was die Zulässigkeit solcher Eigentumseingriffe anbelangt, erweist sich jedoch die Subsumtion unter Art. 5 Satz 2 verfehlt. Denn man kann entgegen Aicher, 9. OJT I/1, 18 - die Zulässigkeitsvoraussetzungen der klassischen Enteignung (wie sie VfSlg. 3666/1959 - siehe weiter unten im Text - formuliert) nicht auf die materielle Enteignung anwenden. Das Erfordernis, daß der Eingriff 
adäquate Lösung ist indes nicht so schwer, sofern man nicht nur das ausdrücklich Verfügte als Sinngehalt von Normen anerkennt. Aus dem Schweigen über Eigentumsbeschränkungen folgt weder, daß Art. 5 Eigentumsbeschränkungen ausschließt, noch, daß diese unter Enteignung zu subsumieren sind und folglich vielleicht gar uneingeschränkter Entschädigungspflicht unterliegen. Wäre eines von beidem der Fall, ginge insoweit die Eigentumsgarantie aus 1867 über das hinaus, was Art. 1 Zusatzprotokoll zur MRK verbürgt, der entschädigungslose Eigentumsbeschränkungen fraglos zuläßt. Vielmehr ist aber aus der Orientierung des Art. 5 an der Eigentumsordnung des ABGB abzuleiten, daß im verfassungsrechtlichen Eigentumsbegriff das mitverstanden ist, was $\$ 364 \mathrm{ABGB}$ so ausdrückt: „Überhaupt findet die Ausübung des Eigentumsrechtes nur insofern statt, als dadurch weder in die Rechte eines Dritten ein Eingriff geschieht, noch die in den Gesetzen zur Erhaltung und Beförderung des allgemeinen Wohles vorgeschriebenen Einschränkungen übertreten werden" ${ }^{61}$.

Von den Eigentumsbeschränkungen ist die Enteignung abzuheben, die nach dem zweiten Satz des Art. 5 nur in den Fällen und in der Art erfolgen darf, die das Gesetz bestimmt. Auch der Enteignungsbegriff ist meines Erachtens unter Orientierung an der Eigentumsordnung des ABGB auszulegen ${ }^{62,63}$. Dort bestimmt $\$ 365$ : „Wenn es das all-

einem im öffentlichen Interesse liegenden konkreten Vorbaben zu dienen hat, taugt nicht auch als Voraussetzung für eine zulässige "materielle Enteignung“ (z. B. für eine in der Schwere einer klassischen Enteignung gleichkommende Änderung einer Widmung im Flächenwidmungsplan). Eingriffe dieser Art sind, abgesehen vom Erfordernis der Entschädigung, zulässig, wenn sie einem öffentlichen Interesse dienen und einer Verhältnismäßigkeitsprüfung standhalten. Es ist daher keineswegs - wie Aicher (9. OJT 1/1,12) meint - eine bloß terminologische Frage, ob man bestimmte Fälle von Eigentumsbeschränkungen dem Enteignungsbegriff subsumiert oder ob man zwischen Enteignung, entschädigungslosen und entschädigungspflichtigen Eigentumsbeschränkungen unterscheidet.

${ }_{61}$ So auch VfSlg. 2685/1954, 4486/1963 und die h. L. Vgl. Korinek (Fn. 20) 21 f.; Aicher, 9. ÖJT 1/1, $12 \mathrm{f}$., 58; Öblinger, EuGRZ 1984, $561 \mathrm{f}$.

62 Öblinger, EuGRZ 1984, 561, ohne daraus allerdings ausdrücklich abzuleiten, daß Enteignungen Entschädigungspflicht nach sich ziehen (für die Lösung der Entschädigungsfrage will Öblinger offensichtlich allein den Gleichheitssatz heranziehen, vgl. ebenda, 571); Aicher (Fn. 10) 35 ff., 73 f., 144 ff., der allerdings die Enteignung i. S. von Art. 5 Satz 2 StGG nicht auf die Enteignung i. S. von $\$ 365$ ABGB beschränkt sehen will, was mit dem verfehlten Versuch (siehe oben Fn. 60) zusammenhängt, unter Art. 5 Satz 2 auch die ,materielle Enteignung“ zu subsumieren.

${ }^{63}$ Der VfGH hat in älteren Erkenntnissen (z. B. VfSlg. 2572/1953, 2680/1954) ausgesprochen, $\$ 365 \mathrm{ABGB}$ sei nicht Bestandteil von Art. 5 StGG geworden. Insbesondere seit VfSlg. 3666/1959 hat er aber ausdrücklich auch $\$ 365$ zur Aus- 
gemeine Beste erheischt, muß ein Mitglied des Staates gegen eine angemessene Schadloshaltung selbst das vollständige Eigentum einer Sache abtreten." Angesichts dieser den rechtsstaatlichen Erfordernissen des Art. 5 freilich nicht entsprechenden Ermächtigung an die Vollziehung meint Enteignung in Art. 5 den gänzlichen oder teilweisen Entzug eines vermögenswerten Privatrechts im Einzelfall, daher mittels Verwaltungsakts zugunsten eines dem allgemeinen Besten dienenden Vorhabens gegen angemessene Schadloshaltung, also das, was man in Österreich - sehen wir von Definitionsabweichungen in Nuancen $\mathrm{ab}^{64}$ - die klassische Enteignung nennt.

Art. 5 StGG gibt danach entgegen der Rechtsprechung des Verfassungsgerichtshof ${ }^{65}$ einer Sozialisierung keine verfassungsrechtliche Deckung ${ }^{66}$. Sozialisierungen wie die Verstaatlichung großer Industrieund Bankunternehmen und praktisch der gesamten E-Wirtschaft in Österreich nach dem Zweiten Weltkrieg ${ }^{67}$ dienten keinem konkreten Vorhaben, sondern waren auf strukturelle Änderungen in der Wirtschaftsordnung gerichtet. Die gegenteilige Auffassung des Verfassungsgerichtshofs stützt sich auf eine isolierte jeden Kontext vernachlässigende und daher methodologisch verfehlte Wortsinninterpretation des Art. 5. Schlechthin unvertretbar ist die Ansicht des Gerichtshofs, die ja auch auf eine einheitliche Front der Ablehnung in der

legung des Enteignungsbegriffs herangezogen. So auch in den Erkenntnissen VfSlg. $5617 / 1967,5807 / 1968$, niemals aber eine Entschädigungspflicht für Enteignungen angenommen.

${ }^{64}$ Allerdings sind entsprechend dem Schutzbereich des Art. 5 StGG nicht nur Grundstücke und dingliche Rechte daran, sondern alle vermögenswerten Privatrechte als Enteignungsobjekt zu begreifen. Das Element der Rechtsübertragung ist für einen klassischen Enteignungsbegriff jedoch unwesentlich. Der völlige oder teilweise Untergang eines vermögenswerten Privatrechts ist ebenso Eigentumsentzug und damit Enteignung.

${ }_{65}$ VfSlg. 1853/1949, 2092/1951, 2374/1952, 2431/1952, 2572/1953, 2680/1954, $3118 / 1956$.

${ }^{66}$ Ermacora/Klecatsky/Ringhofer, Die Rechtsprechung des VfGH im Jahre 1956, ÖJZ 1959, 8; Klecatsky, Das Verhältnis von öfentlicher und privater Wirtschaft in verfassungsrechtlicher Sicht, WipolBl. 1965, 2 (29f.). Oberndorfer, Die verfassungsgerichtliche Rechtsprechung zur Wirtschaftsordnung dargestellt am Beispiel der österreichischen Verstaatlichung, WiVerw. 1976, 46 (60 ff.); für die Qualifikation der Verstaatlichungen nach dem Zweiten Weltkrieg als Enteignung, Wenger (Fn. 20) Rdn. 217.

67 1. VerstaatlichungsG BGBl. 1946/168, 2. VerstaatlichungsG BGBl. 1947/81 (beide in der Folge mehrfach novelliert). 
Lehre stößt $\mathrm{B}^{68}$, Enteignungen dürften auch entschädigungslos erfolgen ${ }^{69}$. Die Annahme, daß der liberale Gesetzgeber von 1867 hinter den schon im Polizeistaat erreichten Standard zurückgegangen sein soll, erscheint geradezu absurd. Auch bedeutet die Rechtsprechung praktisch eine fast gänzliche Preisgabe der Eigentumsgarantie. Denn was bleibt, läßt sich mit Hilfe des Gleichheitsgrundsatzes und rechtsstaatlicher Prinzipien ohne große Not auch bewältigen.

Wenn man den Enteignungsbegriff im historischen Sinne interpretiert, so provoziert dies klarerweise die Frage, wie dann Eigentumsbeschränkungen verfassungsrechtlich zu beurteilen sind, die den Eigentümer gleich schwer belasten wie Enteignungen im hier zugrunde gelegten Sinn. Sie sind selbstverständlich nicht unzulässig, sie sind auch nicht entschädigungslos zu dulden. Leugnete man die Entschädigungspflichtigkeit gravierender Eigentumsbeschränkungen, so unterstellte man dem Verfassungsgesetzgeber eine sachlich nicht zu rechtfertigende Differenzierung innerhalb der Eigentumseingriffe, nämlich zwischen entschädigungspflichtigen Enteignungen klassischen Musters und gleichbelastenden Eigentumsbeschränkungen, die entschädigungslos bleiben dürfen. Hier liegt eine planwidrige Unvollständigkeit vor. Die Lücke muß durch Anerkennung einer besonderen Kategorie von Eigentumsbeschränkungen, die ob ihrer enteignungsgleichen Wirkung Entschädigungspflicht auslösen, geschlossen werden. Im Ergebnis entspricht diese Auffassung der herrschenden Lehre in Österreich ${ }^{70}$.

Aus Art. 1 des Zusatzprotokolls kann meines Erachtens weder für Enteignungen klassischen Musters noch für enteignungsgleich belastende Eigentumsbeschränkungen ein Entschädigungsanspruch für Inländer abgeleitet werden ${ }^{71}$. Art. $5 \mathrm{StGG}$ ist daher insoweit als günstigere Bestimmung im Sinne des Art.60 MRK zu werten.

${ }_{68}$ Aicher (Fn. 10) 33; Rummel (Fn. 40) 26 ff.; Walter/Mayer (Fn. 10) Rdn. 452; Adamovich/Funk (Fn. 10) 424; Spanner, Enteignungsprobleme im österreichischen Recht, Forschungen und Berichte aus dem öffentlichen Recht, Jellinek-GedS (1955) 469(481 f.). A. M. nur Krzizek I (Fn. 35) 438 ff.; Spielbüchler, in Rummel, Kommentar zum ABGB2 ${ }^{2}$ Rdn. 9 zu $\$ 365$.

${ }^{69}$ VfSlg. 1023, 1123/1928, 2572/1953, 2680/1954.

70 Aicher (Fn. 10) 430, ders., 9. ÖJT I/1, 19 ff.; Korinek (Fn. 20) 37 ff.; Pernthaler (Fn. 41) 304 ff.; Walter/Mayer (Fn. 10) Rdn. 1376.

${ }_{11}$ So auch Böckstiegel (Fn. 14) 79; Öblinger, EuGRZ 1984, 571; Barfuß, Eigentum und Vollziehung in Österreich, EuGRZ 1984, 572 (576). Zum nunmehr gegenteiligen Standpunkt der EKMR siehe Peukert, Der Schutz des Eigentums nach Art. 1 des Ersten Zusatzprotokolls zur Europäischen Menschenrechtskonvention, EuGRZ 1981, 97 (108f.). 
Zur begrifflichen Ordnung der zulässigen Eigentumseingriffe bleibt also festzuhalten. Zunächst ist zwischen Eigentumsbeschränkungen und Enteignungen zu unterscheiden. Innerhalb der Eigentumsbeschränkungen sind entschädigungsfreie von ob ihrer enteignungsgleichen Wirkung entschädigungspflichtigen Beschränkungen abzuheben $^{72}$.

Um der Rechtsvergleichung willen lassen Sie mich noch folgende Bemerkung anschließen. Wird rechtswidrig ins Eigentum eingegriffen, so hat der Betroffene in Österreich den Weg des sogenannten primären Rechtsschutzes zu gehen. Ein Amtshaftungsanspruch besteht nur, wenn trotz erfolgreicher Bekämpfung des Eingriffs ein Schaden durch schuldhaft rechtswidriges Organverhalten entstanden ist. Die haftungsrechtlichen Institute, die in Deutschland unter dem Titel „enteignungsgleicher Eingriff“ entwickelt wurden ${ }^{73}$, sind der österreichischen Rechtslage und -praxis fremd. Das gleiche gilt für den enteignenden Eingriff, wie ihn der BGH entwickelt hat ${ }^{74}$.

Nach diesem rechtsvergleichenden Hinweis kehre ich zu den in Österreich eigentumsgrundrechtlich zulässigen Eigentumseingriffen zurück.

\section{B. Eigentumsbeschränkungen}

1. Eigentumsbeschränkungen nach Art. 5 StGG und Art.1 Zusatzprotokoll zur Menschenrechtskonvention

Das Hauptinstrument der Boden- und Umweltschutzpolitik des einfachen Gesetzgebers ist fraglos die Eigentumsbeschränkung und nicht die klassische Enteignung. Der Einsatz dieses Instruments ist der Initiative des Gesetzgebers überlassen. Einen Verfassungsauftrag, bestimmte boden- und umweltpolitische Ziele zu verfolgen, gibt es nicht. Das eingangs erwähnte bundesverfassungsrechtliche Bekenntnis zum Umweltschutz schreibt zwar fest, daß der umfassende Umwelt-

72 Der Enteignung und den entschädigungspflichtigen Eigentumsbeschränkungen entspricht die Eigentumsentziehung i.S. von Art. 1 Abs. $1 \mathrm{ZP}$, während die entschädigungslos zu duldende Eigentumsbeschränkung der Regelung der Benützung des Eigentums i.S. von Art. 1 Abs. 2 ZP entspricht. In diesem Sinne auch Öblinger, EuGRZ 1984, 564.

73 Siehe zu diesen haftungsrechtlichen Instituten Papier, Zum Schicksal des enteignungsgleichen Eingriffs, NVwZ 1983, $258 \mathrm{ff}$.

${ }^{74}$ Nur Bydlinski (Fn. 38) 44 ff. und Aicher (Fn. 10) 386 ff. haben versucht, einen Entschädigungsanspruch für derartige Sonderopferlagen zu entwickeln. 
schutz im öffentlichen Interesse liegt, enthält aber keinen Auftrag an die Gesetzgebung ${ }^{75}$. Gerade einen solchen wollte man ja - das Konrad-Lorenz-Volksbegehren im Visier ${ }^{76}$ - vermeiden. Auch wenn das Grundrecht auf Leben und die Eigentumsgarantie einen Schutz gegen zu großzügige Gefährdungserlaubnisse bieten, kann darin kein Auftrag von echt umweltpolitischer Relevanz gesehen werden. Jenseits des Schutzes, den diese Grundrechte gewähren, beginnt ja erst die umweltpolitische Diskussion ${ }^{77}$. Die Grundrechte auf Leben und auf Unverletzlichkeit des Eigentums sind, um ein plakatives Beispiel zu wählen, gegenüber der Frage der prinzipiellen Zulässigkeit der Stromerzeugung mittels Atomenergie neutral ${ }^{78}$. Ein gesetzliches Verbot, wie wir es derzeit haben ${ }^{79}$, ist ebenso grundrechtskonform wie die Rechtslage vor dem Atomsperrgesetz.

In unserem Zusammenhang ist also kein Gebot zu umweltschützenden Eigentumsbeschränkungen zu erörtern, sondern von den Grenzen solcher Schrankenbestimmungen zu sprechen.

Art. 5 StGG und Art. $1 \mathrm{ZP}$ verzichten weitgehend auf eine inhaltliche Determinierung ihrer Gesetzesvorbehalte. Art. 5 folgt damit dem die Grundrechtsordnung von 1867 kennzeichnenden Vertrauen in die nicht mehr allein dem Monarchen vorbehaltene Gesetzgebung. Eigentumsbeschränkungen müssen dem öffentlichen Wohl dienen ${ }^{80}$. Zu entscheiden, was dem öffentlichen Wohle frommt, bleibt weitestgehend dem einfachen Gesetzgeber überlassen. Liberalistische Gemeinwohlvorstellungen sind nicht festgeschrieben. Gleich offen sind die Gesetzesvorbehalte in Art. 1 ZP. Das heißt indes nicht, daß die beiden Grundrechte dem Gesetzgeber einen Freibrief ausstellen. Der Verfassungsgerichtshof hat allerdings in seiner älteren Rechtsprechung die

75 Marko, Umweltschutz als Staatsziel, ÖJZ 1986, 289 (292); Benjamin Davy, Folgenloses Umweltrecht (1989) 16; Gutknecht/Holoubek/Schwarzer, Umweltverfassungsrecht als Grundlage und Schranke der Umweltpolitik, ZfV 1990, 554 f.

76469 Blg. z. d. StenProt d. Nationalrats XVI. GP, S. 1 f.

77 Isensee, Die Ambivalenz des Eigentumsgrundrechts, in: Ossenbübl (Hrsg.), Eigentum und Umweltschutz (1990) 5, überschätzt die Leistungsfähigkeit der eigentumsgrundrechtlichen Schutzpflichten.

${ }^{78}$ Freilich sind die genannten Grundrechte gegenüber der Stromerzeugung mittels Atomenergie im übrigen (also über die Frage hinaus, ob diese Art der Stromerzeugung überhaupt zulässig ist) keineswegs neutral.

79 Bundesgesetz v. 15.12.1978 über das Verbot der Nutzung der Kernspaltung für die Energieversorgung in Österreich BGBl. 1978/676 (sogenanntes „Atomsperrgesetz").

80 Zur Ableitung dieser Voraussetzung aus $₫ 364$ Abs. 1 ABGB siehe oben im Text nach Fn. 60. 
Gesetzesvorbehalte zumeist nur durch eine weit hinausgeschobene absolute Wesensgehaltsschranke begrenzt gesehen ${ }^{81}$. Bis 1989 hat denn auch der Verfassungsgerichtshof keine einzige gesetzliche Eigentumsbeschränkung wegen Verletzung der Eigentumsgarantie aufgehoben. Er hat allerdings unter Berufung auf den Gleichheitsgrundsatz im Ergebnis mitunter auch Eigentumsschutz gewährt ${ }^{82}$. Seit 1983 vertritt aber nun der Verfassungsgerichtshof - unter Berufung auf Art. 1 ZP - klar und deutlich die Position, daß Eigentumsbeschränkungen dem öffentlichen Interesse dienen müssen ${ }^{83}$. Der Sache nach nimmt er auch eine Verhältnismäßigkeitsprüfung vor, er prüft, ob der Eingriff durch ein öffentliches Interesse geboten und ein taugliches und adäquates Mittel zur Verfolgung des öffentlichen Interesses ist ${ }^{84}$.

Diese Entwicklung der Judikatur ist zu begrüßen. Die neue Linie Anwendung des Verhältnismäßigkeitsgrundsatzes - ist meines Erachtens durch die Funktion der liberalen Grundrechte, Staatseingriffe zu minimieren, geboten, auch wenn die in die Verhältnismäßigkeitsprüfung einzubringenden Werte zu einem guten Teil nicht einem positiv-rechtlich vorgegebenen Maßstab entnommen werden können ${ }^{85}$.

Angesichts des dargelegten Entwicklungsstandes der Rechtsprechung kann ich mich kaum auf Judikate des Verfassungsgerichtshofs berufen, wenn ich nun einige Fragen gesetzlicher Beschränkungen der Nutzung von Boden und Umwelt eigentumsgrundrechtlich beleuchte. Ich möchte die Positivplanung in der Raumordnung, die Plangewährleistung, den Bestandsschutz und die Öko-Lenkungsabgaben bzw. -beiträge ansprechen.

Die Raumplanung als Positivplanung zu gestalten, steht im grundsätzlichen Widerspruch zur Eigentumsgarantie. Denn das alleinige

${ }^{81}$ Der VfGH gebraucht verschiedene Wendungen: Das Gesetz dürfe das Grundrecht in einem Sektor nicht praktisch beseitigen (VfSlg. 3118/1956), das Gesetz dürfe in seiner Wirkung nicht einer Aufhebung des Grundrechts gleichkommen (VfSlg. 6316/1970), der Inhalt des Gesetzes dürfe den Wesensgehalt des Grundrechts nicht aushöhlen (VfSlg. 5150/1965), vgl. auch VfSlg. 3929/1961, 4486/ $1963,7306 / 1974$ u. a.).

$82 \mathrm{Vgl}$. etwa VfSlg. 8233/1978.

${ }^{83}$ VfSlg. $9911 / 1983,10354 / 1985,11402 / 1987$.

84 VfSlg. 10354/1985, 11402/1987.

${ }^{85} \mathrm{Daß}$ der VfGH in seiner älteren Judikatur die dargestellte Zurückhaltung geübt hat, hat seine Ursache (u. a.) gewiß in einer verengten rechtspositivistischen Sicht. Die Auffassung, daß die Gesetzesvorbehalte i. S. des Verhältnismäßigkeitsprinzips auszulegen sind, überschreitet indes nicht die Grenzen einer auf das positive Recht ausgerichteten Rechtsdogmatik. 
Interesse an der Verwirklichung des Planungskonzeptes kann angesichts der Eigentumsgarantie kein anerkennenswertes öffentliches Interesse sein, dem Baugebote zur Erfüllung dienen dürfen ${ }^{86}$. Zutreffend sagen Fröhler/Oberndorfer, daß weitere Gesichtspunkte des Gemeinwohls, z.B. wichtige Erfordernisse des Stadtbildschutzes, zu den für die Baulandwidmung sprechenden Gründen hinzutreten müssen, um im Einzelfall die zwangsweise Durchsetzung der Widmungsnutzung zu rechtfertigen ${ }^{87,88}$.

Was die Plangewährleistung anbelangt, regeln die Gesetze mit wenigen Ausnahmen ausdrücklich, unter welchen Voraussetzungen Raumpläne abänderbar sind ${ }^{89}$. Alles in allem sind die Bestimmungen von dem Anliegen geprägt, das Vertrauen in den Bestand des Plans zu schützen. Sie entsprechen der Eigentumsgarantie und werden vom Verfassungsgerichtshof ohne Berufung auf die Eigentumsgrundrechte stets dahin interpretiert, daß sie Änderungen nur zulassen, wenn diese auf einer gerechten Abwägung der in Betracht kommenden Interessen beruhen ${ }^{90}$. Dort, wo er sich auf keine ausdrückliche Planänderungsregel stützen konnte, hat der Verfassungsgerichtshof mit Hilfe des Sachlichkeitsgebotes des Gleichheitsgrundsatzes gleichen Schutz gewährt ${ }^{91}$.

Ganz anders als in der Bundesrepublik Deutschland wird die Frage des Bestandsschutzes in Österreich so gut wie nicht eigentumsgrundrechtlich thematisiert ${ }^{92}$. Dennoch handelt es sich um ein eigentumsgrundrechtliches Problem. Lassen Sie mich an einigen Beispielen darlegen, wie der einfache Gesetzgeber ohne Anleitung durch eine

${ }^{86}$ Bei Anerkennung eines solchen öffentlichen Interesses würde der Inhalt der Eigentumsgarantie ins Gegenteil verkehrt.

${ }^{87}$ Fröbler/Oberndorfer, Positivplanung (Fn. 35) 73.

${ }_{88}$ Verfassungswidrig ist es daher, wenn ohne Bezug auf ein konkretes Vorhaben und unter Umständen ohne kompetenzrechtliche Deckung eine Enteignungsmöglichkeit allein an die Widmung als Vorbehaltsfläche geknüpft wird (vgl. z. B. $\$ 17$ Bgld. RPIG). Keine Bedenken bestehen gegen die zwangsweise Durchsetzung der Assanierung auf Grund des StadterneuerungsG (BGBl. 1974/287 i.d.g. F.). Das öffentliche Interesse an der Assanierung rechtfertigt in diesem Fall die Durchsetzung der Planung. Unbedenklich ist auch das Instrumentarium, das $\$ 23$ a Stmk ROG zur Verwirklichung der Baulandwidmung vorsieht. $479 \mathrm{f}$.

${ }^{89} \mathrm{Vgl}$. die Darstellung der einschlägigen Bestimmungen bei Pernthaler III (Fn. 20)

90 Fröbler/Oberndorfer, Österreichisches Raumordnungsrecht II (1986) $122 \mathrm{ff}$. m.w. N.

91 VfSlg. 5581/1967, 5794/1968.

92 Ansätze bei Benjamin Davy, Gefahrenabwehr im Anlagenrecht (1990) $513 \mathrm{ff}$. in bezug auf das Betriebsanlagenrecht. 
Eigentumsgrundrechtsrechtsprechung mit Beständen umgeht und wie seine Lösungen zu beurteilen sind.

Die österreichischen raumordnungs- und baurechtlichen Gesetze gewähren - wenngleich nicht ausdrücklich - passiven Bestandsschutz ${ }^{93}$. Rechtskräftig bewilligte Bauten dürfen weiterbestehen, erhalten und genützt werden, auch wenn sie nach der genannten Rechtslage neu so nicht mehr errichtet werden dürften ${ }^{94}$. Nur vier Länder gestatten darüber hinaus, bauliche Änderungen und Ergänzungen in einem die bauliche Situation nicht wesentlich verändernden Umfang vorzunehmen ${ }^{95}$. Dieser aktive Bestandsschutz ist nicht nur sinnvoll, er ist meines Erachtens - wie dies auch in der Bundesrepublik Deutschland herrschende Lehre ist ${ }^{96}$ - auch durch die Eigentumsgarantie geboten ${ }^{97}$.

Im gewerblichen Betriebsanlagenrecht ist die Zumutbarkeitsgrenze für nachträgliche Auflagen sowohl angesichts einer sich als unzulänglich erweisenden Anlagengenehmigung ${ }^{98}$ als auch für die dynamische Anpassung ${ }^{99}$ an den Stand von Technik und Wissenschaft - wie im deutschen Bundes-Immissionsschutzgesetz ${ }^{100}$ - durch ein Verhältnismäßigkeitsgebot bestimmt. Die Auflagen dürfen in der Relation Aufwand für den Betriebsinhaber-erwarteter Erfolg für die Umwelt nicht unverhältnismäßig sein. Soweit allerdings der Schutz von Leben und Gesundheit von Menschen in Frage steht, wird in Österreich jeder Aufwand für verhältnismäßig erachtet ${ }^{101}$.

93 Zur Terminologie Friauf, Zum gegenwärtigen Stand der BestandsschutzProblematik, WiVerw. 1986, 87 (89f.).

94 Unkart, Raumplanung und Eigentumsgarantie, JB1. 1966, 305 f., der diesen Bestandsschutz aus der in allen Bauordnungen normierten Erhaltungspflicht ableitet. Ebenso Fröhler/Oberndorfer I (Fn. 35) 158.

$95 \$ 24$ Abs. 1 Sbg. ROG, $\$ 25$ Abs. 4 Stmk. ROG, $\$ 15$ Abs. 6 Tir. ROG, $\$ 69$ Abs. 1 lit. h. WrBauO.

${ }^{96}$ Friauf, WiVerw. 1986, 95 ff.; Nüßgens/Boujong, Eigentum, Sozialbindung, Enteignung (1986) $27 \mathrm{ff}$.

97 Wo genau die Grenzen des verfassungsrechtlichen Bestandsschutzes liegen, muß letztlich das Verfassungsgericht im wohlerwogenen Ermessen entscheiden. Auf die subtile Differenzierung zwischen einfachem aktiven und sogenanntem überwirkenden oder übergreifenden Bestandsschutz wird daher nicht eingegangen.

$98 \$ 79$ GewO.

99 $\$ 82$ GewO.

$100 \$ 17$ BImmSchG.

101 Donninger, Betriebsanlagenrecht und verwandte Rechtsgebiete (1988) 42; Aichlreiter, $\$ 79$ GewO und Nachbarrecht, WBl. 1990, 162 (163). $\$ 17$ BImmSchG sieht im Gegensatz dazu in diesem Fall den Widerruf der Genehmigung und die Gewährung einer Entschädigung vor. 
Auch die wasserrechtlichen Vorschriften passen ins Bild. Auch das Wasserrechtsgesetz läßt Durchbrechungen der Rechtskraft und Befristungen von Bewilligungen nur nach Maßgabe von Kriterien zu, die eine in der Relation Aufwand-Erfolg unverhältnismäßige Belastung hintanhalten ${ }^{102}$.

Die vorgesehenen Maßnahmen sind vom verfassungsrechtlich anerkannten Interesse am Umweltschutz gedeckt und zur Zielerreichung tauglich und adäquat. Sie haben in Österreich bislang keine Einwände hervorgerufen. Es gibt auch keine Diskussion darüber, ob damit die verfassungsrechtliche Reformgrenze erreicht ist ${ }^{103}$.

Was den Eigentumsschutz gegenüber Öko-Lenkungsabgaben ${ }^{104}$ oder -beiträgen ${ }^{105}$ anbelangt, ist die Frage aus der Sicht der bisherigen Rechtsprechung des Verfassungsgerichtshofs von bescheidenem Interesse. Dieser sieht durch Abgaben- oder Beitragsregelungen das Eigentumsgrundrecht nämlich erst dann als verletzt an, wenn die Pflichtigen exzessiv belastet werden ${ }^{106}$. Wohl aber werden die Interessen der Eigentümer über eine Sachlichkeitsprüfung nach dem Gleichheitsgrundsatz durch den Verfassungsgerichtshof geschützt ${ }^{107}$. Dogmatisch ist die Konzentrierung auf den Gleichheitsgrundsatz freilich problematisch $^{108}$.

102 Wasserbenutzungsbewilligungen $(\$ 21)$ und Bewilligungen von Einwirkungen auf Gewässer $(\$ 32)$ sind befristet zu erteilen. Die Fristlegung hat nach Abwägen des Bedarfs des Bewerbers einerseits und den öffentlichen Interessen andererseits für die jeweils längste vertretbare Zeitdauer (maximal 90 Jahre) zu erfolgen. Nachträgliche Anordnungen zum Schutz der öffentlichen Interessen $(\$ 21 \mathrm{a})$ können für alle Bewilligungen nach dem WRG unter Berücksichtigung des Grundsatzes der Verhältnismäßigkeit getroffen werden. Bei der generellen Festlegung von Emissionswerten $(\$ 33$ a) sind für Altanlagen Sanierungsfristen festzulegen, die nach Abwägung des wirtschaftlichen Aufwands für die Sanierung und des Ausmaßes der zu erwartenden Emissionsminderung verlängert werden können $(\$ 33 \mathrm{c})$.

${ }^{103}$ Anders in der Bundesrepublik Deutschland: Breuer, in von Münch, Besonderes Verwaltungsrecht ${ }^{8}$ (1988) 676; Stettner (Fn. 58) 555 ff.

104 Unter Abgaben sind nach der Rsp. des VfGH (VfSlg. 1465/1932, 3919/1961, 5811/1968, 9335/1982) Geldleistungen zu verstehen, die eine Gebietskörperschaft kraft öffentlichen Rechts zur Deckung ihres Finanzbedarfs erhebt. Beispiel für eine Öko-Lenkungsabgabe: erhöhter Mineralölsteuersatz für verbleites Benzin.

105 Also solche Geldleistungen, die nicht an Gebietskörperschaften erbracht werden. Als Beispiel für einen Ökobeitrag kann die sog. Bodenschutzabgabe nach dem MarktordnungsG angeführt werden, die den Einsatz von Kunstdünger reduzieren soll.

106 VfSlg. $7770 / 1967,7996 / 1977,9750 / 1983$ u.a.

107 VfSlg. 8233/1978, 8457/1978, 10001/1984.

108 So schon zutreffend Karl Korinek, Gedanken zur Bindung des Gesetzgebers an den Gleichheitsgrundsatz nach der Judikatur des VfGH, Melichar-FS (1983) $41 \mathrm{f}$. 
In den bisherigen Erörterungen der eigentumsgrundrechtlichen Zulässigkeit von Eigentumsbeschränkungen blieb die Frage ausgeklammert, wann eine Eigentumsbeschränkung ihrer Schwere wegen eine Entschädigung notwendig macht. Zu dieser Abgrenzungsfrage ist eine Reihe von Theorien entwickelt worden ${ }^{109}$, die berechtigte Kritik erfahren haben. Das Scheitern der von Walter Leisner ${ }^{110}$ so genannten Großformeln liegt in der Eigenart des Problems der Einschätzung der Eingriffsschwere einer Eigentumsbeschränkung im Vergleich mit den für klassische Enteignungen typischen Belastungen. Man kann demnach nur versuchen, Gesichtspunkte herauszuarbeiten, die bei Bewältigung dieser Wertungsfrage sinnvollerweise zu berücksichtigen sind. Ohne Anspruch auf Vollständigkeit erheben zu können, erachte ich folgende Aspekte für relevant. Fraglos ist es für die klassische Enteignung typisch, daß sie den einzelnen oder eine kleine Gruppe trifft, man spricht von Sonderopfer ${ }^{111}$. Auch Eigentumsbeschränkungen können Sonderopfercharakter haben, der nicht notwendig Enteignungsgleichheit bedeutet, aber als ein Indiz zu deuten ist ${ }^{112}$. Relevant ist fraglos auch, inwieweit die Eigentumsbeschränkung eine sinnvolle privatnützige Gebrauchnahme vom Eigentum zuläßt. Nicht ohne guten Grund wird in der Lehre auch darauf abgestellt, ob und inwieweit bereits von der durch die Beschränkung nunmehr verschlossenen Nutzungsmöglichkeit schon Gebrauch gemacht wurde ${ }^{113}$. Dem Eigentümer, der ein ihm gehöriges Grundstück nur zur Vermögensanlage nutzen will, kann das Risiko einer Wertminderung durch Änderung der Widmung zugemutet werden ${ }^{114}$. Die Reihe der topoi ließe sich fortsetzen ${ }^{115}$.

109 Siehe dazu etwa Papier (Fn. 17) Rdn. 283-317.

110 Sozialbindung des Eigentums (1972) 185.

111 Daß darüber hinaus materielle Kriterien notwendig sind, um sozialpflichtige Eigentumsbeschränkung und Enteignung voneinander abzugrenzen (dazu die berechtigte Kritik der Lehre an der sog. Sonderopfertheorie z. B. in Papier [Fn. 17] Rdn. 303 ff.), ändert nichts an der Richtigkeit dieser Feststellung.

112 Das Vorliegen einer Sonderopferlage wird in der Lehre als ein mögliches Abgrenzungskriterium von Eigentumsbeschränkungen und "materieller Enteignung“ herangezogen: Binder, Die Entschädigung für Flächenwidmungsänderungen, ÖJZ 1956, 146 (149), Pernthaler II (Fn. 41) 304 f.; Aicher, 9. ÖJT, I/1 19.

113 Papier (Fn. 17) Rdn. 88-90 zu Art. 14.

114 Dieser Gedanke kommt in der Entschädigungsregelung des Vlbg. RPIG $(\$ 25)$ zum Ausdruck, wonach ein Entschädigungsanspruch unter anderem besteht, wenn ein Grundstück innerhalb einer bestimmten Frist zu einem Baugrundpreis erworben wurde und die Bebauung durch eine Planänderung verhindert wird.

${ }^{115}$ Letztlich ist Korinek (Fn. 20) $43 \mathrm{f}$. darin zu folgen, daß eine Abgrenzung nur im Sinne einer Kombination der verschiedenen Kriterien im Sinne eines beweglichen Systems vorgenommen werden kann. 
Vor dem Hintergrund einer Rechtsprechung, die aus der Eigentumsgarantie überhaupt keine Entschädigungspflicht ableitet, bieten die Regelungen der österreichischen Raumordnungsgesetze zur Frage des Ersatzes von Schäden durch Widmungsänderungen ein buntes Bild. Der Bogen reicht vom Schweigen des Gesetzgebers ${ }^{116}$ über eine Beschränkung des Ersatzes von nutzlos gewordenen Aufwendungen ${ }^{117}$ bis hin zu Regelungen, die eine Sonderopferlage im Vergleich zu Eigentümern in gleicher Situation berücksichtigen ${ }^{118}$ oder auch darauf Bedacht nehmen, ob das nunmehr nicht bebaubare Grundstück innerhalb einer nicht allzu weit zurückliegenden Frist zu Baugrundpreisen erworben wurde ${ }^{119}$. Auch findet sich die Regelung, daß ein durch Widmungsänderung entwertetes Grundstück einen Einlösungsanspruch des Eigentümers gegenüber der $\mathrm{Ge}$ meinde auslöst ${ }^{120}$. Eine genaue Darstellung und eine eingehende verfassungsrechtliche Beurteilung dieser Regelungen muß ich mir versagen. Die meisten sind jedenfalls eigentumsgrundrechtlich unzureichend.

\section{Eigentumsbeschränkungen, die den Liegenschaftsverkebr betreffen}

Eine Sonderproblematik im Kreise der Eigentumsbeschränkungen stellen die Beschränkungen des rechtsgeschäftlichen Verkehrs mit Liegenschaften dar. Da der Verfassungsgerichtshof die Liegenschaftsverkehrsfreiheit nur gegen die ehemaligen Klassenbevorrechtungen gerichtet hält, sieht er die Möglichkeiten des einfachen Gesetzgebers bei Beschränkung des Liegenschaftsverkehrs nicht auf die in Art.6 StGG allein ausdrücklich vorbehaltenen Beschränkungen für kirchliche Einrichtungen begrenzt ${ }^{121}$. Er hatte daher keine grundrechtlichen Vorbehalte gegen das land- und forstwirtschaftliche Grundverkehrsrecht $^{122}$ und das Ausländergrunderwerbsrecht ${ }^{123}$, die - wie eingangs erwähnt - durch Kompetenzvorschriften nunmehr verfassungsrecht-

116 Krnt. ROG.

$117 \$ 24$ nö. ROG.

$118 \$ 34$ stmk. ROG.

$119 \$ 25$ Vlbg. RplG. Vgl. dazu auch oben Fn. 114.

$120 \$ 59 \mathrm{BauO}$ für Wien.

121 So z. B. in VfSlg. 1682/1948, 2404/1952, 6157/1971, 7468/1974, 8766/1980.

122 VfSlg. $21 / 1919,5562 / 1967,8766 / 1980,9131 / 1981$ u. a.

123 VfSlg. 6092/1969, 6718/1972. 
lich unzweifelhaft gedeckt sind ${ }^{124,125}$. Wie ich die Dinge einschätze, wird der Verfassungsgerichtshof bei seiner Rechtsprechung bleiben. Aktuelle Gesetzesvorhaben durch Genehmigungsvorbehalte, den Grundstückverkehr zur Hintanhaltung von Zweitwohnsitzen und bloßen Vermögensanlagen zu beschränken ${ }^{126}$, könnten dann verfassungsrechtlich nur am Mangel der Verhältnismäßigkeit der Eingriffe scheitern.

\section{Enteignungen}

Der schwerste Eingriff ins Eigentum, den die österreichische Eigentumsgarantie zuläßt, ist die klassische Enteignung ${ }^{127}$. Sie besteht im Gegensatz zur Eigentumsbeschränkung im gänzlichen oder teilweisen Entzug eines vermögenswerten Privatrechts und nicht bloß in der Beschränkung der Ausübung eines solchen Rechts. Die Grenze zwischen Teilenteignung und Eigentumsbeschränkung ist fraglos fließend, aber gewiß leichter zu markieren als jene zwischen entschädigungsfreien und entschädigungspflichtigen Eigentumsbeschränkungen. Die Markierung zwischen Teilenteignung und Eigentumsbeschränkung wird wohl nur in der Weise möglich sein, daß man typische Fälle des Entzugs und typische, also unbestritten als solche zu qualifizierende Eigentumsbeschränkungen einander gegenüberstellt und nach Maßgabe der Merkmalsidentität des zu beurteilenden Eingriffs mit dem einen oder dem anderen Pol eine Zuordnung vornimmt. Entschärft wird die Abgrenzungsfrage übrigens durch den Einzelfallcharakter der Enteignung und durch das Erfordernis eines konkreten Bedarfs.

124 Siehe Fn. 3 und 4.

${ }^{125}$ Die Frage, ob über diese beiden verfassungsrechtlich legitimierten Beschränkungen hinaus noch andere Beschränkungen zulässig sind, führt den Interpreten in ein rechtes Dilemma. Anerkennt man die Zulässigkeit, meint man, dic genannten kompetenzrechtlichen Regelungen bestätigten die Rsp. des VfGH, dann stellt sich die nicht leicht plausibel zu beantwortende Frage, warum es dann überhaupt das Grundrecht auf Liegenschaftsverkehrsfreiheit gibt. Genügten da nicht Art. 5 StGG und der Gleichheitsgrundsatz? Geht man den Weg restriktiver Auslegung und läßt man keine weiteren Beschränkungen zu, dann kämpft man mit dem Wertungswiderspruch, warum gerade der Liegenschaftsverkehr in einem liberalistischen Sinn frei sein soll, während die anderen Grundrechte unbestrittenermaßen nicht liberalistisch $\mathrm{zu}$ interpretieren sind.

126 Entwurf des BMJ, JMZ 2035/37-I, 2/90.

${ }_{127}$ Daß Sozialisierungen unzulässig sind, wurde bereits dargelegt. 
Was die materiellen Voraussetzungen einer zulässigen Enteignung anbelangt, hat der Verfassungsgerichtshof 1959 eine aus der übrigen Eigentumsjudikatur herausragende Entscheidung getroffen, die im Gegensatz zu den Verstaatlichungserkenntnissen steht. Er hat dort ausgeführt: „Der Gesetzgeber darf ... eine Enteignung nur ... vorsehen, ... soweit es notwendig ist, Privatrechte zu entziehen, um einem Gebot des allgemeinen Besten zu entsprechen ... Es muß demnach ein konkreter Bedarf vorliegen, dessen Deckung im öffentlichen Interesse liegt, es muß weiters das Objekt der Enteignung überhaupt geeignet sein, diesen Bedarf unmittelbar zu decken, und es muß schließlich unmöglich sein, den Bedarf anders als durch Enteignung zu dek$\mathrm{ken}{ }^{128}$. Hier wird also das Erfordernis eines im öffentlichen Interesse liegenden Vorhabens mit dem Gebot der Verhältnismäßigkeit verknüpft.

Wenn Enteignungen dem öffentlichen Interesse dienen müssen, schließt dies Enteignungen zugunsten Privater nicht aus. Wenn der begünstigte Private die enteignete Sache in einem gemeinnützigen Unternehmen ${ }^{129}$ einsetzt, ist dem Erfordernis entsprochen. Auch die Nutzung der enteigneten Sache in privatnütziger Weise kann, wenn die Erbringung von Leistungen im öffentlichen Interesse liegt, dem allgemeinen Besten dienen ${ }^{130}$.

Das Erfordernis des konkreten Bedarfs trifft insbesondere im Raumordnungsrecht auf entgegenlaufende Interessen. So schließt dieses Erfordernis eine Enteignung allein zur Realisierung eines Bebauungsplanes im Sinne einer Positivplanung aus ${ }^{131}$. Desgleichen sind Enteignungen auf Vorrat, die raumplanerischen Anliegen nützlich sein könnten, ausgeschlossen. Wenn z. B. Raumordnungsgesetze die

128 VfSlg. 3666/1959.

${ }^{129}$ Wie bei jeder Enteignung entsteht auch bei der Enteignung zugunsten Privater ein Rückübereignungsanspruch bei Nichterreichen des angestrebten Zwecks. Darüber hinausgehende Anforderungen an die Dauer des verfolgten Allgemeininteresses zu stellen, ist nicht gerechtfertigt.

${ }_{130}$ Unter diesem Gesichtspunkt stellt das RohrleitungsG sicher einen Grenzfall dar. Zwar bilden gewisse öffentliche Interessen bereits eine Voraussetzung der Konzessionserteilung (gegenwärtiger oder künftiger volkswirtschaftlicher Bedarf). Es kann aber auch für nicht konzessionspflichtige Rohrleitungsanlagen enteignet werden, was verfassungswidrig ist.

$131 \mathrm{Vgl}$. schon oben bei Fn. 86. Die in diesem Zusammenhang geäußerten verfassungsrechtlichen Bedenken treffen auch auf die Möglichkeit einer Enteignung zum Zweck der Weiterveräußerung an Private, die in der Folge das Planungskonzept verwirklichen sollen, zu; zu den entsprechenden Regelungen des BBauG vgl. Bullinger, Die Enteignung zugunsten Privater, Der Staat 1962, 449 (473f.). 
Ausweisung von Vorbehaltsflächen für Baulichkeiten, die öffentlichen Zwecken dienen, vorsehen und an die Widmung von Vorbehaltsflächen die Möglichkeit der Enteignung zugunsten der nach dem Zweck Begünstigten vorsehen, ohne daß eine Bedarfsprüfung und eine Verhältnismäßigkeitsprüfung stattzufinden hat ${ }^{132}$, ist dies mit der Eigentumsgarantie unvereinbar.

Die klassische Enteignung verlangt - wie gesagt - nach einhelliger Lehre $^{68}$ und entgegenstehender ständiger Rechtsprechung des Verfassungsgerichtshofs ${ }^{69}$ eine angemessene Entschädigung. Verfehlt ist es allerdings, den Entschädigungsanspruch unmittelbar aus dem Eigenturnsgrundrecht abzuleiten ${ }^{133}$. Er muß durch Gesetz geregelt werden. Die Entschädigungsregelung kann im Enteignungsgesetz enthalten sein, sie kann unter Wahrung der bundesstaatlichen Kompetenzverteilung auch als generelle für alle Enteignungen einheitlich normiert $\operatorname{sein}^{134}$. Es ist mangels eines ausdrücklichen Junktimgebots meines Erachtens auch zulässig, die Entschädigungsregelung einem späteren Gesetz vorzubehalten, das aber innerhalb angemessener Frist ergehen muß, widrigenfalls das Enteignungsgesetz verfassungswidrig wird ${ }^{135}$.

Nicht geringe Auslegungsprobleme wirft die Frage auf, wie die Entschädigungshöhe der Eigentumsgarantie nach zu bestimmen ist. Art. 5 StGG, aus dem die herrschende Lehre die Entschädigungspflicht ableitet, spricht selbst ausdrücklich nicht von der Entschädigung. Vielmehr wird die Entschädigungspflicht im Hinblick auf die Orientierung des Grundrechtsgesetzgebers an der Eigentumsordnung des ABGB aus $₫ 365$ dieses Gesetzbuches abgeleitet. Diese präkonstitutionelle Eigentumsordnung spricht eher dafür ${ }^{136}$, daß die angemessene Entschädigung im Sinne des $\$ 365$ durch den sogenannten gemeinen Preis zu bestimmen ist, also vom Nutzen bestimmt wird, den die

132 Vgl. etwa $\$ 17$ bgld. ROG.

133 Die gegenteilige Auffassung von Aicher, 9. OJT, I/1, 70f., ist mit dem Legalitätsprinzip und dem speziellen Gesetzesvorbehalt in Art. 5 Satz 2 StGG schwer zu vereinbaren. Ob man die Entschädigung als Begriffsmerkmal oder Rechtsfolge der Enteignung versteht, ist dabei ohne Bedeutung.

${ }_{134} \$ 365$ ABGB i.V.m. $\$ 13$ VerwaltungsentlastungsG 1925 reicht als Anspruchsgrundlage nicht hin, weil $₫ 365$ ABGB nicht mehr als unmittelbar anwendbare Regelung zu verstehen ist. A.M. Barfuß, Eigentum und Vollziehung in Österreich, EuGRZ 1984, 572 (576).

135 Abgesehen von allen anderen gegen die Verstaatlichung vorgebrachten verfassungsrechtlichen Bedenken werden die Entschädigungsregelungen des 1. und 2. Verstaatlichungs-EntschädigungsG, BGBl. 1954/89 und BGBl. 1960/3, dieser Anforderung nicht gerecht.

136 Aicher, 9. ÖJ, I/1, 72. 
Sache mit Rücksicht auf Zeit und Ort gewöhnlich und allgemein leistet ${ }^{137}$. Im Hinblick auf diesen historischen Hintergrund, aber insbesondere wegen der allgemeinen Tendenz des Staatsgrundgesetzes, der Gesetzgebung nicht geringe Gestaltungsspielräume zu gewähren, kann ich mich nicht dazu verstehen, eine vollständige Schadloshaltung für verfassungsrechtlich garantiert zu erachten ${ }^{138}$. Was die Entschädigungsregelungen in den beiden wichtigsten einschlägigen einfachen Gesetzen anbelangt, so gewährt das Eisenbahnenteignungsgesetz in Österreich volle Schadloshaltung ${ }^{139}$, während das Bundesstraßengesetz Ansatzpunkte für eine objektiv-abstrakt zu berechnende Entschädigungshöhe wie auch für eine konkrete Berechnung des Entschädigungsschadens liefert, wozu die überwiegende Judikatur neigt ${ }^{140}$.

Zuletzt sei zur Abrundung der Erläuterung des österreichischen Instituts der Enteignung noch darauf hingewiesen, daß nach neuester Rechtsprechung des Verfassungsgerichtshofs unmittelbar auf Grund der Verfassung ein Rückübereignungsanspruch für den Fall besteht, daß die enteignete Sache nicht für den Enteignungszweck verwendet wird $^{141}$. Dem einfachen Gesetzgeber ist es allerdings unbenommen, die Rückübereignung näher zu regeln. Davon hat z. B. der Gesetzgeber im Bundesstraßengesetz Gebrauch gemacht ${ }^{142}$.

\section{Schlußbemerkung}

Meine Damen und Herren, ich möchte nun mit folgender Bemerkung den Schlußpunkt setzen: Eine überaus zurückhaltende Judikatur des Verfassungsgerichtshofs zur Eigentumsgarantie hat der Eigentumsgarantie gewiß nicht jene Rolle zugeteilt, die ihr in einem Staate mit liberaler Wirtschaftsordnung angemessen ist. In den letzten zehn Jahren ist aber die Grundrechtsrechtsprechung in Bewegung geraten.

$137 \$ 305$ Satz 1 ABGB.

138 Zur Begründung der gegenteiligen Ansicht (Aicher, 9. ÖJT, I/1, 72 ff., Rummel [Fn. 40] $82 \mathrm{ff}$.) können keinesfalls einfachgesetzliche Enteignungsregelungen aus monarchischer Zeit herangezogen werden. Denn dem Verfassungsgesetzgeber kann nicht unterstellt werden, er hätte mit der Rezeption des Art. 5 StGG in Art. 149 B-VG auch unterverfassungsrechtliche Normen mitübernehmen wollen.

139 \$4 Eisenbahnenteignungs $G$.

140 Vgl. die Nachweise bei Aicher, 9. ÖJT, I/1, $76 \mathrm{ff}$.

141 VfSlg. 8981, 8982/1980, 11017/1986.

$142 \$ 20$ a Bundesstraßen $G$. 
Ich erwarte, daß diese Dynamik auch die Eigentumsrechtsprechung erfassen und die Kritik der Lehre Aufmerksamkeit finden wird. Der Boden- und Umweltpolitik werden daraus keine entscheidenden Hindernisse erwachsen. Sinnvolle Boden- und Umweltschutzpolitik kann und wird nicht an den Grundrechten scheitern. 
Leitsätze des Berichterstatters über:

\section{Eigentum, Sozialbindung und Enteignung bei der Nutzung von Boden und Umwelt}

1. Die bundesverfassungsrechtliche Eigentumsgarantie (Art.5 Staatsgrundgesetz aus 1867 [StGG] und seit 1964 Art. 1 ZP MRK) schützt alle vermögenswerten Privatrechte.

2. Den Inhalt des Eigentums und damit den Umfang der Eigentumsgarantie bestimmt die einfache Gesetzgebung innerbalb nicht allzu weit gesteckter bundesverfassungsrechtlicher Schranken.

3. Diese ergeben sich für Art. 5 StGG aus den wesentlichen Elementen der präkonstitutionellen Eigentumsordnung $(A B G B)$, an der sich der Grundrechtsgesetzgeber von 1867 orientiert hat. Welche Elemente das Prädikat wesentlich verdienen, ist nach den die präkonstitutionelle Eigentumsordnung prägenden Grundgedanken und dem Telos der Eigentumsgarantie zu bestimmen. Nach Art. 1 ZP MRK sind die Grenzen durch den Eigentumsbegriff des Völkergewohnheitsrechts fixiert, wodurch nach dem derzeitigen Stand der Rechtsprechung der Umfang des verfassungsrechtlichen Eigentumsschutzes nicht erweitert wird.

4. Das Telos der Eigentumsgarantie besteht in der Gewäbrleistung einer grundsätzlich marktwirtschaftlichen Ordnung.

5. Als für die Nutzung von Boden und Umwelt relevante Schranken für die einfach-gesetzliche Bestimmung des Inhalts des Eigentums sind folgende bundesverfassungsrechtliche Festschreibungen zu erwähnen:

(a) Die Eigentumsgarantie schützt nicht nur das sogenannte persönliche Eigentum, sondern auch das Eigentum an den Produktionsmitteln Boden und Kapital jeder Größenordnung.

(b) Grund und Boden sind obne Unterschied eigentumsfähig.

(c) Das Sacheigentum ist in der präkonstitutionellen Ordnung als ein volles Herrschaftsrecht gestaltet. Exemtionen aus diesem umfassenden Herrschaftsrecht müssen in der präkonstitutionellen Eigentumsordnung angelegt sein, um im Rabmen einfach-gesetzlicher Inbaltsbestimmung verfügt werden zu dürfen. 
(d) Das Eigentum an Grund und Boden muß sich nicht auf die gesamte Bodensubstanz beziehen, der einfache Gesetzgeber darf Mineralien, die ob ibres Gehalts eine besondere volkswirtschaftliche Bedeutung haben, der Nutzungsbefugnis des Grundeigentümers entziehen.

(e) Die Befugnis zur Nutzung des Grundwassers, des Umweltmediums Luft und die Befugnis zur baulichen Nutzung erfließen aus dem Grundeigentum.

6. Das sogenannte Recht am eingerichteten und ausgeübten Gewerbebetrieb ist kein vermögenswertes Privatrecht.

7. Die Eigentumsgarantie schützt nicht das Vermögen als solches.

8. Öffentlich-rechtliche Ansprüche als solche sind nicht Schutzobjekt der Eigentumsgarantie. (Ein über den Schutz der erbrachten eigenen Beitragsleistungen hinausgehender Schutz von sozialversicherungsrechtlichen Ansprüchen ist mit der Zielsetzung der Eigentumsgarantie nicht $z u$ vereinbaren.)

9. Die sogenannten öffentlich-rechtlichen Nachbaransprüche nach Baurecht oder Betriebsanlagenrecht sind nur als Arsprïche gegenüber der Bebörde, die nachbarscbützenden Normen korrekt anzuwenden, öffentlich-rechtlicher Natur, als Ansprüche gegenüber dem Nachbarn sind sie subjektive Privatrechte.

10. Anlagenrechtliche Verfügungen der Gewerbebebörde greifen wie alle Anordnungen, die aus dem Eigentumsrecht erfließende Nutzungsbefugnisse betreffen, ins Eigentum ein.

11. Hobeitlich verliebene (zugeteilte) Nutzungsbefugnisse als solche genießen nicht den Schutz der Eigentumsgarantie, wobl aber die Verfügungs- und Nutzungsbefugnisse des Eigentümers, die er sich dank der hoheitlich verliehenen Befugnis durch seine Investitionen erworben bat.

12. Das Grundrecht auf freien Liegenschaftsverkebr schützt den rechtsgeschäftlichen Verkehr mit Grundstücken unter Einschluß erbrechtlicher Dispositionen.

13. Im Eigentumsbegriff des Art. 5 StGG ist eine Ermächtigung zu gesetzlichen Eigentumsbeschränkungen „zur Erbaltung und Beförderung des allgemeinen Wobles" (\$364 $A B G B)$ mitverstanden.

14. Enteignung im Sinne des Art. 5 StGG meint im Hinblick auf die Orientierung am $A B G B$ den gänzlichen oder teilweisen Entzug eines vermögenswerten Privatrechts mittels Verwaltungsakts zugunsten eines dem allgemeinen Besten dienenden Vorbabens gegen angemessene Schadloshaltung (klassische Enteignung). 
15. Sozialisierungen (1. und 2. Verstaatlichungsgesetz in Österreich) sind entgegen der Rechtsprechung des VfGH durch Art. 5 nicht gedeckt, da sie Maßnabmen struktureller Wirtschaftspolitik darstellen und demnach von der klassischen Enteignung wesensverschieden sind.

16. Eigentumsbeschränkungen von besonderer Schwere unterliegen gemäß Art.5 StGG der Entscbädigungspflicht.

17. Im Hinblick auf die Entschädigungspflicht (Thesen 14 und 16) und dem Ausschluß von Sozialisierungen (These 15) ist Art.5 StGG gegenüber Art.1 ZP MRK die günstigere Bestimmung im Sinne von Art. 60 MRK.

18. Die Haftungsinstitute „enteignungsgleicher Eingriff" und „enteignender Eingriff" sind der österreichischen Rechtslage und -praxis fremd.

19. Die österreichische Bundesverfassung enthält keinen Verfassungsauftrag, bestimmte umweltpolitische Ziele zu verfolgen: Das verfassungsrechtliche Bekenntnis zum umfassenden Umweltschutz schreibt nur fest, daß der Umweltschutz im offentlichen Interesse liegt. - Auch wenn das Grundrecht auf Leben und die Eigentumsgarantie einen Schutz gegen zu großzü̈gige Gefährdungserlaubnisse bieten, kann darin kein Umweltschutz-Gestaltungsauftrag gesehen werden. (Die genannten Grundrechte sind z. B. in der Frage der prinzipiellen Zulässigkeit der Stromerzengung mittels Atomenergie neutral.)

20. Die Gesetzesvorbehalte des Art.5 StGG und des Art. 1 ZP $M R K$ eröffnen dem Gesetzgeber ein weites Feld der Entscheidung darüber, was dem öffentlichen Wohle frommt. Die ältere Rechtsprechung des Verfassungsgerichtshofs hat den Gesetzesvorbehalten eine $z u$ weite Auslegung gegeben. Die neuere Rechtsprechung, die jedenfalls der Sache nach - Eigentumsbeschränkungen nur zuläßt, wenn sie dem öffentlichen Interesse dienen und hierfür tauglich und adäquat sind, ist de constitutione lata wobl begründet.

21. Die Bauplanung als Positivplanung zu gestalten, steht im grundsätzlichen Widerspruch zur Eigentumsgarantie. Die für eine Baulandwidmung sprechenden Gründe allein rechtfertigen keine Baugebote.

22. Der von der Eigentumsgarantie geforderte aktive Bestandsschutz im Baurecht ist in den meisten Bundesländern nicht gewährt.

23. Der Verfassungsgerichtshof schützt das Vertrauen in den Bestand von Raumplänen, stützt sich dabei aber nicht auf die Eigentumsgarantie.

24. Das Betriebsanlagenrecht der Gewerbeordnung, das Luftreinhaltegesetz für Kesselanlagen und das Wasserrechtsgesetz tragen in ibren Ermächtigungen, von rechtskräftigen Bewilligungen Abwei- 
chendes zu verfügen, dem Verbot unverbältnismäßiger Belastung des Eigentümers Rechnung.

25. Der Verfassungsgerichtshof hat bis dato Abgaben-oder Beitragsregelungen - verfehlterweise (These 20) - nur bei exzessiver Belastung des Pflichtigen für unvereinbar mit der Eigentumsgarantie erachtet, aber die Interessen des Eigentümers (vor allem in der jüngeren Rechtsprechung) über eine Sachlichkeitsprüfung nach dem Gleichbeitsgrundsatz geschützt.

26. Für die Abgrenzung der entschädigungsfreien von der entschädigungspflichtigen Eigentumsbeschränkung lassen sich nur Gesichtspunkte herausarbeiten, deren Berücksichtigung bei der Lösung dieser Wertungsfrage berücksichtigt werden sollen, wie Sonderopferlage, Ausmaß der Beschränkung sinnvoller privatnütziger Gebrauchnabme und Ausmaß der Wertminderung, bereits getätigte Investitionen.

27. Die einfach-gesetzliche Rechtslage betreffend die Entschädigung von Eigentumsbeschränkungen ist vor dem Hintergrund der Rechtsprechung des Verfassungsgerichtshofs zu sehen, daß aus Art.5 StGG und Art. 1 ZP MRK überbaupt kein Entschädigungsgebot abgeleitet werden kann. Die Rechtslage ist daber uneinheitlich und entspricht z. B. im Raumordnungsrecht weitgebend nicht den Anforderungen der Eigentumsgarantie.

28. Obgleich Art.6 StGG (Liegenschaftsverkebrsfreiheit) ausdrücklich nur für bestimmte kirchliche Einrichtungen einen Gesetzesvorbehalt enthält, siebt der Verfassungsgerichtshof das Grundrecht nur gegen Klassenbevorrechtungen gerichtet und läßt gesetzliche Verfügungsbeschränkungen $z u$, so daß Art. 6 StGG weitgehend seinen Charakter als lex specialis zu Art. 5 StGG verliert. Es ist daber zu erwarten, daß die in Österreich aktuellen Bestrebungen, den Verkebr mit Baulandgrundstücken verwaltungsbehördlichen Beschränkungen $z$ unterwerfen, an der Liegenschaftsverkehrsfreiheit - vorbehaltich der Beachtung des Verbältnismäßigkeitsgrundsatzes - nicht scheitern werden.

29. Die Grenze zwischen klassischer Enteignung und Eigentumsbeschränkung ist fraglos fließend. Man wird die Teilenteignung von der Eigentumsbeschränkung wobl nur in einem typologischen Verfabren abgrenzen können. Im übrigen erleichtert das Erfordernis der Dekkung eines konkreten Bedarfs die Abgrenzung von Enteignung und Eigentumsbeschränkung (konkret-individuell, abstrakt-generell).

30. Im Gegensatz zum Hauptstrom der Rechtsprechung zur Eigentumsgarantie und lange bevor der Gedanke des Verhältnismäßigkeitsgrundsatzes die Grundrechtsrechtsprechung zu prägen begann, umschrieb der Verfassungsgerichtshof (VfSlg. 3666/1959) die materiel- 
len Voraussetzungen einer verfassungsmäßigen (klassischen) Enteignung völlig zutreffend so: „Der Gesetzgeber darf ... eine Enteignung nur ... vorsehen, ... soweit es notwendig ist, Privatrechte $z u$ entzieben, um einem Gebot des allgemeinen Besten zu entsprechen... Es muß demnach ein konkreter Bedarf vorliegen, dessen Deckung im öffentlichen Interesse liegt, es muß weiters das Objekt der Enteignung überbaupt geeignet sein, diesen Bedarf unmittelbar zu decken, und es muß schließlich unmöglich sein, den Bedarf anders als durch Enteignung zu decken."

31. Eine Enteignung allein zum Zwecke der Durchsetzung eines Flächenwidmungsplans im Sinne einer Positivplanung verletzt die Eigentumsgarantie (vgl. These 21). Es ist daher z. B. eigentumsgrundrechtswidrig, wenn ein Raumordnungsgesetz die Ausweisung sogenannter Vorbehaltsflächen für verschiedene öffentliche Zwecke zuläßt und dem durch den Zweck Begünstigten das Recht auf Enteignung einräumt, obne daß die Enteignung den in These 30 umschriebenen eigentumsgrundrechtlichen Anforderungen genügen muß.

32. Eine Enteignung zugunsten Privater ist zulässig, wenn diese die enteignete Sache im Rahmen eines gemeinnützigen Unternebmens (gemeinnützige Wohnbauvereinigung) einsetzen oder wenn die privatnützige Gebrauchnahme vom enteignetem Gut im öffentlichen Interesse liegt, was der österreichische Gesetzgeber z. B. für Robrleitungsunternehmen ganz generell annimmt.

33. Die Pflicht zur Enteignungsentschädigung folgt nicht unmittelbar aus Art. S StGG, sie muß nach dem Gebot, daß Enteignungen nur in den Fällen und in der Art eintreten, die das Gesetz bestimmt (Art.5 Abs. 2 StGG), gesetzlich geregelt werden.

34. Die Regelung der Entschädigung muß nicht in dem die Enteignung vorsehenden Gesetz enthalten sein. Der einfache Gesetzgeber kann sich auch der Technik bedienen, für alle Enteignungen ein gemeinsames Entschädigungsrecht zu erlassen. Auch ist es nicht verfassungswidrig, wenn das Enteignungsgesetz die Entscbädigungsregelung einem späteren Gesetz vorbehält, das innerhalb angemessener Frist ergeht, widrigenfalls das Enteignungsgesetz verfassungswidrig wird.

35. Für den Fall, daß die enteignete Sache nicht für den Enteignungszweck verwendet wird, bestebt unmittelbar auf Grund der Verfassung oder auf Grund die Rückübereignung allenfalls näher regelnder Vorschriften ein Anspruch auf Rückübereignung (VfSlg. 8981/1980). 


\section{Eigentumsschutz, Sozialbindung und Enteignung bei der Nutzung von Boden und Umwelt}

2. Bericht von Prof. Dr. Dirk Eblers, Münster

\section{Inhalt}

Scitc

I. Der Eigentumsbegriff des Grundgesetzes . . . . . . . 214

II. Die Eigentumsgewährleistung $\ldots \ldots \ldots \ldots \ldots \ldots \ldots 216$

1. Die Institutsgarantie des Eigentums $\ldots \ldots \ldots \ldots \ldots 216$

2. Die Bestandsgarantie des Eigentums . . . . . . . 216

a) Das Recht auf Nutzung des Bodens . . . . . . . 217

b) Das Recht auf Nutzung des Wassers . . . . . . . . 219

c) Das Recht auf Nutzung der Luft . ......... 220

3. Der Schutz vor nicht imperativen Beeinträchtigungen . . 221

III. Die verfassungsrechtlichen Direktiven der Eigentumsgestaltung . .................. 224

1. Die Unterscheidung von Inhalts- und

Schrankenbestimmungen ................ 224

2. Das verfassungsrechtliche Abwägungsgebot $\ldots \ldots \ldots 226$

3. Die Bindung an das Übermaßverbot . . . . . . . . . . 227

a) Der personelle und sachliche Bezugspunkt der Verhältnismäßigkeitsprüfung . . . . . . . . . 227

b) Die Unterscheidung von ausgeübten und nicht ausgeübten Nutzungen . . . . . . . . . 229

c) Die Auferlegung von Positivpflichten ......... 231

d) Die Beachtlichkeit von Kumulationen und Subventionsleistungen . . . . . . . . . . 231

e) Ausgleichspflichtige Inhaltsund Schrankenbestimmungen . . . . . . . . . 232

IV. Die Enteignung . . . . . . . . . . . . . . 234

1. Der Begriff der Enteignung . . . . . . . . . . . . 234

a) Das Merkmal der Entziehung . ........... 236

b) Die Durchbrechung der Eigentumsordnung . . . . . 238

c) Das Kriterium des gezielten öffentlichen Rechtsaktes . 238 
d) Die Indienstnahme für Staatsaufgaben $\ldots \ldots \ldots \ldots 239$

2. Die Zulässigkeit der Enteignung . . . . . . . . . 240

a) Das Allgemeinwohlerfordernis . . . . . . . . . . . 240

(1) Der Enteignungszweck ............... 240

(2) Die gesetzlichen Anforderungen ........... 240

(3) Enteignungsrechtliche Vorwirkungen . . . . . . 241

b) Das Entschädigungserfordernis . . . . . . . 242

V. Die Eigentumsunrechtshaftung $\ldots \ldots \ldots \ldots \ldots \ldots 242$

1. Die Haftung für enteignungsgleiche Eingriffe . . . . 243

2. Die Haftung für enteignende Eingriffe $\ldots \ldots \ldots \ldots 246$

VI. Fazit und Ausblick . . . . . . . . . . . . . 247 
Die intensive Nutzung von Boden, Wasser und Luft hat auch in Deutschland zu erheblichen Mißständen geführt, die etwa in einer starken Landzersiedelung und -versiegelung, der Bodenverseuchung durch Altlasten und andere Kontaminierungen, einem dramatischen Artenrückgang, dem Waldsterben sowie der Wasserverunreinigung und Luftverschmutzung zum Ausdruck kommen ${ }^{1}$. Mitursächlich für diese Entwicklung soll nach einer verbreiteten Ansicht die Eigentumsgarantie des Art. 14 GG sein, weil sie dem Eigentümer ein Recht auf Umweltnutzung und damit vielfach zugleich auf Schädigung der Umwelt einräume ${ }^{2}$. Daß Eigentums- und Umweltschutz in einem Spannungsverhältnis stehen, ist offensichtlich. Nähere Aussagen über dieses Verhältnis lassen sich aber erst gewinnen, wenn Klarheit über den Sinngehalt der Eigentumsgarantie erzielt worden ist.

Die Grundrechtsbestimmung des Art.14 GG wurde unter der Rechtsprechungsägide des Bundesgerichtshofs über Jahrzehnte hinweg eher aus der Sicht ihres Absatzes 3 als aus derjenigen des Absatzes 1 interpretiert: Eigentumsschutz also vornehmlich durch Entschädigung gewährt ${ }^{3}$. Es ist das Verdienst des Bundesverfassungsgerichts, die Eigentumsgarantie von ihrem entschädigungsrechtlichen Kopf auf die grundrechtlichen Füße gestellt zu haben ${ }^{4}$. Drei zutreffende Grundannahmen prägen die Rechtsprechung des Gerichts 5 . Erstens hat die Verfassungsjudikatur deutlich herausgestellt, daß Art. 14 GG in qualitativ und quantitativ anderer Weise als die sonstigen Grundrechte auf gesetzliche Ausgestaltung angelegt ist. Zweitens geht das Gericht davon aus, daß Freiheit und Eigentum keine Gegensätze sind, auch Art. 14 GG vielmehr ein Freiheitsrecht konstituiert. $\mathrm{Da}$ Freiheit nicht kommerzialisierbar ist, bedeutet dies zugleich, daß die Eigentumsgewährleistung in erster Linie eine Bestandsgarantie enthält, die sich nur in Ausnahmefällen in eine Wertgarantie verwandelt. Drittens folgt aus dieser Stoßrichtung des Art.14 GG ein Vorrang des primären vor dem sekundären Rechtsschutz und die Ablehnung eines Wahlrechts nach dem Motto "Wehre dich oder liquidiere“. Im übrigen ist vieles offen oder unklar geblieben.

1 Vgl. Hoppe/Beckmann, Umweltrecht, 1989, \$1 Rdn. 25 ff.; Kloepfer, Umweltrecht, 1989, \$1 Rdn. $8 \mathrm{ff}$.

2 Näher zu dieser Sichtweise - und ihrer Berechtigung - Sendler, UPR 1983, 33 ff.; Isensee, in: Ossenbühl (Hrsg.), Eigentumsgarantie und Umweltschutz, 1990, S. 3 (4 ff.); Schink, DVBl. 1990, 1375 f.

3 Zutreffend dazu Osterlob, DVBl. 1991, 906 (907).

${ }^{4}$ So auch Schoch, Jura 1989, 113.

$5 \mathrm{Vgl}$. bereits (zunächst kaum beachtet) BVerfGE 4, 219 (230ff.); 24, 367 (389); ferner insbes. BVerfGE 58, 300 (318ff.); 68, 193 (222); 83, 201 (208f.). 
Im folgenden wird zunächst zum Eigentumsbegriff (I.), zur Eigentumsgewährleistung (II.) und zu den verfassungsrechtlichen Direktiven der Eigentumsgestaltung (III.) Stellung genommen. Sodann soll das Augenmerk auf die Enteignung (IV.) und die Eigentumsunrechtshaftung (V.) gerichtet werden. Ein Fazit und ein kurzer Ausblick (VI.) schließen die Ausführungen ab. Auf die gestern behandelte Eigentumsfrage in den neuen Bundesländern wird absprachegemäß nicht eingegangen.

\section{Der Eigentumsbegriff des Grundgesetzes}

Als Eigentum im verfassungsrechtlichen Sinne ist das gegen den Staat gerichtete Recht des Bürgers zu verstehen, einen ihm von der Rechtsordnung zugeordneten Vermögensgegenstand innezuhaben und zu nutzen $^{6}$. Da es kein natürliches Eigentum gibt, können Schutzobjekte der Eigentumsgarantie nur die durch Gesetz oder aufgrund Gesetzes eingeräumten Rechtspositionen sein ${ }^{7}$. Entgegen der herkömmlichen Ansicht ${ }^{8}$ ist es deshalb nicht angängig, zum Beispiel bestimmte Anlieger- oder Nachbarrechte ohne einfachgesetzliche Vermittlung verfassungsunmittelbar aus Art. 14 Abs. 1 S. 1 GG herzuleiten?.

Dem Eigentum im Sinne des Grundgesetzes sind zum einen alle vermögenswerten Rechte des privaten Rechts zuzurechnen ${ }^{10}$. Diese Rechte entfalten über Art. 14 Abs.1 S. 1 GG als Transformationsnorm

6 Das BVerfG spricht zwar davon, daß der Begriff des Eigentums aus der Verfassung gewonnen werden müsse (E 58, 300, 335), definiert diesen Begriff aber nicht. Zur Begriffsbildung vgl. auch Wendt, Eigentum und Gesetzgebung, 1985, S. 12, 73.

7 Die Gesetzesabhängigkeit des Schutzbereiches schließt entgegen Kleinlein (DVBl. 1991, 365, 369) die Herleitung eines Folgenbeseitigungsanspruchs und eines Rückenteignungsanspruchs (im Falle der Nichtverwirklichung des Enteignungszwecks) aus Art. 14 GG nicht aus. Vgl. zum letzteren BVerfGE 38, 175 (179ff.); BVerwGE 85, 96 (98f.).

${ }^{8}$ Vgl, zum Anliegerrecht: BVerwGE 30, 235 (238f.); 32, 222 (224 ff.); BVerwG, NJW 1988, 432 (433); zum Nachbarrecht: BVerwGE 32, 173 (178); Hoppe, in: Ernst/Hoppe, Das öffentliche Bau- und Bodenrecht, Raumplanungsrecht, 2. Aufl. 1981, Rdn. 454; Steinberg, Das Nachbarrecht der öffentlichen Anlagen, 1988, S. 20.

9 Läßt sich das einfache Recht nicht verfassungskonform auslegen (vgl. z. B. BVerwGE 81, 329, 335), kann sich aus Art.14 I 1 GG u.U. ein Recht auf Gesetzgebung ergeben. Dagegen stellt die ausfüllungsbedürftige Eigentumsgewährleistung nicht selbst Rechtspositionen bereit.

${ }^{10}$ Vgl. BVerfGE 70, 191 (199); Kimminich, BK, Drittbearb. 1976, Art. 14 Rdn. 55 f. 
eine Tatbestandswirkung im Verfassungsrecht ${ }^{11} . \mathrm{Zu}$ den vermögenswerten Rechten des Privatrechts gehört auch das Recht am eingerichteten und ausgeübten Gewerbebetrieb ${ }^{12}$ - jedenfalls solange dieses als sonstiges Recht im Sinne des $₫ 823$ Abs. 1 BGB angesehen wird ${ }^{13}$. Es handelt sich um ein Auffangrecht, das sich auf die Rechtsgesamtheit ${ }^{14}$ eines wirtschaftlichen Unternehmens bezieht. Da regelmäßig erst die Gesamtheit den besonderen Wert des Unternehmens ausmacht, geht der Schutz über die Summe der ohnehin gewährleisteten Einzelrechte hinaus. Er erstreckt sich darauf, die im Unternehmen zusammengefaßten Rechte behalten und nutzen zu dürfen ${ }^{15}$.

Zum anderen unterfallen die vermögenswerten Rechte des öffentlichen Rechts dem verfassungsrechtlich geschützten Eigentum, sofern sie nicht ausschließlich auf eine staatliche Gewährung zurückgehen ${ }^{16}$. Wie noch zu zeigen sein wird, liegen solche Rechte nicht nur vor, wenn sie auf beträchtlichen Eigenleistungen oder eigenen Opfern beruhen, sondern insbesondere auch dann, wenn sie in einem Zusam-

${ }^{11}$ D.h., sie gelten nicht nur gegenüber Privaten, sondern schützen ihre Inhaber auch gegenüber dem Staat. Vgl. Ramsauer, Die faktischen Beeinträchtigungen des Eigentums, 1980, S. 146 f.; Wendt (Fn. 6), S. 134.

12 So im Ergebnis auch die h. M., vgl. BVerwGE 67, 93 (96); BGHZ 111, 349 (355 f.); Badura, in: Benda/Maihofer/Vogel, HdbVerfR, 1983, S. 653 (692 f.). A. A. z. B. Sendler, UPR 1983, 33 (36); Kutschera, Bestandsschutz im öffentlichen Recht, 1990, S. 40 ff. Bedenken hat auch das BVerfG geäußert (E 51, 193, 221 f.), ohne sich festzulegen.

${ }_{13}$ Dies ist zwar im Privatrecht umstr. (vgl. Medicus, Bürgerliches Recht, 15. Aufl. 1991, Rdn.614), aber ganz h. M. Entgegen der üblichen Auffassung handelt es sich nicht um reines Richterrecht, sondern um die richterrechtliche Ausfüllung eines unbestimmten Rechtsbegriffs („sonstiges Recht“). Geht man davon aus, daß Art. 14 GG alle vermögenswerten Rechte des Privatrechts schützt, müßte begründet werden, warum hier etwas anderes gelten soll.

${ }^{14}$ In der Rspr. wird zumeist von "Sach- und Rechtsgesamtheit“ gesprochen (BGHZ 111, 349, 356), doch werden auch die Sachen nur insoweit geschützt, als sie Gegenstand rechtlicher Zuordnung sind.

${ }_{15}$ Ein Schutz des Unternehmens allein durch Art.12 GG (Rittstieg, AK-GG, Bd. I, 2. Aufl. 1989, Rdn.100; vgl. auch Steinberg/Lubberger, Aufopferung Enteignung und Staatshaftung, 1991, S.79f.) reicht nicht aus, weil z.B. der staatliche Befehl, ein bestehendes Unternehmen aufzugeben, nicht nur den Erwerb, sondern auch das Erworbene betrifft. Die generelle Ausklammerung der Chancen und Verdienstmöglichkeiten aus dem Schutz des Art. 14 I GG (BVerfG, NVwZ 1991, 358) geht daher zu weit. Vielmehr ist zwischen imperativen Einwirkungen und sonstigen Nachteilszufügungen zu unterscheiden. $\mathrm{Vgl}$. auch Bryde, in: v. Münch, GG, Bd. 1, 3. Aufl. 1985, Art. 14 Rdn. 21, sowie die Ausf. zu II.3.

16 Vgl. zum Meinungsstand BVerfGE 53, 257 (289 ff.); 69, 272 (300 ff.); Leisner, in: Isensee/Kirchhof (Hrsg.), HdbStR, Bd. VI, 1989, $\$ 149$ Rdn. 119 ff. Krit. Papier, 
menhang mit den vermögenswerten Rechten des privaten Rechts stehen oder kompensatorisch an deren Stelle treten ${ }^{17}$. Das Vermögen als solches wird nicht geschützt ${ }^{18}$.

\section{Die Eigentumsgewährleistung}

Bekanntlich enthält Art. 14 Abs. 1 S. 1 GG sowohl eine Instituts- als auch eine subjektivrechtliche Bestandsgarantie ${ }^{19}$.

\section{Die Institutsgarantie des Eigentums}

Die Institutsgarantie verpflichtet den Gesetzgeber, Normen zur Verfügung zu stellen, welche die reale Geltung der Eigentumsgewährleistung sichern ${ }^{20}$. Sie zielt inhaltlich im Sinne eines Leitprinzips auf die Gewährleistung der Freiheit im vermögensrechtlichen Sinne ab, garantiert dem Bürger einen Mindeststandard privatnützig zugeordneter Vermögensrechte ${ }^{21}$ und wirkt insoweit als strikt zu beachtendes Untermaßverbot ${ }^{22}$.

\section{Die Bestandsgarantie des Eigentums}

Die subjektivrechtliche Bestandsgarantie schützt alle dem Grundrechtsinhaber zustehenden vermögenswerten Rechtspositionen vor Beeinträchtigungen des Staates. Hier geht es um die Frage, ob ein Recht auf Nutzung des Bodens, des Wassers und der Luft besteht.

Eigentumsgarantie des Grundgesetzes im Wandel, 1984, S.9ff. Für eine grds. Einbeziehung der Wirtschaftssubventionen in den Schutz des Art. 14 GG: Stücke, Eigentum an Wirtschaftssubventionen, 1991, S. $54 \mathrm{ff}$.

17 Vgl. die Ausf. zu II.2.a) u. b).

18 BVerfGE 74, 129 (148); BVerwG, DVBl. 1991, 938 (940).

${ }^{19}$ Die Institutsgarantie (BVerfGE 24, 367, 389f.; 31, 229, 240f.) stell eine besondere Ausprägung des objektivrechtlichen Gehalts des Art. 14 I 1 GG dar, die subjektivrechtliche Bestandsgarantie räumt dem einzelnen ein Grundrecht ein.

20 Sie kann auch organisatorische und verfahrensrechtliche Vorkehrungen gebieten. Vgl. Papier, in: Maunz/Dürig, GG, 1983, Art. 14 Rdn. 43 ff.; Schmidt$A \beta$ mann, in: FS der Juristischen Fakultät zur 600-Jahr-Feier der Ruprecht-KarlsUniversität Heidelberg, 1986, S. 107 (123 f.).

${ }^{21}$ Von der Privatnützigkeit wird grds. auch die Verfügungsbefugnis mitumfaßt (vgl. dazu BVerfGE 83, 201, 208 f.). Daß sich der Gesetzgeber nicht allein an Art. 14 I 1 GG auszurichten hat, ergibt sich aus Art. 14 I 2 u. II GG. Vgl. die Ausf. zu III. 2 .

22 Allgemein zum grundrechtlichen Untermaßverbot Scherzberg, Grundrechtsschutz und „Eingriffsintensität“, 1989, S.208ff. 
a) Das Recht auf Nutzung des Bodens. Was die bauliche Nutzung des Bodens betrifft, ist heftig umstritten, ob zu den Elementen des verfassungsrechtlich geschützten Eigentums auch die Baufreiheit gehört. Die Befürworter dieser Ansicht leiten eine entsprechende Rechtsposition aus Art.14 Abs. 1 S. 1 GG $^{23}$ oder $\$ 903$ BGB $^{24}$ her, während die Gegenmeinung ${ }^{25}$ nur eine von vornherein beschränkte, rein öffentlich-rechtliche Verleihung der Bebauungsbefugnis auf einfachgesetzlicher Grundlage anerkennt. Keiner dieser Auffassungen ist zu folgen.

Die Berufung allein auf Art. 14 Abs. 1 S. 1 GG greift nicht durch, weil die Eigentumsgarantie notwendigerweise der gesetzlichen Ausformung bedarf. $\$ 903$ BGB wird weitgehend durch die Normen des öffentlichen Rechts ${ }^{26}$ überlagert. Die rein öffentlich-rechtliche Konzeption ist mit dem Untermaßverbot der Institutsgarantie nicht vereinbar. Die bauliche Nutzung von Grundstücken gehört zum elementaren Bestand der vermögensrechtlichen Betätigung, welcher der Privatrechtsordnung nicht gänzlich entzogen werden darf ${ }^{27}$. Eine nur öffentlich-rechtliche Verleihung der Bebauungsbefugnis würde sich weitgehend im grundrechtsfreien Raum bewegen. Der Grundeigentümer hat aber einen Anspruch darauf, daß seine aus dem privatrechtlichen Eigentum resultierenden Belange bei der Baurechtsgesetzgebung und vor allem der Bebauungsplanung berücksichtigt werden. Im Ergebnis kommt es daher nicht auf das private oder öffentliche Recht, sondern auf die Gesamtheit der baurechtlich relevanten Vorschriften beider Rechtskreise an ${ }^{28}$. Art. 14 Abs. 1 S. 1 GG schützt das Recht des

${ }^{23}$ Hoppe, in: Ernst/Hoppe (Fn. 8), Rdn. 165 (der in Rdn. 166 aber einschränkend von einer "potentiellen“ Baufreiheit spricht); Oldiges, in: Steiner (Hrsg.), Besonderes Verwaltungsrecht, 3. Aufl. 1988, IV Rdn. 136 ff.; Maurer, Allgemeines Verwaltungsrecht, 7. Aufl. 1990, $\$ 9$ Rdn.51. Vgl. auch BVerwGE 48, 271 (273); BGHZ 88, 51 (59).

${ }^{24}$ Wendt (Fn. 6), S. 170 ff.; vgl. auch Papier (Fn. 20), Rdn. 59 ff.; Peine, Raumplanungsrecht, 1987, S. 101; Leisner (Fn. 16), Rdn. 104.

${ }^{25}$ Breuer, Die Bodennutzung im Konflikt zwischen Städtebau und Eigentumsgarantie, 1976, S. $162 \mathrm{ff}$.; ders., in: Schrödter, BauGB, 4. Aufl. 1980, $\$ 44$ Rdn. 8 ff.; Schulte, DVBl. 1979, 133 ff.; Rittstieg (Fn. 15), Art. 14 Rdn. 92.

26 Insbes. die $\$ \$ 29 \mathrm{ff}$. BauGB.

${ }_{27}$ Zum elementaren Bestand grundrechtlich geschützter Betätigung vgl. BVerfGE 24, 367 (389); 58, 300 (339).

28 Zur Maßgeblichkeit des privaten und öffentlichen Rechts vgl. BVerfGE 58, 300 (335f.); 72, 66 (77). 
Grundeigentümers, sein Grundstück auf der Grundlage und im Rahmen dieser Vorschriften zu bebauen ${ }^{29}$.

Dies schließt die Teilhabe der Baufreiheit an der Institutsgarantie des Eigentums nicht aus ${ }^{30}$. Da sich die Institutsgarantie aber nur an den Gesetzgeber wendet und gerade nicht allein den Inhalt der Gesetze bestimmt, hat der einzelne kein Grundrecht auf Baufreiheit im Sinne eines umfassenden Rechts, das nur nachträglich Beschränkungen unterworfen werden darf. So hängt die bauliche Nutzung des Bodens vielfach von einer vorgängigen Bebauungsplanung und damit von der pflichtgebundenen „Freiheit" eines anderen - nämlich der planerischen Gestaltungsfreiheit der Verwaltung - ab, ohne daß der Grundeigentümer die Aufstellung der Bauleitpläne beanspruchen $k a_{n}{ }^{31}$. Was von der Freiheit übrigbleiben muß, bestimmt wiederum das Untermaßverbot. Insbesondere darf die Erteilung der Bebauungsbefugnis - von den Planvorbehalten ${ }^{32}$ und Besonderheiten atomrechtlicher Anlagegenehmigungen ${ }^{33}$ abgesehen - nicht in das Ermessen der Verwaltung gestellt werden ${ }^{34}$.

$\mathrm{Da}$ die Nutzungszuweisungen der öffentlich-rechtlichen Baugesetze und Bebauungspläne vor dem Hintergrund und im Zusammenhang mit den durch $\$ 903 \mathrm{BGB}$ eingeräumten Herrschaftsbefugnissen des Grundeigentümers gesehen werden müssen, unterfallen sie stets der verfassungsrechtlichen Eigentumsgarantie, obwohl sie nicht das Äquivalent eigener Leistung darstellen. An dem Grundrechtsschutz nehmen ferner die rechtmäßigen ${ }^{35}$, wegen der Gesetzesabhängigkeit des Schutzbereiches dagegen nicht die rechtswidrigen ${ }^{36}$ Baugenehmigungen teil.

${ }^{29} \mathrm{Zu}$ Unrecht stellt das BVerfG nur auf den „Rahmen der Gesetze“ ab (E 35, 263, 276f.).

${ }^{30}$ Erbguth, Bauplanungsrecht, 1989, Rdn. $16 \mathrm{ff}$.

31 Vgl. \$2 III BauGB.

32 Näher dazu Wabl, DVBl. 1982, 51 (56f.).

33 \$ 7 II AtG statuiert ein repressives Verbot mit Befreiungsvorbehalt (Eblers, in: Achterberg/Püttner, Besonderes Verwaltungsrecht, Bd. 1, 1990, S. 211; a. A. die h. M., vgl. BVerfGE 49, 89, 145).

${ }^{34}$ Demgemäß muß $₫ 35$ II BauGB i.S. einer zwingenden Norm ausgelegt werden (BVerwGE 18, 247, 249 ff.; BGH, MDR 1981, 652; a. A. Ortloff, NVwZ 1988,320 ff.).

35 A. A. Stettner, BayVBl. 1991, 550 (556) m. w. N.

${ }^{36}$ A. A. Krebs, in: Grimm/Papier (Hrsg.), Nordrhein-westfälisches Staats- und Verwaltungsrecht, 1986, S. 379 (413 f.); Knoke, Rechtsfragen der Rücknahme von Verwaltungsakten, 1989, S. $199 \mathrm{ff}$. Einen „enteignungsgleichen Eingriff“ i. S. d. $\$ 48$ VI letzter Halbs. VwVfG gibt es nach der hier vertretenen Ansicht nicht. 
Für die sonstige Nutzung des Bodens - etwa der Naturgüter gelten grundsätzlich dieselben Maßstäbe wie für die bauliche Nutzung ${ }^{37}$.

b) Das Recht auf Nutzung des Wassers. Prinzipiell anders als die Nutzung des Bodens ist dagegen die (wirtschaftliche) Nutzung des Wassers geregelt, weil das Wasserhaushaltsgesetz die Gewässerbenutzung und den Ausbau der oberirdischen Gewässer zwar nicht vollständig, aber weitgehend der Privatrechtsordnung entzogen und von einer im Ermessen der Verwaltung stehenden Zulassung abhängig gemacht hat ${ }^{38}$. Wegen der lebenswichtigen Bedeutung des Wassers, seiner Empfindlichkeit und der überindividuellen Zugriffsfolgen sind die sehr einschneidenden Regelungen des Wasserhaushaltsgesetzes nicht nur für das Grund-, sondern auch für das Oberflächenwasser mit dem Untermaßverbot der Institutsgarantie vereinbar ${ }^{39}$. Die prinzipielle Herausnahme der Gewässerbenutzung aus dem Grundeigentum besagt aber nicht, daß die Gewährleistung des Art. 14 Abs. 1 S. 1 GG für die Gewässerbehörden unbeachtlich ist. Zum einen müssen die Behörden im Rahmen ihres Ermessens die Auswirkungen ihrer Entscheidungen auf den durch Art. 14 Abs.1 S.1 GG geschützten Bereich - zum Beispiel die bauliche Nutzbarkeit der Erdoberfläche oder den eingerichteten und ausgeübten Gewerbebetrieb - mitberücksichtigen ${ }^{40}$. Dies spricht für die Annahme eines Anspruchs des

37 Bestimmte Ausübungsrechte sind zur Verfolgung öffentlicher Zwecke auf öffentlich-rechtliche Realkörperschaften mit Zwangsmitgliedschaft - wie z.B. Wasser- und Bodenverbände - übertragen worden, wobei die Körperschaften nicht selbst Träger des Eigentumsgrundrechts werden (teilweise a. A. Hoppel Beckmann, DVBl. 1990, $177 \mathrm{ff}$.). Ferner sind gew. Sachkategorien - wie die bergfreien Bodenschätze ( 3 II 2 BBergG; grundlegend dazu BVerwGE 81, $329 \mathrm{ff}$;; Hoppe, Das Spannungsverhältnis von Bergwerkseigentum und Oberflächeneigentum im Lichte des Verfassungsrechts, 1991, S. 9 ff.), die öffentlichen Straßen und Wege (z.B. $\$ 2$ FStrG) oder die besonderen spaltbaren Stoffe (Art.86 EAGVertrag), nicht aber die landesrechtlichen Schatzregale (a. A. Lorenz, NVwZ 1989, $812,816)$ - ganz oder teilweise aus dem privatrechtlichen Grundeigentum herausgenommen und einem öffentlich-rechtlichen bzw. europarechtlichen Nutzungsregime unterstellt worden.

$38 \$ \$ 1$ a III, $2 \mathrm{ff}$. WHG.

39 Zum Grundwasser: BVerfGE 58, 300 ff. Vgl. ferner Brener, Öffentliches und privates Wasserrecht, 2. Aufl. 1987, Rdn. 80. Krit. Wendt (Fn.6), S. 222 ff.; Papier (Fn. 20), Rdn. 371 aff.

${ }_{40} \mathrm{Vgl}$. auch Krebs, in: Krebs/Oldiges/Papier, Aktuelle Probleme des Gewässerschutzes, 1990, S. 1 (24). Ferner: BGHZ 90, 4 (10); krit. dazu Soell, NuR 1984, $185 \mathrm{ff}$. 
Nutzungsinteressenten auf ermessensfehlerfreie Entscheidung, der sich in bestimmten Fällen sogar zu einem Anspruch auf Zulassung verdichten kann. Zum anderen dürften die dem Grundeigentümer rechtmäßig erteilten Erlaubnisse oder Bewilligungen eine Kompensation für die aus dem Grundeigentum herausgenommenen Nutzungsbefugnisse darstellen und daher Eigentumsqualität besitzen ${ }^{41}$.

c) Das Recht auf Nutzung der Luft. Wenden wir uns dem dritten Umweltmedium - der Luft - zu, liegt die Frage auf der Hand, ob das, was dem oft so arg malträtierten Wasser recht ist, nicht der häufig kaum besser behandelten Luft billig sein muß $\$^{42}$. Im Schrifttum wird eine analoge rechtliche Behandlung von Wasser und Luft nach Maßgabe eines Bewirtschaftungsermessens der Verwaltung zunehmend gefordert ${ }^{43}$. Die überragende Bedeutung einer reinen Luft rechtfertige es, diese als „öffentliches Gut ${ }^{\text {“44 }}$ oder „öffentliche Sache ${ }^{\alpha 45}$ einzustufen. Die Luftbenutzung beruhe daher nicht auf dem Eigentum, sondern auf einer öffentlich-rechtlichen Zuteilung der Nutzungschancen, die wie eine Subventionierung wirke ${ }^{46}$.

Diese Auffassung geht nicht nur am geltenden Gesetzesrecht insbesondere der $\$ \$ 905 \mathrm{BGB}, 6 \mathrm{BImSchG}{ }^{47}$ - vorbei, sondern setzt sich auch zum Untermaßverbot der Institutsgarantie in Widerspruch. Eine Grundstücksnutzung ist in der Regel ohne Inanspruchnahme des

${ }^{41}$ Allgemein zum Kompensationsgedanken: Kutschera (Fn. 12), S. $63 \mathrm{ff}$. Zum Vertrauensschutz im Wasserrecht vgl. Salzwedel, FS für Sendler, 1991, S. $321 \mathrm{ff}$. (ohne Bezugnahme auf Art. 14 GG).

42 Ausdrücklich zu dieser Fragestellung Sendler, UPR 1983, 33 (38).

43 Murswiek, Die staatliche Verantwortung für die Risiken der Technik, 1986, S. 357 ff.; Stettner, BayVBl. 1991, 550 (553). Vgl. auch Jarass, BImSchG, 1983, Vor $\$ 4$ Rdn. 5 .

${ }_{44}$ Murswiek, in: Scholz (Hrsg.), Wandlungen in Technik und Wirtschaft als Herausforderung des Rechts, 1985, S. 67 (68, 110); Soell, NuR 1985, 205 (209). Krit. zum juristischen Gehalt des Ausdrucks Schulte, VerwArch. 77 (1986), 372 (401 f. m. Fn. 139).

45 Lorenz, NVwZ 1989, 812 (816, 819). Ob nur körperliche Gegenstände öffentliche Sachen sein können (so Papier, Recht der öffentlichen Sachen, 2. Aufl. 1984, S. 2), mag hier dahinstehen. Jedenfalls ist der Luftraum nach geltendem Recht nur partiell einer öffentlich-rechtlichen Nutzungsordnung unterstellt worden (vgl.

z. B. $\$ 1$ I LuftVG, $\$ 1$ IV Nr. 2 FStrG).

46 So Sendler, UPR 1983, 33 (41).

47 Die Vorschrift ist als präventives Verbot mit Erlaubnisvorbehalt ausgestaltet. Vgl. BVerwGE 55, 250 (253 f.); Sellner, Immissionsschutzrecht und Industrieanlagen, 2. Aufl. 1988, Rdn. 21. 
Wassers, aber niemals ohne Inanspruchnahme der Luft möglich. Ein zweidimensionales „luftleeres“ Grundeigentum wäre für jedermann funktionslos ${ }^{48}$ und würde de facto einer Abschaffung des Privateigentums an Grund und Boden nahekommen. Der Eigentümer muß daher berechtigt sein, nicht nur den Boden, sondern auch die Luftsäule über dem Boden bis zu einer gewissen Höhe auf der Grundlage und im Rahmen der Gesetze zu benutzen, ohne daß die Zulassung der Nutzung von einem Bewirtschaftungsermessen der Verwaltung abhängig gemacht werden darf ${ }^{49}$. Das schließt einen effektiven Umweltschutz - insbesondere die Verpflichtung eines Anlagenbetreibers auf das Vorsorgeprinzip - nicht aus ${ }^{50}$, verlangt aber entsprechende gesetzliche Normierungen ${ }^{51}$.

\section{Der Schutz vor nicht imperativen Beeinträchtigungen}

Die Reichweite des Eigentumsschutzes bei der Nutzung der Umwelt wird maßgeblich davon beeinflußt, ob Art. 14 Abs. 1 S. 1 GG auch vor nicht imperativen Beeinträchtigungen schützt. Insoweit geht es in der Regel nicht um eine Begrenzung des Umweltschutzes, sondern im Gegenteil um einen Schutz der Umwelt durch Abwehr umweltbelastender Vorhaben des Staates oder Privater, die sich störend auf das Eigentum Dritter auswirken. Verfassungsrechtlich ist hierbei zu differenzieren. Weder schützen die Grundrechtsbestimmungen nur die Adressaten staatlicher Regelungsakte, noch gewähren sie Schutz vor jeder realen Nachteilszufügung ${ }^{52}$. Ein Schutz nur der Adressaten liefe auf eine erhebliche Freistellung der Staatsgewalt von der Grundrechtsbindung, ein Schutz vor jeder Nachteilszufügung auf eine uferlose Ausdehnung des subjektiven grundrechtlichen Abwehranspruchs im Sinne eines allgemeinen Rechtsvollziehungsanspruchs

\footnotetext{
48 Friauf, WiVerw. 1986, 87 (102 ff.). Vgl. auch Schröder, UPR 1986, 127 (130).

49 Anderenfalls müßte z. B. auch die baurechtliche Genehmigung eines Einfamilienhauses in das Ermessen der Verwaltung gestellt werden, weil auch insoweit Luft in Anspruch genommen wird.

50 A. A. Wieland, WuR 1991, 128 (131), der davon ausgeht, daß das Vorsorgeprinzip immer mit einem Bewirtschaftungssermessen verbunden ist. Zutreffend weist Henseler (in: Scholz, Fn. 44, S. 95, 98) unter Bezugnahme auf das Vollzugsdefizit im Wasserrecht darauf hin, daß mehr Flexibilität der Behörden auch weniger Umweltschutz bedeuten kann.

51 Wie die bau- unterfällt auch die immissionsschutzrechtliche Genehmigung dem Schutz des Art. 14 I 1 GG (str., vgl. Dolde, NVwZ 1986, 873, 874, Fn. 15).

52 Vgl. zur Problematik statt vieler Bleckmann/Eckhoff, DVB1. 1988, $373 \mathrm{ff}$.
} 
hinaus. Notwendig erscheint die Erarbeitung einer Typologie ${ }^{53}$. Im Falle mittelbarer Nachteilszufügungen kommt es vor allem auf die Zurechenbarkeit und die Intensität der Beeinträchtigung $a^{54}$.

So kann die staatliche Genehmigung privater Vorhaben Eingriffscharakter für den Nachbarn haben, weil der feststellende, gestaltende und unter Umständen auch rechtsverleihende Regelungsgehalt einer Genehmigung ${ }^{55}$ Bindungswirkungen gegenüber dem Nachbarn zu entfalten vermag ${ }^{56}$. Dies wird besonders deutlich, wenn das Gesetz an die Genehmigung ausdrücklich eine Duldungspflicht des Nachbarn knüpft (wie dies etwa im Planfeststellungs-, Immissionsschutz-, Atom-, Wasser- und Gentechnikrecht der Fall ist) ${ }^{57}$. Im übrigen liegt die Eingriffsvorstellung auch der Rechtsschutzbestimmung des $\$ 80 \mathrm{a}$ VwGO zugrunde. Soweit der negatorische Grundrechtsschutz zum Zuge kommt, bedarf es nicht der Annahme einer grundrechtlichen Schutzpflicht des Staates zugunsten des Nachbarn. Damit ist noch nicht die Frage beantwortet, wann ein Eingriff in die Rechte des Nachbarn anzunehmen ist. Der grundrechtliche Eigentumsschutz setzt die Beeinträchtigung oder Verletzung einer nachbarschützenden Norm des einfachen Rechts voraus. Der nachbarschützende Charakter kann sich aber aus einer verfassungskonformen Auslegung ergeben. Das Untermaßverbot der Institutsgarantie verpflichtet den Gesetzgeber nicht nur, den Nachbarn vor schweren und unerträgli-

${ }^{53}$ Formal wäre zwischen Rechts- und Realakten, unmittelbaren und mittelbaren Nachteilszufügungen sowie finalen und unbeabsichtigten Folgen staatlichen Verhaltens zu unterscheiden.

${ }^{54} \mathrm{Vgl}$. Ramsauer, Die faktischen Beeinträchtigungen des Eigentums, 1980, S. 174 ff.; Erichsen, Jura 1987, 367 (369). Gegen ein Abstellen auf die Intensität Schulte, DVBl. 1988, 512 (517). Zu anderen Kriterien vgl. BVerwG, NJW 1989, 2272 (2273).

${ }_{55}$ Die Feststellung bezieht sich auf die Übereinstimmung des Vorhabens mit den Gesetzen, die Gestaltung auf die Aufhebung des Verbots, ohne Genehmigung tätig zu werden. Eine Rechtsverleihung liegt jedenfalls vor, wenn die Genehmigung auf einem Dispens beruht.

56 So auch die h.M. Vgl. BVerwGE 32, 173 (178f.); 50, 282 (286ff.); LübbeWolff, Die Grundrechte als Eingriffsabwehrrechte, 1988, S. 178 ff. Nach a. A. (z. B. Rauschning, VVDStRL 38, 1980, 167, 184 f.; Schwerdtfeger, NVwZ 1982, 5, 7; Hoppe/Beckmann, Fn. 1, $\$ 4$ Rdn. 42) soll nur der Private, der von der Genehmigung Gebrauch macht, nicht der Staat den Nachbarn beeinträchtigen. Das schlösse zwar einen Anspruch des Nachbarn auf staatlichen Schutz vor rechtswidrigen Übergriffen des Privaten nicht aus. Doch würde ein solcher (auf Leistung gerichteter) Schutz später als der Schutz vor staatlichen Eingriffen einsetzen (anders Dimberger, Recht auf Naturgenuß und Eingriffsregelung, 1991, S. 97).

57 Vgl. die $\$ \$ 75$ II VwVfG, 14 BImSchG, 7 VI AtG, 11 I 1 WHG, 23 GenTG. 
chen Belastungen zu schützen ${ }^{58}$, sondern gebietet einen weitergehenden Schutz. Die von der Rechtsprechung mit Hilfe des Gebotes der Rücksichtnahme begründete teilweise Subjektivierung der $\mathbb{\$} \$ 34,35$ BauGB $^{59}$ ist daher im Prinzip unerläßlich, sollen die Vorschriften nicht als verfassungswidrig angesehen werden ${ }^{60}$.

Im Falle einer mittelbaren Einwirkung auf den eingerichteten und ausgeübten Gewerbebetrieb sind besonders strenge Anforderungen an die Zurechenbarkeit des Beeinträchtigungserfolges zu stellen ${ }^{61}$. Schon im Privatrecht wird vorausgesetzt, daß der Eingriff betriebsbezogen erfolgt $^{62}$. Da Art. 14 Abs. 1 S. 1 GG nur hinsichtlich des Schutzobjektes an das Privatrecht anknüpft, die grundrechtliche Eingriffsschwelle gegenüber öffentlich-rechtlichen Einwirkungen aber originär verfassungsrechtlich zu bestimmen ist, können insoweit andere und das heißt zugleich auch höhere Maßstäbe als im Privatrecht gelten. Hervorzuheben ist, daß ein Betriebsinhaber grundsätzlich nicht die Aufrechterhaltung günstiger Umweltbedingungen außerhalb seines Grundstückes beanspruchen $\mathrm{kann}^{63}$. Eigentumsrechtlich gesehen ist ein Krabbenfischer daher nicht vor Erteilung einer Erlaubnis zur Einleitung von Dünnsäure in die Nordsee geschützt ${ }^{64}$.

${ }^{58}$ Lediglich einen solchen Schutz leitet das BVerwG (E 32, 173, 178f.; 50, 282, 287 f.; 66, 307, 309) aus Art. 14 I GG her - allerdings im Wege einer verfassungsunmittelbaren Anwendung der Vorschrift.

59 Vgl. BVerwGE 52, 122 (130f.); BVerwG, NVwZ 1987, 409 f. Die Rspr. ist inzwischen auf zahlreiche weitere Vorschriften übertragen worden, vgl. BVerwGE $78,40(43 \mathrm{f}$.).

${ }^{60}$ Wie hier Lübbe-Wolff (Fn. 56), S. 202. Die verfassungsrechtlichen Wurzeln des Rücksichtnahmegebots werden vom BVerwG (NVwZ 1985, 37, 38) verkannt. Die nähere Ausgestaltung des Nachbarrechts (vgl. etwa Wabl, JuS 1984, 578, 582) ist verfassungsrechtlich nicht vorgegeben. Zur Kritik der Rspr. vgl. Peine, DÖV $1984,963 \mathrm{ff}$.

${ }^{61}$ Erst in zweiter Linie kommt es auf die Intensität der Beeinträchtigung an. Vgl. auch Fn. 63.

${ }_{62}$ Vielfach wird ein Eingriff in die Substanz (vgl. schon BVerfGE 13, 225, 229) verlangt. Näher zum Ganzen Nüßgens/Boujong, Eigentum, Sozialbindung, Enteignung, 1987, Rdn. $76 \mathrm{ff}$.

${ }_{63} \mathrm{Zu}$ den (grds. nicht geschützten) Lagevorteilen gewerblicher Anlieger vgl. BVerfG, NVwZ 1991, 358; VGH Bad.-Württ., NVwZ 1991, 387 (388 f.).

${ }_{64}$ Unklar BVerwGE 66, 307 (309). Wie hier Kunig, JZ 1981, 295 (297 f.); a. A. Ossenbübl, in: ders. (Fn. 2), S. 35 (40ff.). Dagegen läßt sich der staatlichen Warnung vor dem Genuß bestimmter Weine (vgl. BVerwG, DVBl. 1991, $699 \mathrm{ff}$.), der Einführung eines Anschluß- und Benutzungszwangs oder der Verhängung eines Embargos der Eingriffscharakter (grds.) nicht absprechen. 
Eine andere als durch Einschaltung eines Dritten bewirkte Form mittelbarer Einwirkung auf die Eigentumsobjekte stellt die Verpflichtung zur Zahlung von Abgaben dar. Den Abgabeschuldnern bleibt die Wahl, mit welchen Mitteln sie ihre Leistung bewirken wollen. Unmittelbar wird daher nur auf das durch Art. 14 Abs. 1 S.1 GG nicht geschützte Vermögen, indirekt aber auf die Gesamtheit der vermögenswerten Rechte oder auf Einzelpositionen zugegriffen. Soweit die Abgabenerhebung - wie bei einer Umweltsteuer - in imperativer Form erfolgt, ist sie stets an Art. 14 Abs. 1 S. 1 GG zu messen, weil der Eigentümer ${ }^{65}$ genötigt wird, eine vermögenswerte Rechtsposition in Anspruch zu nehmen ${ }^{66}$. Handelt es sich um sonstige Abgaben ${ }^{67}$, kommt es darauf an, ob an die Innehabung und den Gebrauch von Eigentumsrechten angeknüpft wird. Im Ergebnis geht die dadurch erreichte Bindung nicht wesentlich über das hinaus, was sich anderenfalls auch aus sonstigen Verfassungsbestimmungen ${ }^{68}$ herleiten ließe.

\section{Die verfassungsrechtlichen Direktiven der Eigentumsgestaltung}

\section{Die Unterscheidung von Inhalts- und Schrankenbestimmungen}

Nach Art. 14 Abs. 1 S. 2 GG ist der Gesetzgeber dazu berufen, Inhalt und Schranken des Eigentums zu bestimmen. Soweit der Parlamentsvorbehalt nicht eingreift, kommen auch Verordnungen und Satzungen, nicht dagegen Verwaltungsvorschriften in Betracht, weil letztere nicht auf unmittelbare Außenwirkung angelegt sind ${ }^{69}$. In

65 Von der Kreditaufnahme und der altruistischen Hilfe Dritter abgesehen.

66 A. A. das BVerfG, das in st. Rspr. (vgl. E 81, 108, 122) nur übermäßige Geldleistungspflichten, die den Betroffenen grundlegend in seinen Vermögensverhältnissen beeinträchtigen, an Art. 14 GG mißt (vgl. aber auch BVerfGE 58, 137, 144 - Naturalleistungspflicht in Form einer Abgabe). Wie hier die h. L. Vgl. zum Meinungsstand: Birk, Das Leistungsfähigkeitsprinzip als Maßstab der Steuernormen, 1983, S. $205 \mathrm{ff}$; Friauf, Steuerrecht und Verfassungsrecht, 1989, S. $19 \mathrm{ff}$;; Vogel, in: Isensee/Kirchhof (Fn. 16), Bd.IV, 1990, $\$ 87$ Rdn. 85; Kirchhof, ebd., $\$ 88 \mathrm{Rdn} .886 \mathrm{ff}$. Speziell zur Vereinbarkeit von Umweltabgaben mit Art. 14 GG Meßerschmidt, Umweltabgaben als Rechtsproblem, 1986, S. $136 \mathrm{ff}$.

${ }_{67}$ D. h. um Vorzugslasten (Gegenleistungen des Bürgers für eine Leistung des Staates). Zu den "naturschutzrechtlichen Ausgleichsabgaben" vgl. Kloepfer (Fn. 1), $\$ 10$ Rdn. $37 \mathrm{ff}$.

${ }^{68}$ Insbes. Art. 2 I GG. Zur Anwendbarkeit des Verhältnismäßigkeitsprinzips (Äquivalenzprinzips) auf Gebührenerhebungen vgl. BVerfGE 28, 66 (88).

69 A.A. die wohl h.M., die normkonkretisierende Verwaltungsvorschriften anerkennt (BVerwGE 72, 300, 320f.). Vgl. zum Meinungsstand: J.Ipsen, VVDStRL 48 (1990), 177 (191). 
jedem Falle ist es bedenklich, wenn grundlegende Wertungen und Entscheidungen auf die Ebene der Verwaltungsvorschriften verlagert werden - wie dies bei den „Technischen Anleitungen“ zum Teil der Fall ist ${ }^{70}$.

Die Inhaltsbestimmungen einerseits und die Schrankenbestimmungen andererseits lassen sich nicht materiell, sondern nur zeitlich voneinander unterscheiden ${ }^{71}$. Inhaltsbestimmungen regeln oder definieren die Eigentümerstellung für die Zukunft, Schrankenbestimmungen greifen in eine nach bisherigem Recht bestehende Position ein ${ }^{72}$. Dagegen kann nicht $\mathrm{zwischen}$ der Normierung von Befugnissen und Pflichten differenziert werden ${ }^{73}$. Zunächst ist der Gesetzgeber nicht gehalten, die Rechtsstellung im Sinne einer quasi unbegrenzten Freiheit zu definieren, um anschließend bestimmte Herrschaftsbefugnisse wieder von ihr auszuschließen ${ }^{74}$. Selbst $\$ 903$ BGB enthält schon einen tatbestandlichen Vorbehalt zugunsten anderweitiger Gesetze und Rechte Dritter. Des weiteren haben die Inhaltsbestimmungen keinen juristischen Mehrwert gegenüber den Schrankenbestimmungen. Schließlich läßt sich eine materielle Unterscheidung von Inhalt und Schranken praktisch nicht durchführen, wie sich besonders deutlich bei den vermögenswerten Rechten des öffentlichen Rechts zeigt ${ }^{75}$.

70 Zur EG-Problematik vgl. EuGH, NVwZ 1991, $866 \mathrm{ff}$.

71 A. A. z. B. Ramsauer (Fn. 54), S. 73 ff.; Leisner (Fn. 16), Rdn. 133 ff.; Stein, Staatsrecht, 12. Aufl. 1990, \$27 III 1. Vgl. auch Fn. 73.

72 So wohl auch Pieroth/Scblink, Grundrechte, Staatsrecht II, 7. Aufl. 1991, $\$ 23$ Rdn. 995, 1013; vgl. auch Schmitt-Kammler, FS für E. Wolf, 1985, S. 595 (598f.). Üblicherweise wird zwischen Inhalts- und Schrankenbest. keinerlei Unterschied gemacht (vgl. Papier, Fn. 20, Rdn. 251).

73 So aber Lutz, Eigentumsschutz bei "störender" Nutzung gewerblicher Anlagen, 1983, S. 163 ff.; Wendt (Fn. 6), S. 147 ff.; prinzipiell zust. Schwabe, Staat 1988, 93 ( $97 \mathrm{f}$.$) .$

74 BVerfGE 58, 300 (336). Vgl. auch Häberle, Die Wesensgehaltgarantie des Art. 19 Abs. 2 Grundgesetz, 3. Aufl. 1983, S. 179 f.; dens., AöR 109 (1984), 36 (63 ff.).

75 Z.B. ist es nicht angängig, dem einzelnen einen Anspruch auf unbegrenzte Sozialversicherung zuzugestehen und alle Best. über die Entstehungsvoraussetzungen des Rechts und die Höhe der Versicherungsleistung als Schrankenregelungen anzusehen. Die Ablehnung einer materiellen Unterscheidung gebietet nicht, den Maßnahmen gegenüber einem "Störer" mangels einer Befugnis desselben die Eingriffstauglichkeit abzusprechen und als Folge in Kauf zu nehmen, daß best. Grundsätze, wie das Übermaßverbot, ihre Geltung verlieren (so die Befürchtung von Wendt, Fn. 6, S. 160). So greift eine rechtmäßige Abrißverfügung schon deshalb in die Eigentumsgarantie ein, weil der "Schwarzbauer" verpflichtet wird, sein privatrechtliches Eigentum zu zerstören. Wird nur eine Baueinstellung verlangt, ist jedenfalls Art. 2 I GG berührt. 


\section{Das verfassungsrechtliche Abreägungsgebot}

Bei der Erfüllung des ihm in Art.14 Abs.1 S.2 GG erteilten Auftrags, Inhalt und Schranken des Eigentums zu bestimmen, muß der Gesetzgeber einerseits die Institutsgarantie des Art. 14 Abs. 1 S. 1 GG und andererseits das Gebot des Art. 14 Abs. 2 GG beachten ${ }^{76}$. Eine Gemeinwohlbindung gem. Art. 14 Abs. 2 GG ist erforderlich, wenn das Eigentumsobjekt in einem sozialen Bezug steht ${ }^{77}$. Dies ist bei der Nutzung der Umwelt in einem eklatanten Ausmaß der Fall, so daß der Gesetzgeber nicht nur zu einem wirksamen Umweltschutz berechtigt, sondern auch verpflichtet ist ${ }^{78}$. Gerade weil sich Art. 14 Abs. 1 S. 1 GG als Freiheitsrecht darstellt, muß die von vornherein mitangelegte soziale Komponente dieses Rechts um so deutlicher hervorgehoben werden ${ }^{79}$. Allerdings soll der Gebrauch des Eigentums nur "zugleich", niemals allein dem Allgemeinwohl dienen. Es ist deshalb eine umfassende materielle Abwägung zwischen den Privatnützigkeitsinteressen des einzelnen und den Belangen der Allgemeinheit geboten.

Die in Rechtsprechung und Schrifttum entwickelten allgemeinen Sozialbindungsklauseln können das Ergebnis der Abwägung nicht vorwegnehmen. So haben zwar die sog. Enteignungstheorien ${ }^{80}$ nach wie vor einen nicht zu unterschätzenden heuristischen Wert, wenn man sie nicht primär zur Bestimmung der Enteignungsakte, sondern der verfassungsrechtlichen Grenzen zulässiger Eigentumsgestaltung heranzieht ${ }^{81}$. Doch stellen sie nur auf einzelne Gesichtspunkte ab. Zum Beispiel kann die Schwere des Eingriffs nicht ohne weiteres und in jedem Fall den Ausschlag geben, weil es nicht nur auf die Perspektive des Eigentümers, sondern zugleich auf diejenige des Gemeinwohlzwecke verfolgenden Gesetzgebers ankommt ${ }^{82}$.

Zurückhaltung ist auch gegenüber dem vor allem im Natur- und Denkmalschutzrecht beliebten Kriterium der "Situationsgebunden-

76 Vgl. z. B. BVerfGE 37, 132 (140); 52, 1 (29).

7 Böbmer, NJW 1988, 2561 (2573).

${ }^{78}$ Bei der Diskussion über eine „Verankerung des Umweltschutzes im Grundgesetz“ (vgl. Öffentl. Anhörung d. Rechtsausschusses d. Dt. Bundestages, in: Zur Sache 2/88) kann es daher nur um eine zusätzliche Absicherung des Umweltschutzes gehen.

79 I. d.S. bereits H.P. Ipsen, VVDStRL 10 (1952), $74 \mathrm{ff}$.

so Vgl. Ossenbübl, Staatshaftungsrecht, 4. Aufl. 1991, S. $144 \mathrm{ff}$.

81 Ähnlich Schmidt-Aßmann (Fn. 20), S. 118; ders., DVBl. 1987, 216 (218). S. 397.

${ }^{82}$ Vgl. auch v. Brünneck, Die Eigentumsgarantie des Grundgesetzes, 1984, 
heit des Grundeigentums“ ${ }^{\text {83 }}$ geboten. Die Rechtsprechung sieht die "Situationsgebundenheit" zumeist als immanente Beschränkung der Eigentümerrechte an. Indessen lassen sich weder aus der Sozialbindungsklausel des Art. 14 Abs. 2 GG $^{84}$ noch gar aus der „Natur der Sache" verfassungsunmittelbare Pflichten des Eigentümers ableiten. Es ist daher nicht auf den „vernünftigen Eigentümer" ${ }^{\text {"85 }}$ oder die „Verkehrsanschauung ${ }^{486}$, sondern allein auf die gesetzlichen Bestimmungen abzustellen. Der Gesetzgeber kann und muß unter Umständen zwar die unterschiedlichen Realfaktoren verschieden gewichten. Doch reichen hierfür Schlagworte wie das von der Situationsgebundenheit nicht aus.

\section{Die Bindung an das Übermaßverbot}

In der Regel kommt es entscheidend auf die Verhältnismäßigkeit der staatlichen Inpflichtnahme (im engeren Sinne) ${ }^{87}$ und damit auf die Abwägung zwischen der Intensität der Belastung und dem Gewicht der zu ihrer Rechtfertigung angeführten Gründe $a^{88}$.

a) Der personelle und sachliche Bezugspunkt der Verbältnismäßigkeitsprüfung. Da die Inhalts- und Schrankenbestimmungen die Rechte und Pflichten des Eigentümers grundsätzlich generell und abstrakt festlegen, beurteilt sich die Verhältnismäßigkeit der Regelungen prinzipiell nach einer typisierenden Betrachtungsweise. Sind die Verhältnisse sehr unterschiedlich, muß differenziert werden, wobei der

${ }^{83} \mathrm{Vgl}$. etwa BVerfG, NVwZ 1991, 358; BGHZ 105, 15 (18f.); BVerwGE 84, 361 (371); grundlegend Weyreuther, Die Situationsgebundenheit des Grundeigentums, 1983; krit. Papier (Fn. 20), Rdn. 326; Leisner, Situationsgebundenheit des Eigentums - eine überholte Rechtssituation?, 1990; Scbink, DVBl. 1990, 1375 (1381 ff.).

${ }^{84}$ A. A. Badura (Fn. 12), S. 661; Bryde (Fn. 15), Rdn. 67.

${ }^{85}$ So BGHZ 87, 66 (71 f.).

${ }^{86}$ BVerwGE 49, 365 (372).

${ }^{87} \mathrm{Da}$ etwas nicht Vorhandenes nicht übermäßig beschränkt werden kann, entfaltet das Übermaßverbot nicht schon bei der erstmaligen Best. des Eigentumsinhalts, sondern erst dann seine vollen Wirkungen, wenn die einfachgesetzlich ausgeformten Eigentumspositionen durch Änderung des Gesetzesrechts verkürzt werden. Da die Nutzung der Umwelt aber seit langem einfachgesetzlich geregelt ist, kann der Gesetzgeber auf diesem Gebiet grds. nicht Neuland betreten, sondern nur ändernd tätig werden.

${ }_{88}$ Zur Bindung an den Gleichheitssatz vgl. BVerfGE 79, 174 (198); zur Bindung an die Wesensgehaltsgarantie: Chlosta, Der Wesensgehalt der Eigentumsgewährleistung, 1975, S. $39 \mathrm{ff}$. 
Gesetzgeber auch mit Generalklauseln, Dispensmöglichkeiten, Optimierungsgeboten, Ermessensermächtigungen oder Härteausgleichsregelungen arbeiten dar ${ }^{89}$. In dem Ausmaß, in dem das Gesetz auf die Umstände des Einzelfalls verweist, tritt an die Stelle der generellabstrakten eine individuell-konkrete Verhältnismäßigkeitsprüfung ${ }^{90}$. Auch in diesem Falle ist grundsätzlich ein objektiver Maßstab zugrundezulegen $^{91}$.

Die dadurch erreichte Flexibilität darf nicht sofort wieder durch Pauschalüberlegungen unterlaufen werden. Zum Beispiel entfällt die polizei- oder ordnungsrechtliche Zustandsverantwortlichkeit nicht stets, wenn eine Altlast durch Fremdeinwirkungen wie wilde Ablagerungen hervorgerufen worden ist. Vielmehr sind Risiko- und Billigkeitsüberlegungen erst bei der Frage zu berücksichtigen, was dem Verantwortlichen konkret abverlangt werden darf ${ }^{92}$. Nicht gefolgt werden kann daher auch der Ansicht ${ }^{93}$, die Behörde müsse zur Gefahrenerforschung bei einer vermuteten Altlast stets selbst tätig werden und dürfe vom Eigentümer höchstens die Duldung der Untersuchungsmaßnahmen verlangen.

In sachlicher Hinsicht ist grundsätzlich auf das konkrete Eigentumsobjekt abzustellen. So bestimmt sich die Zumutbarkeit denkmalschützender Maßnahmen nach dem verbleibenden Nutzwert des Denkmals und nicht nach den allgemeinen Vermögensverhältnissen des Eigentümers ${ }^{94}$. Stellt sich das Eigentumsobjekt als Teil eines durch Art. 14 Abs. 1

${ }^{89} \mathrm{Vgl}$. Schmidt-Aßmann (Fn. 20), S. 117; ferner: Schulze-Fielitz, DV 1987, 307 (334).

${ }^{0} \mathrm{Zu}$ der (bisher nicht hinreichend geklärten) Unterscheidung von „großer" und „kleiner" Verhältnismäßigkeit vgl. allgemein Jakobs, Der Grundsatz der Verhältnismäßigkeit, 1985, S. 139 f., 164; speziell zum Immissionsschutzrecht: Jarass, DVBl. 1986, 314 (316 ff.); Ossenbübl, NVwZ 1986, 161 (167f.).

91 Das Gesetz kann etwa anderes vorsehen und z. B. zur Vermeidung persönlicher Härten eine Befreiung zulassen. Auch in solchen Fällen reicht ein Hinweis auf die schlechte Finanzlage nicht aus. Hinzu kommen muß etwa, daß der Eigentümer diese Lage nicht selbst zu verantworten hat.

92 So auch der Rat von Sachverständigen für Umweltfragen, Altlasten, Sondergutachten, 1990, S. 205 (der allerdings die Verantwortlichkeit auf Duldungspflichten beschränken will). A. A. Papier, Altlasten und polizeiliche Störerhaftung, 1985, S. 49 ff. Vgl. auch BVerwG, NVwZ 1991, 475.

$93 \mathrm{Zu}$ Unrecht bezeichnet der HessVGH, UPR 1991, 197, unter Berufung auf Breuer, NVwZ 1987, 751 (754), diese Ansicht als nahezu unstreitig; wie hier BayVGH, DVBl. 1986, 1283 (1285); VGH Bad.-Württ., NVwZ-RR 1991, 24 ff. zugleich auch zur Frage, ob zwischen der Verantwortlichkeit und der Kostentragungspflicht differenziert werden kann.

94 Vgl. VGH Bad.-Württ., DÖV 1989, 79 (80 f.); Moench, NVwZ 1988, 304 (309); a. A. Eberl/Martin/Petzel, Bay. DSchG, 3. Aufl. 1985, Art. 4 Rdn. 12 f. 
S. 1 GG geschützten Ganzen dar, ist dies bei der Proportionalitätsabwägung zu berücksichtigen. Werden etwa einzelne Flächen eines landwirtschaftlichen Betriebes unter Naturschutz gestellt oder Veränderungen einer immissionsschutzrechtlichen Anlage verlangt, die technisch, organisatorisch und funktionell in einen Betrieb eingegliedert ist, entscheiden die Auswirkungen auf den Gesamtbetrieb mit über die eigentumsrechtliche Zulässigkeit ${ }^{95}$.

b) Die Unterscheidung von ausgeübten und nicht ausgeübten Nutzungen. Inhaltlich macht es einen erheblichen Unterschied aus, ob sich die Beschränkungen auf bereits verwirklichte oder nur mögliche Nutzungen der Umwelt beziehen. Der durch legale Eigentumsausübung geschaffene Bestand genießt infolge der Aufwendungen und Dispositionen des Eigentümers einen besonderen Vertrauensschutz, der sich unmittelbar aus der Gewährleistung des Eigentums und nicht erst aus dem Rechtsstaatsprinzip ergibt ${ }^{96}$. Im einzelnen hängt die Reichweite dieses Schutzes von der Art des Eigentumsobjektes, dessen Schutzbedürftigkeit in der Zeit und dem tatsächlichen Kontinuitätsvertrauen $a b^{97}$. In der Regel muß eine Umgestaltung der „wohl erworbenen“ Rechte zumindest durch eine Übergangsregelung „abgefedert" werden.

Besonders ausgeprägt ist der Bestandsschutz im Baurecht. Daß es selbst insoweit keinen absoluten Schutz gibt, zeigen etwa die sog. Schweinemästerfälle ${ }^{98}$. Wesentlich größer ist der gesetzgeberische Freiraum im Umweltrecht ${ }^{99}$. Dies läßt sich damit rechtfertigen, daß Umweltbelastungen nicht an der Grundstücksgrenze haltzumachen pflegen, die Eigentümer selbst von den ökologischen Maßnahmen

95 In seiner Tunnelofen-Entscheidung (E 50, 49, $52 \mathrm{ff}$.) hat das BVerwG diesen Gesichtspunkt nicht hinreichend gewürdigt. Krit. auch Dolde, NVwZ 1986, 873 (884). Vgl. ferner $\$ 1$ III 1 der 4. BImSchVO; BVerwGE 69, 351 (355f.).

${ }_{96}$ Zur Grundlage des Vertrauensschutzes vgl. Kunig, Das Rechtsstaatsprinzip, 1986, S. 160; Maurer, in: Isensee/Kirchhof (Fn. 16), Bd. III, 1988, $\$ 60$ Rdn. 23 f., 45.

97 Vgl, zum Meinungsstand: BVerwG, DÖV 1974, 814 (815); Schulze-Fielitz, DV 1987, 307 ff.; Pietzcker, NVwZ 1991, 418 (422); Stettner, BayVBl. 1991, $550 \mathrm{ff}$.

$98 \mathrm{Vgl}$. etwa BVerwG, UPR 1987, $380 \mathrm{ff}$. Ändert sich die Umgebung eines emittierenden, nur durch eine Baugenehmigung abgesicherten Betriebes durch das Heranrücken einer störanfälligen Umgebung, darf vielfach seine Einstellung verlangt werden. Nach der wohl h.M. ist in solchen Fällen keine „Entschädigung“ zu leisten. Krit. dazu Schenke, NuR 1989, 8 (14); Kutschera (Fn. 12), S. 228 ff.

99 Vgl. auch BVerwGE 65, 313 (317f.). Zum Naturschutzrecht: Czybulka, NuR 1988,214 (218). 
profitieren ${ }^{100}$ und es um den Schutz der Lebensgrundlagen aller geht. So unterliegt der Betrieb genehmigungsbedürftiger Anlagen nach dem Bundesimmissionsschutzgesetz dynamischen Dauerpflichten, das heißt Beschränkungen, die sich mit wechselnden Umweltbedingungen, fortschreitenden technischen Standards sowie neuen wissenschaftlichen Erkenntnissen ändern können ${ }^{101}$. Dementsprechend sind in weitgehendem Ausmaß nachträgliche Anordnungen zulässig ${ }^{102}$. Insbesondere kommt es nicht allein auf die wirtschaftliche Vertretbarkeit und damit auf die betriebswirtschaftlichen Folgen $\mathrm{an}^{103}$. Im Rahmen der Verhältnismäßigkeitsprüfung sind die wirtschaftlichen Auswirkungen - etwa die Frage einer Amortisierung der getätigten Investition $^{104}$ - nur mitzuberücksichtigen.

Werden aus wichtigen Gemeinwohlgründen noch nicht verwirklichte Nutzungen des Eigentums ausgeschlossen ${ }^{105}$, muß dies der Eigentümer grundsätzlich hinnehmen, es sei denn, daß die einzige wirtschaftlich sinnvolle Verwendung des Eigentumsobjektes verhindert wird. Auch insoweit bestehen aber bemerkenswerte Unterschiede zwischen dem Bau- und dem Umweltrecht. Zum Beispiel darf die zulässige, jedoch noch nicht ins Werk gesetzte bauliche Nutzung eines Grundstücks innerhalb einer Frist von sieben Jahren prinzipiell nur gegen „Entschädigung“ aufgehoben oder geändert werden ${ }^{106}$, während es im Umweltrecht ähnliche Vorschriften nicht gibt.

100 Grundlegend dazu Leisner, Umweltschutz durch Eigentümer, 1987, S. $26 \mathrm{ff}$.

101 Vgl. Jarass, DVBl. 1985, 193 ff.; Kloepfer (Fn. 1), \$7 Rdn. 93.

102 Erst durch den Erlaß solcher Anordnungen (nach Maßgabe des $\$ 17$ BImSchG) kann die Befolgung der dynamischen Dauerpflichten durchgesetzt werden.

${ }^{103}$ Anders noch die bis zum Inkraftreten der 2. Novelle zum BImSchG geltende Fassung des $\$ 17$.

104 Vgl. dazu Murswiek (Fn. 43), S. 265 ff.; Scbröder, UPR 1986, 127 (131). Krit. Stettner, BayVBl. 1991, 550 (557).

105 Solche Nutzungen unterfallen ebenfalls dem Schutz des Art.14 I GG (Pietzcker, NVwZ 1991, 418, 422). Aus der viel kritisierten Äußerung des BVerfG, daß sich die Problematik der Legalenteignung nur stelle, wenn von einer Nutzungsbefugnis bereits Gebrauch gemacht worden sei (E 58, 300, 338), kann schon deshalb nichts anderes gefolgert werden, weil diese Aussage Art. 14 I GG nicht betrifft (a. A. Steinberg/Lubberger, Fn. 15, S. 63).

$106 \$ 42$ BauGB. Die Vorschrift genügt den verfassungsrechtlichen Anforderungen (a.A. Papier, NWVBL 1990, 397, 399), ist im Grundsatz aber auch verfassungsrechtlich geboten (vgl. dazu Battis, in: Battis/Krautzberger/Löhr, BauGB, 3. Aufl. 1990, $\$ 42$ Rdn. 3). 
Soweit der Eigentümer die bestehenden bau- bzw. immissionsschutzrechtlichen Anlagen verändern oder erweitern will, läßt sich zugunsten solcher Folgemaßnahmen der Gedanke des aktiven Bestandsschutzes fruchtbar machen ${ }^{107}$. Hierbei kann es entgegen der Rechtsprechung ${ }^{108}$ aber von vornherein nur um eine verfassungskonforme Ausgestaltung und Interpretation des Gesetzesrechts, nicht um seine Verdrängung durch Richterrecht gehen. Abzulehnen ist daher auch die Rechtsfigur einer „eigentumskräftig verfestigten Anspruchsposition " ${ }^{109}$, wenn und soweit sie dazu dienen soll, dem Eigentümer einen Genehmigungsanspruch contra legem zu verschaffen.

c) Die Auferlegung von Positivpflichten. Seit dem Übergang von der Auffang- zur Entwicklungsplanung und dem starken Ausbau des öffentlichen Bau-, Umwelt- und Wirtschaftsrechts bürden die Gesetze den Eigentümern immer häufiger positive Handlungspflichten auf. Hinzuweisen ist etwa auf die Entwicklungs-, Pflege- und Erschließungsmaßnahmen des Naturschutzrechts ${ }^{110}$. Da der Sozialauftrag des Art. 14 Abs. 2 GG nicht nur auf Duldung und Unterlassung abzielt, bestehen gegen die Statuierung solcher Handlungspflichten im Grundsatz keine Bedenken ${ }^{111}$. Die Sozialbindungsgrenze wird im Regelfall aber früher als bei der Auferlegung von Negativpflichten erreicht. Der Spielraum des Gesetzgebers ist relativ weit, wenn ein gegebener Zustand (zum Beispiel durch Pflege naturnaher Lebensräume) erhalten bleiben soll. Er verringert sich, wenn es um die Anpassung an Zeitanforderungen geht (wie bei den Modernisierungsmaßnahmen), und wird noch kleiner, wenn neuartige Verbesserungen angestrebt werden (etwa in Form erstmaliger Anpflanzungen).

d) Die Beachtlichkeit von Kumulationen und Subventionsleistungen. Unzulässig sind ferner unverhältnismäßige Eingriffskumulationen,

107 Vielfach wird weiter zwischen dem einfachen und dem überwirkenden aktiven Bestandsschutz unterschieden. Vgl. Friauf, WiVerw. 1986, 87 (90ff.) m. w. N.

108 BVerwGE 47, 126 (128); 49, 365 (369ff.); 50, 49 (55 ff.); 72, 362 ff.; BGHZ 94, 77 (81f.). Die h. L. hat sich der Rspr. angeschlossen, vgl. Papier (Fn. 20), Rdn. $340 \mathrm{ff}$.

109 BVerwGE 26, 111 (116 ff.); 47, 126 (130 ff.); 49, 365 (371 f.); 67, 84 (91 f.) u. 93 (96 f.); Oldiges (Fn. 23), Rdn. 205; Finkelnburg/Ortloff, Öffentliches Baurecht I, 2. Aufl. 1990, S. 14 f. Krit. Schulze-Fielitz, DV 1987, 307 (329ff.); Schenke, NuR 1989, 8 (17). Vgl. neuerdings auch BVerwG, BayVBl. 1991, 180 (182).

110 Vgl. etwa $\$ \$ 11$ BNatSchG, 26 LG NW. Zu den Bau-, Modernisierungs-, Instandsetzungs-, Pflanz- und Abbruchgeboten des Baurechts s. $\$ \$ 175 \mathrm{ff}$. BauGB. 111 Vgl. auch Papier (Fn. 20), Rdn. 408 ff.; Czybulka, NuR 1988, 215 (218f.). 
das heißt Beschränkungen des Eigentums, die für sich gesehen nur unproblematische Belastungen mit sich bringen, in der Summe aber eine zu weitgehende Inanspruchnahme des Eigentümers zur Folge haben. Gesetzgeber und gesetzesvollziehende Verwaltung müssen zwar nicht alle betroffenen Belange positiv gegeneinander abwägen, jedoch vor jedem neuen Eingriff negativ prüfen, ob das Faß der Sozialpflichtigkeit den neuen Tropfen der Sozialbindung noch aufzunehmen vermag oder bereits überläuft ${ }^{112}$.

Auf der anderen Seite darf nicht außer Betracht bleiben, daß der Staat Wirtschaftszweige wie die Landwirtschaft in erheblichem Ausmaß fördert. Wer laufend hohe Subventionen in Anspruch nimmt, unterliegt einer höheren Sozialpflichtigkeit als derjenige, der auf sich selbst angewiesen ist ${ }^{113}$.

e) Ausgleichspflichtige Inbalts- und Schrankenbestimmungen. Schließlich kann der Gesetzgeber zur Wahrung der Verhältnismäßigkeit gezwungen sein, eine aus Gemeinwohlgründen für erforderlich gehaltene Inhalts- und Schrankenbestimmung durch einen finanziellen Ausgleich abzumildern ${ }^{114}$. Anders als bei der Enteignung geht es in solchen Fällen nicht um eine Durchbrechung der Eigentumsordnung gegen Entschädigung, sondern um deren Verhinderung durch eine Kompensation, welche die Belastung auf ein erträgliches Maß reduziert. Die im Schrifttum gegen diese Konstruktion erhobenen Bedenken ${ }^{115}$ greifen nicht durch. Insbesondere überläßt Art. 14 GG den Schutz der Vermögensinteressen nicht allein dem Art. 14 Abs. 3 GG.

So kann die Auferlegung positiver Handlungspflichten einen Eigentümer unverhältnismäßig belasten, wie dies etwa für die Pflicht der Waldbesitzer zur Wiederaufforstung ${ }^{116}$ nach größeren Sturmschäden oder Waldbränden zutreffen dürfte. Eine Enteignung kommt insoweit

${ }_{112}$ Kloepfer, Beilage I/1986 in AgrarR 12/1986, 3 (14ff.); Leisner (Fn. 16), Rdn. 154 f.; Schink, Naturschutz- und Landschaftspflegerecht Nordrhein-Westfalen, 1989, Rdn. 662 .

113 Aufschlußreich BVerfGE 21, 150 (158f.).

114 Als Leitentscheidung gilt BVerfGE 58, $137(147,149$ f.). Vgl. ferner BVerfGE 79, 174 (192); BVerwGE 84, 361 (368f.); BGHZ 102, 350 (360); 110, 12 (16); SchulzeOsterloh, Das Prinzip der Eigentumsopferentschädigung im Zivilrecht und im öffentlichen Recht, 1980, S. 232 ff.; dies., NJW 1981, 2537 (2543 ff.).

115 H. P. Ipsen, VVDStRL 10 (1952), 74 (93); Papier (Fn. 20), Rdn. 283 ff.; Wendt (Fn.6), S. $314 \mathrm{ff}$.; J.Ipsen, Neuere Entwicklungen der Eigentumsdogmatik, in: Osnabrücker Rechtswissenschaftliche Abhandlungen, Bd.1, 1985, S. 129 (143ff.). Krit. auch Pietzcker, JụS 1991, 369 (370ff.). Vgl. ferner die Ausf. zu V.

116 Vgl. $\$ \$ 11$ BWaldG u. (z. B.) 44 LFoG NW. 
nicht in Betracht, weil die zwangsweise Wegnahme der Grundstücke über das Ziel hinausschießen würde. Da die Pflicht der Waldbesitzer auf eine vertretbare Handlung gerichtet ist, kann sie aber durch einen Dritten vorgenommen und demgemäß mit Geld ausgeglichen werden. Art. 14 Abs.1 S.1 GG wirkt insoweit nicht anders als Art. 12 Abs. 1 $\mathrm{GG}^{117}$, da auch diese Vorschrift bestimmte Indienstnahmen zugunsten des Staates nur gegen finanziellen Ausgleich zuläßt ${ }^{118}$.

Wegen des Vorrangs des Bestandsschutzes dürfen finanzielle Zuwendungen allerdings stets nur das letzte Mittel sein, um an sich unverhältnismäßige Regelungen vor dem Verdikt der Verfassungswidrigkeit zu retten ${ }^{119}$. Sie vermögen Eigentumsbeschränkungen lediglich $\mathrm{zu}$ rechtfertigen und sind auch nur dann geboten, wenn andere Regelungen (wie z. B. Dispensbestimmungen) nicht in gleicher Weise den Gemeinwohlerfordernissen genügen und nach Art der berührten Belange eine Verweisung des Eigentümers auf die Befriedigung seiner Vermögensinteressen zulässig ist ${ }^{120}$. In Anbetracht der besonderen Grundrechtsrelevanz einerseits und der Folgen für die öffentlichen Haushalte andererseits bedürfen die Ausgleichszahlungen einer formell gesetzlichen Grundlage, die den Tatbestand sowie die Art und das Ausmaß der Kompensation als Rechtsfolge regelt ${ }^{121}$. Somit gelten

117 Vgl. BVerfGE 54, 251 (271); 57, 107 (117). Näher zum Härteausgleich gem. Art. 12 I u. 14 I GG Dörr, NJW 1988, 1049 (1051 f.).

118 Ferner gebietet das Verhältnismäßigkeitsprinzip etwa in den Fällen der sog. privatrechtlichen Aufopferung die Zubilligung eines finanziellen Ausgleichs (vgl. zur Rspr. Schwabe, JZ 1983, 273, 276). Z. B. ist die Regelung des $\$ 906$ II BGB nur deshalb verfassungsmäßig, weil der Nachbar einen Ausgleich in Geld verlangen kann. Der Rekurs auf Art. 14 III GG scheidet in solchen Fällen von vornherein aus, weil es eine privatrechtliche Enteignung nicht gibt (BVerfGE 14, 263, 277).

119 Zum Ausnahmecharakter vgl. auch Maurer (Fn. 23), \$26 Rdn. 68.

120 Entgegen Schulze-Osterlob (NJW 1981, 2537, 2543) und Leisner (DÖV 1991, 781,786 ) ist nicht eine zweistufige Prüfung dergestalt vorzunehmen, daß zunächst untersucht wird, ob der Eingriff zulässig ist und bejahendenfalls abgewogen wird, ob ein finanzieller Ausgleich geleistet werden muß. Erweist sich die Inanspruchnahme des Eigentümers als zulässig, erübrigt sich eine weitere Prüfung. Nur wenn der Eingriff an sich zu weit geht, aber auf gesetzlicher Grundlage ein finanzieller Ausgleich erbracht wurde, muß noch untersucht werden, ob dadurch dem Übermaßverbot genügt worden ist.

121 Papier, NWVBL 1990, 397 (400 f.); Pietzcker, JuS 1991, 369 (372). A. A. etwa BVerwGE 84, 361 (367f. - „zumindest“ für eine Übergangszeit); Schwerdtfeger, Die dogmatische Struktur der Eigentumsgarantie, 1983, S. 29 (im Hinblick auf enteignende Eingriffe); Nüßgens/Boujong (Fn. 62), Rdn. 340; Steinberg/Lubberger (Fn. 15), S. 152. 
für die ausgleichspflichtigen Inhalts- und Schrankenbestimmungen ähnliche Vorgaben wie für die Enteignung. Nicht ausreichend ist zum Beispiel eine Bestimmung, nach der unzumutbare Belastungen angemessen zu entschädigen sind. Eine solche Normierung überläßt die

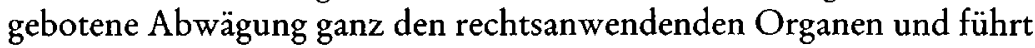
vielfach dazu, daß entweder die Sozialbindung oder die Grundrechtsverletzung erkauft werden. $\mathrm{Da}$ es dem Gesetzgeber nicht versagt ist, mit Generalklauseln und Regelbeispielen zu arbeiten, wird ihm nichts Unmögliches abverlangt ${ }^{122}$. Die zahlreichen salvatorischen Ausgleichsbestimmungen des geltenden Rechts können allenfalls noch für eine Übergangszeit hingenommen werden.

Von den verfassungsrechtlich gebotenen Ausgleichs- sind die reinen Billigkeitsregelungen zu unterscheiden. Sie werden von Art.14 GG nicht erfaßt ${ }^{123}$. Ihre Finanzierung muß allerdings über den öffentlichen Haushalt erfolgen und darf nicht einer anderen Gruppe von Eigentümern auferlegt werden, wie dies für den Ausgleich nach $\$ 19$ Abs. 4 WHG in vielen Bundesländern zutrifft ${ }^{124}$. Da die Billigkeitszahlungen in der Regel Subventionscharakter haben, wird außerdem in Zukunft stärker auf die Vereinbarkeit mit den Regelungen des GATT und des europäischen Gemeinschaftsrechts zu achten sein.

\section{Die Enteignung}

\section{Der Begriff der Enteignung}

Unter bestimmten Voraussetzungen ist der Staat befugt, im Wege der Enteignung auf das Eigentum zuzugreifen. Wann eine Enteignung

122 A.A. z.B. Ossenbübl, JZ 1991, 89 (90f.); ders. (Fn. 80), S. 153 f. Da der Gesetzgeber bei der Schaffung von Ausgleichsbest. zumindest typische Fallkonstellationen vor Augen haben muß, können diese auch normiert werden (vgl. etwa $\int \$ 177$ IV BauGB, 8 a V FStrG). Zu den salvatorischen Entschädigungsklauseln des Enteignungsrechts s. Fn. 163.

${ }^{123}$ Neben reinen Billigkeitsregelungen kennt das geltende Recht Inhalts- und Schrankenbest., die eine nur im Kern gebotene, aber über das verfassungsrechtlich Geforderte hinausgehende Kompensation gewähren. Als eine solche Regelung sicht das BVerwG (E 77, 295, 298; 84, 361, 368) zu Unrecht $\$ 74$ II 3 VwVfG an (krit. auch Wabl, $\mathrm{NVwZ} 1990,426,440)$. Es handelt sich um eine verfassungsrechtlich gebotene Ausgleichsbest., allerdings salvatorischer Art. Abzulehnen daher auch BGHZ 97, 114 (117 - Billigkeitsregelung) u. Kleinlein, DVBl. 1991, 365 (371 - Enteignungsregelung).

${ }^{124}$ Der Ausgleich nach $\$ 19$ IV WHG ist verfassungsrechtlich nicht geboten (F. Kirchbof, NVwZ 1987, 1031, 1033; a. A. Weyreuther, UPR 1987, 41, 50), wie sich aus dem Zusammenhang mit Absatz 3 ergibt (der sich bei Zugrundelegung des sogleich zu erörternden Enteignungsbegriffs dogmatisch nicht als Enteignungs-, sondern als ausgleichspflichtige Inhalts- und Schrankenbest. darstellt). Zur Verfas- 
vorliegt, ist bis heute äußerst unklar geblieben. Während die Anhänger eines weiten Enteignungsbegriffs ${ }^{125}$ alle über die Sozialbindung hinausgehenden Eingriffe in eine Eigentumsposition als zumindest potentiell enteignungsfähig ansehen, verwendet insbesondere das Bundesverfassungsgericht ${ }^{126}$ einen engeren Begriff und stellt auf die Entziehung vermögenswerter Rechtspositionen ab. Für eine engere Begriffsbildung spricht neben dem Ausnahmecharakter des Absatzes $3^{127}$ vor allem der Umstand, daß die verschiedenen Absätze des Art. 14 GG Maßstäbe für die Steuerung staatlichen Handelns aufstellen. Die unterschiedlichen Einwirkungen auf das Eigentum müssen daher primär handlungsbezogen und nicht folgenorientiert voneinander abgegrenzt werden. Es kommt entscheidend auf die Ausrichtung der Maßnahmen, nicht auf ihre erst ex post bestimmbaren Wirkungen an. Die Inhaltsbestimmungen legen die Rechte und Pflichten des Eigentümers für die Zukunft fest, während die Enteignungsakte auf die Aufhebung bestimmter Rechtspositionen abzielen. Die Enteignung stellt somit keine Steigerung der Inhaltsbestimmung, sondern ein aliud dar ${ }^{128}$.

Mehrdeutig ist die Annahme des Bundesverfassungsgerichts, daß eine neue, für die Zukunft geltende objektivrechtliche Regelung im Sinne des Art. 14 Abs. 1 S. 2 GG zugleich eine Legalenteignung bewirken könne ${ }^{129}$. Sollte das Gericht dahingehend zu verstehen sein, daß

sungswidrigkeit der hier angesprochenen Landesregelungen (z.B. Art.74 VI BayWG; \$15 III LWG NW) vgl. Murswiek, NuR 1990, 289 (294ff. - allerdings ohne Bezugnahme auf Art.14 GG).

125 Grundlegend BGHZ 6, 270 ff.; 23, $32 \mathrm{ff}$. Vgl. ferner v. Brünneck (Fn. 82), S. $401 \mathrm{ff}$;; Breuer, in: v. Münch (Hrsg.), Besonderes Verwaltungsrecht, 8. Aufl. 1988, S. 618; Leisner (Fn. 16), Rdn. 168 f.; Papier, NWVBL 1990, 397 (398); Stein (Fn. 71), \$27 IV 1 .

126 Vgl. z. B. BVerfGE 24, 367 (394); 70, 191 (199f.).

127 Bei Zugrundelegung eines weiten Enteignungsbegriffs oder der Annahme, daß die Wertinteressen des Eigentümers nur über Art. 14 III GG geschützt sind, wandelt sich die Enteignung von einem „extraordinären" Institut (Wendt, Fn.6, S. 326) in ein normales Instrument staatlicher Eigentumsgestaltung.

${ }_{128}$ Vgl. auch Schmitt-Kammler (Fn.72), S. 595 (599). Anderes gilt für das Verhältnis von Schranken- und Enteignungsbest., sofern die Schrankenbest. einen Entzug von Eigentumspositionen betreffen - vgl. die Ausf. unten zu b); abw. insoweit Rittstieg (Fn. 15), Rdn. 182; Lege, NJW 1990, 864 (865). Dies bedeutet zugleich, daß entgegen BVerfGE 58, 300 (331), zwischen Inhalts- und Schrankenbest. unterschieden werden muß. Für ein Wahlrecht des Gesetzgebers in best. Fällen: Schmidt-Aßmann, JuS 1986, 833 (836); Kleinlein, DVBl. 1991, 365 (370).

129 Vgl. BVerfGE 45, 297 (332f.); 52, 1 (28); 58, 300 (331 f., 337f.); 72, 9 (22 f.). Krit. Bryde (Fn. 15), Rdn. 54 f.; Schmitt-Kammler, FS der Rechtswissenschaftlichen Fakultät zur 600-Jahr-Feier der Universität zu Köln, 1988, S. 821 (827ff.); Schoch, Jura 1989, 113 (121). 
ein und dieselbe Regelung einen Doppelcharakter aufweisen kann, wäre ihm nicht zu folgen. Denkbar ist nur, daß in einem Rechtssatz rein äußerlich verschiedene Regelungen zusammengefaßt werden, die teils dem Art. 14 Abs. 1, teils dem Art. 14 Abs. 3 GG zuzuordnen sind. Zum Beispiel könnte der Gesetzgeber durch Inhaltsbestimmung das Entstehen von Rechten, die nach bisherigem Recht möglich waren, für die Zukunft ausschließen und zusätzlich im Wege der Legal-, besser Legislativenteignung ${ }^{130}$ die bereits entstandenen Rechtspositionen entziehen ${ }^{131}$.

Folgt man diesen Weichenstellungen, dürfte die Enteignung des näheren zu definieren sein als die vollständige oder teilweise Entziehung einer subjektiven Eigentumsposition ${ }^{132}$ im Wege einer Durchbrechung der Eigentumsordnung durch einen gezielten öffentlichen Rechtsakt zum Zwecke der Indienstnahme der entzogenen Position für die Erfüllung von Staatsaufgaben. Dies bedarf der Erläuterung.

a) Das Merkmal der Entziehung. Im Unterschied zum klassischen Enteignungsbegriff des 19. Jahrhunderts, der nur auf die Übertragung von Grundstücken abstellte, erstreckt sich die Entziehung auf alle Rechtspositionen des Art.14 Abs.1 S.1 GG und läßt die bloße Aufhebung des Rechts ausreichen ${ }^{133}$. Eine teilweise Entziehung ist anzunehmen, wenn sich der Zugriff auf rechtlich selbständige oder verselbständigungsfähige Bestandteile einer umfassenderen Eigentü-

130 Maurer (Fn. 23), \$26 Rdn. 36 .

131 Nach BVerfGE 83, 201 (211 f.) - vgl. dazu Fn. 144 -, soll Art. 14 III GG nicht unmittelbar anwendbar sein, wenn der Gesetzgeber im Zuge der generellen Neugestaltung eines Rechtsgebietes bestehende Rechte abschafft. Dies kann aber nicht bedeuten, daß eine Enteignung dann immer ausgeschlossen ist. Beseitigt der Staat die Sozialversicherung, um Geld zu sparen, liegt gegenüber denjenigen, die bereits einen Anspruch erworben haben, eine Enteignung vor. Nach Maurer, FS für Dürig, 1990, S. 293 (307f.), soll es sich dagegen niemals um eine Enteignung, sondern immer um ein Übergangsproblem handeln.

132 Das BVerfG spricht von der Notwendigkeit einer Entziehung „konkreter“ Eigentumsrechte, die "rechtmäßig“" erworben worden sind (E 58, 300, 330 f.). Doch kann es eine Entziehung abstrakter Rechte nicht geben (entweder besteht Eigentum oder nicht). Ferner werden rechtswidrig erworbene Positionen von Art. 14 GG nicht erfaßt (vgl. die Ausf. oben mit Fn. 36).

${ }^{133} \mathrm{Vgl}$. zur klassischen Enteignung: Kirchbeimer, Die Grenzen der Enteignung, 1930, S. 7 ff. Der Devise „Zurück zum klassischen Enteignungsbegriff“ (Dürig, JZ 1954, 4 ff.; Osterlob, DVBl. 1991, 906, 911) ist zuzugeben, daß ein solcher Enteignungsbegriff am einfachsten handhabbar wäre. Doch knüpft Art.14 III an Art. 14 I GG und damit nicht nur an das Sacheigentum an. Gegen ein Abstellen nur auf Güterbeschaffungsvorgänge auch BVerfGE 83, 201 (211 m. w. N.). 
merstellung richtet ${ }^{134}$, wie dies zum Beispiel bei dinglichen Belastungen von Grundstücken der Fall ist. Dagegen können die sonstigen Nutzungs- und Verfügungsbeschränkungen ${ }^{135}$ - etwa in Gestalt bauplanerischer Herabzonungen des Grundstücks oder der Festsetzung von Naturdenkmälern - entgegen der herkömmlichen Ansicht $^{136}$ mangels rechtlicher Selbständigkeit der abgespaltenen Befugnisse keine tauglichen Gegenstände einer Enteignung $\operatorname{sein}^{137}$. Dies gilt selbst dann, wenn sie eine sinnvolle wirtschaftliche Nutzung des Grundstücks unmöglich machen. Soweit eine finanzielle Kompensation zu gewähren ist und sich der Eigentümer darauf verweisen

${ }^{134}$ Im Ergebnis ebenso oder ähnlich Maurer (Fn. 131), S. 305; Pieroth/Schlink (Fn. 72), Rdn. 1016.

135 Krit. zur Unterscheidung von Entziehungen und Beschränkungen z.B. Pietzcker, JuS 1991, 369 (371); Osterloh, DVBI. 1991, 906 (912). Auch das BVerfG hat gelegentlich die Entziehung und Beschränkung nebeneinander gestellt (z. B. in E 56, 249, 260). Sieht man in jeder Beschränkung zugleich eine Entziehung (vgl. Steinberg/Lubberger, Fn. 15, S. 98), gibt das letzte Kriterium keinen Sinn mehr. Die Entziehung geht typischerweise weiter als die bloße Beschränkung. Daß dies im Einzelfall anders sein kann - etwa weil sich eine Beschränkung u. U. auch in Form einer Dienstbarkeit verselbständigen ließe - schadet nicht, da der Staat den Weg selbst bestimmen kann, die Ausgleichspflicht nach Art. 14 I GG zur Relativierung beiträgt und nicht jede Entziehung eine Enteignung darstellt. Im Parl. Rat ist der Antrag, nicht nur die Entziehung, sondern auch die Einschränkung des Eigentumsrechts als Enteignung anzusehen, ausdrücklich abgelehnt worden (Prot. der 44. Sitzung des Hauptausschusses, S. $579 \mathrm{f}$.).

${ }_{136} \mathrm{Vgl}$. Fn. 125. Vielfach wird davon ausgegangen, daß jedenfalls die sog. Aufopferungsenteignung dem Art. 14 III GG unterfällt (vgl. Schmidt-Aßmann, JuS 1986, 833, 835 f.; unklar BVerfGE 45, 297, 332). Ordnet man die "schweren und unzumutbaren" Nutzungs- und Verfügungsbeschränkungen der Aufopferungsenteignung zu, besteht indessen kaum noch ein Unterschied zum weiten Enteignungsbegriff bzw. zur „Umschlagstheorie“. Damit wird der Ansatz des BVerfG nicht modifiziert, sondern aufgegeben. Stuft man die planerische Herabzonung gem. $\$ 42$ BauGB als Fall der Administrativenteignung ein (z. B. Koch/Hosch, Baurecht, Raumordnungsrecht, Landesplanungsrecht, 1988, S. $194 \mathrm{ff}$.; Bielenberg, in: Ernst/ Zinkhahn/Bielenberg, BauGB, 1989, Vorb. $\$ \$ 39-44$ Rdn. 92), ist sie verfassungswidrig, weil $\$ 42$ BauGB nicht ihre Zulässigkeit, sondern nur ihre Rechtsfolge regelt.

${ }^{137}$ Ebenso ist die Ausübung eines gesetzlich eingeräumten Vorkaufsrechts zugunsten eines Trägers von Staatsgewalt (etwa nach $\$ 24$ BauGB oder Art. 34 BayNatSchG) keine Enteignung, weil das Vertragsverhältnis zwischen Verkäufer und Erstkäufer unberührt bleibt, ein Recht also nicht entzogen wird (vgl. auch BGH, NJW 1989, 37, 38; BayVGH, BayVBl.1990, 277; a.A. Numberger, BayVBl. 1991, 278f.). 
lassen muß, handelt es sich um den Fall einer ausgleichspflichtigen Inhalts- und Schrankenbestimmung, anderenfalls um einen unzulässigen Eingriff in das Eigentum.

b) Die Durchbrechung der Eigentumsordnung. Nicht jedem Entziehungsakt kommt Enteignungsqualität zu. Insbesondere gibt es Entziehungsakte, welche die Eigentumsordnung nicht durchbrechen, sondern sich noch innerhalb der Sozialbindungsgrenze des Art. 14 Abs. 2 GG halten. Da die Enteignung die Erfüllung von Gemeinwohlaufgaben ermöglichen soll, die sonst an der Garantie des Art. 14 Abs. 1 S. 1 GG scheitern müßte ${ }^{138}$, können derartige Akte nicht als Enteignungen angesehen werden ${ }^{139}$. In Betracht kommt eine solche Konstellation vornehmlich bei der Aufhebung rechtsgeschäftlich eingeräumter vermögenswerter Rechte des öffentlichen Rechts. So ist der rechtmäßige Widerruf eines von der Eigentumsgarantie erfaßten Verwaltungsaktes wegen der Nichtbefolgung einer Auflage schon deshalb keine Enteignung, weil sich die Belastungswirkungen innerhalb der Sozialbindungsgrenze halten und der Eigentümer mit dieser Rechtsfolge rechnen mußte ${ }^{140}$. Im Hinblick auf die Abgrenzung der verschiedenen Entziehungsakte bedarf es daher weiterhin einer materiellen Bestimmung der Enteignungsschwelle.

c) Das Kriterium des gezielten öffentlichen Rechtsaktes. Das Erfordernis des gezielten öffentlichen Rechtsaktes schließt „Zufallsenteignungen " ${ }^{141}$ sowie die Enteignung durch Realakt oder privaten Rechtsakt aus. Auch spricht vieles für die Annahme, daß es eine Enteignung

138 Böhmer, BVerfGE 56, 266 (271); ders., NJW 1988, 2561 (2573).

${ }_{139} \mathrm{Im}$ Ergebnis ebenso Schmitt-Kammler (Fn.72), S. 599; ders. (Fn. 129), S. 825 f. A. A. offenbar Böhmer, BVerfGE 56, 266 (291).

140 Die eigentumsrechtliche Qualifizierung der Widerrufsbest. ist bisher nicht gelungen. Z. B. sieht Maurer (Fn. 96), Rdn. 80, in $\$ 49$ VwVfG „eine kombinierte Eigentums- und Enteignungsregelung". Nach der hier vertretenen Ansicht stellen die Widerrufsbest. in keinem Fall eine Enteignung dar, weil es entweder an einer Durchbrechung der Eigentumsordnung oder an einer (positiven) Indienstnahme für Staatsaufgaben fehlt. Geht man dagegen von einer Enteignung aus, dürfte ein Widerruf unzulässig sein, weil die Widerrufsbest. die Verwaltung tatbestandlich nicht an das Allgemeinwohlerfordernis des Art.14 III 1 GG binden und als Rechtsfolge teilweise noch nicht einmal eine Entschädigung, im übrigen nur die Ersetzung des Vertrauensschadens (dazu Stelkens/Sachs, in: Stelkens/Bonk/Leonhardt, VwVfG, 3. Aufl. 1990, $\$ 49$ Rdn. $52 \mathrm{ff}$.) vorsehen.

${ }^{141}$ A. A. Ossenbübl, JZ 1991, 89 (90). 
durch Privatrechtsgesetzgebung nicht gibt, weil die Enteignung kein Instrument privatnütziger Eigentumsumschichtung ist ${ }^{142}$.

d) Die Indienstnabme für Staatsaufgaben. Mittels des Erfordernisses einer Indienstnahme der entzogenen Rechtsposition für die Erfüllung von Staatsaufgaben ${ }^{143}$ wird die Enteignung von eigentumsentziehenden Maßnahmen mit anderer Zwecksetzung unterschieden. An der genannten Indienstnahme fehlt es, wenn sich der Staat die in Anspruch genommene Eigentumsposition nicht unmittelbar oder mittelbar positiv zunutze machen will ${ }^{144}$ - wie zum Beispiel bei der Zwangsversteigerung von Grundstücken und der Tötung seuchenkranker Tiere ${ }^{145}$ - oder wenn der Zugriff zumindest gleichgewichtig den Interessen des betroffenen Eigentümers dient ${ }^{146}$. Letzteres ist etwa bei der "normalen“ Umlegung und Flurbereinigung ${ }^{147}$, nicht

${ }^{142}$ Es kommt also auf die (öffentliche) Rechisinatur des Rechtssatzes, nicht des Rechtssetzungsaktes an. Das BVerfG hat - soweit ersichilich - noch niemals eine Legislativenteignung durch eine Privatrechtsnorm bejaht, die Enteignung aber aus anderen Gründen scheitern lassen (näher dazu Scbwabe, JZ 1983, 273, 275; ders., JZ 1991, 777, 778). Vgl. aber auch Papier (Fn. 20), Rdn. 451 einerseits, Rdn. 499 andererseits.

${ }^{143}$ Das BVerfG spricht verschiedentlich davon, daß sich die Enteignung auf die „Erfüllung bestimmter öffentlicher Aufgaben“ richtet (E 72, 66, 76 m.w. N.). Vgl. auch Schulte, Eigentum und öffentliches Interesse, 1970, S. 85 ff.; dens., Ausgleich ökologischer Schäden und Duldungspflicht geschädigter Grundeigentümer, 1990, S. 133. Das Begriffsmerkmal „Indienstnahme für Staatsaufgaben" ist mit dem Zulässigkeitskriterium „Wohl der Allgemeinheit“ i.S.d. Art.14 III 1 GG nicht identisch. Z. B. dient eine Enteignung zum Zwecke des öffentlichen Straßenbaus immer der Erfüllung von Staatsaufgaben, ist aber keineswegs immer gerechtfertigt. Krit. zum Zweckkriterium: Schwabe, Die sogenannte Drittwirkung der Grundrechte, 1971, S. 139.

${ }^{144} \mathrm{Da}$ die Enteignung darauf abzielt, „daß das enteignende Objekt für die Aufgabe, die mit dem Unternehmen erfüllt werden soll, zur Verfügung steht ${ }^{\text {“ }}$ (Böhmer, BVerfGE 56, 266, 272), dürfte die bloße Vernichtung von Eigentumspositionen nicht ausreichen (vgl. auch BVerfGE 20, 351, 359; a.A. Steinberg/ Lubberger (Fn. 15, S. 104). Aus diesem Grunde (ferner auch wegen des privatrechtlichen Charakters der gesetzlichen Best.) ist dem BVerfG (E 83, 201, 211 f.) im Ergebnis zu folgen, wenn es die Beseitigung von Vorkaufsrechten durch das BBergG nicht als Enteignung ansieht.

145 Vgl. einerseits BVerfGE 49, 220 (225) u. 252 (256); andererseits BVerfGE 20, 351 (359). Ferner z. B. BVerfG, JZ 1990, 290 (Beschlagnahme und Einziehung von Tieren und Pflanzen nach $\$ 21 \mathrm{f} B \mathrm{NatSchG})$.

${ }_{146} \mathrm{Vgl}$. BVerfGE 42, 263 (299 - Rechtsentzug „zugunsten fremder Belange“).

147 Vgl. zur Umlegung die Nachw. des BVerwG (E 85, 96, 98); zur Flurbereinigung: BVerwGE 1, 225 (227f.). 
aber bei der städtebaulichen Flurbereinigung oder Unternehmensflurbereinigung ${ }^{148}$ der Fall.

\section{Die Zulässigkeit der Enteignung}

a) Das Allgemeinwoblerfordernis

(1) Der Enteignungszweck. Die Enteignung ist nur zum Wohle der Allgemeinheit zulässig ${ }^{149}$. Da die Durchbrechung der Eigentumsordnung gerechtfertigt werden muß, sind strengere Anforderungen als im Rahmen des Art. 14 Abs. 2 GG zu stellen ${ }^{150}$. Entscheidend ist der Enteignungszweck, nicht die Person des Begünstigten, so daß auch eine Enteignung zugunsten Privater in Betracht kommt ${ }^{151}$, wenn das vom Privaten durchzuführende Vorhaben zum Wohle der Allgemeinheit zwingend erforderlich ist.

(2) Die gesetzlichen Anforderungen. In formeller Hinsicht darf die Enteignung nur durch Parlamentsgesetz oder aufgrund eines solchen Gesetzes erfolgen ${ }^{152}$. Unklar ist die notwendige Regelungsdichte. Eine minuziöse gesetzliche Normierung kann von Verfassungs wegen nicht verlangt werden ${ }^{153}$, weil dies auf eine - auch im Regelungsbereich des Art. 14 Abs. 3 GG problematische - Einzelfallgesetzgebung hinausliefe ${ }^{154}$.

$148 \iint 190$ BauGB, 87 FlurbG. Vgl. dazu BVerfGE 74, 264 (279f.).

149 Dazu v. Brünneck, NVwZ 1986, $425 \mathrm{ff}$.

150 Besonders aus diesem Grunde ist die Frage, ob eine Enteignung oder nur eine (ausgleichspflichtige) Beschränkung vorliegt, auch inhaltlich von Bedeutung (vgl. auch Osterloh, DVBl. 1991, 906, 909f.).

151 BVerfGE 74, 264 (285). Näher dazu Schmidbauer, Enteignung zugunsten Privater, 1989.

152 Nach BVerfGE 74, 264 (286f.) müssen der Enteignungszweck, die Voraussetzungen der Enteignung, das Verfahren sowie die dauerhafte Sicherung des Enteignungszwecks gesetzlich geregelt werden. Daher reicht die Aufnahme von Abwägungsgeboten in die gesetzlichen Regelungen zur Lösung des Problems der salvatorischen Klauseln nicht aus (so aber Olivet, DÖV 1985, $697 \mathrm{ff}$.).

${ }^{153}$ Vgl. BVerwG, NVwZ 1991, 987 (988ff.). Problematisch ist die nur beispielhafte Aufzählung der Enteignungszwecke in einigen neueren Landesenteignungsgesetzen (z. B. \$2 LEntG Bad.-Württ.; Art. 1 BayEntG).

${ }^{154}$ Die Rechtsschutzvorbehalte des BVerfG (E 24, 367, $401 \mathrm{ff}$.) gegen die Legislativenteignung dürften zwar übertrieben sein, weil einerseits immer verwaltungsgerichtliche Feststellungsklagen oder Verfassungsbeschwerden möglich bleiben, andererseits gegen die Administrativenteignung in Form einer Verordnung oder Satzung dieselben Bedenken bestehen müßten, sofern eine Kontrolle gem. $\$ 47$ VwGO ausgeschlossen ist. Doch muß eine derartige Enteignung auch deshalb die 
So reicht es für die Festlegung der Zwecke und Enteignungsvoraussetzungen aus, wenn ein Fachplanungsgesetz die planakzessorische Enteignung zur Erfüllung notwendiger Allgemeinwohlbelange zuläß $\mathfrak{t}^{155}$. Hinsichtlich der bebauungsplanakzessorischen Enteignung scheint das Bundesverfassungsgericht striktere Maßstäbe anlegen zu wollen. Bei Zugrundelegung seiner Ausführungen in der BoxbergEntscheidung ${ }^{156}$ müßten konsequenterweise alle bebauungsplanakzessorischen Enteignungen mangels hinreichender Bestimmtheit der \$\$ 85 Abs. 1 S. 1, 87 Abs. 1 und 3 BauGB als verfassungswidrig angesehen werden ${ }^{157}$. Doch dürften die genannten Bestimmungen den enteignungsrechtlichen Vollzug eines gültigen Bebauungsplans noch hinreichend determinieren, weil die bauplanerischen Festsetzungen, an die sie anknüpfen, Gesetzescharakter im Sinne des Art. 14 Abs. 1 S. 2 GG haben ${ }^{158}$. Der Rückgriff auf das Baugesetzbuch ist unzulässig, wenn das geltende Recht speziellere Enteignungsregelungen kennt ${ }^{159}$.

(3) Enteignungsrechtliche Vorwirkungen. Vor allem in Planungszusammenhängen stellt sich die Frage, ob Verwaltungsentscheidungen, die dem förmlichen Enteignungsverfahren vorangehen, enteignungsrechtliche Vorwirkungen entfalten. Dies beurteilt sich allein

Ausnahme bleiben, weil der Betroffene im Gesetzgebungsverfahren keine gesicherte Rechtsstellung hat.

155 BVerfGE 45, 297 (319f.); 56, 249 (264f.); BVerfG, DVBI. 1987, 895 f. Vgl. auch BVerfGE 66, 248 (259).

156 BVerfGE 74, 264 (284ff.); krit. Papier, JZ 1987, 619 ff,; Schmidt-Aßmann, NJW 1987, 1587 ff.; Dolde, FS für Sendler, 1991, S. 225 (233 ff.); vgl. auch Brugger, ZfBR 1987, $60 \mathrm{ff}$.

157 So im Ergebnis Labbé, AnwB1. 1989, 530 (531). Zu Recht betont Dolde (a. a. O., S. $228 \mathrm{f}$ ), daß sich die Ausf. des BVerfG nicht auf den Fall der Enteignung zugunsten Privater beschränken lassen. Nach OLG München (NJW 1990, 519) soll $\$ 85$ I Nr. 1 BauGB nur noch eine Enteignung zur Erfüllung „rein städtebaulicher Belange" erlauben (vgl. auch BVerfGE 56, 249, 265). Dieser Ansicht ist schon wegen der mangelnden Bestimmtheit des Kriteriums nicht zu folgen.

${ }^{158}$ Es wird also gerade nicht nur an die vagen Planvorgaben des $\$ 1$ BauGB angeknüpft. Eine nähere Präzisierung der Enteignungszwecke dürfte dem Gesetzgeber auch schwerfallen. Nicht von ungefähr landet das BVerfG in seiner BoxbergEntscheidung beim Einzelfallgesetz. Im Ergebnis wie hier BGHZ 105, 94 (97); Papier, JZ 1987, 619 (621); Dolde (a. a. O.), S. 239.

159 Stellt man dagegen darauf ab, ob das Land eine Gesetzgebungskompetenz zur Regelung des Enteignungsrechts hat (so wohl BVerfGE 56, 249, 265), dürfte sich z. B. eine Enteignung zugunsten der Errichtung einer Grundschule kaum noch auf das BauGB stützen lassen, weil das Land speziellere Enteignungsregelungen schaffen könnte. 
nach der Gesetzeslage. So sehen die Fachplanungsgesetze vielfach vor, daß der festgestellte Plan dem Enteignungsverfahren zugrundezulegen ist und die Enteignungsbehörde bindet ${ }^{160}$. Wegen dieser vorgreiflichen Bindung unterliegt der Plan nicht nur dem Gebot der gerechten Abwägung, sondern bedarf einer besonderen Rechtfertigung am Maßstab des Art. 14 Abs. 3 S. 1 GG. Dagegen ist für den Bebauungsplan eine solche Vorwirkung - auch in Ausnahmefällen - nicht vorgesehen $^{161}$.

b) Das Entschädigungserfordernis. Jede Enteignung löst zwingend eine Entschädigungspflicht aus ${ }^{162}$. Art und Ausmaß der Entschädigung sind vom Gesetzgeber zu regeln. Salvatorische Entschädigungsklauseln werden der Verfassung nicht gerecht ${ }^{163}$, zumal es dem Gesetzgeber etwa durch Verweis auf das Baugesetzbuch oder die allgemeinen Enteignungsgesetze ohne weiteres möglich ist, die Entschädigungsfolgen festzulegen. Da sich im Falle der Enteignung die Bestandsgarantie des Eigentums in eine Wertgarantie verwandeln soll, ist von einem formellen Regel-Ausnahme-Verhältnis zugunsten der Verkehrswertentschädigung auszugehen. Dies bedeutet, daß ein Abweichen von der Verkehrswertentschädigung nach unten hin erlaubt ist, aber einer besonderen Rechtfertigung bedarf.

\section{Die Eigentumsunrechtshaftung}

Die Rechtsstellung des Eigentümers bei der Nutzung von Boden und Umwelt hängt schließlich maßgeblich davon ab, ob den Staat in den Fällen des sog. enteignungsgleichen und enteignenden Eingriffs eine haftungsrechtliche Verantwortlichkeit trifft. Die ganz überwiegende Ansicht bejaht dies, stützt sich dabei allerdings anders als früher nicht mehr auf Art. 14 Abs. 3 GG, sondern entweder auf den Aufopfe-

${ }_{160}$ Vgl. z. B. $\$ \$ 19$ II FStrG; 30 PBefG; 44 II WaStrG.

161 Nach dem BVerwG (NVwZ 1991, 873) soll eine Vorwirkung "grundsätzlich" nicht bestehen. Kann ein Bebauungsplan aller Voraussicht nach nur im Wege der Enteignung verwirklicht werden, sind die Enteignungsvoraussetzungen zwar aus rein planerischen Erwägungen antizipierend zu prüfen. Eine Rechtsbindung des Bürgers, dessen Grundstück von der Enteignung bedroht ist, ergibt sich daraus aber nicht.

162 Art. 14 III 2 GG; vgl. BVerfGE 4, 219 (230); 46, 268 (285).

$163 \mathrm{Vgl}$. BVerwGE 84, 361 (365 ff.); Weyreuther, Über die Verfassungswidrigkeit salvatorischer Entschädigungsregelungen im Enteignungsrecht, 1980, S. 29ff.; Leisner, DVBl. 1981, 76 ff.; a. A. BGHZ 99, 24 (27 ff.); 105, 15 (16f.). 
rungsgedanken der $\$ \mathbb{\$ 4}, 75$ Einl. ALR in seiner richterrechtlich geprägten Ausformung ${ }^{164}$ oder auf Gewohnheitsrecht ${ }^{165}$. Solcher Konstruktionen bedarf es indessen von vornherein nicht, wenn spezialgesetzliche Regelungen - wie das als Landesrecht fortgeltende Staatshaftungsgesetz der DDR ${ }^{166}$ - eine Haftung des Staates vorsehen. Im übrigen ist weder an das auf eine rechtmäßige Inanspruchnahme zugeschnittene Institut der Aufopferung noch an das vor der Neuordnung der Eigentumsdogmatik vorherrschende Gewohnheitsrecht, sondern an Art. 14 Abs. 1 GG anzuknüpfen ${ }^{167}$.

\section{Die Haftung für enteignungsgleiche Eingriffe}

Richtet man das Augenmerk zunächst auf die enteignungsgleichen Eingriffe - d.h. auf die rechtswidrigen öffentlich-rechtlichen Eingriffe in eigentumsmäßig geschützte Positionen -, wird man sich vergegenwärtigen müssen, daß die Freiheitsgrundrechte in ihrem abwehrrechtlichen Gehalt in erster Linie Unterlassungs-, in zweiter Linie Folgenbeseitigungsansprüche verbürgen. Ist der rechtswidrige Eingriff bereits verwirklicht und eine Folgenbeseitigung nicht mehr möglich, gebieten die Freiheitsrechte ihrem objektivrechtlichen Gehalt nach eine Wiedergutmachung ${ }^{168}$. Art. 34 GG läßt sich entnehmen, daß die nähere Ausgestaltung dieser Wiedergutmachung dem Gesetzgeber überlassen bleiben soll. Da aber ernste Zweifel bestehen, $o b$ allein die derzeitige Amtshaftung die verfassungsrechtlichen Mindestanforderungen einzulösen vermag ${ }^{169}$, wird man die Gerichte bei einem Schweigen des Gesetzgebers für berechtigt und auch für verpflichtet halten müssen, im Wege des Richterrechts eine finanzielle Wiedergutmachung für die nicht durch Inanspruchnahme des primären Rechtsschutzes abwendbaren Folgen rechtswidriger Freiheitsbe-

164 BGHZ 90, 17 (29ff.); 91, 20 (27f.). Weitere Rspr.-Nachw. bei Schwager/ Krobn, WM 1991, 33 (40f.); ferner: Lege, NJW 1990, 864 (869); Schenke, NJW 1991, 1777 (1778ff.); Scherzberg, DVBl. 1991, 84 (88f.).

165 So J.Ipsen, DVBl. 1983, 1029 (1037); Papier (Fn. 20), Rdn. 632; Ossenbübl (Fn. 80), S. $185 \mathrm{f}$.

166 Vgl. dazu Ossenbiül, NJW 1991, $1201 \mathrm{ff}$.

167 Vgl. auch Götz, DVBl. 1984, 395 (396); Maurer (Fn. 131), S. 314 ff.; teilw. auch Kreft, FS für Geiger, 1989, S. 399 (411 ff.). A. A. Scherzberg, DVBl. 1991, 84 $(87$ m.w. N.).

168 Vgl. auch Weyreuther, Gutachten für den 47. DJT, 1968, S. B 164 ff.; $M . R e$ deker, DÖV 1987, $194 \mathrm{ff}$.; Maurer, a. a. O.

$169 \mathrm{Vgl}$. zu den Mängeln der Amtshaftung Schäfer/Bonk, Staatshaftungsgesetz, 1982, Einf. Rdn. 45 ff.; Ossenbühl (Fn. 80), S. 358 f. 
einträchtigungen - einschließlich der Einwirkungen auf das Eigentum - zu gewähren ${ }^{170}$.

Entscheidend ist der sich aus der Regelungsintention der Grundrechte ergebende Vorrang abwehrrechtlicher Maßnahmen ${ }^{171}$. Wird durch Gesetz oder aufgrund Gesetzes das Eigentum beschränkt bzw. entzogen, ohne daß das Gesetz hierfür einen Ausgleich oder eine Entschädigung vorsieht, muß sich der Betroffene, der den Eingriff für rechtswidrig hält, gegen diesen selbst wenden ${ }^{172}$. Er kann nicht unter Verzicht auf den Primärrechtsschutz Entschädigung oder Schadensersatz verlangen. Ähnlich ist die Rechtslage, wenn gesetzliche Ausgleichs- oder Entschädigungsklauseln existieren und der Betroffene die Rechtswidrigkeit der Maßnahme rügt, da sich die genannten Klauseln nur auf rechtmäßige Maßnahmen beziehen, die Geltendmachung der Rechtswidrigkeit also dem Primärrechtsschutz vorbehalten bleibt ${ }^{173}$. Schließlich sind die Fälle des rechtswidrigen Vollzugs gültiger Ausgleichs- oder Entschädigungsregelungen durch Verwaltungsakt auszuklammern. Soweit der Verwaltungsakt nicht aufgehoben wird - was gemäß $₫ 48$ VwVfG in der Regel eine Entschädigung nach sich zieht - , bestimmt er verbindlich die Rechtslage ${ }^{174}$. Der Betroffene kann daher die im Verwaltungsakt vorgesehene finanzielle Leistung verlangen, ohne gewissermaßen auf Verdacht den Verwaltungsakt angreifen zu müssen ${ }^{175}$.

170 Zur Ausdehnung der Haftung auf weitere Grundrechtsverletzungen vgl. auch Schmitt-Kammler (Fn.72), S.610; Scboch, Jura 1989, 529 (534f.); Maurer (Fn. 23), \$26 Rdn. 76; Steinberg/Lubberger (Fn. 15), S. 352; Schenke, NJW 1991, $1777 \mathrm{ff}$.

171 Dagegen leitet der BGH die Subsidiarität des „enteignungsgleichen Eingriffs" nur aus $\$ 254$ BGB ab (BGHZ 90, 17, 32). Näher dazu die Ausf. unten mit Fn. 179.

172 Vgl. BVerfGE 58, 300 (324).

173 Abzulehnen daher z. B. BGHZ 99, 24 (29); 105, 15 (16f.). Zutreffend weist Hermes, NVwZ 1990, 733 (734), darauf hin, daß beim Vollzug von „Entschädigungsklauseln" durch Verwaltungsakt nicht offenbleiben darf, ob ein finanzieller Ausgleich zu leisten ist. Enthält der Verwaltungsakt keine entspr. Regelung, bedeutet dies, daß der Betroffene den Eingriff ohne Ausgleich hinzunehmen hat. Will er dies nicht akzeptieren, muß er sich wiederum des Primärrechtsschutzes bedienen.

${ }_{174}$ Entgegen Ossenbühl, JZ 1989, 190 (191), kann sich die Verwaltung im „Entschädigungsprozeß“ also nicht einfach auf die Rechtswidrigkeit des Eingriffs berufen.

175 In solchen Fällen besteht eine Leistungspflicht nicht „wegen“, sondern "trotz" Rechtswidrigkeit der Maßnahme (vgl. Bender, BauR 1983, 1, 8f.). A.A. Schoch, Jura 1989, 529 (535); grds. auch Hendler, DVBl. 1983, 873 (882). 
Somit bleiben als Anwendungsfelder des enteignungsgleichen Eingriffs - richtiger der Eigentumsunrechtshaftung - im wesentlichen nur die Fälle eines Verzögerungsschadens und der sofortigen Durchführung rechtswidriger Maßnahmen übrig ${ }^{176}$. Ferner greift der Anspruch ausnahmsweise durch, wenn es der Geschädigte schuldlos unterlassen hat, Maßnahmen des Primärrechtsschutzes zu ergreifen. Hierbei wird man sich entgegen der Zivilrechtsprechung aber nicht an $\$ 254 \mathrm{BGB}$, sondern an den strengeren Anforderungen des $\$ 839$ Abs. 3 BGB zu orientieren haben ${ }^{177}$ und diese einengender auslegen müssen, als dies derzeit ${ }^{178}$ geschieht ${ }^{179}$.

Aus grundrechtlicher Sicht ist es unerheblich, welche Staatsgewalt rechtswidrig in das Eigentum eingegriffen hat ${ }^{180}$. Ob das Haftungsinstitut des enteignungsgleichen Eingriffs auch eine tragfähige Grundlage für den Ausgleich von Nachteilen bietet, die durch ein verfassungswidriges Parlamentsgesetz verursacht worden $\operatorname{sind}^{181}$, ist allein eine Frage der funktionellrechtlichen Grenzen von Richterrecht.

Als Rechtsfolge ist entgegen der herrschenden Meinung ${ }^{182}$ wegen des Unrechtscharakters grundsätzlich nicht Entschädigung, sondern

176 Vgl. dazu Nüßgens/Boujong (Fn. 62), Rdn. 433.

177 Auch um Wertungswidersprüche zu vermeiden (vgl. Schoch, Jura 1990, 140, 150).

$178 \mathrm{Vgl}$. etwa BGHZ 113, $17 \mathrm{ff}$.

179 Die Rspr. (vgl. dazu Nüßgens/Boujong, Fn. 62, Rdn. 435 ff.) und h. L. (Rüfner, in: Erichsen/Martens, Allgemeines Verwaltungsrecht, 9. Aufl. 1992, S.613) interpretieren die Subsidiarität des „enteignungsgleichen Eingriffs“ sehr „flexibel“. Abgestellt wird vor allem auf die Zumutbarkeit des Primärrechtsschutzes. An dieser soll es z. B. bereits dann fehlen, wenn die Rechtmäßigkeit des Eingriffs nur schwer beurteilt werden kann, das Kostenrisiko groß ist oder mit einer langen Prozeßdauer gerechnet werden muß. Damit wird die Bestandsgarantie und der Vorrang des Primärrechtsschutzes in unzulässiger Weise relativiert (krit. zu Recht Schlichter, FS für Sendler, 1991, S.241, 245 ff.). Vgl. nunmehr aber auch BGHZ 110, 12 (13ff.). Soweit bestehende Regelungen auf ein Mitverschulden abstellen (vgl. z. B. $\$ 40$ IV OBG NW), sind sie i.S. d. hier herausgestellten verfassungsrechtlichen Vorgaben auszulegen.

180 Als Eingriff kommt auch ein Unterlassen in Betracht, wenn eine Rechtspflicht zum Handeln besteht (Ossenbübl, Fn. 80, S. 212 ff.; einschränkender BGHZ 102, 350, 364 f.). Dagegen fehlt einer rechtswidrigen Erlaubnis (z. B. Baugenehmigung für ein „altlastenverdächtiges“ Grundstück) der Eingriffscharakter, vgl. (im Hinblick auf $\$ 39$ I b OBG NW) aber auch BGHZ 109, 380 (393).

181 Vgl. zum Meinungsstand: BGHZ 102, 350 (358ff.); Schenke, NJW 1988, $857 \mathrm{ff}$.

${ }_{182}$ BGHZ 90, 17 (29ff.); Rüfner (Fn. 179), S. $646 \mathrm{ff.} \mathrm{Wie} \mathrm{hier} \mathrm{Ossenbübl,} \mathrm{FS} \mathrm{für}$ Geiger, 1989, S. 475 (497); Steinberg/Lubberger (Fn. 15), S. 371. 
Dirk Ehlers

Schadensersatz zu gewähren. Der Rechtsweg bestimmt sich nach $\$ 40$ Abs. 2 S. 1 VwGO ${ }^{183}$.

\section{Die Haftung für enteignende Eingriffe}

Unter enteignenden Eingriffen versteht die Rechtsprechung Beeinträchtigungen des Eigentums, die als Nebenfolge rechtmäßigen Verwaltungshandelns eintreten und die Schwelle des enteignungsrechtlich $\mathrm{Zu}$ mutbaren überschreiten ${ }^{184}$. Da die Grundrechte auf das Einstehenmüssen für den Erfolg abstellen, handelt es sich jedoch auch in diesen Fällen nicht um Aufopferung oder gar Enteignung, sondern um staatliche Unrechtshaftung ${ }^{185}$. Diese kann sich nur auf die unvorhersehbaren rechtswidrigen (Unfall-)Folgen rechtmäßiger Handlungen beziehen ${ }^{186}$.

Dagegen haben die Zivilgerichte gerade die vorhersehbaren und vor den Verwaltungsgerichten angreifbaren Nachteilszufügungen etwa in Gestalt langandauernder Straßenbauarbeiten oder unzumutbarer Verkehrsimmissionen als enteignenden Eingriff angesehen ${ }^{187}$. Die Rechtsprechung läßt sich offenbar von der Vorstellung leiten, daß den Interessen des Staates an der Fortführung seines „an sich“ rechtmäßigen Handelns jedenfalls dann der Vorrang vor dem Abwehranspruch des betroffenen Eigentümers gebührt, wenn das dem Eigentümer auferlegte Opfer durch eine Entschädigung ausgeglichen werden

${ }^{183}$ Entspr. gilt für den Anspruch aus „enteignendem Eingriff“. A. A. insoweit Schwerdtfeger (Fn. 121), S. 39 f.; Maurer, DVBl. 1991, 781 (785). Rechtspolitisch empfiehlt sich eine Streichung des Art. 14 III 4 GG und aller weiteren Rechtswegklauseln, die eine Aufspaltung des primären und sekundären Rechtsschutzes zur Folge haben.

184 BGHZ 91, 20 (26f.); 102, 350 (361); Scbwager/Krobn, WM 1991, 33 (40 ff. m. w. N.).

185 Zum prinzipiellen Unterschied von Aufopferung und Staatshaftung vgl. auch Steinberg/Lubberger (Fn. 15), S. 18 ff. (die allerdings den "enteignenden Eingriff“ der Aufopferung zuordnen, S. 241 ff.). Wird die Rechtswidrigkeit - anders als hier - nur verhaltensbezogen definiert (vgl. zum Ganzen Olivet, Erfolgsunrechtslehre und Handlungsunrechtslehre aus der Sicht des öffentlichen Rechts, 1989), würde das nichts am Ergebnis ändern. Es läge zwar keine Unrechts-, wohl aber eine Art Gefährdungshaftung für grundrechtswidrige Eingriffe vor.

${ }_{186}$ Der „enteignende Eingriff“ stellt bei Zugrundelegung der hier vertretenen Ansicht nur eine Modalität des "enteignungsgleichen Eingriffs“ - richtiger der Eigentumsunrechtshaftung - dar. Im Ergebnis wie hier Schmitt-Kammler (Fn. 72), S.602f., 614. Dagegen soll nach Maurer, DVBl. 1991, 781 (784), der enteignende Eingriff ganz entfallen und in der ausgleichspflichtigen Inhaltsbest. aufgegangen sein.

${ }_{187} \mathrm{Vgl}$. einerseits BGHZ 57, 359 (365 f.); BGH, NJW 1980, $2703 \mathrm{f}$;; andererseits BGHZ 64, 220 (222); BGH, NJW 1986, 2423 (2424). 
kann. Jedoch unterliegt die Abmilderung übermäßiger Eigentumsbeschränkungen durch Gewährung eines finanziellen Ausgleichs dem Gesetzesvorbehalt des Art. 14 Abs. 1 S. 2 GG $^{188}$. Inhaltlich geht es fast ausnahmslos um nachbarrechtliche Ausgleichsansprüche ${ }^{189}$. Vielfach hat sich mittlerweile der Gesetzgeber dieser Materie angenommen ${ }^{190}$. Fehlen unmittelbar einschlägige Bestimmungen, kann eine analoge Anwendung bestehender Vorschriften oder die Heranziehung des in ihnen verkörperten allgemeinen Rechtsgedankens in Betracht kommen $^{191}$. Im übrigen bleibt der Gesetzgeber aufgerufen, die bestehenden Lücken des öffentlichen Nachbarrechts zu schließen.

\section{Fazit und Ausblick}

Kehren wir zum Schluß zur Ausgangsfrage nach dem Verhältnis von Eigentums- und Umweltschutz zurück, läßt sich feststellen, daß die Verfassung beides erfordert. Dies kann auch nicht weiter verwundern, weil ohne Nutzung der Umwelt kein Leben, ohne Eigentum keine Freiheit und ohne Umweltschutz auf Dauer gesehen weder das eine noch das andere möglich ist. Art. 14 GG enthält wichtige Vorgaben für die Zuordnung der kollidierenden Interessen, überläßt im übrigen aber die Herstellung einer praktischen Konkordanz in besonders weitgehendem Ausmaße dem Gesetzgeber. Die Eigentumsgarantie eignet sich daher nicht als „Sündenbock“ für etwaige Versäumnisse der Umweltpolitik.

Um ein ausgewogenes Sozialmodell verwirklichen zu können, bedarf der Gesetzgeber der Anleitung durch eine klare Eigentumsdogmatik. Die Rechtsprechung - insbesondere die Verfassungsrechtsprechung - hat hierfür wichtige Bausteine geliefert, ein fertiges Gebäude aber nicht zu errichten vermocht. Auch zehn Jahre nach der $\mathrm{Naßauskiesungsentscheidung} \mathrm{des} \mathrm{Bundesverfassungsgerichts} \mathrm{bleibt}$ daher die Wissenschaft besonders herausgefordert.

188 Zutreffend Maurer, DVBl. 1991, 781 (784f.).

$189 \mathrm{Vgl}$. Steinberg/Lubberger (Fn. 15), S. 242 ff. Neben dem Nachbarrecht i. e.S. ist ferner das Anliegerrecht zu nennen.

190 Vgl. z.B. $\$ \$ 74$ II 3, 75 II 4 VwVfG; 8 a IV u. V FStrG.

191 Zur verfassungsrechtlichen Zulässigkeit einer analogen Gesetzesanwendung im Rahmen des Art. 14 I GG vgl. BVerfG, DVBl. 1990, 690 f.; zur Verallgemeinerung nachbarrechtlicher Vorschriften: BVerwGE 79, 254 (262f.); 80, 184 (190). 
Leitsätze des 2. Berichterstatters über:

\section{Eigentumsschutz, Sozialbindung und Enteignung bei der Nutzung von Boden und Umwelt}

1. Eigentums- und Umweltschutz stehen in einem Spannungsverbältnis, weil mit dem Eigentumsrecht vielfach ein Recht auf Umweltnutzung verbunden ist und diese Nutzung die Umwelt schädigen kann.

2. Die Auslegung des Art.14 GG wird beute vornebmlich durch die Rechtsprechung des Bundesverfassungsgerichts geprägt. Das Bundesverfassungsgericht hat insbesondere die Gesetzesabhängigkeit, den Charakter des Eigentumsgrundrechts als Freibeitsrecht sowie den Vorrang des primären vor dem sekundären Rechtsschutz berausgearbeitet. Es hat damit die Eigentumsgarantie von ihrem entschädigungsrechtlichen Kopf auf die grundrechtlichen Füße gestellt, im übrigen aber viele Fragen offengelassen.

\section{Der Eigentumsbegriff der Verfassung}

3. Unter Eigentum im verfassungsrechtlichen Sinne ist das gegen den Staat gerichtete Recht des Bürgers zu verstehen, einen ihm von der Rechtsordnung zugeordneten Vermögensgegenstand innezubaben und zu nutzen.

4. Die Eigentumsgarantie stellt selbst keine Rechtspositionen bereit. Schutzobjekte der Eigentumsgarantie können nur die durch Gesetz oder aufgrund Gesetzes eingeräumten Positionen sein.

5. Von Art. 14 Abs. 1 S. 1 GG werden zum einen alle vermögenswerten Rechte des privaten Rechts einschließlich des Rechts am eingerichteten und ausgeübten Gewerbebetrieb, zum anderen alle vermögenswerten Rechte des öffentlichen Rechts erfaßt, die nicht ausscbließlich auf staatlicher Gewäbrung beruben.

\section{Die Eigentumsgewäbrleistung}

6. Die Institutsgarantie des Eigentums zielt auf die Gewährleistung der Freibeit im vermögensrechtlichen Sinne ab und sichert dem Bürger 
in Gestalt eines Untermaßverbotes einen freiheitlichen Mindeststandard $\mathrm{zu}$.

7. Die subjektivrechtliche Bestandsgarantie des Eigentums schützt alle dem Grundrechtsinhaber zustehenden vermögenswerten Rechtspositionen vor Beeinträchtigungen des Staates.

8. Ein Grundrecht auf Baufreibeit kennt das Grundgesetz nicht. Die Baufreiheit wird nur von der Institutsgarantie des Eigentums erfaßt. Verfassungsrechtlich geschützt ist das Recht des Grundeigentümers, sein Grundstück auf der Grundlage und im Rabmen des privaten und öffentlichen Rechts zu bebauen. An dem Schutz nehmen auch die bauplanerischen Nutzungszuweisungen und rechtmäßigen Baugenebmigungen teil.

9. Der Grundeigentümer hat in der Regel keinen Anspruch auf Nutzung des Grund- oder Oberflächenwassers, wobl aber einen Anspruch auf fehlerfreie Ausübung des Bewirtschaftungsermessens der Verwaltung.

10. Die Nutzung der Luftsäule über dem Grundstück darf nicht der Gewässerbenutzung gleichgestellt werden, sondern ist im Grundsatz wie die Nutzung des Bodens zu bebandeln.

11. Art.14 Abs.1 S. 1 GG gebietet einen Nachbarschutz, der nicht erst dann einsetzt, wenn der Nachbar durch eine staatliche Genebmigung privater Anlagen oder Vorbaben „schwer und unerträglich“ getroffen wird.

12. Im Falle einer mittelbaren staatlichen Einwirkung auf den eingerichteten und ausgeübten Gewerbebetrieb sind besonders strenge Anforderungen an die Zurechenbarkeit des Beeinträchtigungserfolges zu stellen.

13. Imperative Abgabenerhebungen sind immer an Art.14 Abs.1 S. 1 GG zu messen.

\section{Die verfassungsrechtlichen Direktiven der Eigentumsgestaltung}

14. Inhalts- und Schrankenbestimmungen lassen sich nicht materiell, sondern nur zeitlich voneinander unterscheiden. Inbaltsbestimmungen definieren das Eigentum für die Zukunft, Schrankenbestimmungen greifen in eine nach bisherigem Recht bestehende Position ein.

15. Der Gesetzgeber muß eine umfassende Abwägung zwischen den durch Art. 14 Abs. 1 S. 1 GG geschützten Privatnützigkeitsinteressen des einzelnen und den durch Art.14 Abs. 2 GG geschützten Allgemeinwoblbelangen vornebmen. Allgemeine Formeln - wie sie die Enteignungstheorien oder die Lebre von der Situationsgebundenheit des Grundeigentums anbieten - können das Ergebnis dieser 
Abwägung nicht vorwegnehmen. Art. 14 Abs. 2 GG verpflichtet den Gesetzgeber zu einem wirksamen Umweltschutz. Die Beurteilung der Verhältnismäßigkeit der Regelungen hängt vor allem davon $a b$, ob ein generell-abstrakter oder konkret-individueller Maßstab zugrundezulegen ist.

16. Der durch legale Eigentumsausübung geschaffene Bestand genießt infolge der Aufwendungen und Dispositionen des Eigentümers einen böberen Schutz als eine noch nicht verwirklichte Nutzung. Der Bestandsschutz ist im Baurecht stärker ausgeprägt als im Umweltrecht.

17. Bei der Auferlegung von Positivpflichten wird die Sozialbindungsgrenze in der Regel früber als bei der Statuierung von Duldungsoder Unterlassungspflichten erreicht.

18. Unzulässig sind Bescbränkungen des Eigentums, die für sich geseben unbedenklich sind, in der Summe den Eigentümer aber unverbältnismäßig einengen.

19. Zur Abmilderung von Belastungen kann der Gesetzgeber zum Erlaß ausgleichspflichtiger Inbalts- und Scbrankenbestimmungen gezwungen sein. Ausgleichsbestimmungen vermögen Eigentumsbeschränkungen aber nur zu rechtfertigen, wenn andere Regelungen nicht in gleicher Weise dem Gemeinwohlerfordernis genügen und nach Art der berübrten Belange eine Verweisung des Eigentïmers auf die Befriedigung seiner Vermögensinteressen zulässig ist. Sie bedürfen nach Art und Ausmaß einer formell-gesetzlichen Regelung.

\section{Die Enteignung}

20. Unter Enteignung ist die vollständige oder teilweise Entziehung einer subjektiven Eigentumsposition im Wege der Durchbrechung der Eigentumsordnung durch einen gezielten öffentlichen Rechtsakt zum Zwecke der Indienstnabme der entzogenen Position für die Erledigung von Staatsaufgaben zu verstehen.

21. Da sich die Entziebung nur auf rechtlich selbständige oder verselbständigungsfähige Eigentumspositionen bezieht, stellen sich die Nutzungs- und Verfügungsbeschränkungen grundsätzlich nicht als Enteignung dar.

22. Die Enteignungszwecke und -voraussetzungen bedürfen keiner minutiösen gesetzlichen Regelung, weil dies auf eine Einzelfallgesetzgebung hinausliefe.

23. Anders als viele Fachpläne entfaltet ein Bebaunngsplan keine enteignungsrechtlichen Vorwirkungen.

24. Jede Enteignung löst eine Entschädigungspflicht aus. Salvatorische Entschädigungsklauseln sind unzulässig. Hinsichtlich der Höbe 
der Entschädigung ist von einem formellen Regel-Ausnabme-Verbältnis zugunsten der Verkebrswertentschädigung auszugehen.

\section{Eigentumsunrechtshaftung}

25. Alle Freibeitsrechte verpflichten ibrem Grunde nach den Staat $z u$ einer finanziellen Wiedergutmachung für die nicht durch Inanspruchnabme des primären Rechtsschutzes abwendbaren Folgen rechtswidriger Freibeitsbeeinträchtigungen.

26. Die Haftungsinstitute des sog. enteignungsgleichen und enteignenden Eingriffs finden ibre Rechtsgrundlage in Art. 14 Abs. 1 S. 1 GG in Verbindung mit zulässigem Richterrecht. In beiden Fällen handelt es sich um Unrechtshaftung. Der enteignungsgleiche Eingriff bezieht sich auf die rechtswidrigen, das Eigentum beeinträchtigenden Handlungen (Handlungsunrecht), der enteignende Eingriff auf den Fall der nicht voraussebbaren rechtswidrigen Folgen rechtmäßiger Handlungen (Erfolgsunrecht).

27. Die Subsidiarität der Haftung ergibt sich aus Art. 14 Abs. 1 S. 1 $G G$ und nicht aus einer analogen Anwendung des $₫ 254 B G B$.

28. Als Rechtsfolge der Eigentumsunrechtshaftung ist Schadensersatz und nicht nur Entschädigung zu gewäbren. 


\section{Eigentumsschutz, Sozialbindung und Enteignung bei der Nutzung von Boden und Umwelt}

3. Bericht von Privatdozent Dr. Peter Hänni, Freiburg i. Ue.

\section{Inhalt}

I. Die Eigentumsgarantie nach der schweizerischen Bundesverfassung . . . . . . . . . . . . . . . . . . . 254

1. Historische Ausgangslage ............... 254

a) Die schweizerische Eigentumsordnung als Ergebnis problembezogener Gesetzgebung . . . . . . . . . . 254

b) Von der Anerkennung der Eigentumsgarantie als ungeschriebenes Verfassungsrecht zur Aufnahme in die BV ....................... 255

2. Die verfassungsrechtlichen Rahmenbedingungen von Eigentumsschutz, Sozialbindung und Enteignung . . . . 256

a) Der Verfassungstext ................. 256

b) Instituts- und Bestandesgarantie . . . . . . . . . . . 258

3. Die Besonderheiten des Grundeigentums . . . . . . . 259

a) Nochmals zur Institutsgarantie . . . . . . . . . 259

b) Grundeigentum und offene Verfassung . . . . . 260

c) Die geschützten Teilinhalte des Grundeigentums . . . 261

4. Die Besitzstandsgarantie ................. 264

5. Das Recht am eingerichteten und ausgeübten Gewerbebetrieb ........................... 267

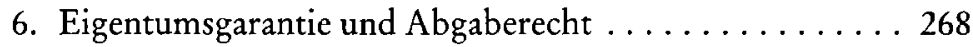

II. Inhalts- und Schrankenbestimmungen des Gesetzgebers und Sozialbindung des Eigentums . . . . . . . . . . . . . . 270

1. Sozialbindung kein verfassungsrechtlicher Begriff? . . . . 270

2. Inhalts- und Schrankenbestimmungen durch den Gesetzgeber . . . . . . . . . . . . . . . . . . . 271

3. Nutzungsbeschränkungen an Grund und Boden ..... 272

a) Schwäche der Bestandesgarantieformel oder notwendige Folge der Unvermehrbarkeit des Bodens? . . . . . 272

b) Planerische Abwägungsgebote und demokratische Rechtssetzung als neue Korrektive . . . . . . . . 273 
c) Zusammenfassung $\ldots \ldots \ldots \ldots \ldots \ldots \ldots \ldots \ldots \ldots \ldots \ldots \ldots$

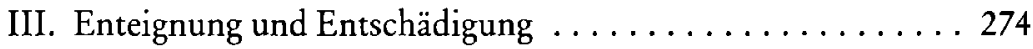

1. Die verfassungsrechtlichen Grundlagen der Enteignung . 274

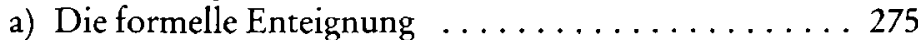

b) Die materielle Enteignung $\ldots \ldots \ldots \ldots \ldots \ldots 275$

c) Polizeilich motivierte Eigentumsbeschränkungen . . . 277

d) Sonderfälle . . . . . . . . . . . . . . . . . . 277

2. Junktim-Klausel und Entschädigungshöhe ....... 278

Diese Arbeit ist unter besonderen Umständen entstanden. Ich danke Herrn Prof. Walter Haller, dem ursprünglich vorgesehenen Berichterstatter, für die wertvolle Unterstützung, die er mir hat zuteil werden lassen. Insbesondere geht mein Dank an seine Assistentin, Frau Elisabeth Lang, die mit ihrem großen Engagement wesentlich zur zeitgerechten Fertigstellung beigetragen hat. 
Peter Hänni

\section{Die Eigentumsgarantie nach der schweizerischen Bundesverfassung}

\section{Historische Ausgangslage}

Die schweizerische Eigentumsordnung mit dem ihr zugrundeliegenden Eigentumsbegriff läßt sich nur dann in adäquater Weise erfassen, wenn am Anfang der Ausführungen in groben Zügen die historische Entwicklung des Eigentumsbegriffs und des Verfassungsrechts nachgezeichnet wird ${ }^{1}$. Anders als in der deutschen Verfassungsgeschichte hat die ausdrückliche verfassungsmäßige Verankerung der Eigentumsgarantie im fast 150jährigen helvetischen Bundesstaat eine noch sehr kurze Laufbahn hinter sich: Erst im Jahre 1969 hat sie Aufnahme in die schweizerische Bundesverfassung gefunden.

\section{a) Die schweizerische Eigentumsordnung als Ergebnis problembezogener Gesetzgebung}

Durchaus im Sinne der schweizerischen Verfassungstradition, die stark pragmatische Züge trägt und individuelle Garantien erst dann in der Verfassung verankert, wenn eine aktuelle Bedrobungslage deutlich wird, hat sich die Gesetzgebung des Bundes mit den konkreten jeweiligen Ansprüchen von Staat und Gesellschaft im Zusammenhang mit der Eigentumsordnung punktuell und einzelfallbezogen angenommen: So wurde beispielsweise schon im Jahre 1850 ein erstes eidgenössisches Expropriationsgesetz erlassen ${ }^{2}$, um im Hinblick auf den einsetzenden Eisenbahnbau ${ }^{3}$ die Rechte der Grundeigentümer wirksam schützen zu können. Und geradezu modern mutet das in seiner Bedeutung kaum zu überschätzende und noch heute in Kraft stehende Forstpolizeigesetz aus dem Jahre $1902 \mathrm{an}^{4}$, das in Art. 31 Abs. 1 kurz und knapp bestimmt: „Das Waldareal der Schweiz soll nicht vermindert werden. "Von erheblicher Wichtigkeit sind selbstver-

1 Zur Entwicklung der Eigentumsgarantie in der Schweiz vgl. Peter Saladin, Grundrechte im Wandel, 3. Aufl., Bern 1982, $111 \mathrm{ff}$.

${ }^{2}$ Bundesgesetz betreffend die Verbindlichkeit zur Abtretung von Privatrechten, vom 1. Mai 1850 (AS a. F. I 319).

${ }^{3} \mathrm{Vgl}$. dazu das Bundesgesetz über den Bau und den Betrieb von Eisenbahnen im Gebiete der Eidgenossenschaft, vom 28. Juli 1852 (AS a. F. III 170).

${ }_{4}$ Bundesgesetz betreffend die eidgenössische Oberaufsicht über die Forstpolizei, vom 11. Oktober 1902 (SR 921.0). Dieses Gesetz löste ein älteres Bundesgesetz aus dem Jahre 1876 ab (AS n. F. 2 353), das sehr ähnlich formulierte Nutzungsbeschränkungen im Interesse der Allgemeinheit enthielt. Vgl. auch unten I. 3.c) bb). 
ständlich auch die Grund und Boden betreffenden Vorschriften des Schweizerischen Zivilgesetzbuches (ZGB) ${ }^{5}$, das 1912 in Kraft gesetzt worden ist. Das heute noch gültige Enteignungsgesetz ${ }^{6}$ des Bundes stammt aus dem Jahre 1930; weitere, für die Eigentumsordnung wichtige Erlasse ${ }^{7}$ sind in ihren ursprünglichen Fassungen erheblich älter als die in der Verfassung verankerte Eigentumsgarantie. Es läßt sich daher feststellen, daß zentrale Elemente der schweizerischen Eigentumsordnung vom einfachen Gesetzgeber ohne ausdrückliche verfassungsrechtliche Grundlagen bezüglich der Eigentumsgarantie festgelegt worden sind.

\section{b) Von der Anerkennung der Eigentumsgarantie als ungeschriebenes Verfassungsrecht zur Aufnabme in die $B V$}

Das schweizerische Bundesgericht hat zunächst angesichts des Fehlens einer ausdrücklichen Gewährleistung des Privateigentums in der BV seine Urteile auf die Garantiebestimmungen der kantonalen Verfassungen abgestützt, wobei es anfänglich den unterschiedlichen Formulierungen der Verfassungen sorgfältig Rechnung getragen hat ${ }^{8}$. Erst allmählich bezeichnete es die Differenzen zwischen den einzelnen Verfassungsbestimmungen ausdrücklich als rechtlich irrelevant ${ }^{9}$. Der bundesrechtliche Durchbruch erfolgte im Jahre $1960^{10}$, als das Gericht die Eigentumsgarantie in den Rang eines ungeschriebenen Verfassungsrechts erhob und damit bewirkte, daß die kantonalen Bestimmungen ihre rechtliche Bedeutung überhaupt verloren, sofern ihre

5 SR 210. Mit dem Grundeigentum befaßt sich der 19. Titel des ZGB (Art. 655 ff.). Vgl. dazu z. B. Arthur Meier-Hayoz, Berner Kommentar zum ZGB, Sachenrecht, Grundeigentum I (Art. 655-679 ZGB), 3. Aufl., Bern 1965; Grundeigentum II (Art. 680-701 ZGB), 3. Aufl., Bern 1975. Rechtshistorisch wertvolle Hinweise zum Eigentumsbegriff des ZGB finden sich bei Eugen Huber, System und Geschichte des Schweizerischen Privatrechtes, 3. Bd., Basel 1889, $137 \mathrm{ff}$.

6 SR 711. Zum eidgenössischen Enteignungsrecht vgl. Heinz Hess/Werner Weibel, Das Enteignungsrecht des Bundes, Kommentar, 2 Bde., Bern 1986.

$7 \mathrm{Vgl}$. z. B. Bundesgesetz über die Wasserbaupolizei, vom 22. Juni 1877 (SR 721.10); Bundesgesetz betreffend die elektrischen Schwach- und Starkstromanlagen (Elektrizitätsgesetz), vom 24. Juni 1902 (SR 734.0); Bundesgesetz über die Nutzbarmachung der Wasserkräfte, vom 22. Dezember 1916 (SR 721.80) usw.

8 BGE 37 I $516 \mathrm{ff} . ; 47$ II $497 \mathrm{ff}$., insb. 511.

9 So in BGE 74 I 470; 93 I 137. Vgl. dazu Saladin (Anm. 1), $114 \mathrm{f}$.

10 Entscheid des Bundesgerichtes vom 11. Mai 1960, in: ZBI. 62 (1961) 69 ff. (mit Hinweis auf zwei nicht veröffentlichte Urteile aus dem Jahr 1959, in denen das Bundesgericht die Anerkennung der Eigentumsgarantie als ungeschriebenes Grundrecht der Bundesverfassung bereits vorweggenommen hatte). 
Schutzwirkung nicht über diejenige der bundesrechtlichen Gewährleistung hinausging. Die schweizerische Lehre hat dieser Rechtsprechung beinahe ausnahmslos zugestimmt ${ }^{11}$.

Der Verfassungsgeber sah sich allerdings erst im Jahre 1969 veranlaßt - im Zug der gleichzeitig in die Verfassung aufgenommenen verfassungsrechtlichen Grundlage für ein vom Bund in den Grundsätzen zu regelndes Raumplanungsrecht -, der Eigentumsgarantie auch die ausdrückliche verfassungsrechtliche Gewährleistung zuteil werden $\mathrm{zu}$ lassen. Einmal mehr hatte erst eine konkrete Herausforderung, nämlich das Problem der Raumordnung und die damit verbundenen neuen Einschränkungen, eine stärkere verfassungsrechtliche Absicherung notwendig erscheinen lassen.

2. Die verfassungsrechtlichen Rabmenbedingungen von Eigentumsscbutz, Sozialbindung und Enteignung

a) Der Verfassungstext

Art. 22 ${ }^{\text {ter }} \mathrm{BV}$ lautet wie folgt:

1) Das Eigentum ist gewährleistet.

2) Bund und Kantone können im Rahmen ihrer verfassungsmäßigen Befugnisse auf dem Wege der Gesetzgebung im öffentlichen Interesse die Enteignung und Eigentumsbeschränkungen vorsehen.

3) Bei Enteignung und bei Eigentumsbeschränkungen, die einer Enteignung gleichkommen, ist volle Entschädigung zu leisten.

Die so formulierte Eigentumsgarantie gewährleistet nach herrschender schweizerischer Lehre und Rechtsprechung das Rechtsinstitut "Eigentum“; eine bestimmte Eigentumsordnung wird indessen dadurch nicht garantiert. Gewandelten Auffassungen und veränderten Verhältnissen kann der Gesetzgeber aufgrund von Abs. 2 Rechnung tragen $^{12}$. Dabei darf er sich allerdings nicht zu weit von den bisherigen

$11 \mathrm{Vgl}$. Saladin (Anm. 1), $116 \mathrm{~m} . \mathrm{H}$.

12 Auch die andern Staatsfunktionen, insbesondere die höchstrichterliche Rechtsprechung, gestalten das Eigentum und entwickeln es weiter. So hat das Bundesgericht den verfassungsrechtlichen Begriff des Eigentums vom privatrechtlichen gelöst und ihm eine weit umfassendere Bedeutung beigemessen, indem es ihn auf andere vermögenswerte Privatrechte, z. B. obligatorische Rechte, und auch auf bestimmte dem öffentlichen Recht entspringende Berechtigungen - wie Vermögensrechte aus Konzessionen und von Beamten - ausdehnte (Hans Huber, Über die Konkretisierung der Grundrechte, in: Der Staat als Aufgabe, Gedenkschrift für Max Imboden, Basel 1972, 196). Zur großen Bedeutung, die dem Bundesgericht bei Fragen der materiellen Enteignung zukommt, vgl. hinten III.1.b) sowie Walter 
Vorstellungen über das Eigentum entfernen. Insofern läßt sich nicht sagen, Inhalt und Umfang des Eigentums als verfassungsmäßiges Recht werde allein durch die Gesetzgebung bestimmt ${ }^{13}$. Immerhin gilt es, dabei der schweizerischen Besonderheit Rechnung zu tragen, daß die Verfassungsgerichtsbarkeit sich grundsätzlich nur auf das kantonale Recht erstreckt, wäbrend der Bundesgesetzgeber keiner richterlichen Kontrolle unterworfen ist ${ }^{14}$.

Wesentlich ist sodann, daß zwischen der Eigentumsgarantie und anderen Verfassungsbestimmungen, welche die jeweilige Ausgestaltung des Eigentums mitbestimmen, nach der Praxis des Bundesgerichtes und der neueren Lehre nicht ein Verhältnis der Über- und Unterordnung besteht, sondern eine prinzipielle Gleichrangigkeit anerkannt wird ${ }^{15}$. Dies hat für die Bestimmung des Inhalt des Eigentums erhebliche praktische Konsequenzen.

Eine besondere Stellung nimmt in diesem Zusammenhang die Handels- und Gewerbefreiheit (HGF) ein, die im Unterschied zur Eigentumsgarantie seit 1874 in der BV verankert ist. Sie gewährleistet als Individualrecht gegenüber dem Staat die freie Wahl und Ausübung jeder Art erwerbswirtschaftlicher Tätigkeit an jedem Orte der Schweiz ${ }^{16}$. Der Gesetzgeber hat der HGF nach neuerer Rechtspre-

Kälin, Verfassungsgerichtsbarkeit in der Demokratie, Bern 1987, 44, $134 \mathrm{f}$. - Zur Wandelbarkeit des Eigentumsbegriffs im allgemeinen vgl. statt vieler Peter Häberle, Vielfalt der Property Rights und der verfassungsrechtliche Eigentumsbegriff, AöR 1984, $36 \mathrm{ff}$., insb. $59 \mathrm{ff}$.

13 Georg Müller, Kommentar zu Art. 22 ${ }^{\mathrm{tcr}}$ BV, in: Kommentar zur Bundesverfassung der Schweizerischen Eidgenossenschaft, Basel/Zürich/Bern $1987 \mathrm{ff}$., Rdn. 1; Ulrich Häfelin/Georg Müller, Grundriß des Allgemeinen Verwaltungsrechts, Zürich 1990, 336 (N.1574); Yvo Hangartner, Besonderheiten der Eigentumsgarantie, in: Im Dienst an der Gemeinschaft, Festschrift für Dietrich Schindler, Basel/Frankfurt a. M. 1989, $714 \mathrm{f}$.

14 Art. 113 Abs. 3 BV und Art. $114^{\text {bis }}$ Abs. 3 BV. Vgl. zu dieser Eigenart des schweizerischen Verfassungsrechts Andreas Aner, Die schweizerische Verfassungsgerichtsbarkeit, Basel/Frankfurt a.M. 1984, $61 \mathrm{ff}$.; ders., «... Le tribunal fédéral appliquera les lois votées par l'Assemblée fédérale ...»: réflexions sur l'art. 113 al. 3 Cst., ZSR NF 99/I (1980) 107 ff.; Walter Haller, Kommentar zu Art. 113 BV, in: Kommentar zur Bundesverfassung der Schweizerischen Eidgenossenschaft, Basel/ Zürich/Bern 1987 ff., Rdn. 142 ff.; Walter Kälin, Das Verfahren der staatsrechtlichen Beschwerde, Bern 1984, $34 \mathrm{ff}$.

15 BGE 105 I a 336 (Fall Zizers); René A. Rhinow/Beat Krähenmann, Schweizerische Verwaltungsrechtsprechung, Ergänzungsband, Basel/Frankfurt a.M. 1990, Nr. 123 IV.c). Vgl. auch unten III. 1. b) a. E.

16 Leo Schürmann, Wirtschaftsverwaltungsrecht, 2. Aufl., Bern 1983, 27; René A. Rhinow, Kommentar zu Art. $31 \mathrm{BV}$, in: Kommentar zur Bundesverfassung der 
chung des Bundesgerichtes bei raumplanerischen Maßnahmen Rechnung zu tragen. Zwar ziehen letztere regelmäßig eine Einschränkung der gewerblichen und wirtschaftlichen Betätigungsmöglichkeiten nach sich. Weder mit der HGF noch mit der Eigentumsgarantie wäre es jedoch zu vereinbaren, wenn unter dem Deckmantel raumplanerischer Maßnahmen ein Eingriff in den wirtschaftlichen Wettbewerb bezweckt wird, um bestimmte Gewerbezweige oder Betriebsformen vor Konkurrenz zu schützen oder in ihrer Existenz zu sichern ${ }^{17}$.

\section{b) Instituts- und Bestandesgarantie}

Die äußerste Grenze des verfassungsrechtlich Zulässigen bildet die Institutsgarantie. Diese ist dann verletzt, wenn der Gesetzgeber, dem die Erhaltung des Instituts „Eigentum“ aufgetragen ist, Normen aufstellt, welche das Eigentum als Institut beseitigen, aushöhlen, seiner Substanz berauben, seinen Wesenskern antasten. Der Gesetzgeber muß die Verfügungs- und Nutzungsrechte, die sich aus dem Eigentum ergeben, wahren, und den Privaten ein Mindestmaß an Selbstbestimmung über ihre vermögenswerten Rechte einräumen ${ }^{18}$.

Die Bestandesgarantie setzt demgegenüber beim individuellen Träger der Eigentumsgarantie an und schützt ibn in seinen konkreten

Schweizerischen Eidgenossenschaft, Basel/Zürich/Bern 1987 ff., Rdn. 68 ff.; Ulrich Häfelin/Walter Haller, Schweizerisches Bundesstaatsrecht, 2. Aufl., Zürich 1988, $423 \mathrm{ff}$. (N. $1382 \mathrm{ff}$.); BGE 100 I a 174; 103 I a 259; 116 I a 121.

17 BGE 102 I a 115 f.; 110 I a 174; 111 I a 99. Die Frage des Zusammenhangs der HGF mit der Eigentumsgarantie hat sich vor allem bei planerischen Maßnahmen zur Eindämmung von Einkaufszentren gestellt (BGE 102 I a $119 \mathrm{ff}$.; 110 I a $167 \mathrm{ff}$.; Peter Saladin/Christoph Lanz, Rechtliche Probleme im Zusammenhang mit Einkaufszentren, ZBl. 77 [1976] 89 ff.; Peter Hess, Einkaufszentrum, Raumplanung und Handels- und Gewerbefreiheit, Diss. Fribourg 1976). - Zum Verhältnis zwischen Eigentumsgarantie und HGF vgl. auch BGE 113 I a 126 ff.; ferner JeanFrançois Aubert, Traité de droit constitutionnel suisse, Supplément 1967-1982, Neuchâtel 1982, 279 f. (ad No. 2204 ff.); André Grisel, Traité de droit administratif, Bd.II, Neuchâtel 1984, 677ff.; Paul Zimmermann, Das Verhältnis zwischen Wirtschaftsfreiheit und Eigentumsgarantie, Diss. Zürich 1979.

18 BGE 103 I a 418f.; 105 I a 140f.; 106 I a 348; 113 I a 132; Georg Müller, Kommentar (Anm. 13), Rdn. 12 zu Art. $22^{\text {ter }}$ BV; ders., Privateigentum heute, Vom Sinn des Eigentums und seiner verfassungsrechtlichen Gewährleistung, ZSR NF 100/II (1981) $97 \mathrm{ff}$;; Jörg Paul Müller, Die Grundrechte der schweizerischen Bundesverfassung, 2. Aufl., Bern 1991, 331; Grisel, Traité II (Anm. 17), 675 ff.; Saladin (Anm. 1), $122 \mathrm{ff}$. Für die deutsche Lehre und Rechtsprechung Karl Nüßgens/Karlheinz Boujong, Eigentum, Sozialbindung, Enteignung, München 1987, $4 \mathrm{f}$, mit zahlreichen Hinweisen. 
Vermögensrechten ${ }^{19}$. Eingriffe in diese individuellen Rechtspositionen sind nur dann zulässig, wenn sie auf einer gesetzlichen Grundlage ${ }^{20}$ beruhen, aufgrund eines überwiegenden öffentlichen Interesses erfolgen, verhältnismäßig sind und - soweit ein Eigentumsübergang oder enteignungsähnliche Folgen damit verbunden sind - der Eingriff voll entschädigt wird ${ }^{21}$. Die Bestandesgarantie wird hier zur Wertgarantie, indem der Eingriff als solcher zwar nicht abgewehrt werden kann, der Staat aber mindestens die damit verbundene Wertminderung auszugleichen hat ${ }^{22}$.

\section{Die Besonderheiten des Grundeigentums}

\section{a) Nochmals zur Institutsgarantie}

Der wichtigste Anwendungsbereich der Eigentumsgarantie ist zweifellos das Grundeigentum. Verschiedene der oben erwähnten Grundsätze sind im Zusammenhang mit dem Grundeigentum entwikkelt worden oder haben eine spezifische Ausprägung erfahren. Nach der Praxis des Bundesgerichtes liegt der geltenden Verfassung ein elastischer Eigentumsbegriff zugrunde, was dazu führt, daß dem Gesetzgeber weite Ermessensspielräume eröffnet werden ${ }^{23}$. Erst einmal hat das Gericht erkannt, daß der Gesetzgeber die Grenzen der Institutsgarantie überschritten hat: Die Schaffung eines kantonalen Bodenmonopols durch den (freiwilligen) Zukauf von Land, verbunden mit einem Wiederverkaufsverbot, wurde als mit der Institutsgarantie unvereinbar erachtet ${ }^{24}$. Keinen grundsätzlichen Angriff auf das Institut des Grundeigentums vermochte das Gericht dagegen in der Bewilligungspflicht für den Umbau oder Abbruch von Wohnungen, in zeitlich unbefristeten Abbruchverboten oder in einer Bewilligungs-

19 Häfelin/Haller (Anm. 16), 415 (N.1360); Georg Müller, Kommentar (Anm. 13), Rdn. 16 zu Art. 22 ${ }^{\text {cer BV. }}$

${ }^{20}$ Zum Erfordernis der gesetzlichen Grundlage vgl. ausführlich Georg Müller, Kommentar (Anm.13), Rdn. $27 \mathrm{ff}$. zu Art. 22ter BV. In zwei neuesten, die Stadt Zürich betreffenden Entscheidungen lehnte das Bundesgericht die Schaffung einer sog. Kernzone wegen fehlender gesetzlicher Grundlage ab (Entscheide des Bundesgerichtes vom 6. November 1991, in: Neue Zürcher Zeitung Nr.259 vom 7. November 1991, 53).

${ }^{21}$ Jörg Paul Müller (Anm. 18), 333; Häfelin/Haller (Anm. 16), 415 (N. 1360); Grisel, Traité II (Anm. 17), $674 \mathrm{f}$.

22 Häfelin/Haller (Anm. 13), 337 f. (N. 1579).

${ }^{23}$ Hangartner (Anm. 13), 716.

${ }^{24}$ Entscheid des Bundesgerichtes vom 17. Juni 1959, in: ZBl. 61 (1960) $281 \mathrm{ff}$. 
pflicht bei Veräußerungen von Wohnungen, an welchen auf dem Wohnungsmarkt Mangel herrscht, zu erblicken ${ }^{25}$. Zulässig ist sodann die Förderung des Wohnungsbaus durch ein dem Kanton eingeräumtes Vorkaufsrecht, ebenso ein allgemeines Vorkaufsrecht des Staates im Falle von Bauzonenänderungen und die Verpflichtung des Gemeinwesens, das für den sozialen Wohnungsbau benötigte Bauland nötigenfalls auf dem Expropriationsweg zu beschaffen ${ }^{26}$. Das Verwaltungsgericht des Kantons Zürich entschied, daß Vorschriften über den Natur- und Heimatschutz gar nicht geeignet seien, mit der Institutsgarantie in Widerspruch zu geraten, weil sonst die entsprechende Verfassungsbestimmung eines großen Teils ihres Sinnes beraubt würde ${ }^{27}$.

Was den Bereich der unüberprüfbaren Bundesgesetzgebung betrifft, sticht unter dem Aspekt der Eigentumsgarantie insbesondere die sog. Lex Friedrich hervor ${ }^{28}$. Dieses Gesetz unterstellt den Erwerb von Grundstücken durch Personen im Ausland einer Bewilligung. Weitergehende Beschränkungen können durch die Kantone vorgesehen werden, so namentlich die Bewilligungssperre, das Vorkaufsrecht zum Verkehrswert zugunsten nicht bewilligungspflichtiger Käufer sowie die Beschränkung des Erwerbs auf Baurecht, Wohnrecht oder Nutznießung statt Eigentum. All diese Beschränkungen wurden vom Bundesgesetzgeber als mit der Institutsgarantie vereinbar bezeichnet, insbesondere auch die Anknüpfung an die Nationalität als Kriterium für die Einschränkung der Vertrags- und damit der Verfügungsfreiheit ${ }^{29}$. Immerhin wurde festgestellt, daß die zuletzt beschriebenen Formen der völligen Verhinderung des Eigentumserwerbs, würden sie auf Inländer angewendet, einer verfassungswidrigen Verletzung der Institutsgarantie gleichkommen würden.

\section{b) Grundeigentum und offene Verfassung}

Wichtig ist in diesem Zusammenhang der Hinweis auf die jederzeit mögliche Revision der Bundesverfassung, mit der die heute geltende

25 BGE 101 I a 513; 99 I a $35 \mathrm{ff}$; 113 I a $126 \mathrm{ff}$.

26 BGE 114 I a 14 bzw. BGE 88 I 248.

27 Entscheid des Verwaltungsgerichtes des Kantons Zürich vom 3. April 1973, in: Rechenschaftsbericht an den Kantonsrat 1973, Nr.76.

28 Bundesgesetz über den Erwerb von Grundstücken durch Personen im Ausland, vom 16. Dezember 1983 (SR 211.412.41).

29 Vgl. dazu die Botschaft des Bundesrates vom 16. September 1981 (BBl. 1981 III 585 ff., insb. $639 \mathrm{ff}$.). 
Konzeption der Eigentumsgarantie in grundsätzlicher Weise abgeändert werden kann. Diese Möglichkeit ist keineswegs nur eine theoretische Verbeugung vor der als offen konzipierten Verfassung zu verstehen. Volk und Stände haben 1988 über eine Verfassungsinitiative zu befinden gehabt, die u.a. vorsah, daß Grundeigentum „nur zum Eigengebrauch bei nachgewiesenem Bedarf oder zur Bereitstellung preisgünstiger Wohnungen" erworben werden dürfe ${ }^{30}$. Im Gegensatz zu dieser vom Verfassungsgeber abgelehnten Änderung der Verfassung wurde die sog. Rothenthurm-Initiative, die einen umfassenden Schutz für Moore und Moorlandschaften unter gleichzeitiger Anordnung eines totalen Bauverbots und einer Abbruchpflicht für bestimmte Bauten und Anlagen verbindlich in der Verfassung verankert, von Volk und Ständen im Jahre 1987 angenommen ${ }^{3 !}$.

\section{c) Die geschützten Teilinhalte des Grundeigentums}

aa) Baufreiheit. Die für das Grundeigentum (mindestens dogmatisch) bedeutsame Frage, ob die Eigentumsgarantie auch die Baufreibeit als eine der zentralen Nutzungsmöglichkeiten mitbeinhalte, wird in der schweizerischen Lehre ebenso wie in der deutschen unterschiedlich beantwortet, und beide Seiten bringen für ihre Auffassung beachtliche Gründe vor ${ }^{32}$. Das Bundesgericht hat sich aus diesem Theorienstreit herausgehalten ${ }^{33}$ und im Rahmen seiner Rechtsprechung die Kriterien herausgearbeitet, mit Hilfe derer sich die entschädigungslos zu duldenden Eingriffe von den entschädigungspflichtigen abgrenzen lassen.

$30 \mathrm{Vgl}$. dazu die Botschaft des Bundesrates vom 16. Dezember 1985 (BBl. 1986 I $153 \mathrm{ff}$.).

31 Art. 24 sexies Abs. 5 BV; vgl. dazu ferner die Botschaft des Bundesrates vom 11. September 1985 (BBl. 1985 II 1445 ff.).

32 Die Existenz einer Baufreiheit bejaht z. B. Leo Schürmann, der das Recht zu bauen als Ausfluß der Institutsgarantie betrachtet (Bau- und Planungsrecht, 2. Aufl., Bern 1984, 33). Zurückhaltender Martin Lendi, Planungsrecht und Eigentum, ZSR NF 95/II (1976) $142 \mathrm{ff}$.; Walter Haller/Peter Karlen, Raumplanungsund Baurecht, Zürich 1990, $109 \mathrm{ff}$. (N.3ff.). - Zur Kontroverse in Deutschland vgl. Nüßgens/Boujong (Anm. 18), 22ff.; Hans-Jürgen Papier, in: Maunz/Dürig, Kommentar zum Grundgesetz, Art. 14 GG, Rdn. 59 ff., insb. 66; Rüdiger Breuer, Die Bodennutzung im Konflikt zwischen Städtebau und Eigentumsgarantie, München 1976, $162 \mathrm{ff}$.; ders., Entschädigungsrechtliche Konsequenzen von Eingriffen in die Baufreiheit, DÖV 31 (1978) $189 \mathrm{ff}$., insb. $191 \mathrm{f}$.

${ }_{33} \mathrm{Vgl}$. BGE 105 I a 143. Das Bundesverfassungsgericht anerkennt demgegenüber die Baufreiheit ausdrücklich als Teilgehalt der Eigentumsgarantie (BVerfGE $35,263,276 \mathrm{f}$.). 
Dabei ist nicht zu verkennen, daß diese Rechtsprechung im Zuge der einsetzenden Planungs- und Umweltschutzgesetzgebung seit Mitte der sechziger Jahre die bauliche Nutzung mebr und mebr nur noch als Funktion der raumplanerischen Grundordnung begreift ${ }^{34}$. So stellt das Bundesgericht in einem Entscheid aus dem Jahre 1986 fest, daß vom „Entzug einer wesentlichen, aus dem Eigentum fließenden Befugnis zum vorneherein nur dann gesprochen werden (kann), wenn im Zeitpunkt der geltend gemachten Eigentumsbeschränkung eine raumplanerische Grundordnung galt, welche die Berechtigung zum Bauen auf dem fraglichen Grundstück einschloß ${ }^{\star 35}$.

bb) Die Nutzung von Umweltmedien. Soweit die Nutzung des Grundeigentums die Beanspruchung von Umweltmedien nach sich zieht, ist die Frage nach der Beziehung zur Eigentumsgarantie gestellt. Von besonderem Interesse ist in diesem Zusammenhang die Nutzung des Grundwassers, ein Problem, mit dem sich in Deutschland bekanntlich das Bundesverfassungsgericht 1981 im überaus folgenreichen Naßauskiesungsbeschlu $\beta^{36}$ eingehend auseinandergesetzt hat. Die Feststellung des BVerfG, wonach die Unterstellung des Grundwassers unter eine vom Grundstückseigentum getrennte öffentlichrechtliche Benutzungsordnung mit dem Grundgesetz im Einklang steht, bietet sich in außerordentlicher Weise für rechtsvergleichende Betrachtungen mit den diesbezüglichen schweizerischen Verhältnissen an.

Im Unterschied zum BGB sieht das schweizerische ZGB in Art. 704 Abs. 3 i.V. mit 667 Abs. 2 und 704 Abs. 1 ausdrücklich vor, daß das Grundwasser Bestandteil des Grundstückes ist. Art. 664 Abs. 2 bestimmt demgegenüber, daß an öffentlichen Gewässern kein Privateigentum möglich ist. Das schweizerische Bundesgericht hatte im Jahre 1929 im Entscheid Zinggeler ${ }^{37}$ darüber zu befinden, ob die

34 Vgl. dazu Enrico Riva, Hauptfragen der materiellen Enteignung, Bern 1990, 200 f. mit weiteren Hinweisen. Zur Relativität des Theorienstreits ferner Jörg Paul Müller (Anm. 18), $329 \mathrm{f}$.

35 BGE 112 I b 398, E. 5 a.

36 BVerfGE 58, 300 ff. Kritisch zu diesem Entscheid Walter Leisner, Eigentumswende?, DVBl. 1983, 66 f.; Josef Isensee, Die Ambivalenz des Eigentumsgrundrechts, in: Eigentumsgarantie und Umweltschutz, Symposion zu Ehren von Jürgen Salzwedel aus Anlaß seines 60. Geburtstages, Heidelberg 1990, 15.

37 BGE 55 I 397 ff. Vgl. zur Problematik der Grundwassernutzung auch BGE 65 II 146; 93 II 180; Entscheid des Bundesgerichtes vom 17. März 1976, in: ZBl. 77 (1976) $462 \mathrm{ff}$.; Peter Liver, Die Entwicklung des Wasserrechts in der Schweiz seit hundert Jahren, ZSR NF 71/I (1952) 314 ff., 346f.; ders., Das Eigentum, in: 
Kantone Grundwasservorkommen von mehr als 300 Minutenlitern zu öffentlichen Gewässern erklären dürfen und ob dies gegebenenfalls als entschädigungspflichtige Enteignung zu qualifizieren sei. Das Gericht kam dabei zum Ergebnis, daß sich Art. 704 Abs. 3 ZGB entgegen seinem Wortlaut bloß auf kleine, wenig bedeutende Grundwasservorkommen beziehe. Die vorbehaltlose Fassung des fraglichen Artikels bildete für das Gericht dabei kein Hindernis, indem es erklärte, der Gesetzgeber habe zum Zeitpunkt des Erlasses des ZGB von der Existenz mächtiger Grundwasserströme nichts gewußt, ansonsten er kein allgemeines Recht auf Grundwassernutzung eingeräumt bätte. Die Beantwortung der Frage, ob der Eingriff als entschädigungspflichtig zu gelten hatte, hing davon ab, ob die Maßnahme als Inhaltsbeschränkung (weil subjektive Rechte nur mit dem Inhalt gewährleistet werden, den sie nach Maßgabe der jeweiligen Ordnung des objektiven Rechtes haben) des Eigentums zu qualifizieren war oder ob sie gegenüber dem Berechtigten eine Enteignung darstellte. Das Gericht erwog, daß die bloße Überführung größerer Gewässer in das öffentliche Gut noch keine Enteignung darstelle, insbesondere da Gründe des öffentlichen Wobls maßgebend waren und da die Gewässer eigentlich schon ihrem Namen nach öffentlichen Charakter hätten. Vor diesem Hintergrund war der Entzug der bisherigen Berechtigung zur Grundwassernutzung im konkreten Fall zu prüfen. Für das Gericht war dabei das Kriterium ausschlaggebend, ob der Eigentümer von der bisherigen Möglichkeit der Grundwasserausbeutung bereits tatsächlichen Gebrauch gemacht hatte, denn dieser Umstand hätte die Entschädigungspflicht des Staates ausgelöst. Wegen dem bloß abstrakten Interesse des Eigentümers, der keinerlei Anlagen zur Grundwasserausbeutung erstellt hatte, war der Eingriff entschädigungslos hinzunehmen.

$\mathrm{Ob}$ diese souveräne Korrektur eines für die Eigentumsordnung absolut zentralen Gesetzes überzeugend begründet worden ist, mag dahingestellt bleiben. Abstrahiert man von der in Deutschland gebräuchlichen Terminologie, sind die Parallelen zum Naßauskiesungsbeschluß offensichtlich, selbst das Recht am eingerichteten und ausgeübten Gewerbebetrieb schimmert durch. Überraschend ist allenfalls die Tatsache, daß das Bundesgericht seinen Entscheid 50 Jahre früher gefällt hat als das Bundesverfassungsgericht.

Ebenfalls eine sehr lange Tradition hat die schon angesprochene Regelung mit Bezug auf den Wald. Spätestens seit dem zweiten 
Forstpolizeigesetz aus dem Jahre 1902 gilt in der Schweiz der Grundsatz, daß den Eigentümern von Waldgrundstücken keine andere Nutzung offensteht. Lediglich in Ausnahmefällen darf Wald gerodet werden, wobei die Verpflichtung besteht, eine gleiche Fläche Waldes andernorts neu aufzuforsten ${ }^{38}$. Diese Nutzungsbeschränkung des Umweltmediums „Wald“ hat keinerlei Diskussionen über Entschädigungspflichten ausgelöst, sondern gilt allgemein nach wie vor als eine der Pioniertaten auf dem Gebiete des Umweltschutzes ${ }^{39}$.

\section{Die Besitzstandsgarantie}

Die herrschende Auffassung in der schweizerischen Lehre und Rechtsprechung geht davon aus, daß die Gesetzgebung auf bisherige Besitzstände gebübrend Rücksicht zu nebmen hat. Dies müßte im wesentlichen im Rahmen des intertemporalen Rechts vorgesehen werden, doch wird bei der Abfassung von Übergangsbestimmungen nicht immer mit der erforderlichen Sorgfalt legiferiert. Dies führt im konkreten Streitfall zur Frage, ob altrechtliche Bauten, Anlagen und Bewilligungen einen unmittelbaren verfassungsrechtlich abgestützten Schutz genießen. Dabei bieten sich der aus Art. 4 BV abgeleitete Anspruch auf Treu und Glauben bzw. der Vertrauensgrundsatz, das Prinzip der Nichtrückwirkung der Gesetze und schließlich die Eigentumsgarantie als Anspruchsgrundlagen $\mathrm{an}^{40}$. Die Lehre ist in dieser Frage gespalten, und die Rechtsprechung hat sich zu keiner eindeutigen Stellungnahme veranlaßt gesehen ${ }^{41}$.

38 Vgl. Art. 31 des Bundesgesetzes betreffend die eidgenössische Oberaufsicht über die Forstpolizei, vom 11. Oktober 1902 (SR 921.0); Art. 24 ff. der Verordnung betreffend die eidgenössische Oberaufsicht über die Forstpolizei, vom 1. Oktober 1965 (FPolV) (SR 921.1). Beispiele für die in Art. 26 Abs. 1 FPolV geforderte Abwägung zwischen dem Interesse an der Walderhaltung und dem Rodungsinteresse: BGE 108 I b 268 f.; 112 I b 204 ff.; 112 I b 558 ff.; 113 I b 344 ff.; 113 I b 412 ff.; $115 \mathrm{Ib} 227 \mathrm{ff}$.

39 Thomas Fleiner-Gerster, Grundzüge des allgemeinen und schweizerischen Verwaltungsrechts, 2. Aufl., Zürich 1980, 369. Zur Forstgesetzgebung des Bundes vgl. Dieter Meier, Nutzungspflichten des Grundeigentümers, Diss. Bern 1984, $36 \mathrm{ff}$. (mit weiterführenden Literaturhinweisen).

40 Rhinow/Kräbenmann (Anm. 15), Nr. 122, B XIII.

${ }^{41}$ Nach Alfred Kölz z. B. folgt die Besitzstandsgarantie aus dem Vertrauensgrundsatz, also aus Art. $4 \mathrm{BV}$, und nicht aus der Eigentumsgarantie (Intertemporales Verwaltungsrecht, ZSR NF 102/II [1983] 191); vgl. auch Riva (Anm. 34), $329 \mathrm{ff}$. - Das deutsche Recht kennt in der aus Art.14 Abs.1 GG entwickelten 


\section{a) Besitzstandsgarantie im Planungsrecht}

Mit Bezug auf bestehende Bauten und Anlagen, die aufgrund von Zonenplanungsmaßnahmen nach neuem Recht nicht mehr erstellt werden dürften, ergibt sich unmittelbar aus der Eigentumsgarantie ein Anspruch auf Erneuerung und Unterbalt derartiger baulicher Werte ${ }^{42}$. Ein Unterhaltsverbot würde dementsprechend die Eigentumsgarantie verletzen, ausgenommen den Sonderfall, wo bestehende Bauwerke im engen Sinne polizeiwidrige Zustände schaffen.

Was den Wiederaufbau und die teilweise Änderung zonenwidriger Bauten betrifft, hat das RPG den Kantonen die Kompetenz eingeräumt, diese völlig zu verbieten oder aber soweit zu gestatten, als sie mit den "wichtigen Anliegen der Raumplanung" vereinbar sind ${ }^{43}$. Die überwiegende Mehrheit der Kantone hat von der Kompetenz in dem Sinne Gebrauch gemacht, daß der Wiederaufbau und die teilweise Änderung neurechtswidriger Bauten, die nach altem Recht rechtmäßig erstellt worden sind, zulässig ist ${ }^{44}$. Umgekehrt hat das Bundesgericht ausdrücklich festgestellt, daß sich aus Art. 22 ${ }^{\text {ter }}$ BV kein Anspruch ergibt, zerstörte oder abgebrochene Bauten, die dem neuen Recht widersprechen, wiederaufzubauen ${ }^{45}$.

\section{b) Besitzstandsgarantie im Umweltschutzrecht}

Die Prinzipien der Besitzstandsgarantie und des Vertrauensschutzes gelten grundsätzlich auch im Rahmen des Umweltschutzes, doch kommt ihnen hier lediglich abgeschwächte Bedeutung zu, weil nach herrschender Auffassung die Investitionen nur selten die von der Besitzstandsgarantie geforderte Qualität erreichen. Der Gesetzgeber

Rechtsfigur des Bestandsschutzes ein der Besitzstandsgarantie verwandtes Institut (vgl. dazu Nüßgens/Boujong [Anm. 18], 26 ff.).

${ }_{42}$ BGE 113 I a 119; vgl. dazu ferner Entscheid des Bundesgerichtes vom 17. September 1987, in: ZBI. 90 (1989) 543 ff.; Entscheid des Verwaltungsgerichtes des Kantons Aargau vom 28. Mai 1982, in: ZBl. 83 (1982) 448; Martin Pfisterer, Die Anwendung neuer Bauvorschriften auf bestehende Bauten und Anlagen, Diss. Bern $1979,81$.

43 Art. 24 Abs. 2 des Bundesgesetzes über die Raumplanung (RPG), vom 22. Juni 1979 (SR 700). Vgl. dazu Eidgenössisches Justiz- und Polizeidepartement, Erläuterungen zum Bundesgesetz über die Raumplanung, Bern 1981, 301 ff.; BGE $107 \mathrm{Ib} 236 \mathrm{f}$.

${ }_{44}$ Vgl. dazu BGE 113 I a 119, 122 f.; Rhinow/Kräbenmann (Anm. 15), Nr. 122, B XIII.

${ }^{45}$ Entscheid des Bundesgerichtes vom 17. September 1987, in: ZBl. 90 (1989) 545. 
ließ sich beim Umweltschutz vom Gedanken der Rechtsgleichbeit und damit verbunden von der dem Staat aufgetragenen Wettbewerbsneutralität leiten: Inhaber von Altanlagen sollten keinen ungerechtfertigten Vorteil gegenüber den Erstellern von Neuanlagen haben, weshalb das Prinzip der Sanierungspflicht für sämtliche Anlagen gilt. Soweit allerdings wohlerworbene Rechte oder öffentlich-rechtliche Verträge zur Diskussion stehen, genießen diese den Schutz der Eigentumsgarantie.

Das Spannungsverhältnis zwischen dem Anliegen, die Umwelt möglichst wirksam zu schützen, und den wirtschaftlichen Interessen der Inhaber von Altanlagen ist indessen auch außerhalb dieser Sonderfälle nicht zu übersehen. Im Rahmen der Besitzstandsgarantie ist weitreichenden Dispositionen Rechnung zu tragen, die von den Anlageninhabern nach altem Recht erlaubterweise getätigt worden sind. In erster Linie ist dabei der Gesetzgeber aufgerufen, den verfassungsrechtlich gebotenen Vertrauensschutz zu konkretisieren. Das eindeutig bevorzugte Mittel ist die Gewährung von Anpassungsfristen. $\mathrm{Zu}$ Recht wird dies als unnötige und wenig kreative gesetzgeberische Selbstbeschränkung kritisiert ${ }^{46}$. Darüber hinaus kommen gemäß Art. 17 Abs. 1 USG „Erleichterungen im Einzelfall“ in Frage, wenn eine Sanierung einer Altanlage unverhältnismäßig wäre, wobei allerdings die Immissionsgrenzwerte für Luftverunreinigungen und Erschütterungen sowie der Alarmwert für Lärmimmissionen nicht überschritten werden dürfen. Als Erleichterungen kommen Fristverlängerungen und mildere Emissionsgrenzwerte in Betracht ${ }^{47}$. Der Umstand, daß das Spannungsverhältnis zwischen Umweltschutz und Besitzstandsgarantie in erster Linie durch den Gesetzgeber zu harmonisieren ist, schließt eine Entschädigung wegen (materieller) Enteignung im Einzelfall nicht aus, doch hat das Bundesgericht noch keine Gelegenheit gehabt, sich dazu zu äußern ${ }^{48}$.

${ }^{46}$ Kölz (Anm. 41), 226; André Schrade, Vorbemerkungen zu Art. 16-18, N. 7, in: Kommentar zum Umweltschutzgesetz (Hrsg. Alfred Kölz/ Hans-Ulrich Müller), Zürich $1985 \mathrm{ff}$.

$47 \mathrm{Vgl}$. dazu z. B. Art. 11 Abs. 2 der Luftreinhalteverordnung vom 16. Dezember 1985 (SR 814.318.142.1); ferner zum Verhältnis zwischen Besitzstandsgarantie und umweltschutzrechtlicher Sanierungspflicht (Schweinemästerei) den Entscheid des aargauischen Verwaltungsgerichtes vom 18. März 1988, in: ZBl. 90 (1989) $175 \mathrm{ff}$.

${ }^{48}$ André Grisel, Expropriation matérielle, L'arrêt Commune de Zizers et ses développements, in: Aktuelle Probleme des Staats- und Verwaltungsrechts, Festschrift für Otto K. Kaufmann, Bern/Stuttgart 1989, $104 \mathrm{f}$. 


\section{Das Recht am eingerichteten und ausgeübten Gewerbebetrieb}

Diese in Deutschland gebräuchliche Rechtsfigur ${ }^{49}$ ist dem schweizerischen Recht - mindestens mit Bezug auf die Terminologie unbekannt. Werden durch staatliche Maßnahmen die Interessen von Inhabern eingerichteter und ausgeübter Gewerbebetriebe tangiert, ist die Vereinbarkeit des Eingriffs mit der Eigentumsgarantie allenfalls unter dem Gesichtspunkt der schon angesprochenen Besitzstandsgarantie zu prüfen. Thematische Berührungspunkte weist das Recht am eingerichteten und ausgeübten Gewerbebetrieb sodann mit dem aus Art. 4 BV abgeleiteten Vertrauensschutz auf ${ }^{50}$. So wird das Problem zum Teil über den Widerruf von Verfügungen gelöst ${ }^{51}$; dabei ist namentlich der Widerruf von atomrechtlichen Bewilligungen ausdrücklich im Gesetz geregelt ${ }^{52}$.

Verwandtschaften lassen sich herstellen mit den sog. woblerworbenen Rechten, die besonderen Schutz genießen und denen in der schweizerischen Rechtsordnung eine eigentliche Ausnahmestellung zukommt. Ihren Ursprung haben die wohlerworbenen Rechte im wesentlichen einerseits in Verträgen oder vertragsäbnlichen Verbältnissen des Verwaltungsrechts, insbesondere in Konzessionen, andererseits können sie auf historischen Wurzeln beruhen, wie beispielsweise Fischereirechte oder andere Nutzungsrechte an öffentlichen Gewässern. Die wohlerworbenen Rechte werden durch die Eigentumsgarantie und - nach neuerer Rechtsprechung - auch durch den Grundsatz von Treu und Glauben geschützt. Sie können nur entzogen werden

${ }^{49} \mathrm{Vgl}$. Peter Badura, Der Eigentumsschutz des eingerichteten und ausgeübten Gewerbebetriebes, AöR 98 (1973) 153 ff.; Otto Kimminich, in: Bonner Kommentar zum Grundgesetz, Art. 14, Rdn. 75 ff.; Nüßgens/Boujong (Anm. 18), 39 ff., jeweils mit weiteren Hinweisen.

${ }^{50}$ Das Bundesgericht hat sich in BGE 101 I a 336, 347 f. am Rande mit der Rüge auseinandergesetzt, die Eigentumsgarantie und die Handels- und Gewerbefreiheit seien verletzt worden durch eine unverhältnismäßig kurze Übergangsfrist eines kantonalen Verbotes von Geldspielautomaten. Im konkreten Fall verneinte indessen das Gericht eine Beeinträchtigung verfassungsrechtlich geschützter vermögenswerter Ansprüche. Kritisch dazu Beatrice Weber-Dürler, Vertrauensschutz im öffentlichen Recht, Basel/Frankfurt a. M. 1983, 62.

51 Vgl. als Beispiel BGE 107 I b $35 \mathrm{ff}$.

52 Art. 9 des Bundesgesetzes über die friedliche Verwendung der Atomenergie und den Strahlenschutz vom 23. Dezember 1959 (SR 732.0). Vgl. in diesem Zusammenhang auch den Bundesbeschluß über eine Vereinbarung betreffend Nichtrealisierung des Kernkraftwerkes Kaiseraugst, vom 17. März 1989 (SR 732.10). 
aufgrund einer gesetzlichen Grundlage, wenn der Entzug im öffentlichen Interesse liegt, verhältnismäßig ist und gegen volle Entschädigung erfolgt. Das besondere Merkmal der wohlerworbenen Rechte ist ferner ihre Gesetzesbeständigkeit, d.h. spätere Gesetze dürfen ein solches Recht grundsätzlich nicht entschädigungslos einschränken oder aufheben ${ }^{53}$.

Die Tatsache, daß sich in der Schweiz kein eigentlicher Begriff des eingerichteten und ausgeübten Gewerbebetriebes hat entwickeln können, hängt freilich auch mit der sebr restriktiven Rechtsprechung des Bundesgerichtes mit Bezug auf die Rechtsstellung des Anstößers zusammen. Nach dieser Praxis handelt es sich bei den Interessen der Anstößer lediglich um faktische Interessenlagen, die vom Schutz der Eigentumsgarantie nicht erfaßt werden. Trotz heftiger und grundsätzlicher Kritik, die gegen die begriffliche Unterscheidung von rechtlich geschützten und faktischen Interessen vorgebracht worden ist ${ }^{54}$, hat das Gericht bisher an seiner Auffassung festgehalten. Es wird sich zeigen müssen, ob die in der neuesten Rechtsprechung vereinzelt gemachten Andeutungen tatsächlich eine Änderung der Praxis ankün$\operatorname{den}^{55}$.

\section{Eigentumsgarantie und Abgaberecht}

Nachdem das Bundesgericht bis in die späten 70er Jahre daran festgehalten hatte, die Eigentumsgarantie schütze nur einzelne vermögenswerte Positionen und nicht das Vermögen in seiner Gesamtheit,

${ }_{53} \mathrm{Zu}$ den wohlerworbenen Rechten im einzelnen vgl. Häfelin/Müller (Anm.13), 168 (N.773ff.), 339 (N.1584); Max Imboden/René A. Rhinow, Schweizerische Verwaltungsrechtsprechung, Bd.II (Besonderer Teil), 6. Aufl., Basel/Frankfurt a. M. 1986, Nr. 122; Rhinow/Krähenmann (Anm. 15), Nr. 122 mit weiteren Hinweisen. Ein neues Beispiel findet sich in BGE $117 \mathrm{I}$ a $35 \mathrm{ff}$., wo das Bundesgericht die Aufhebung ehehafter Weiderechte für verfassungswidrig erklärte.

${ }^{54}$ Vgl. dazu Saladin (Anm.1), 135 ff.; Georg Müller, Kommentar (Anm. 13), Rdn. 6 zu Art.22ter BV; Imboden/Rhinow II (Anm.53), Nr.117 B III sowie Rhinow/Krähenmann (Anm. 15), Nr.122 B Ig und 117 B III zur neueren Praxis. Riva (Anm.34), 244f., befürwortet eine Lösung, die bei der Bestimmung des Schutzobjektes der Eigentumsgarantie an das Vermögen als die Gesamtheit der einem Individuum zustehenden vermögenswerten Interessen anknüpft und dieses unter den Schutz der Eigentumsgarantie stellt.

$55 \mathrm{Vgl}$. dazu Georg Müller, Kommentar (Anm. 13), Rdn. 6 zu Art. 22 ${ }^{\text {ter }}$ BV; Riva (Anm. 34), 243. 
stand die Steuer- und Abgabengesetzgebung nicht unter dem Vorbehalt der Eigentumsgarantie ${ }^{56}$. Diese von der Lehre heftig kritisierte Rechtsprechung hat es aufgegeben und festgestellt, die Gewährleistung des Eigentums verpflichte den Steuergesetzgeber, die bestehenden Vermögen in ihrer Substanz zu bewahren und die Möglichkeit der Neubildung von Vermögen in dem Sinne zu erhalten, daß das Einkommen nicht dauernd und vollständig wegbesteuert werden darf ${ }^{57}$.

Bezogen auf das Grundeigentum ergeben sich dadurch keine spezifisch andersartigen Folgerungen als auf übrige Vermögenswerte, insbesondere sind dadurch Abschöpfungen von planerisch bedingten Mebrwerten nicht ausgeschlossen, auch wenn sie $100 \%$ betragen. Eine andere Frage ist, ob die Eigentumsgarantie Schutz bietet gegenüber umweltspezifischen Abgaben. In der Schweiz stellt sich dieses Problem weniger unter dem Aspekt der Eigentumsgarantie als vielmehr unter dem Gesichtswinkel der Kompetenzverteilung zwischen Bund und Kantonen. Umweltspezifische Lenkungsabgaben verstoßen dann gegen die verfassungsrechtliche Kompetenzvermutung zugunsten der Kantone, wenn der Bund dadurch in das Steuersubstrat der Kantone eingreift ${ }^{58}$. In der Praxis ist die Frage allerdings bis anhin noch nicht aktuell geworden.

${ }^{56}$ Vgl. zu dieser früheren Praxis Saladin (Anm. 1), 140 ff. m. w. H.

57 BGE 106 I a $348 \mathrm{ff} . ; 105$ I a $135 \mathrm{ff}$. Angesprochen ist hier die Institutsgarantie (vgl. Aubert, Supplément [Anm. 17], ad No.2176; Grisel, Traité II [Anm. 17], 676 f.; Häfelin/Haller [Anm. 16], 414 [N.1356f.]). Georg Müller vertritt die Auffassung, die Eigentumsgarantie müsse gegen die Erhebung von Abgaben sowohl als Instituts- wie auch als Bestandesgarantie angerufen werden können (Kommentar [Anm. 13], Rdn. 8 zu Art. 22 ter BV). - Kritisch zur deutschen Rechtsprechung, die einen Verstoß gegen Art.14 GG ebenfalls erst dann in Betracht zieht, wenn der Steuerpflichtige übermäßig belastet und seine Vermögensverhältnisse in grundlegender Weise beeinträchtigt werden, Konrad Hesse, Grundzüge des Verfassungsrechts der Bundesrepublik Deutschland, 17. Aufl., Heidelberg 1990, 175 (Rdn. 447).

58 Thomas Fleiner, in: Kommentar zur Bundesverfassung der Schweizerischen Eidgenossenschaft, Basel/Zürich/Bern $1987 \mathrm{ff}$., Rdn. $76 \mathrm{ff}$. zu Art. 24septics BV; ders., Rechtsgutachten über die Verfassungsmäßigkeit des Vorentwurfes zu einem Bundesgesetz über den Umweltschutz vom 18. Dezember 1973, Wirtschaft und Recht 27 (1975) $306 \mathrm{ff}$; Ruedi Meier/Felix Walter, Umweltabgaben für die Schweiz, Chur/Zürich 1991, 176 ff. m.w.H. 


\section{Inhalts- und Schrankenbestimmungen des Gesetzgebers und Sozialbindung des Eigentums}

\section{Sozialbindung kein verfassungsrechtlicher Begriff?}

Die verfassungsrechtliche Konzeption der Eigentumsgarantie kennt keine dem deutschen Grundgesetz vergleichbare Bestimmung im Sinne von Art. 14 Abs. $2 \mathrm{GG}^{59}$. Die Verfassung beschränkt sich darauf, die Möglichkeit von Eigentumsbeschränkungen und Enteignungen im öffentlichen Interesse vorzusehen. Sozialbindung oder Sozialpflichtigkeit sind in der schweizerischen Literatur und in der bundesgerichtlichen Praxis kaum thematisiert worden ${ }^{60}$. Im Grunde genommen hat sich die schweizerische Verfassungsrechtsdogmatik darauf beschränkt, Inhalts- und Schrankenbestimmungen des Eigentumsrechts auf ihre Vereinbarkeit mit der Eigentumsgarantie unter dem Gesichtspunkt der Entschädigungsfrage zu prüfen. Dies hat zur Herausbildung des Begriffs der materiellen Enteignung ${ }^{61}$ geführt, ein sehr elastischer Begriff, der nicht zuletzt mit Blick auf die finanziellen Ressourcen des Gemeinwesens konkretisiert wird.

Aus dem Fehlen des Begriffs der Sozialbindung darf nun freilich nicht verkürzend geschlossen werden, dieses Element sei überhaupt irrelevant. Unter dem Begriff des „öffentlichen Wohls“ (Entscheid Zinggeler $^{62}$ ), bei der Bestimmung des als verfassungsrechtlich anerkannten öffentlichen Interesses (Entscheide Dafflon ${ }^{63}$, Armengol $^{64}$ ) sowie unter dem Titel der „... erhöhten Anforderungen an die Regelung eines menschenwürdigen Zusammenlebens in der Gesellschaft ${ }^{" 65}$ werden Anklänge an die Sozialbindung deutlich, die durchaus vergleichbar sind mit der Konzeption von Art. 14 Abs. 2 GG. Allerdings hat das Element der Sozialbindung keine eigenständige Bedeutung ${ }^{66}$.

59 Martin Lendi, Umweltschutz und Eigentum, in: Lebensraum, Technik, Recht, Zürich 1988, 72.

60 Martin Lendi ([Anm.59], 72) wirft sogar die Frage auf, ob der Begriff „Sozialbindung“ nicht besser fallengelassen werden sollte.

61 Vgl. unten III. 1. b).

62 BGE 55 I 397 ff., insb. 401.

${ }^{63}$ BGE 88 I 248, insb. $252 \mathrm{ff}$.

${ }_{64}$ BGE 113 I a $126 \mathrm{ff}$.

${ }^{65}$ BGE 105 I a $336 \mathrm{f}$. (Fall Zizers).

${ }_{66}$ In Deutschland dagegen kommt der Frage der Sozialpflichtigkeit des Eigentums eine große Bedeutung zu. Die Sozialbindung enthält nach Rechtsprechung und herrschender Lehre nicht nur einen Gestaltungsauftrag an den Gesetzgeber, sondern begründet auch unmittelbare Rechtspflichten für den Eigentümer 


\section{Inbalts- und Schrankenbestimmungen durch den Gesetzgeber}

Nach der Verfassung sind Beschränkungen der Eigentumsgarantie zulässig, wenn sie auf einer gesetzlichen Grundlage beruhen, im öffentlichen Interesse liegen und verbältnismäßig sind. Dabei hat die schweizerische Lehre und Rechtsprechung es überwiegend abgelehnt, zwischen Inhalts- und Schrankenbestimmungen zu unterscheiden ${ }^{67}$, weil letztere im Grunde genommen austauschbar sind. $\mathrm{Zu}$ fragen ist in diesem Zusammenhang daher, ob dem Gesetzgeber selber Schranken auferlegt sind bei seiner Aufgabe der Konkretisierung der Eigentumsgarantie.

Die Schranke der Institutsgarantie ist - wie gesehen - angesichts der damit verbundenen erheblichen Gestaltungsfreiheit des Gesetzgebers kaum geeignet, das Eigentum wirkungsvoll vor legislatorischen Übergriffen zu schützen. Bei den weiteren Voraussetzungen für die Verfassungsmäßigkeit des Eingriffs interessiert die Frage der Steuerungsfähigkeit des öffentlichen Interesses. Die Antwort fällt ernüchternd aus: Die Praxis hat praktisch jedes erdenkliche öffentliche Interesse anerkannt ${ }^{68}$. Georg Müller, der nicht zu Unrecht nur noch im Prinzip der Verhältnismäßigkeit ein wirkungsvolles Kontrollinstrument sieht, hat vorgeschlagen, vermehrt auf die in der Verfassung

(BVerfGE 21, 83; Kimminich, in: Bonner Kommentar, Art. 14, Rdn. 105, 107 f.; Brun-Otto Bryde, in: von Münch, Grundgesetz-Kommentar, Bd. 1, 3. Aufl., München 1985, Art. 14, Rdn. 67; Breuer, Bodennutzung [Anm. 32], 142; Nüßgens/ Boujong [Anm. 18], 68 f.; a. M. Papier [Anm. 32], Art. 14, Rdn. 250).

67 Vgl. z.B. Grisel, Expropriation matérielle (Anm.48), 100; Georg Müller, Privateigentum heute (Anm. 18), 44; Alfred Kuttler, Materielle Enteignung aus der Sicht des Bundesgerichts, ZBl. 88 (1987) 188; BGE 105 I a 336 (Fall Zizers). Ebenso erachten das Bundesverfassungsgericht und mehrheitlich auch die deutsche Doktrin (vgl. statt vieler Nüßgens/Boujong [Anm. 18], 63, m. w.H.) eine begrifflicd. Unterscheidung zwischen Eigentumsinhalt und -schranken für unnötig. Für eine konsequente Trennung von Inhalt und Schranken des Eigentums allerdings Walter Leisner, Eigentum, in: Handbuch des Staatsrechts der Bundesrepublik Deutschland, Bd. VI (Freiheitsrechte), Heidelberg 1989, 1076 (Rdn. 135 ff.).

${ }^{68}$ Ausgeschlossen sind lediglich Eigentumsbeschränkungen aus rein fiskalischen Motiven. Vgl. die Darstellung der bundesgerichtlichen Rechtsprechung zum öffentlichen Interesse bei Saladin (Anm.1), S.146ff.; Georg Müller, Kommentar (Anm. 13), Rdn.34f. zu Art.22 rer BV; Jörg Paul Müller (Anm. 18), 335; JeanFrançois Aubert, Traité de droit constitutionel suisse, Bd. II, Neuchâtel 1967, $761 \mathrm{ff}$. (No. 2183 ff.); ders., Supplément (Anm. 17), 273 (ad No. 2183 ff.); Arthur MeierHayoz, Berner Kommentar zum ZGB, Sachenrecht, Systematischer Teil und Allgemeine Bestimmungen (Art.641-654 ZGB), 5. Aufl., Bern 1981, $199 \mathrm{ff}$. (N. $504 \mathrm{ff}$.). 
selber enthaltenen Werte, Güter und Ziele zurückzugreifen, um dem Begriff wenigstens gewisse minimale Konturen zurückzugeben ${ }^{69}$.

\section{Nutzungsbeschränkungen an Grund und Boden}

a) Schwäche der Bestandesgarantieformel oder notwendige Folge der Unvermebrbarkeit des Bodens?

Vor dem Hintergrund dieser Darlegungen erstaunt es nicht, daß die bundesgerichtliche Rechtsprechung - sofern jeweils die weiteren verfassungsrechtlichen Voraussetzungen der gesetzlichen Grundlage und der Verhältnismäßigkeit erfüllt waren - weitgehende Nutzungsbeschränkungen des Bodens als verfassungskonform anerkannt hat. So sind Maßnahmen zur Trennung des Baugebiets vom Nichtbaugebiet sowie die Redimensionierung übergroßer Bauzonen ebenso im überwiegenden öffentlichen Interesse wie das Walderbaltungsgebot und die Anforderungen des Umweltschutzes, des Gewässerschutzes und des Natur- und Heimatschutzes ${ }^{70}$. Planungszonen und mit ihnen Bausperren sind als im öffentlichen Interesse liegend hinzunehmen; die zeitliche Begrenzung dieser Maßnahmen schließt es in aller Regel auch aus, daß sie enteignungsrelevant sind ${ }^{71}$. Vermehrt sehen neuere bau- und planungsrechtliche Vorschriften auch Nutzungspflichten vor, z. B. Wohnanteilpläne, Vorschriften über den Zweitwohnungsbau, oder sogar eigentliche Baupflichten ${ }^{72}$. Auch diese Nutzungspflichten werden als verfassungskonform betrachtet. Die Legislative des Kantons Genf hat vor wenigen Tagen eine Volksinitiative als gültig und nicht im Widerspruch mit der BV erklärt, die den Eigentümern von Mietwohnungen eine Vermietungsverpflichtung auferlegt.

69 Georg Müller, Privateigentum heute (Anm. 18), 60. Kritisch gegenüber der bundesgerichtlichen Praxis bereits Hans Huber, Das Gemeinwohl als Voraussetzung der Enteignung (1965), in: Rechtstheorie, Verfassungsrecht, Völkerrecht, Bern 1971, $505 \mathrm{ff}$.

70 BGE 115 I a 387; 114 I a 255; 114 I a $368 \mathrm{f}$. (Redimensionierung von Bauzonen); 105 I a 336 (Raumplanung, Umweltschutz, Walderhaltung und Gewässerschutz); BGE 115 I a 373; 112 Ib E. 4 (Natur- und Heimatschutz). Vgl. dazu auch allgemein Rbinow/Krähenmann (Anm.15), Nr.124, B I mit zahlreichen weiteren Beispielen.

71 BGE 113 I a 365.

72 BGE 112 I a 65; 111 I a 95; 115 I a 378; vgl. dazu ferner Georg Müller, Baupflicht und Eigentumsordnung, in: Festschrift für Ulrich Häfelin, Zürich 1989, 167 ff. m.w.H. Zu den Nutzungspflichten des Grundeigentümers allgemein vgl. Meier (Anm. 39), 6 ff., insb. $112 \mathrm{ff.}$ 
Als Sanktion sieht das vorgeschlagene Gesetz das Mittel der temporären Enteignung vor, d.h. die Wohnung wird so lange zwangsvermietet, bis der Eigentümer von sich aus einen Mietvertrag eingeht ${ }^{73}$.

\section{b) Planerische Abwägungsgebote und demokratische Rechtssetzung als neue Korrektive?}

Die Frage der baulichen Nutzung eines Grundstückes wird im Rahmen der Richt- und insbesondere der Nutzungsplanung entschieden. Nach neuerer Auslegung des Bundesgerichtes ${ }^{74}$ haben die Planungsbehörden bei der Erfüllung raumplanerischer Aufgaben die im positiven Recht normierten Ziele und Grundsätze optimal zu berücksichtigen. Dabei hat insbesondere bei der Zonenplanung eine umfassende Abwägung und Abstimmung aller privaten und öffentlichen Interessen stattzufinden. Die im RPG selber verankerten Planungsgrundsätze $\mathrm{e}^{75}$ sind als Zielvorstellungen, als Wertungshilfen und Entscheidungskriterien zu betrachten. Weil sie nicht widerspruchsfrei zueinander stehen, sind sie im einzelnen Anwendungsfall gegeneinander abzuwägen. Die bisherige Rechtsprechung hat das Argumentationsmuster der umfassenden Abwägung und Abstimmung tendenziell eher als Rechtfertigung für Nutzungsbeschränkungen herangezogen.

Während das umfassende Abwägungs- und Abstimmungsgebot sich nicht eindeutig als Korrektiv für die sich (notwendigerweise?) erweiternde staatliche Festlegung von Nutzungsmöglichkeiten an Grund und Boden erweist, kann den Partizipationsmöglichkeiten bei der Planung eine eigentumsschützende Wirkung nicht abgesprochen werden. Für den Erlaß der eigentümerverbindlichen kommunalen Nutzungsplanung sind nach schweizerischem Recht überwiegend die Stimmberechtigten selber zuständig. Diese demokratische Komponente der Planung trägt zweifellos zu einer angemessenen Berücksichtigung der Grundeigentümerinteressen bei $^{76}$.

73 Vgl. dazu «Rapport de la commission législative chargée d'étudier la recevabilité de l'initiative «contre les logements vides et la spéculation»» vom 2. August 1991.

${ }_{74}$ Vgl. z. B. BGE 115 I a 353; 114 I a 368 f., 374 (je mit Hinweisen); Urteil des Bundesgerichtes vom 22. März 1989, in: ZBl. 90 (1989) $456 \mathrm{ff}$.

75 Art. 1 und 3 RPG, aber auch die Art. 14 ff. RPG.

${ }^{76} \mathrm{Vgl}$. dazu auch Georg Müller, Konflikte von Grundeigentum und Bodenfunktion, ZSR NF 110/I (1991), $138 \mathrm{f}$.; Pierre Tschannen, Richterstaat in der Raumplanung?, in: Perspektiven des Raumplanungs- und Bodenrechts, Beihefte zur ZSR 11, Basel 1990, 117 f.; Walter Haller, Raumplanung im demokratisch- 


\section{c) Zusammenfassung}

Zusammenfassend läßt sich feststellen, daß der Gesetzgeber bei der Ausgestaltung und Konkretisierung der Nutzungsmöglichkeiten des Grundeigentums große Ermessensspielräume vorfindet und diese auch nutzt. Diese Tatsache hat mit einer wachsenden Bedeutung der Forderung nach „Gemeinverträglichkeit“ der Bodennutzung zu tun. Die geringe Wirksamkeit der verfassungsrechtlich zum Schutze des Eigentums vorgesehenen Leitplanken erscheint so als unabwendbare Folge dieser Entwicklung. Diese Dynamik greift auf den Bestand und den Inhalt der Grundeigentümerpositionen über, indem das Bundesgericht der Erhaltung dieser Interessen eine ganze Reihe von anderen Interessen gegenübergestellt hat, die verfassungsrechtliche Gleichrangigkeit beanspruchen können ${ }^{77}$.

\section{Enteignung und Entschädigung}

Zentraler Punkt beim Themenkreis Enteignung und Entschädigung ist die Frage nach dem entschädigungspflichtigen Eingriff, der selber keine formelle Enteignung darstellt. Daneben sind - mit einem Seitenblick auf das deutsche Recht - die Junktimklausel und die Entschädigungshöhe zu diskutieren.

\section{Die verfassungsrechtlichen Grundlagen der Enteignung}

Art. $22^{\text {ter }}$ der schweizerischen Bundesverfassung anerkennt ausdrücklich zwei Formen der Enteignung als entschädigungspflichtig: die formelle Enteignung und die sog. materielle Enteignung. In beiden Fällen handelt es sich um rechtmäßige hoheitliche Eingriffe in verfassungsrechtlich geschützte individuelle Rechtspositionen, die eine gesetzliche Grundlage voraussetzen, im überwiegenden öffentlichen Interesse sein müssen und verhältnismäßig zu sein haben.

föderalistischen Rechtsstaat, in: Menschenrechte - Föderalismus - Demokratie, Festschrift zum 70. Geburtstag von Werner Kägi, Zürich 1979, $171 \mathrm{ff}$.; Riccardo Jagmetti, Kommentar zu Art. 22quater BV, in: Kommentar zur Bundesverfassung der Schweizerischen Eidgenossenschaft, Basel/Zürich/Bern $1987 \mathrm{ff} ., \mathrm{Rdn} .78$.

77 So auch Rhinow/Kräbenmann (Anm. 15), Nr. 130, B II und B II h. 


\section{a) Die formelle Enteignung}

Die formelle Enteignung stellt einen rechtmäßigen öffentlich-rechtlichen Akt dar, mit dem Ziel, dem Enteigner die volle Verfügung über diejenigen Rechte zu geben, die er für die Verwirklichung eines Werkes im öffentlichen Interesse benötigt. Die Enteignung hat demnach die Übertragung eines Rechts auf den Enteigner gegen Entschädigung zum Zweck ${ }^{78}$. Systemwidrig und im Sinne einer Ausnabme sind dem Enteignungsgesetz auch die von einem öffentlichen Werk ausgehenden Immissionen unterstellt, denn soweit diese Eingriffe in nachbarrechtliche Abwehrrechte als „übermäßig“ qualifiziert werden, sind diese Abwehrrechte formell $z u$ enteignen ${ }^{79}$. Übermäßig sind die Immissionen, wenn sie unvorhersehbar waren, einen einzelnen Grundeigentümer in ganz besonderer Weise treffen und einen schweren Schaden verursachen ${ }^{80}$. Um die Systemwidrigkeit zu kompensieren, werden an das Vorhandensein der Übermäßigkeit hohe Anforderungen gestellt, es wird gleichsam eine "Sozialpflichtigkeit" vorgeschaltet, die große Ähnlichkeiten mit den charakteristischen Merkmalen der materiellen Enteignung aufweist ${ }^{81}$.

\section{b) Die materielle Enteignung}

Soweit die formelle Enteignung die Beschränkung von Nachbarrechten zum Gegenstand hat, befindet sie sich in unmittelbarer Nähe zur zweiten verfassungsrechtlich anerkannten Form der Enteignung, der materiellen Enteignung. Diese charakterisiert sich dadurch, daß hier kein Wechsel des Rechtsträgers stattfindet, sondern das Eigentumsrecht beim bisherigen Träger verbleibt, dieser aber Beschränkungen in Kauf zu nehmen hat, die einer formellen Enteignung gleich-

${ }_{78}$ Rhinow/Kräbenmann (Anm.15), Nr. 126, B I; Häfelin/Müller (Anm.13), 342 ff. (N. 1600); Grisel, Traité II (Anm. 17), 715 ff.; vgl. ferner Hess/Weibel, Bd. I (Anm. 6), 10ff.

79 Die neueste Rechtsprechung hat trotz dagegen erhobener Kritik in der Lehre ausdrücklich daran festgehalten, vgl. dazu BGE 116 Ib 11 mit ausführlicher Begründung; ferner Felix Schöbi, Zur Unterscheidung von formeller und materieller Enteignung am Beispiel von Immissionsstreitigkeiten, Recht 1985, $126 \mathrm{ff}$; Georg Müller, Kommentar (Anm. 13), Rdn. 62 ff. zu Art. 22 ${ }^{\text {ter }}$ BV); Grisel, Traité II (Anm. 17), 742 f.; Imboden/Rbinow II (Anm. 53), Nr.127 B.

${ }^{80}$ BGE 116 I b 11, 20 f.; 111 I b 233, 234; 110 I b 48 E. 4; 346 E. 2. Dabei müssen alle drei Voraussetzungen kumulativ erfüllt sein. Im übrigen ist die Schwere des Schadens nicht von einer bestimmten Wertgrenze abhängig, sondern kann schon bei einem Minderwert von $10 \%$ vorliegen (vgl. dazu auch BGE 102 I b 276).

${ }^{81}$ Georg Müller, Kommentar (Anm. 13), Rdn. 64 zu Art. 22 ${ }^{\text {trr }}$ BV. 
kommen. Wann die Schwelle vom entschädigungslos zu duldenden Eingriff überschritten ist, entscheidet nicht die Gesetzgebung, sondern der Richter.

Die bundesgerichtliche Rechtsprechung anerkennt das Vorliegen einer materiellen Enteignung im Zusammenhang mit der Grundstücksnutzung, wenn der bisherige oder ein voraussebbarer künftiger Gebrauch untersagt oder besonders stark eingeschränkt wird, weil eine wesentliche aus dem Eigentum fließende Befugnis entzogen wird. Geht der Eingriff weniger weit, so wird gleichwohl eine materielle Enteignung bejaht, wenn ein einziger oder einzelne Grundeigentümer so betroffen werden, daß ihr Opfer gegenüber der Allgemeinheit unzumutbar erschiene und es mit der Rechtsgleichheit nicht vereinbar wäre, wenn hierfür keine Entschädigung geleistet würde (sog. Sonderopfer $)^{82}$. Unbeachtlich ist nach der Konzeption der materiellen Enteignung, ob die Enteignungsähnlichkeit eine direkte Folge des Eingriffs ist, und ob sie aufgrund eines Gesetzes, einer Verfügung oder eines Realaktes erfolgt ${ }^{83}$.

Dieses großzügige Konzept der materiellen Enteignung wird in der Praxis allerdings mit Bezug auf die Nutzungsrechte am Grundeigentum erheblich relativiert und ist zuweilen vom bloßen Willkürverbot kaum mehr zu unterscheiden. Die Rechtsprechung hat mit dem Entscheid Zizers ${ }^{84}$ raumplanerische Maßnahmen, die mit der Herstellung eines bundesrechtkonformen Zustandes verbunden sind, grundsätzlich als entschädigungslos hinzunehmende Inbaltsbestimmungen des Grundeigentums bezeichnet. Damit konnten mit einem Schlag die potentiellen Ansprüche von materiell Enteigneten als Nichteinzonungen deklariert werden, während sie als Auszonungen möglicherweise hätten entschädigt werden müssen ${ }^{85}$. Einen ähnlichen Effekt hat der von der Rechtsprechung entwickelte Gedanke der grundsätzlichen

82 BGE 114 I b 103; 113 I b 320; 112 I b 389; vgl. ferner Kuttler (Anm. 67), 190 ff.

${ }^{83}$ In der Lehre werden diesbezüglich unterschiedliche Ansichten vertreten. Vgl. dazu Riva (Anm.34), 225 f;; Weber-Dürler, Vertrauensschutz (Anm. 50), 62; Lendi, Planungsrecht und Eigentum (Anm. 32), 206f. - In Deutschland hingegen fallen nach der Rechtsprechung des Bundesverfassungsgerichts unter den Begriff der Enteignung im Sinne von Art. 14 III GG nur staatliche Eingriffsakte (Rechtsakte), die unmittelbar auf die Entziehung bzw. Beschränkung oder Aufhebung subjektiver Eigentumspositionen zielen (BVerfGE 79, 174, 191 m.w.H.; Hesse [Anm. 57], 179; vgl. auch Riva [Anm.34], 225 Anm. 29).

${ }^{84}$ BGE 105 I a $330 \mathrm{ff}$.

${ }^{85}$ Vgl. z. B. BGE 109 Ib 17; 117 Ib 6 ff.; Entscheid des Bundesgerichtes vom 21. November 1984, in: ZBl. 86 (1985) 211. 
Gleichrangigkeit verfassungsrechtlich verankerter öffentlicher Interessen, die als Kompetenznormen ihren Ausdruck gefunden haben, mit der Eigentumsgarantie ${ }^{86}$.

\section{c) Polizeilich motivierte Eigentumsbeschränkungen ${ }^{87}$}

Diese lösen - fast eine Selbstverständlichkeit - keine Entschädigungspflicht aus. Allerdings gilt dies nur mit Bezug auf Maßnahmen, denen ein enger Polizeibegriff zugrundegelegt wird. Sie müssen verbältnismäßig, d.h. notwendig zur Erreichung des polizeilichen Zwecks, sein und zur Abwebr einer ernsthaften und unmittelbar drobenden Gefahr dienen. Der Grundsatz des entschädigungslos zu duldenden polizeilich motivierten Eingriffs wurde vom Bundesgericht bis ins Jahr 1980 ohne Ausnahme gehandhabt ${ }^{88}$. Heute kann sich die Entschädigungsfrage bei polizeilichen Eingriffen in drei Fällen stellen $^{89}$ :

- wenn ein Bauverbot nicht nur polizeilich, sondern auch raumplanerisch begründet ist ${ }^{90}$;

- wenn eine bisherige Nutzung verboten wird und

- wenn die Schaffung von Schutzzonen eine Auszonung von baureifem und grob erschlossenem Land bewirkt ${ }^{91}$.

\section{d) Sonderfälle}

Als eigentliche Sonderfälle sind Landumlegungen (landwirtschaftliche Güterzusammenlegungen, Baulandumlegungen) zu betrachten.

86 So auch Rbinow/Kräbenmañn (Anm.15), Nr.130 B II.

87 Häfelin/Müller (Anm.13), 368 (N.1723 ff.); Grisel, Traité II (Anm.17), 775 f.; Beatrice Weber-Dürler, Der Grundsatz des entschädigungslosen Polizeieingriffs, ZBl. 85 (1984) 289 ff.; Meier-Hayoz (Anm. 68), 244 f. (N. 642).

${ }_{88}$ Georg Müller, Kommentar (Anm. 13), Rdn. 60 zu Art. 22 auf die kritischen Stimmen in der Lehre).

89 Vgl. dazu BGE 106 Ib 332 E. 4 und 106 I b 336 ff.; Weber-Dürler (Anm. 87), 279 ff., insb. 301. Nach Georg Müller, Kommentar (Anm. 13), Rdn.61 zu Art. $22^{\text {ter }}$ $\mathrm{BV}$, ist es angesichts dieser neuen Rechtsprechung fraglich, ob überhaupt noch am Grundsatz der Entschädigungslosigkeit polizeilich motivierter Eigentumsbeschränkungen festzuhalten ist.

90 Z.B. Ausscheidung von Grundwasserschutzzonen, deren Freihaltung sich auch aus Gründen der Ortsplanung aufdrängt.

91 Unter der zusätzlichen Voraussetzung allerdings, daß die polizeiliche Einschränkung nicht unmittelbar zum Schutz des Grundeigentümers selber erlassen wird (z. B. Lawinenzonen), sondern zum Schutz eines öffentlichen Werkes (z. B. Grundwasserpumpwerk). 
Hier erfolgt die Maßnahme in der Absicht, die Nutzungsmöglichkeiten der betroffenen Grundstücke zu erhöhen ${ }^{92}$. An ihrer Durchführung besteht nicht nur ein öffentliches Interesse, sondern regelmäßig auch ein erbebliches privates Interesse. Grundstückeigentümer können gezwungen werden, sich an einer Landumlegung zu beteiligen. Charakteristisches Merkmal derartiger Umlegungsmaßnahmen ist sodann, daß der Ausgleich für den Eingriff in Form von Realersatz geleistet wird, es liegt daher weder eine formelle noch eine materielle Enteignung im klassischen Sinne vor ${ }^{93}$.

\section{Junktim-Klausel und Entschädigungshöhe}

Beide angesprochenen Problemkreise sind in der Schweiz von verfassungs wegen völlig anders geregelt als in Deutschland ${ }^{94}$. Enteignungen sind - wie gesehen - nicht an das Vorhandensein einer Bestimmung über die Entschädigung geknüpft. Es gilt der Grundsatz: Keine Enteignung ohne Entschädigung. Formelle und materielle Enteignung unterscheiden sich mit Bezug auf die Entschädigung insofern, als bei ersterer die Entschädigung Voraussetzung für den Eigentumsübergang bildet, während sie bei der materiellen Enteignung als Folge des Eingriffs behandelt wird. Die Geltendmachung der materiellen Enteignung setzt nicht voraus, daß sich der Betroffene vorher gegen die Planungsmaßnahme als solche gewendet hat.

Sowohl bei der formellen wie bei der materiellen Enteignung gilt der Grundsatz der vollen Entschädigung. „Voll“ ist die Entschädigung dann, wenn die durch den Eingriff eingetretene Werteinbuße ausgeglichen wird ${ }^{95}$. Regelmäßig wird dieser Ausgleich in Form von Geldleistungen erbracht. Realersatz ist dagegen verfassungsrechtlich vorgesehen bei Güterzusammenlegungen und Baulandumlegungen sowie im Rahmen der formellen Enteignung - für öffentliche Einrichtungen, Kulturland und Wasser ${ }^{96}$.

Die der schweizerischen Konzeption des Enteignungsrechts typische Verpflichtung zur vollen Entschädigungsleistung kann für alle

92 Haller/Karlen (Anm. 32), 74 (N. 51 ff.); Schürmann, Bau- und Planungsrecht (Anm. 32), 82 ff.; Meier-Hayoz (Anm. 68), 232 f. (N. 609 ff.).

${ }_{93}$ Georg Müller, Kommentar (Anm. 13), Rdn. 47 zu Art. 22 ${ }^{\text {ter } B V . ~}$

${ }_{94}$ Zur Entschädigungsregelung in Deutschland vgl. Bryde (Anm.66), Art. 14, Rdn. 85 ff.; Papier (Anm. 32), Art. 14, Rdn. 485 ff.

95 Jörg Paul Müller (Anm.18), 346f.; Georg Mïller, Kommentar (Anm. 13), Rdn. 66 zu Art. 22 ${ }^{\text {er }}$ BV; Imboden/Rbinow II (Anm. 53), Nr. 128 B III.

$96 \mathrm{Vgl}$. Imboden/Rhinow II (Anm. 53), Nr. 129. 
Beteiligten gewisse Härten mit sich bringen ${ }^{97}$. Immerhin sieht das Raumplanungsgesetz vor, daß das kantonale Recht einen angemessenen Ausgleich vorsehen kann für erhebliche Vor- und Nachteile von Planungen, ohne daß diese schon die Intensität einer materiellen Enteignung erreichen ${ }^{98}$. Die bundesrechtliche Regelung der materiellen Enteignung darf jedoch mit solchen Kompensationsvorschriften nicht unterlaufen werden ${ }^{99}$. Die Kantone haben allerdings diesen Spielraum kaum in kreativer Weise ausgenützt.

97 In der Lehre findet sich daher die Forderung nach einer flexibleren Gestaltung der Entschädigungsregelung (vgl. die Hinweise bei Jörg Paul Müller [Anm.18], 347).

98 Art. 5 Abs. 1 RPG.

99 BGE 109 I b 114 f.; 110 Ib 31 f.; Entscheide des Zürcher Verwaltungsgerichts vom 2. Mai und 26. Oktober 1984, in: Rechenschaftsbericht an den Kantonsrat 1984, Nr. 122 (Praxisänderung); Rhinow/Kräbenmann (Anm. 15), Nr. 130 B II. 
Leitsätze des 3. Berichterstatters über:

\section{Eigentumsschutz, Sozialbindung und Enteignung bei der Nutzung von Boden und Umwelt}

1. Die Eigentumsgarantie nach der schweizerischen Bundesverfassung

1. Die Eigentumsgarantie ist in der Schweiz eines der jüngsten verfassungsmäßig ausdrücklich verankerten Grundrechte. Entsprechend derschweizerischen Verfassungstradition bildeten erst die Bedürfnisse der Raumplanung Anlaß zur förmlichen Gewäbrleistung der Eigentumsgarantie. Wesentliche, noch beute geltende Teile der schweizerischen Eigentumsordnung wurden obne diese Garantie gestaltet.

2. Die Eigentumsgarantie gewährleistet nicht eine bestimmte Eigentumsordnung, sondern gebt von einem wandelbaren Eigentumsbegriff aus.

3. Die Eigentumsgarantie darf nicht von anderen Grundrechten isoliert betrachtet werden; dies gilt ganz besonders mit Bezug auf die Handels- und Gewerbefreiheit. Der Doppelcharakter der Eigentumsgarantie wird mit der Instituts- und der Bestandesgarantie deutlich gemacht.

Besonderbeiten des Grundeigentums

4. Im Rabmen des Grundeigentums läßt die Institutsgarantie dem Gesetzgeber schon im Rabmen der geltenden Verfassung erbebliche Gestaltungsspielräume. Dabei gewährleistet das schweizerische System nicht immer eine einwandfreie Einhaltung der Spielregeln.

5. Die offene Verfassung läßt für das Grundeigentum grundsätzliche Anderungen bis hin zu eigentlichen Systemwechseln zu.

6. Die dogmatisch umstrittene Frage der Baufreiheit spielt praktisch nur eine sebr untergeordnete Rolle und wird mebr und mebr verdrängt von der Tatsache, daß sich Nutzungsmöglichkeiten des Grundeigentums nur noch in Abbängigkeit vom Staat realisieren lassen.

7. Die Beschränkung der Nutzungsmöglichkeiten bzw. die Ausklammerung vom Privateigentum der beiden wichtigen Umweltmedien Wald und Wasser hat eine lange und unbestrittene Tradition. 


\section{Besitzstandsgarantie}

8. Die Eigentumsgarantie schützt im Rabmen des Planungsrechts bestehende, neurechtswidrig gewordene Bauten und Anlagen insofern, als sie dem Eigentümer einen Anspruch auf Erneuerung und Unterhalt vermittelt; mit Bezug auf den Wiederanfbau und die teilweise Änderung können die Kantone einen weitergehenden Schutz vorsehen.

9. Im Bereich des Umweltschutzes kommt der Eigentumsgarantie nur abgeschwächte Bedeutung zu (Übergangsfristen): Rechtsgleichbeit und Wettbewerbsneutralität haben zusammen mit dem allgemeinen Sanierungsprinzip grundsätzlich Vorrang vor der Besitzstandsgarantie.

10. Die Rechtsfigur des eingerichteten und ausgeübten Gewerbebetriebes existiert in der Schweiz als solche nicht. Besitzstandsgarantie und Vertrauensschutz, insbesondere im Zusammenhang mit dem Widerruf von Verfügungen, stehen als Alternativen zur Verfügung. Eine (dogmatisch kaum zu rechtfertigende) Ausnabmestellung nebmen die woblerworbenen Rechte ein, die nicht nur unter dem Schutz der Eigentumsgarantie stehen, sondern sogar Gesetzesbeständigkeit genießen.

11. Problematisch ist der feblende Schutz für sog. faktische Interessenlagen (z. B. Anstößerrechte).

12. Das Vermögen ist nunmebr auch als solches geschützt. Mit Bezug auf umweltspezifische Abgaben stellt sich das Problem ibrer Zulässigkeit unter dem Gesichtspunkt der Kompetenzverteilung zwischen Bund und Kantonen.

II. Inbalts- und Schrankenbestimmungen des Gesetzgebers und Sozialbindung des Eigentums

13. Sozialbindung bzw. Sozialpflichtigkeit sind keine verfassungsrechtlichen Begriffe des schweizerischen Rechts. Inhaltlich nimmt aber die bundesgerichtliche Praxis schon sehr lange darauf Bezug.

14. Die schweizerische Lebre und Rechtsprechung lebnt (zu Recht) die Unterscheidung zwischen Inhalt und Schranken des Grundeigentums als unergiebig ab.

15. Dem Gesetzgeber steben im Rabmen der Konkretisierung des Inhalts des Grundeigentums sebr weite Ermessensspielräume offen. Dabei nimmt die Bedeutung der "Gemeinverträglichkeit" der Bodennutzung laufend zu: Raumplanung, Umwelt-, Gewässer- und Naturund Heimatschutz sowie das Walderhaltungsgebot sind der Eigentumsgarantie als gleichwertige verfassungsrechtliche Interessen gegenüberzustellen. Als Gegengewicht zum Schutz der Eigentumsgarantie 
vor einer kalten Beseitigung erscheinen das planerische Abwägungsgebot sowie insbesondere die demokratischen Mitwirkungsrechte im Planungsverfabren.

\section{Enteignung und Entschädigung}

16. Formelle und materielle Enteignung sind auseinanderzubalten: Erstere charakterisiert sich als Übertragung eines Rechts auf den Enteigner, letztere als Nutzungsbeschränkung (ohne Übertragung eines Rechts), die wegen ibrer Intensität einer formellen Enteignung gleichkommt.

17. Die Grenze zwischen entschädigungslos binzunebmender Inhalts-oder Schrankenbestimmung einerseits und materieller Enteignung andererseits wird vom Richter gezogen, der damit zum zentralen Akteur der Bodenpolitik wird. Polizeilich motivierte Eigentumsbeschränkungen sind grundsätzlich immer entschädigungslos $z u$ dulden.

18. Formelle und materielle Enteignung sind von verfassungs wegen immer voll zu entschädigen. Für erstere ist die Entschädigung Voraussetzung, für letztere Folge des Eingriffs. Die Junktim-Klausel findet in der Scbweiz keine Entsprechung. 


\section{Aussprache und Schlußworte}

\section{Eigentumsschutz, Sozialbindung und Enteignung bei der Nutzung von Boden und Umwelt}

Vorsitzender (Papier): Hiermit eröffne ich die Aussprache zum zweiten Beratungsgegenstand „Eigentumsschutz, Sozialbindung und Enteignung bei der Nutzung von Boden und Umwelt“. Der Vorstand hatte den Referenten einen Katalog von Fragen vorgelegt*\%, um insbe-

\section{* Eigentumsschutz, Sozialbindung und Enteignung bei der Nutzung von Boden und Umwelt}

Zusammenstellung der wichtigsten Fragestellungen: (Empfehlungen des Vorstandes)

1. Welchen Inhalt und welchen Umfang hat der verfassungsrechtliche Eigentumsbegriff?

a) Das bezieht sich insbesondere auf das Grundeigentum. Umschließt dieses beispielsweise auch die Baufreiheit sowie die Nutzung der Umweltmedien, etwa des Grundwassers? b) In welchem Umfang wird das Recht am eingerichteten und ausgeübten Gewerbebetrieb geschützt? c) Gibt es einen verfassungsrechtlichen Schutz des Eigentums gegenüber einer öffentlich-rechtlichen (umweltspezifischen) Abgabenerhebung? d) Welche Bedeutung hat die verfassungsrechtliche Eigentumsgewährleistung bei Entscheidungen der Bauleitplanung und der Fachplanung? e) Welche Bedeutung hat die verfassungsrechtliche Eigentumsgewährleistung in bezug auf den Bestand vorhandener Anlagen und bestehender Genehmigungen?

2. Welche verfassungsrechtlichen Schranken bestehen für die Gesetzgebung, die Inhalt und Schranken des Eigentums regelt?

3. Gibt es entschädigungspflichtige Inhalts- und Schrankenbestimmungen des Eigentums?

4. Was ist unter einer Enteignung im verfassungsrechtlichen Sinne zu verstehen? Worin besteht der Unterschied zu den Inhalts- und Schrankenbestimmungen des Eigentums durch den Gesetzgeber?

5. Inwieweit ist der Gesetzgeber von Verfassungs wegen gehalten, bei Enteignungen eigene Entschädigungsregelungen zu treffen?

6. Welche Aussagen trifft die Verfassung zur Höhe der Entschädigung? Gibt es die Möglichkeit entschädigungsloser Enteignungen?

7. Gibt es aufopferungsrechtliche bzw. enteignungsgleiche Haftungstatbestände außerhalb des eigentlichen Enteignungsrechts? 
sondere dem Anliegen der Rechtsvergleichung Rechnung zu tragen. Dieser Fragenkatalog liegt auch Ihnen vor. Ich hatte am Schluß der Referate am heutigen Vormittag Ihnen einen Vorschlag für die Strukturierung der Diskussion unterbreitet, der auf diesem Fragenkatalog basiert und den ich in einigen wenigen Sätzen wiederholen möchte. Wir sollten mit der Frage nach Inhalt und Umfang der verfassungsrechtlichen Eigentumsgarantie beginnen, insbesondere mit dem geschützten Eigentumsobjekt, und in diesem Zusammenhang etwa die Fragen der Baufreiheit und der Nutzung der Umweltmedien einbeziehen. In einem zweiten Komplex sollten wir die Möglichkeiten des Gesetzgebers diskutieren, Inhalt und Schranken des Eigentums zu bestimmen. Hier wird es auch um die Frage gehen, inwieweit aus Art. 14 Abs. 1 S. 2 GG das Erfordernis einer Entschädigungspflicht für bestimmte Arten oder Formen der Inhalts- und Schrankenbestimmung folgen kann. In einem dritten Abschnitt könnten wir uns dann der Enteignung und den parallelen Instituten, also etwa dem enteignungsgleichen Eingriff oder den enteignenden Eingriffen zuwenden, ebenso der Frage der Entschädigungshöhe, der Entschädigungsregelung und des Entschädigungsjunktims.

Meine Damen und meine Herren, die rechtliche Bewältigung der offenkundigen Spannungen zwischen der Eigentumsgewährleistung einerseits und dem Schutz der Umweltmedien andererseits kann, so meine ich, nur erreicht werden, wenn wir wieder zu einer halbwegs gesicherten Eigentumsdogmatik zurückfinden. Die tradierte Eigentumsdogmatik, die ja vor allem von der zivilgerichtlichen Judikatur geprägt worden war und die bekanntlich, auch Herr Ehlers hat in seinem Referat darauf hingewiesen, den Eigentumsschutz primär über das Entschädigungsrecht gewährleistete, ist durch die Judikatur des Bundesverfassungsgerichts, übrigens nicht ohne Beifall eines erheblichen Teils der Staatsrechtslehre, ins Wanken geraten, ja teilweise sogar obsolet geworden. Das Bundesverfassungsgericht hat aber nicht nur dieser tradierten Eigentumsdogmatik den Todesstoß versetzt, sondern es hat auch Bausteine für eine neue Dogmatik geliefert. Aber ich stimme Herrn Eblers zu, wenn er sagt, ein fertiges Gebäude konnte auch das Bundesverfassungsgericht bisher nicht errichten. Und eine neue Dogmatik, die halbwegs gesichert und anerkannt ist, ist, wie ich meine, auch im Augenblick nicht in Sicht. In einer solchen Situation ist es vor allem auch die Aufgabe der Staatsrechtswissenschaft, in dieser Beziehung Fortschritte zu bewirken. Wir müssen uns also am heutigen Tag Mühe geben, hier einen Schritt weiterzukommen, denn nur dann können wir auch die eher praktischen Probleme bewältigen. Mir scheint, die Rechtsvergleichung kann dazu einen wesentlichen 
Beitrag leisten, und ich meine, die heutigen Referate haben insoweit auch bereits einen wertvollen Beitrag geleistet.

Meine Damen und meine Herren, ich möchte nunmehr die Aussprache eröffnen. Ich darf zunächst Herrn Ossenbühl bitten.

Ossenbühl: Herr Vorsitzender, wenn Sie erlauben, möchte ich, bevor ich zu meinem Sachbeitrag komme, eine Feststellung treffen, durch die diese Jahrestagung als besondere gekennzeichnet ist, und ich meine, es ist notwendig, daß wir die drei Gründe, die dafür sprechen, auch gewissermaßen für die Nachwelt ins Tagungsprotokoll schreiben.

Der erste Grund ist der, daß wir in diesem Jahr die 50. Jahrestagung begehen, also ein Jubiläum feiern. In diesem Alter nimmt man natürlich von seinem Geburtstag nur ungern Notiz. Deshalb sind wir in preußischer Pflichterfüllung und Bescheidenheit schmucklos und ohne das weiter zu erwähnen, an die Arbeit gegangen. Vor 20 Jahren, 1971, haben wir den 30. Jahrestag gefeiert. Damals hat Herr Scheuner in Regensburg einen Vortrag über die Geschichte und Aufgabe der Vereinigung gehalten, der in AöR 97 (1972), S. 349 ff. abgedruckt ist. Ich erwähne das gewissermaßen zur Traditionspflege für die jüngeren Mitglieder unserer Vereinigung. Der zweite Grund ist der, daß mir keine Tagung einfällt, bei der die beiden Kriterien für eine optimale Themenauswahl so gut erfüllt worden sind wie bei dieser Tagung, nämlich die Verbindung zwischen dem grundsätzlichen Aspekt, der grundsätzlichen Perspektive des Rechts und der aktuellen Problematik, die allen auf den Nägeln brennt. Ich glaube, auch diese glückliche Themenauswahl muß, nach allem, was zu diesem Punkt gesagt worden ist, hervorgehoben werden. Drittens: Die Vereinigung hat gestern den ersten nationalen Feiertag nach der Wiedervereinigung, den 3. Oktober 1991, mit ihrer ersten Sitzung ausgefüllt, und ich hätte mir keine, diesem Anlaß würdigere und angemessenere Form vorstellen können als die Veranstaltung, die gestern hier abgelaufen ist. Ich glaube, wir müssen dem Vorstand für diese hervorragende Regie Dank und Anerkennung aussprechen.

Auch das heutige Thema, meine Damen und Herren, steht in diesem Aktualitätsbezug, allerdings wiederum mit einer Besonderheit, nämlich der, daß das Eigentum und die mit ihm verbundene Enteignungsproblematik eine ewige Problematik darstellt. Die Grenzen des Eigentums müssen für jede Epoche, für jede Zeit und für jeden Raum ständig neu gezogen werden. Durch den vorgegebenen Fragenkatalog ist für den Rechtsvergleich, den wir hier erlebt haben, eine gute Vergleichbarkeit der Probleme und Ergebnisse von vornherein gege- 
ben. Die Strukturen und Problemstellungen, die Kriterien, Kategorien und Begriffe wie Bestandsgarantie, Institutsgarantie, Enteignungen, Eigentumsbeschränkungen, Bestandsschutz, Vertrauensschutz, Verhältnismäßigkeit haben wir in allen drei Rechtsordnungen in ganz vergleichbarer Form vorgefunden und eigentlich nur im Detail Abweichungen konstatieren können. Es gilt also hier auch wiederum die alte Erkenntnis: Im Grundsatz sind die Probleme gleich, der Teufel steckt im Detail. Und Sie haben dazu eingeladen, daß wir zu diesen Details Stellung nehmen. Gleichwohl möchte ich versuchen, nochmals aus einer grundsätzlichen Perspektive heraus das Thema anzugehen und von dort aus ins Detail vorzustoßen, und zwar unter drei Gesichtspunkten. Erstens: Inhalt und Funktion des Eigentums. Zweitens: Wer definiert das Eigentum? Drittens: Aktuelle Probleme des Eigentumsschutzes.

Die erste Frage, die wir uns stellen müssen, ist die nach Inhalt und Funktion des Eigentums, und bei der Funktion haben wir zumindest zwei unterschiedliche Dinge zu beachten. Zunächst einmal dies, daß die Eigentumsgarantie der Sicherung eines materiellen Bestandes als Voraussetzung der Freiheitsausübung dient. Eigentum als Freiheitssicherung, das ist die Formulierung, die in der Dürigschen Fassung aus den 50er Jahren die Formel gefunden hat: „Eigentum ist Freiheit". Es ist, wenn ich den Bogen zu den Referaten von gestern spannen darf, gewissermaßen in erster Linie hier natürlich das „kleine Eigentum" gemeint, das Herr Berg angesprochen hat. Aber wir müssen bedenken, daß das Eigentum auch darüber hinaus eine systemstabilisierende, eine systemstützende Funktion hat. Es ist nämlich das Agens, der Motor der Marktwirtschaft, und insoweit steht das Eigentum auch in seiner makroökonomischen Funktion hier zur Diskussion. Herr Rill hat das sehr deutlich im Leitsatz 4 angesprochen mit dem Satz „Das Telos der Eigentumsgarantie besteht in der Gewährleistung einer grundsätzlich marktwirtschaftlichen Ordnung“. Und ich möchte hinzufügen, daß diese Marktwirtschaft eben nicht nur ein disponibles Modell unserer Verfassungsordnung ist. Die Vorgänge der letzten Zeit haben uns gelehrt, daß die Marktwirtschaft nicht ein, sondern das System einer freiheitlichen Ordnung ist, und ich glaube, aus dieser Fixierung heraus kann man auch zu praktischen Folgerungen kommen, in vertretbarer Weise etwa zu der, daß, wenn das so ist, auch der Schutz des eingerichteten und ausgeübten Gewerbebetriebs unter die Eigentumsgarantie fallen muß, so wie es für die Bundesrepublik anerkannt ist, aber in Österreich und in der Schweiz noch aussteht. Dazu gehört dann auch etwa die Baufreiheit. 
Zweiter Punkt: Wer definiert das Eigentum? Die Definitionsmacht schließt ein, dessen müssen wir uns von Anfang an bewußt sein, die Umgrenzung der zulässigen Eingriffe in das Eigentum und damit auch den Umfang des Eigentumsschutzes. Diese Definitionsmacht ist ferner nicht zu trennen von den Differenzierungen, die ja eine große Rolle spielen bei Enteignungen und Eigentumsbeschränkungen. Insoweit bin ich gegenüber der Nützlichkeit des Naßauskiesungsbeschlusses aus dem Jahre 1981 reservierter als vielleicht manche im Saal. Ich bin der Meinung, daß der Naßauskiesungsbeschluß uns in den brennenden Fragen des Eigentumsschutzes nicht viel weitergeholfen hat. Im Naßauskiesungsbeschluß wurde nämlich eigentlich nur, was vielfach übersehen worden ist, der Kompetenzkonflikt zwischen dem Bundesgerichtshof und dem Bundesverfassungsgericht ausgeräumt. Das Bundesverfassungsgericht hat in dem Bestreben, diesen Kompetenzkonflikt für sich zu entscheiden, den Enteignungsbegriff wieder formalisiert, nach der alten Parole: „Zurück zum klassischen Enteignungsbegriff" ; aber damit sind die Probleme nicht gelöst, sondern verdrängt worden, und zwar von Art. 14 Abs. 3 GG in Abs. 1. Dort tauchen sie jetzt auf. Bei den Inhaltsbestimmungen und Eigentumsbeschränkungen. Die Frage, wann sind Inhaltsbestimmungen und Eigentumsbeschränkungen ausgleichspflichtig, wann nicht, das ist das moderne Problem. Insoweit stellen sich die als verabschiedet geltenden Probleme wieder neu. Die Schwellentheorien haben insoweit nach wie vor ihre Bedeutung. Die Problematik der salvatorischen Klausel wird erneut diskutiert. Wir erleben also die fröhlichen Urständ der alten Eigentumsprobleme. Nochmals die Frage: Wer definiert das Eigentum? Wir sagen: natürlich der Gesetzgeber. Aber der Gesetzgeber kann es nicht in voller Souveränität tun, sonst könnte die Eigentumsgarantie ihm gegenüber keinen Schutz entfalten. Der Gesetzgeber muß gesellschaftliche Anschauungen berücksichtigen und grundgesetzliche Vorgaben, die ihrerseits wiederum vom Richter gewissermaßen interpretatorisch geprägt werden. Diese Vorgaben tauchen dann als Kontrollmaßstäbe auf, die letztlich die Grenze $z$ wischen gesetzgeberischer Gestaltungsfreiheit und Gerichtskompetenz ziehen. Dazu gehört die Trias: Verhältnismäßigkeit, Gleichheitssatz, Vertrauensschutz. Das ist das Modell, das ist das Muster, nach dem die Eigentumsgesetze des Gesetzgebers gerichtlich überprüft werden und das die Arbeitsteilung zwischen Gesetzgeber und Gericht markiert. Hier muß, wie ich meine, die Fortentwicklung der Eigentumsdogmatik ansetzen, denn die Verfeinerung, die Differenzierung dieser Kontrollmaßstäbe hat selbstredend auch eine unmittelbare 
reflexive Wirkung gegenüber dem Gesetzgeber. Sie zwingt ihn dazu, von vornherein Eigentumspolitik zu „rationalisieren“.

Wie kann man das machen? Es gibt sicher mehrere Ansätze, die ich nur ganz kurz andeuten will. Erster Ansatz: Man kann weiter ausbauen die schon aus dem Bereich des Schutzes offentlich-rechtlicher Rechtsstellungen bekannten Schutzabstufungen innerhalb des Eigentumsschutzes; ich nenne nur die Stichworte „persönliches Eigentum“, "geistiges Eigentum“, „Wirtschaftseigentum“, „kleines und großes Eigentum“, „Bodeneigentum“, „Betriebseigentum“. Die Schutzabstufungen können sich also nach den verschiedenen Eigentumsformen richten. Der zweite Ansatz wäre, zu den allgemeinen Kriterien sachbereichsspezifische Zusatzkriterien zu entwickeln. Ich könnte mir vorstellen, daß für den Naturschutz beispielsweise andere zusätzliche Kriterien gelten können als beim übrigen Umweltschutz. Dritter Ansatz wäre, einen Mindestschutz, einen Mindeststandard aufzuzeigen. Wir haben, nachdem uns Herr Lerche vor 30 Jahren das Übermaßverbot präsentiert hat, jetzt auch das dazugehörige Gegenstück, nämlich das Untermaßverbot, das uns Herr Eblers präsentiert hat. Ich selbst bin allerdings noch etwas unsicher, was man darunter verstehen soll. Insbesondere ist es, wenn ich es recht verstehe, ein sehr defensives Prinzip. Das offensive Prinzip in der Eigentumsgarantie ist das Übermaßverbot. Darauf möchte ich mich doch eher verlassen.

Ganz kurz einige aktuelle Aspekte des Eigentumsschutzes. Daß die Eigentumsgarantie der Umweltpolitik nicht entgegensteht, ist hier in einem Resümee von Herrn Eblers ausdrücklich hervorgehoben worden. Ich glaube, das kann man nur unterstreichen. Wenn man gleichwohl Eigentumsgarantic und Umweltpolitik verbinden, beide miteinander verknüpfen und die Kollisionen aufzeigen will, dann kann man das auch so machen, daß man sich zunächst einmal vergegenwärtigt, mit welchen Instrumenten denn in der Umweltpolitik gearbeitet wird. Und dann gibt es zunächst die bekannten Instrumente, mit denen wir uns immer beschäftigen, nämlich Gebote, Verbote und Nutzungsbeschränkungen und dergleichen. Was mir aber scheint, ist, daß die aktuelle Gefährdung der Eigentumsgarantie nicht in diesen Bereichen liegt, sondern in dem Instrument „Auferlegung von Geldleistungen und Umweltabgben". Hier wird an der offenen Flanke der Eigentumsgarantie Umweltschutzpolitik getrieben. Nicht zuletzt wird Umweltschutz möglicherweise als Vorwand benutzt, um die allgemeinen Einnahmen des Haushaltes zu erhöhen, und mir scheint, daß das Augenmerk insbesondere darauf gelegt werden muß, daß die Eigentumsgarantie nicht über die Negierung einer Vermögensgarantie ausgehöhlt wird. 
Badura: Ob Eigentum Naturrecht ist, wie gestern zu hören war, werden wir vielleicht nie wissen. Sicher aber ist, daß der Schutz und die Sicherung des Eigentums ein, nach unserer Auffassung unverzichtbarer, Bestandteil eines Rechtsstaates ist, und auf diesem Boden, glaube ich, läßt sich auch eine brauchbare, theoretisch gegründete und praktisch nützliche Eigentumsdogmatik entwickeln. Der Naßauskiesungsbeschluß des Bundesverfassungsgerichtes steht, wir mir scheint, in viel höherem Maße in der Tradition der verfassungsrechtlichen Eigentumsgarantie, als es gelegentlich angenommen wird oder scheint. Und Herr Eblers hat, soweit ich das überblicken konnte, in einer sehr gelungenen Form die Grundlinien einer Eigentumsdogmatik moderner Art, wenn ich mal so sagen darf, hier uns vorgelegt, und das wird um so mehr dadurch bestätigt, daß die Referate aus Österreich und der Schweiz doch in einer überraschenden Konvergenz, trotz ganz unterschiedlicher Verfassungslagen und gesellschaftlicher Entwicklungen, in den Hauptlinien mit diesem Referat und seinen Thesen übereinzustimmen scheinen. Das gibt zu den schönsten Hoffnungen Anlaß, wenn wir bedenken, daß Österreich und die Schweiz ja vermutlich in nicht allzu ferner Zukunft auch der Europäischen Gemeinschaft angehören werden und damit also das Eigentums-Grundrecht noch stärker, als es bisher schon der Fall ist, auch als eine Garantie des Gemeinschaftsrechtes in Erscheinung treten wird.

Erlauben Sie mir nur vier Bemerkungen zu einigen Punkten, die mir aufgefallen sind. Wir sind gewohnt, bei den Grundrechten nach der "Funktion“ zu fragen, das haben auch die Referenten getan: die Funktion des Eigentums sowohl wie auch die Funktion der Eigentumsgarantie, und ich fand es richtig, vor allem in der These von Herrn Eblers unter 2), daß das Eigentum klar und deutlich als Freiheitsrecht bezeichnet worden ist und die gelegentlich vertretene Lehre vom „Funktionsgrundrecht" nicht auf das Eigentum angewandt worden ist. Die Verfassung schreibt dem Eigentümer nicht eine bestimmte Funktion seines Eigentums vor.

Zweiter Punkt: Es ist auf der anderen Seite unvermeidlich, daß eine Abstufung in der Gewährleistungswirkung durch den Gesetzgeber vorgenommen wird, das Wirtschaftseigentum, das Grundeigentum, das "kleine" und "große" Eigentum sind in der Tat, wenn wir die Formulierung des Bundesverfassungsgerichts nehmen, von einem unterschiedlichen sozialen Bezug und einer unterschiedlichen sozialen Funktion. Es ist Sache des Gesetzgebers, diese Situation im einzelnen zu gestalten und abzugrenzen. In den Einzelheiten treten dann in der Tat gewisse Unterschiede auf. Wenn Herr Rill etwa in seiner These $5 \mathrm{e}$ 
das Grundwasser dem Eigentum zuzählt, ist das ein Standpunkt, der zwar dem alten preußischen Recht zu entsprechen scheint, aber sonst in Süddeutschland nicht verbreitet war und der wohl auch nicht dem geltenden deutschen Recht entspricht, oder auch die These in 21 und 31, daß die baurechtliche Entwicklungsplanung grundsätzlich in einen Konflikt mit der Eigentumsgarantie treten könnte. Sie sagten „Positivplanung". Diesen Standpunkt würde ich nicht teilen. Natürlich, wenn es generell so wäre, dann in der Tat. Aber das ist ja keine praktische Frage, sondern, wenn es für gewisse Bereiche wäre, Problemzonen, muß dem Gesetzgeber diese Möglichkeit eröffnet werden. Auf der anderen Seite meine ich, daß Herr Ehlers vielleicht zu weit geht, in These 8, wenn er das Eigentum unter einen Planungsvorbehalt stellt, während Herr Hänni, wie es eben der Schweiz entspricht, den gesunden Mittelweg in der These 6 geht, und auf diese Weise, glaube ich, auch der deutschen Praxis am nächsten kommt.

Ein dritter Punkt: Der grundrechtliche Schutz- und Abwehranspruch ist wohl doch in neuerer Zeit in der deutschen Rechtspraxis als geltendes Recht anzusehen. Ich stimme Herrn Ossenbübl zu, der in der jüngsten Auflage seines großen Staatshaftungsrechtes deswegen zu Recht dem einen eigenen Abschnitt gewidmet hat. In den Referaten ist das, vor allem bei Herrn Ehlers, nicht so eindeutig. Vielleicht kann das erklärt werden, These 4 und These 11 . Dieser unmittelbare grundrechtliche Schutz- und Abwehranspruch ist ja schon durch die eigentumsrechtliche Nachbarklage des Bundesverwaltungsgerichtes vorgezeichnet. Wenngleich in der Tat die gesetzliche Schutznorm den Vorrang vor einem derartigen verfassungsunmittelbaren Anspruch haben muß, wie im Immissionsschutzrecht und anderen Bereichen das ja auch geregelt ist. Herr Ehlers hat zu Recht die Frage gestellt und auch beantwortet, ob nicht eine gesetzliche Regelung immer nötig ist, also eine Art Gesetzesvorbehalt im Rahmen von Art. 14 Abs. 1 GG auch zugrunde zu legen wäre, indem etwa die Ausgleichsansprüche, die wir seit dem Naßauskiesungsbeschluß suchen, zum Teil auch gefunden haben, demnach also einer gesetzlichen Regelung bedürften. Das ist mir nicht sicher, ob man das in derselben Striktheit sagen kann, weil es ja gewissermaßen die Junktimklausel des Abs. 3 in den Abs. 1 im Wege einer bestimmten Analogie transferiert.

Und vierter und letzter Punkt: Der Schutz der natürlichen Lebensgrundlagen steht zwar nicht im Grundgesetz, aber es ist ja auch, glaube ich, unzweifelhaft und durch Ihre Referate im einzelnen dargetan, daß der Schutz der natürlichen Lebensgrundlagen ein Element der Institutsgarantie des Eigentums ist, wenngleich nicht eine Blankovoll- 
macht für Eingriffe in bestehende Rechte. Über Art. 14 Abs. 2 GG allerdings hinausgehende Beschränkungen durch die Exekutive zum Schutz der natürlichen Lebensgrundlagen sind wohl nach dem geltenden Rechtszustand nicht möglich, insoweit bedürfte es in der Tat einer gesetzlichen Regelung, und selbst die Einführung einer Umweltstaatszielbestimmung würde an dieser grundsätzlichen Einschätzung ja wohl nichts Nennenswertes ändern können. Und dasselbe, was man für den Schutz der natürlichen Lebensgrundlage sagen kann, gilt, wie ich meine, auch für die Erfordernisse der städtebaulichen Planung, das sind Elemente der Institutsgarantie des Eigentums, und in dem Sinne treten sie nicht nur von außen an das Eigentum als Rechtsinstitut heran, unbeschadet der Notwendigkeit, Eingriffe in bestehende Rechte verfassungsrechtlich zu rechtfertigen und nur auf der Grundlage des Gesetzes zuzulassen.

Wahl: Das heutige Thema ist sowohl von zeitloser Problematik wie auch zugleich ein Feld von raschen Entwicklungen angesichts der immens gesteigerten Herausforderungen im Bereich des Umweltrechts. Dabei haben sich die hier einschlägigen Änderungen im wesentlichen auf der Ebene des einfachen Rechts, im Rahmen der verfassungsrechtlichen Vorgaben, abgespielt. Was vor zwei bis drei Jahrzehnten noch als Verstoß gegen die Eigentumsgarantie verstanden worden wäre, wird inzwischen auf der Basis der geänderten Sachprobleme hingenommen und gilt als völlig selbstverständlich, wie etwa die dynamischen Anpassungspflichten im Immissionsschutzrecht oder die dort weit vorangetriebene Befugnis zu nachträglichen Anordnungen. Deshalb ist es, Herr Eblers, heute auch noch nicht ausgemacht, ob sich die Nutzung der Luftsäule nicht noch für lange Zeit von der Regelung der Gewässerbenutzung unterscheiden wird; die Antwort auf diese Frage ist nicht abhängig von der Struktur der Eigentumsgarantie als solcher, sondern vom Zusammenspiel zwischen den verfassungsrechtlichen Vorgaben und den Anforderungen, die sich aus der Sache ergeben. Der entscheidende Punkt, um den es mir geht, ist, daß die komplizierte, aber auch offene Struktur der Eigentumsgarantie es ermöglicht, daß gewichtige Problemlagen im Umweltbereich bewältigt werden können; dies ist in den Referaten heute auch dargestellt worden. Verantwortlich dafür ist insbesondere eine Besonderheit des Eigentumsgrundrechts, daß nämlich nicht nur die Schranken, sondern schon der Inhalt des Eigentums durch den Gesetzgeber ausgestaltet werden kann. Dies ist eine auffällige und vielleicht in mancher Hinsicht auch bestürzende Eigentümlichkeit des 
Eigentumsrechts, die, wie wir alle wissen, inzwischen zwar verfassungsrechtlich gebändigt und gehegt worden ist, aber die nicht völlig zum Verschwinden kommt. Am Ende aller verfassungsrechtlichen Operationen bleibt es bei Gestaltungsspielräumen des Gesetzgebers; dazu möchte ich noch einiges ausführen.

Die Befugnis zur inhaltlichen Ausgestaltung des Eigentums bezieht sich nicht nur darauf, was als Eigentum geschützt wird, sondern sie erfaßt auch alle anderen Regelungsprobleme und Institute. Illustrieren möchte ich dies an einem Beispiel, das von den Referenten immer wieder aufgegriffen worden ist, bei der Frage des Bestandsschutzes bzw. des Vertrauensschutzes. Dies ist nun ein Feld, an dem sich - anknüpfend an die gestrigen Überlegungen zeigen läßt, daß die konkreten Lösungen nicht nur und nicht in erster Linie Ableitungen aus dem allgemeinen Rechtsstaatsprinzip sind; darüber hinaus ist der Vertrauens- oder Bestandsschutz auch nicht in erster Linie als Institut des Allgemeinen Verwaltungsrechts generell ausgestaltet. Sondern es liegt gerade an der inhaltlichen Ausgestaltungsbefugnis des Gesetzgebers bei Art.14 GG, daß es insoweit Vielfalt im Besonderen Verwaltungsrecht gibt und geben darf. Insoweit war von Herrn Eblers zu Recht hervorgehoben, daß der Bestandsschutz im Baurecht anders und stärker geregelt ist als sonst im Umweltrecht, wobei es im übrigen auch im Baurecht, bei dem der Bestandsschutz aus guten Gründen sehr weit vorangetrieben ist, Grenzen gibt; wenn eine konkrete Gefahr für die Gesundheit von Bewohnern besteht, etwa wenn von einem Gebäude Gefahren wegen Asbest ausgehen, dann gibt es durchaus Durchbrechungen des Bestandsschutzes auch im Baurecht. Und wenn man den Blick weiter auf das Umwelt- und das Immissionsschutzrecht richtet, dann wird deutlich, welche Unterschiede der jeweilige Gesetzgeber im Rahmen der verfassungsrechtlichen Vorgaben wegen der Inhaltsbestimmungsbefugnis anordnen kann. So ist es auch bei anderen Problemen, etwa der Legalisierungswirkung einer Genehmigung; soweit es sie gibt, ist sie durchaus unterschiedlich in den einzelnen Gesetzen ausgebildet, und sie ist an den konkreten Vorschriften dieser Gesetze im einzelnen abzugreifen. Insgesamt und zusammenfassend zeigt sich, daß diese Inhaltsbestimmungsbefugnis des Gesetzgebers weithin die Grundlage für die Vielfalt im Besonderen Verwaltungsrecht und der Grund dafür ist, daß es diese Vielfalt geben kann und darf. Eben deshalb kann aber auch auf die Sachprobleme des Umweltschutzes reagiert werden, die in der Zukunft noch eine größere Dimension erreichen werden, etwa im Zusammenhang der globalen Klimaprobleme. 
Beim zweiten Teil meiner Überlegungen geht es nochmals um die Inhaltsausgestaltungsbefugnis und um ihre Grenzen. Die Frage ist, ob sie bei all den Grenzen, die wir inzwischen eingebaut haben, nicht doch zum Verschwinden kommt. Die hier einschlägigen rechtlichen Elemente sind bekannt; es geht um die Sozialbindung und den Sozialbezug einerseits, die Institutsgarantie andererseits sowie um die verhältnismäßige Zuordnung dieser beiden Elemente. Meine entscheidende Frage richtet sich jetzt auf die allgemein anerkannte und vom $B V e r f G$ auch so gezeichnete Aufgabe des Ausgleichs zwischen diesen beiden grundsätzlichen Anforderungen. Da stellt sich dann unsere Lieblingsfigur, das Verhältnismäßigkeitsprinzip ein. Dazu haben wir heute gehört, daß es nicht nur das Übermaßverbot, sondern auch ein Untermaßverbot gibt. Letzteres möchte ich durchaus unterstreichen. Damit wird Symmetrie hergestellt, hier zugunsten der Sozialbindung. Nur bleibt dabei die Frage, gerade auch im Hinblick auf die Besonderheiten der einzelnen Rechtsgebiete und auf die Reaktionsfähigkeit des Rechts auf Probleme, ob dann noch etwas übrigbleibt als Gestaltungsspielraum des Gesetzgebers; oder kommt man dann nicht, sozusagen in einer Doppelzange mit dem Übermaßverbot und dem Untermaßverbot, letztlich dahin, daß es nur eine einzig-richtige Entscheidung geben kann. Dann bliebe vom ursprünglichen Ansatz nichts übrig, daß das Eigentum zu einem gewissen Maße der Gestaltungsbefugnis des konkreten Gesetzgebers anheimgegeben ist, der einmal eigentumsfreundlicher als ein anderer Gesetzgeber sein kann, der aber andererseits auch einmal die Sozialbindung höher bewerten kann als ein konkurrierender Gesetzgeber. Fragt man also abschließend, ob für eine Gestaltungsbefugnis des Gesetzgebers noch etwas übrigbleibt, so muß nach meiner Meinung bei der allgemeinen Figur des Verhältnismäßigkeitsprinzips unterschieden werden; der verhältnismäßige Ausgleich, um den es hier geht, ist nicht ohne weiteres zu vergleichen mit der klassischen Verhältnismäßigkeit eines konkreten Eingriffes im Hinblick auf einen konkreten Zweck. Bei der Verwirklichung des in Art.14 GG enthaltenen Sozialmodells muß der Gesetzgeber zwei gegenläufige normative Prinzipien, nämlich die Sozialbindung einerseits, die Institutsgarantie andererseits, einander angemessen zuordnen. Was hier Verhältnismäßigkeit bedeutet, bedarf meiner Meinung nach noch der weiteren Diskussion. Mir scheint, daß VerhältnismäBigkeit im Sinne der Angemessenheit der Zuordnung zweier Prinzipien eher eine Gestaltungsaufgabe ist und mehr Spielraum enthält, als es sonst bei der Bestimmung des verhältnismäßigen Eingriffs der Fall ist. Nur in dieser Interpretation - und damit komme ich zum Schluß 
- bleibt für den Gesetzgeber im Ergebnis wirklich etwas übrig zu bestimmen und zu gestalten.

Schmidt-Aßmann: Das anspruchsvolle Thema ist durch seine doppelschichtige Struktur bestimmt: Zum einen geht es um einen Rechtsvergleich zur Dogmatik der Eigentumsgarantie allgemein; zum anderen - und das ist die konkrete Schicht - um die Leistungsfähigkeit dieser Garantie auf einem der wichtigsten Politikfelder, der Nutzung von Boden und Umwelt. Wir müssen uns vor allem auf die Schnittstelle dieser beiden Ebenen konzentrieren, um die allgemeindogmatischen Erkenntnisse durch die Erfahrungen in einem Sektor des Besonderen Verwaltungsrechts zu erhärten, und auf der anderen Seite die Lösungen der je besonderen Fachprobleme von der im Rechtsvergleich wirksamen Idee allgemeiner Prinzipien her zu erhellen. Hier scheint mir eine in allen drei Referaten deutlich gewordene und damit allen drei Rechtsordnungen erkennbare gemeinsame Erfahrung über die Steuerungswirkungen der Eigentumsgarantie im Bereiche der Boden- und Umweltpolitik wichtig, die etwa folgendermaßen formuliert werden kann: Der Breite des Anwendungsbereichs dieser Garantie auf dem bezeichneten Felde korrespondiert ein Nachlassen der Steuerungsintensität. Zunächst zur Breite, mit der die Eigentumsgarantie in das Umweltrecht hineinwirkt. Insofern das Umweltrecht $\mathrm{zu}$ wesentlichen Teilen ein raumbezogenes Recht ist, ist Art.14 GG eine allgegenwärtige Größe. Dabei dürfen die Interessen des Eigentumsschutzes und des Umweltschutzes nicht nur in einem Spannungsverhältnis gesehen werden; vielmehr besteht zwischen beiden auch ein komplementäres Verhältnis. Erinnert sei nur an den eigentumsrechtlich begründeten Nachbarschutz und an die hinter ihm stehenden grundrechtlichen Schutzpflichten. Auf einer bestimmten Bandbreite werden Eigentumsinteressen folglich auch als Umweltschutzinteressen wirksam und umgekehrt. Auch diese Seite des Verhältnisses von Eigentumsschutz und Umweltschutz muß im Blick bleiben, und sie ist ein Beleg für die Breite des Wirkungsbereichs der Eigentumsgarantie. Der Ausweitung entspricht jedoch eine nachlassende Tiefe der Steuerungswirkungen. Das zeigt sich schon auf der Ebene der Gesetzgebung. Zutreffend haben die Referenten hervorgehoben, daß globale eigentumsrechtliche Zuweisungsformeln wenig Ertrag bringen. Das belegen die sog. Enteignungstheorien ebenso wie die traditionelle Baufreiheit, die Herr Eblers richtigerweise durch ein Differenzierungsmodell ersetzt wissen will. Ein Nachlassen der Steuerungswirkungen der Eigentumsgarantie zeigt sich aber auch in verwal- 
tungsrechtlichen Zusammenhängen. Die Garantie hat ihre höchste Dichte dort, wo es um überschaubare Gefahrensituationen und klare, singuläre Abwehrpositionen geht. Die über das Baurecht hinausreichenden Anforderungen des Immissionsschutzrechts bewirken jedoch, daß der Zuweisungsgehalt der überkommenen eigentumsrechtlichen Dogmen nachläßt. Das spiegelt sich etwa in der Entwicklung der Maßstäbe vom baurechtlichen zum immissionsschutzrechtlichen Bestandsschutz wider, wie sie in These 16 von Herrn Ehlers nachgezeichnet worden ist. Noch deutlicher wird das dort, wo die eine moderne Umweltpolitik prägenden Prinzipien der Vorsorge und der Pflege ins Spiel kommen. Die Vorsorgepflicht knüpft nicht mehr an den Nachweis eines Individualbeitrages zur Umweltbeeinträchtigung. Der Pflegeauftrag greift noch darüber hinaus und orientiert sich an Verhaltensweisen von Nutzergruppen. Man denke nur an die Neubestimmung der Rolle der Landwirtschaft im Naturschutzrecht. - Zu welchen Folgeüberlegungen muß die Beobachtung nachlassender Steuerungswirkungen des Art. 14 GG veranlassen? Falsch wäre es, einen Abgesang auf die Eigentumsgarantie im komplexen Interessengefüge des Umweltschutzes anzustimmen. Die Institutsgarantie muß vielmehr aus ihrer defensiven Rolle herausgeführt und neu zu strukturieren versucht werden. Vor allem im Bereich gesetzlicher Eigentumsinhaltsbestimmung nach Art.14 Abs.1 S.2 GG müssen neue Instrumente der Interessenabwägung und des gebietsspezifischen Interessenausgleichs als eine "Zwischenschicht" breiter entfaltet werden. Bauelemente hierzu gibt es durchaus. $\mathrm{Zu}$ erinnern ist an die rechtsstaatliche Disziplinierung, die die eigentumsgestaltende Bauleitplanung durch die Abwägungsdogmatik der Rechtsprechung erfahren hat. Der Einbindung des Individualrechts in größere Gestaltungszusammenhänge wird hier zutreffend Rechnung getragen. Zu denken ist auch an die privatrechtlichen Ausgleichsinstrumente des Flurbereinigungsrechts. Wenn in den Referaten neben der Enteignungsentschädigung nach Art. 14 Abs. 3 GG ein Geldausgleich nach Art. 14 Abs. 1 S. 2 GG mit Übergängen zum reinen Billigkeitsausgleich und zum Abfangen eigentumsverkürzender Wirkungen durch eine Förderungspolitik genannt worden ist, so sehe ich hierin ebenfalls einen Ansatz, um die überkommene punktuelle Steuerungsintensität durch neue Formen eines den Strukturen des Umweltschutzes adäquaten Eigentumsschutzes zu ersetzen.

Häberle: Herr Vorsitzender, verehrte Kollegen! Die Vorredner haben die drei vortrefflichen Referate mit Recht als solche gewürdigt. Ich frage nur, ob die europarechtliche Dimension, etwa die EMRK- 
Rechtsprechung, die EuGH-Judikatur sowie die wachsende Dynamik des Umweltschutzrechts der Europäischen Gemeinschaft und bald auch des Europäischen Wirtschaftsraums genügend behandelt wurden - der schweizer und der österreichische Kollege bzw. ihre Länder wollen ja demnächst der einen oder anderen Gemeinschaft beitreten. Mein Gespräch mit den Referenten suche ich anhand der Leitsätze unter folgenden zwei Gesichtspunkten. Zunächst: Stehen wir jetzt dank der Herausforderung durch die Umweltschutzrechtsfragen nicht erneut vor der Aufgabe, einen auf der Verfassungsebene von vornherein differenzierten Eigentumsbegriff anzusiedeln? Die heute quantitativ zunehmende qualitativ konstitutionelle Verankerung von Umweltschutzthemen zwingt uns zu der Frage, ob und wie der Verfassungsschutz des Eigentums Privater bereits in Verfassungshöhe differenziert ist. Ich erwähne die These 9 von Herrn Hänni von der „abgeschwächten Bedeutung", die dem recht nahe kommt. An einer anderen Stelle spricht er von dem „elastischen " Eigentumsverständnis des Schweizer Bundesgerichts, und in These 15 sind die auf Schweizer Verfassungsebene gleichwertigen Interessen des Umweltschutzes und des Eigentums erwähnt. Ich verweise zustimmend auf Herrn Eblers' These 15 Satz 2, wonach Art. 14 Abs. 2 GG den Gesetzgeber zu einem wirksamen Umweltschutz verpflichtet. Damit stellt sich doch die Umweltschutzpflichtigkeit des Eigentums als Unterfall bzw. wichtiger Beispielsfall der klassischen Sozialpflichtigkeit des verfassungsrechtlichen Eigentumsbegriffs dar. Herr Rill hat in These 19 an das konstitutionelle Bekenntnis zum Umweltschutz in Österreich erinnert. - Zur These von der Differenzierung des verfassungsrechtlichen Eigentumsschutzes erwähne ich hier in Gießen besonders gerne, daß einer der wenigen, die ganz früh für das GG sagten, man müsse das Eigentum auf Verfassungsebene von vornherein differenzieren, und zwar nach stärkeren und schwächeren Eigentumsarten, ich meine kleines und großes Eigentum, Wirtschafts-, Bodeneigentum, Urheberrechtseigentum, kein geringerer als Ludwig Raiser war. Jener Ludwig Raiser, der wohl im 10. Band 1951 Gast unserer Vereinigung war, was sich leider nie wiederholt hat; derselbe Raiser, dessen Neffe uns gestern vormittag als Dekan namens der Gießener Juristenfakultät in unverkennbarer Familienähnlichkeit in der Stimme begrüßt hat. Auch die Herren Badura und Ossenbübl schienen mir in ihren Voten von soeben ganz dicht vor dieser Differenzierungsidee zu stehen, das ist jedenfalls meine Interpretation ihrer Abstufungskriterien. Ich berufe mich auf den "frühen" Badura, der dieser Abstufungsthese sehr nahe stand, der "mittlere" Badura folgte eher der herrschenden Meinung, während der heutige Badura der Differenzierungsthese 
zuneigt - er möge mich gleich anschließend korrigieren. Wir haben im Verfassungsstaat von heute viele unterschiedliche Eigentumsarten. Denken Sie an die Schweiz, die mit dem knappen Waldeigentum relativ rigoros umgeht - Herr Hänni hat dies sehr schön herausgearbeitet. Bei uns kennen wir das Urheberrechtseigentum mit der immanenten Schutz- bzw. Sperrfrist von 70 Jahren, was für die These vom einheitlich geschützten Eigentum eigentlich eine Provokation ist: ein von vornherein konstitutionell nur beschränkt geschütztes ideelles Eigentum! - Jetzt zur zweiten Frage, zu den Umweltschutzpflichtigkeiten, die wir in den verschiedensten Äußerungsformen schon in unserem deutschen Verfassungsrecht haben und die uns erst recht zwingen, das Eigentum Privater bereits auf der konstitutionellen Ebene differenziert zu sehen - analog dem ebenfalls schon differenzierten verfassungsrechtlichen Begriff "Kunst“. Herr Badura hat am Schluß seines Votums die schöne Formulierung geprägt, der Umweltschutz sei unabhängig vom Fehlen einer Umweltschutzklausel im GG längst ein Element des Eigentumsschutzes. Wir wissen alle, daß die Denninger/Oppermann/Badura-und-andere-Staatszielekommission von 1983 einen sehr geglückten Vorschlag zum Umweltschutz als Staatsziel unterbreitet hat, der leider formell bis heute noch nicht umgesetzt wurde, anders die Schweiz. Doch lassen sich auf andere Weise Elemente und Schichten herausarbeiten mit dem Ergebnis, daß auf der Verfassungsebene des GG in Verbindung mit Landesverfassungen heute der Umweltschutz bereits "ungeschriebenes" Verfassungsgut ist. Man kann ihn nicht nur im Kontext von Art. 2 Abs. 2 und Art. 1 GG ansiedeln. Hinzu kommen die Landesverfassungen. Sie stehen ja in einem Verhältnis des Gebens und Nehmens auch zum Grundgesetz und sind ihm nicht hierarchisch einfach untergeordnet. Und sie besitzen höchst eindrucksvolle Umweltschutzklauseln. Natürlich muß ich aus Westdeutschland zuerst die Bayerische Verfassung zitieren, nicht nur ihren Art. 3 Abs. 2, vor allem ihr Erziehungsziel (Art. 131). Welche Klugheit und Konsequenz, den Umweltschutz als Erziehungsziel zu normieren und damit als "Soft-Law" zu integrieren! Erlauben Sie noch einen Blick auf die Prozesse des Werdens der neuen ostdeutschen Landesverfassungen von 1990/91: in dem ersten vorzüglichen Entwurf Brandenburgs, in dem Verfassungsentwurf Mecklenburg-Vorpommerns, in einer Reihe anderer Entwürfe wie in Sachsen, findet sich der Umweltschutz vielfältig als großes Staatsziel, übrigens auch in der nur kurze Zeit geltenden Verfassung Berlin-Ost von 1948/1990. Längst wachsen also Umweltschutzelemente auf konstitutioneller Ebene heran, es entsteht gemeindeutsches Verfassungsrecht der Länder und des Bundes, und dieses müssen wir 
in die komplexen Abwägungsprozesse mit dem differenziert-gestaffelten Schutz des Eigentums Privater einbringen. Es kommt so zu einer Art „Vorwirkung“ von Verfassungsentwürfen der deutschen Länder im Osten mit einer Ausstrahlung auf das GG, dies im Verbund mit Verfassungen in Westdeutschland, die den Umweltschutz bereits textlich integriert haben.

Vorsitzender: Schönen Dank, Herr Häberle. Herr Badura, ich gehe davon aus, daß Sie von Ihrem Recht, auf die Badura-Phasen als Betroffener einzugehen, keinen Gebrauch machen wollen, im Augenblick jedenfalls. (B. nickt.)

Stolzlechner: Ich möchte auf zwei Punkte insbesondere des Rillschen Referates eingehen, nämlich 1. zur grundsätzlichen Frage, ob und inwieweit öffentlich-rechtliche Ansprüche der Eigentumsgarantie unterliegen können, das sind insbesondere die Thesen 1, 6, 8, 9 und 10, und dann zum 2. Punkt die Frage der Enteignung zugunsten Privater, These 32.

1.Punkt: Unterliegen auch öffentlich-rechtliche Ansprüche der Eigentumsgarantie? Ich bin mir aufgrund des Referats nicht ganz im klaren darüber, welcher Ansicht der Referent eigentlich anhängt. Bei den Thesen werden öffentlich-rechtliche Ansprüche teils als der Eigentumsgarantie unterliegend qualifiziert, teils folgen sie der alten Anschauung. These 1, die bundesverfassungsrechtliche Garantie umfaßt alle vermögenswerten Privatrechte. These 6, Recht auf eingerichteten und ausgeübten Gewerbebetrieb kein vermögenswertes Privatrecht. These 8, offentlich-rechtliche Ansprüche als solche sind nicht Schutzobjekte der Eigentumsgarantie. Das ist der einheitliche Block, wo das verneint wird. Dann bei der These 9, da kommt jetzt, scheint mir, irgendwie ein gewisser Bruch herein. Die sog. öffentlichrechtlichen Nachbaransprüche werden jetzt als subjektive Privatrechte qualifiziert, obwohl sie im Öffentlichen Recht verankert sind; ähnliches gilt für These 10: Anlagenrechtliche Verfügungen der Gewerbebehörde greifen ins Eigentum ein. Ich stelle mir darunter etwa vor, Vorschreibungen nach $\$ 79$ der Gewerbeordnung, nachträgliche Vorschreibungen, zusätzliche Auflagen, das sind solche anlagenrechtlichen Verfügungen, die in der Gewerbeordnung, damit in einer öffentlichen Norm ihre Grundlage haben. Sie werden hier als Eingriff ins Eigentum qualifiziert. Ich meine, unabhängig davon, wie der Standpunkt jetzt auch ist, ich halte es für hoch an der Zeit, daß die Eigentumsgarantie auch auf öffentliche Ansprüche ausgedehnt wird. Die Frage für die österreichische Rechtsordnung ist nur die, wie legt 
man sie an. Wo ist der grundrechtsdogmatische Ansatzpunkt zu finden für eine solche Weiterentwicklung des grundrechtlichen Eigentumsschutzes? Angesichts der starren, historisch versteinernden Interpretationsmethode unseres Verfassungsgerichtshofes meine ich, daß der Eigentumsbegriff des Art. 5 des alten Staatsgrundgesetzes von 1867 sich dafür nicht eignet, sondern man sollte auf die modernere Eigentumsgarantie des Art. 1 des 1. Zusatzprotokolls der Menschenrechtskonvention, Herr Häberle hat das hier gerade angesprochen, zurückgreifen. Diese Norm ist in Kraft getreten zu einem Zeitpunkt, wo die These, daß sich die Eigentumsgarantie nur auf vermögenswerte Privatrechte konzentrieren sollte, nicht mehr so ein festgefügtes Gut war, sondern wo durchaus schon die Ansicht vertreten wurde, daß die Eigentumsgarantie auch öffentlich-rechtliche Ansprüche umfassen konnte, und es besteht daher von diesem Gesichtspunkt, meiner Meinung nach, nicht mehr die Notwendigkeit zu dieser einengenden Interpretation. Das ist der erste sozusagen innerstaatliche Interpretationsgesichtspunkt, der zweite ist, daß die Straßburger Instanzen, die natürlich auch zur Auslegung des Zusatzprotokolls befugt sind, sich auf eine derart versteinernde historische Interpretationsmethode erst gar nicht einlassen, wie das unser Verfassungsgerichtshof macht. Sondern die interpretieren ja das Grundrecht von der Schutzfunktion her (teleologisch), und von daher ist es im Grunde genommen kein Problem, die Möglichkeit anzuerkennen, daß subjektive öffentliche Rechte der Eigentumsgarantie unterliegen.

Die Hauptfrage ist daher für mich bereits die Frage der Abgrenzung, denn es kann nicht so sein, daß alle subjektiven öffentlichen Rechte der Eigentumsgarantie unterliegen, sondern die Hauptfrage ist die Abgrenzungsfrage. Wie sind jene öffentlich-rechtlichen Ansprüche, die der Eigentumsgarantie unterliegen, von jenen abzugrenzen, die ihr nicht unterliegen? Welche Kriterien bieten sich an? Einen normativen Ansatzpunkt sehe ich weder im Art. 5 Staatsgrundgesetz noch im Art. 1 des ersten Zusatzprotokolls. Daher meine ich, wäre es sinnvoll, daß man einen ähnlichen Gedanken hier heranzieht wie bei der Auslegung des Begriffes der civil rights im Art. 6 der Menschenrechtskonvention. Dort wurde gesagt, auch öffentlich-rechtliche Ansprüche unterliegen dem Begriff der civil rights, und zwar, wenn sie bei Ausübung der Zivilrechte von entscheidender Bedeutung sind. Auf diese Weise wurde etwa die grundverkehrsbehördliche Genehmigung einer Grundstückstransaktion, ein öffentlich-rechtlicher Anspruch, unter den Zivilrechtsbegriff des Art. 6 EMRK subsumiert. In Orientierung an diesen Gedanken würde ich daher sagen, da kann man weiterdenken; das wäre eine erste Orientierung. Öffentlich- 
rechtliche Ansprüche sind dann von der Eigentumsgarantie erfaßt, wenn sie für die Ausübung des privaten Eigentumsrechts von zeesentlicher Bedeutung sind. Danach würde etwa, um ein Beispiel zu nennen, der Entzug einer wasserrechtlichen Bewilligung für den Betrieb einer gewerblichen Mülldeponie auch einen grundrechtlich zu beurteilenden Eingriff in die Eigentumsgarantie bedeuten, weil mit dem Entzug der Bewilligung die verwaltungsrechtliche Erlaubnis zur Benutzung als gewerbliche Fläche entzogen ist, damit auch in die eigentumsrechtliche Benutzungsfreiheit in gravierender Weise eingegriffen wird.

Zur zweiten Frage - Enteignung zugunsten Privater: Das ist eine Frage, die auch in zunehmendem Maße Bedeutung im Zusammenhang mit dem Fremdenverkehr etwa bei der Anlegung von Langlaufloipen, Golfplätzen, Skiabfahrten eine große Rolle spielt. Professor Rill hält es für zulässig, wenn entweder die Enteignung der Sache im Rahmen eines gemeinnützigen Unternehmens genützt wird, eingesetzt wird, oder die privatnützige Gebrauchnahme im öffentlichen Interesse liegt. Ich halte das für einen guten und sinnvollen Grundsatz, allerdings mit einer Einschränkung, nämlich der, daß diese Kriterien nicht alternativ genommen werden, sondern daß es sich um kumulative Voraussetzungen handelt, denn es kann nicht so sein, daß der Antrag des gemeinnützigen Golfvereins auf Enteignung von Grundstücken allein genügt, um das öffentliche Interesse nachzuweisen, sondern da müssen natürlich auch das öffentliche Interesse und die Verhältnismäßigkeit des Eingriffs zusätzlich geprüft werden.

Roellecke: Ich möchte zum Eigentumsbegriff sprechen und knüpfe an die These 3 von Herrn Eblers an. Herr Eblers schreibt dort, unter Eigentum sei das Recht zu verstehen, einen dem Bürger von der Rechtsordnung zugeordneten Vermögensgegenstand innezuhaben und zu nutzen. Mir fehlt ein wichtiger Gesichtspunkt. Ich bin aber nicht sicher, ob Herr Eblers ihn nicht mit gemeint hat. Mir fehlt der Gesichtspunkt der Verfügungsbefugnis. Diesen Gesichtspunkt hat das Bundesverfassungsgericht in seiner Eigenbedarfsentscheidung in das Zentrum seiner Begründung gestellt, und er scheint mir, gerade für den Umweltschutz, besonders wichtig zu sein. Man denke an das Problem des Bauerwartungslandes. Ich meine, die Verfügungsbefugnis gehört zur positiven Rechtsordnung. Der Gesetzgeber hat das dadurch gezeigt, daß er den Eigentumsübergang geregelt hat. Aber noch wichtiger ist, daß die Verfügungsbefugnis für eine Marktwirtschaft konstituierend ist. Wenn man sagt, das Eigentum habe etwas mit Markt zu tun, dann muß man den Eigentumsbegriff auch so 
definieren, daß er den Markt ermöglicht. Das geht nur dadurch, daß man in den Eigentumsbegriff die Verfügungsbefugnis aufnimmt. Die Güter, die auf dem Markt gehandelt werden, müssen universal austauschbar sein. Das verlangt außerdem einen einheitlichen Eigentumsbegriff. Die universale Austauschbarkeit schließt eine Differenzierung des Eigentumsbegriffes nach großem und kleinem Eigentum und ähnlichen Unterscheidungen aus. Die allgemeine und gleiche Verfügungsfähigkeit über Güter ist übrigens das entscheidende Kriterium für die Unterscheidung zwischen Marktwirtschaft und sozialer Planwirtschaft. Die sozialistische Planwirtschaft hat zwischen Eigentum an Produktionsmitteln und persönlichem Eigentum unterschieden und an diese Unterscheidung die Planwirtschaft gehängt. Eine Marktwirtschaft, die von der allgemeinen Mobilität der Güter ausgeht, läßt diese Unterscheidung nicht zu.

Lange: Ich möchte ebenfalls anknüpfen an die Äußerung von Herrn Rill, daß die Gewährleistung einer grundsätzlich marktwirtschaftlichen Ordnung Telos der Eigentumsgewährleistung sei. Herr Ossenbübl hat sich ja eher noch dezidierter für das deutsche Recht in dieser Richtung geäußert. Ich möchte demgegenüber zu bedenken geben, daß die Eigentumsgewährleistung sicherlich nur ein Segment der marktwirtschaftlichen Ordnung absichern kann. Zu einer marktwirtschaftlichen Ordnung gehört natürlich auch ein funktionsfähiger Wettbewerb. Es ist nicht sehr plausibel, eine verfassungsrechtliche Gewährleistung der marktwirtschaftlichen Ordnung aus der verfassungsrechtlichen Verankerung nur eines Teils ihrer Elemente abzuleiten. Zu ihrer Begründung müßte man einen funktionsfähigen Wettbewerb entweder in anderen Bestimmungen der Verfassung gewährleistet sehen, oder man müßte auch dessen Garantie der Eigentumsgewährleistung entnehmen, was mir sehr wenig überzeugend schiene und darauf hinausliefe, die Eigentumsgewährleistung zu einem Funktionsgrundrecht $\mathrm{zu}$ machen, wogegen sich Herr Badura gerade ausgesprochen hat. Ich halte es für wesentlich sinnvoller, mit dem Bundesverfassungsgericht und in der Richtung, in der sich Herr Berg gestern auch geäußert hat, hinzuweisen auf den Charakter der Eigentumsgewährleistung als materielle Fundierung von Freiheitsrechten. Und meine Frage an Herrn Rill wäre die, ob dieser Gedanke nicht doch auch im österreichischen Recht Ausdruck gefunden hat. Mir scheint die verfassungsrechtliche Anerkennung als Eigentum im Falle von Beitragsleistungen zur Sozialversicherung oder auch im Falle von ausgenutzten hoheitlichen Nutzungsbefugnissen sehr viel eher unter dem Gesichtspunkt der Gewährleistung von Freiheitsrechten als unter 
dem der Sicherung einer marktwirtschaftlichen Ordnung verständlich zu sein.

Mein zweiter Punkt betrifft die Konzeption von Herrn Ehlers, der, wie ich finde, sehr überzeugend den Primat des Gesetzgebers bei der Ausgestaltung dessen, was Eigentum ist, betont hat. Nach meinem Eindruck hat er allerdings nicht nur das Recht und den Vorrang des Gesetzgebers zum Ausdruck gebracht, zu bestimmen, was Eigentum ist, sondern auch die Pflicht des Gesetzgebers, dieses zu tun. Das ist in den Thesen 15 und 19 geschehen. Beides wirft, denke ich, Probleme auf: Im Falle der These 19, wo Sie, Herr Eblers, eine formellgesetzliche Regelung ausgleichspflichtiger Inhalts- und Schrankenbestimmungen gefordert haben, stellt sich mir die Frage, wie das Verhältnis einer solchen Konzeption zu der entschädigungspflichtigen Enteignung ist - ob das dann nicht doch schon der entschädigungspflichtigen Enteignung sehr ähnlich wird, nur im Grunde genommen hinauslaufend auf eine nicht volle, sondern partielle Entschädigungsleistung. Mir scheinen die Konturen da etwas ins Verschwimmen zu geraten. Das schwierigere Problem betrifft für mich die Frage, wie weit der Gesetzgeber eine solche Ausgestaltung des Eigentumsrechts überhaupt zu leisten vermag und inwieweit Verwaltung und Rechtsprechung doch darauf angewiesen sind, auf Konzeptionen wie die Situationsgebundenheit des Eigentums zurückzugreifen. Soweit Verwaltung und Rechtsprechung Eigentum und Eigentumsbindungen im Einzelfall konkretisieren müssen, weil der Gesetzgeber dieses nicht in einer hinreichend präzisen Form tun kann, wird Art. 14 Abs. 2 GG Sozialbindung des Eigentums - allerdings nicht nur für die Gesetzgebung gelten können, sondern auch die beiden anderen Gewalten unmittelbar binden müssen.

Dritter und letzter Punkt: Herr Eblers, Sie haben bei der Baufreiheit darauf hingewiesen, daß rechtmäßige Baugenehmigungen an dem eigentumsrechtlichen Schutz teilnehmen. Hier stellt sich natürlich gleich die Frage, wie es mit rechtswidrigen Baugenehmigungen steht. Es ist ja wohl zweifelsfrei, daß auch insofern ein Vertrauensschutz bestehen muß. Woraus entnehmen Sie diesen Vertrauensschutz? Leiten Sie ihn aus dem Rechtsstaatsprinzip ab, so würde das eigentlich der gestern, insbesondere in der Diskussion geäußerten These, daß man eher auf speziellere Verfassungsgewährleistungen wie die Eigentumsgarantie abstellen solle, zuwiderlaufen. Mir selbst wäre es gleichwohl plausibel, den Vertrauensschutz bei rechtswidrigen, aber wirksamen Baugenehmigungen im Rechtsstaatsprinzip zu verorten, weil ein solcher Vertrauensschutz nicht nur vermögenswerte, sondern auch nicht vermögenswerte staatliche Erlaubnisse betreffen muß. 
Fleiner-Gerster: Ich möchte ganz kurz zu drei Punkten sprechen. Zunächst zur Eigentumsgarantie als solcher. Ein australischer Richter hat mir einmal erklärt, er hätte größte Schwierigkeiten mit der ganzen Eigentumsfrage im Zusammenhang mit den Aborigines, denn die hätten die Vorstellung, sie gehörten dem Boden und nicht der Boden gehörte ihnen. Dies bringt mich zur Überlegung, ob die Eigentumsfrage und das Eigentumsrecht nicht in erster Linie auch unter der Beziehung zur Sache zu verstehen ist, und ob wir nicht, wenn wir vor allem auch schweizerisches Recht betrachten, und da hätte ich eine Frage an Herrn Hänni, anstelle von der Sozialbindung eigentlich von der Verantwortung des Eigentümers sprechen müßten. Die Verantwortung ist eben anders geartet, ob ich ein Tier habe, ob ich landwirtschaftlichen Boden nutze, ob ich Waldboden pflege oder ob ich Eigentümer von Bauland mitten in einer Stadt bin, in der es dringend neue Wohnungen braucht. Je nachdem ist die Verantwortung des Eigentümers eine andere.

Die zweite Frage betrifft die Schranken. In allen drei Referaten ist eine Frage offengeblieben, und da hätte ich eine Frage an alle drei Referenten. Müßte nicht auch angesichts der rasanten Entwicklung, in der wir uns heute befinden, auch die Zeit als Schranke oder eben auch unzulässige Schranke eingebaut werden? Wenn wir bedenken, daß infolge unzähliger Genehmigungen und Bewilligungen von größeren Unternehmungsprojekten manchmal viele Jahre vergehen, bis sie überhaupt verwirklicht werden können, so daß Zeit, aber nicht nur Zeit, sondern auch Geld verlorengeht für Investitionen, die letztlich auch zugunsten des Umweltschutzes gemacht werden könnten, stellt sich doch die Frage, ob wir nicht angesichts der Eigentumsgarantie Verfahrensabläufe zur Verfügung stellen müßten, die es uns ermöglichen, verantwortlich, aber in relativ kurzer Zeit entsprechende Projekte auf die Beine zu stellen, und ob es im Zusammenhang mit der Eigentumsgarantie nicht sinnlos ist, wenn die Eigentumsgarantie durch unsinnige Verfahrensabläufe praktisch ausgehöhlt wird.

Und die dritte Bemerkung betrifft nun gerade das Verfahren. Herr Hänni hat darauf hingewiesen. Ich glaube, die Tatsache, daß wir in der Schweiz beispielsweise das Vermögen über die Eigentumsgarantie nicht so weit schützen, wie etwa in der Bundesrepublik Deutschland im Zusammenhang mit dem Steuerrecht, ist doch wohl auf die direkte Demokratie zurückzuführen. Wenn der Bürger mitspricht bei den Steuern, wenn er mitspricht bei den Ausgaben, z. B. Bau von Straßen, Schulen usw., wenn er aber vor allem mitspricht, Herr Hänni hat darauf hingewiesen, bei der Zonenplanung als Eigentümer, Interessierter oder als Mieter, dann kann er direkt in die gerechte Entschei- 
dung des Gesetzgebers miteinwirken und deshalb mehr zu dem Eigentumsschutz tun, als es letztlich das Gericht tun könnte.

Zacher: Ich stehe sehr in den Fußstapfen von Herrn SchmidtAßmann. Ich bitte trotzdem um Nachsicht, wenn ich meine Version der rechtsvergleichenden Aspekte hier aus meiner Sicht noch einmal unterbreite. Ich habe mich sehr gefragt, wie sieht denn eigentlich die rechtsvergleichende Problematik des Themas von heute aus? Wo liegt denn das vorrechtliche Problem? Denn Rechtsvergleichung setzt ja immer voraus, daß man ein gemeinsames vorrechtliches Problem identifiziert. Und ich meine, das vorrechtliche Problem ist hier ein doppeltes. Es liegt zunächst in der spezifischen Ordnungsproblematik: in der Sache Grund und Boden, in ihrem Gemeinschaftsbezug und in der Antwort, welche die Rechtsordnung, das einfache Recht, auf diese Herausforderung gibt. Dann haben wir aber auch noch die Dialektik dieser potentiellen Antworten des einfachen Rechts mit der Verfassungsordnung. Und ich meine, wir sollten uns mit den Referenten genau Mühe geben, diese doppelte vorrechtliche Problematik so gut als möglich herauszuarbeiten.

Erlauben Sie mir, einige Bemerkungen über das Ordnungsproblem Grund und Boden zu sagen. Warum ist dies ein Eigentum besonderer Art? Ich meine, zunächst ist da die vertikale Dimension in Betracht zu ziehen: $\mathrm{da} ß$ es Grundwasser darunter, Bodenschätze darunter und Luft darüber gibt. Dann sind dem Grund und Boden ganz besondere Nutzungen vorbehalten. Sie kamen zur Sprache: das Bauen - nicht nur privates, sondern auch genuin öffentliches Bauen, wie der Bau von Straßen - oder die Landwirtschaft, der Wald, die Moore; das sind ganz spezifische Nutzungsweisen. Und wo immer Eigentum hier stattfindet, müssen wir in einem Mindestmaß eine Treuhänderschaft für diese Nutzungsmöglichkeit ins Auge fassen. Dazu kommt jedoch ein Aspekt, der heute, wenn ich nichts überhört habe, bisher zu kurz gekommen ist, nämlich die Knappheit des Gutes Grund und Boden. Grund und Boden ist das nicht vermehrbare Gut schlechthin. Das heißt, daß Eigentum an Grund und Boden genuin einen Privilegiencharakter hat. Daß Eigentum an Grund und Boden genuin etwas Ungleiches ist. Und dann kommt etwas, was Herr Eblers und jeder der Referenten irgendwie angesprochen hat: die Situationsgebundenheit. Ich möchte aber vor allem den Akzent setzen, daß Grund und Boden in einem vorgegebenen natürlichen, wesentlichen und unvermeidlichen Zusammenhang steht. Kein Grundstück kann in einer Weise aus der Gesamtheit der Erdoberfläche herausgenommen werden, so wie Gold oder Bücher isoliert werden können. Grund und 
Boden steht in einem festen Zusammenhang. Diese „Unbarmherzigkeit" dieses Zusammenhangs, glaube ich, müssen wir in der Ordnungsproblematik noch sehr viel schärfer artikulieren. Und ich möchte hier ein Stichwort hinzufügen, das uns immer mehr beschäftigt in unserer Rechtsordnung und in unserer Politik. Das ist, was ich einmal die Dialektik zwischen Eingrenzung und Entgrenzung nennen möchte. Wir haben in Grund und Boden etwas Abgrenzbares, zugleich aber etwas genuin Entgrenztes. Vom Grund und Boden gehen die wichtigsten Ausstrahlungen im Sinne von Luftverseuchung, von Schall usw. aus. Das geht ja alles irgendwie von Grund und Boden aus. Je nachhaltiger es ist, desto mehr geht es von Grund und Boden aus. Und umgekehrt ist Grund und Boden der Einstrahlung ausgesetzt aus nah und fern. Und hier, glaube ich, in dieser Dialektik zwischen Eingrenzung und Entgrenzung steckt eine zentrale Ordnungsproblematik, deren Gewicht immer intensiver zunimmt.

Und hier sehe ich nun, um es auf den Punkt zu bringen, beim Eigentum von Grund und Boden eine Doppelnatur. Es ist individuelles Eigentum. Das wollen wir festhalten. Aber Grund und Boden ist genuin, apriorisch auch ein Gemeinschaftsgut. Diese Verschränkung, daß es individuell sein soll, und daß es zugleich ein Gemeinschaftsgut ist, das ist, glaube ich, der Nenner unserer Ordnungsproblematik. Darauf beruht die Besonderheit der Antworten, die heute beschrieben wurden, die der einfache Gesetzgeber geben kann. Darin liegt auch der große Konvergenzstrom.

Und nun war das Spannende, das heute hinzukam, daß wir einen großen Konvergenzstrom auch in der verfassungsrechtlichen Vorordnung haben - einen großen Konvergenzstrom, der sich aus der Natur unserer Verfassungsstaatlichkeit ergibt. Und hier liegt auch das Problem, das Herr Schmidt-Aßmann als die Steuerungsschwäche bezeichnet hat. Aber dazu möchte ich doch noch einige Bemerkungen machen. Das Verfassungsrecht gibt seine spezifischen Antworten sehr unterschiedlich. Das, glaube ich, ist in der Rechtsvergleichung heute gut herausgekommen. In der Bundesrepublik, in der Verfassungsordnung der Bundesrepublik, ist die Eigentumsgarantie eine ganz allgemeine Vermögensgarantie. Was wir an Eingrenzungen haben, ist gegenüber unserem Problem mehr oder weniger zufällig. Ich danke Herrn Eblers sehr, daß er auf die Fehlentwicklung so nachdrücklich hingewiesen hat, daß unsere Eigentumsdogmatik zunächst vom Absatz 3 des Art. 14 GG her gemacht worden ist, und wir uns erst allmählich und sehr ungern auf die Absätze 1 und 2 zubewegt haben. Aber die Ordnung der Probleme, um die es hier und heute geht, kann überhaupt nicht in Absatz 3, sondern nur in Absatz 1 und in Absatz 2 
des Art. 14 GG gesucht werden. Aber auch das sind ganz unspezifische Antworten. In Österreich haben wir ein Verfassungsgesetz aus dem Jahr 1867 - aus einer Zeit also, in der die Probleme von Grund und Boden, die wir heute sehen, überhaupt nicht bewußt waren. Hier muß das Verfassungsgericht das, wie Herr Rill sagte, die Antworten auf die Herausforderungen von heute in einer dynamischen Rechtsprechung erst hineininterpretieren. In der Schweiz ist der Verfassungsgeber sehr spät daran gewesen, $d$.h. wir haben eine ganz lange Vorlaufzeit der Antworten des einfachen Rechts und ein ganz langes Sich-Verschweigen des Verfassungsgebers. So konnte die späte Antwort des Verfassungsrechts die spezifischste sein. Aber selbst dann bleibt ja immer noch die zurückhaltende Geltung schweizerischen Verfassungsrechts als Schwäche der sachlichen Vorordnung. Bleibt, was Herr Häberle angesprochen hat: gibt es nicht programmatische Antworten im Verfassungsrecht? Wir wissen, die programmatischen Antworten im Verfassungsrecht sind genuin schwächer als die freiheitsrechtlichen Antworten. Auch wenn der Umweltschutz in der Verfassung steht, kann er es mit einem Abwehrrecht, wie einem Freiheitsrecht, nicht aufnehmen.

Damit komme ich zu meiner letzten Bemerkung. Ich glaube, die verfassungsrechtliche Eigentumsdogmatik, die ja jetzt in allen drei Ländern geschuldet und unterwegs ist, muß trotz aller dieser intensiven Durchdringung einer individuellen Position mit der eines Gemeinschaftsgutes eine freiheitsrechtliche Dogmatik bleiben. Wir sollten nicht darauf hinaus, daß, jetzt spreche ich nur vom deutschen Recht, die Absätze 1 und 2 des Art. 14 GG so interpretiert werden, als ob die Verfassungsordnung diese Probleme auch hinsichtlich der Ausdifferenzierung der Gemeinschaftsbindung löst. Von der Verfassungsrechtsprechung oder überhaupt von der Verfassungsdogmatik her kann die intensive Verflechtung von Individualität und Gemeinschaft, welche die Problematik von Grund und Boden kennzeichnet, nicht nach beiden Seiten hin in gleicher Weise gelöst werden. Hier muß ein Spiel bleiben. Das individuelle Recht muß so interpretiert werden, daß die Politik des Gemeinwesens ihren Auftrag in Richtung auf die Gemeinschaftsgebundenheit von Grund und Boden erfüllen kann. Aber das Abwehrrecht muß schlagkräftig bleiben. Denn wenn wir das vermengen und die Problemlösungen unmittelbar aus der Verfassung entnehmen wollen, dann wird das Freiheitsrecht in den Werten und in den Notwendigkeiten des Gemeinschaftlichen untergehen.

Vorsitzender: Vielen Dank, Herr Zacher. Ich erteile nun den Referenten das Wort, möchte aber gleichzeitig darauf hinweisen, daß wir 
noch 16 Wortmeldungen haben, und die dringende Bitte an die Referenten richten, auf diesen Umstand Rücksicht zunehmen, so daß wir in etwa in der Zeit bleiben können.

Rill: Ich möchte zuerst auf die Äußerung des Herrn Ossenbübl Bezug nehmen und die Rückkehr zum klassischen Enteignungsbegriff noch einmal erläutern. Ich glaube, daß historisch betrachtet eben Enteignung im Sinne unseres Eigentumsgrundrechts als klassische Enteignung zu definieren ist, und daß im Gefolge dann innerhalb der Eigentumsbeschränkungen zwischen entschädigungspflichtigen und entschädigungsfreien unterschieden werden muß. Die große Bedeutung, die eine Orientierung an diesem historischen Ausgangspunkt hat, ist die, daß damit Verstaatlichungen und Sozialisierungen mit dem Eigentumsgrundrecht nicht vereinbar sind, sondern nur die klassische Enteignung. Das hat für das Verständnis der Eigentumsgarantie, glaube ich, eine grundlegende Bedeutung, und darauf wollte ich noch einmal hinweisen. Herr Badura hat die These $5 \mathrm{e}$,Grundwasser angesprochen. Ich habe die These aufgestellt, daß Grundwasser dem Benutzungsrecht des Eigentümers vorbehalten ist, und das ist seit 1934 noch immer einfach gesetzliche Rechtslage in Österreich, also anders etwa als in Süddeutschland. Vorher war das Grundwasser im Wasserrecht unzulänglich geregelt und gab zu vielen Zweifelsfragen Anlaß.

Was These 21 anbelangt, also meine Ablehnung der Positivplanung, so meine ich, daß allein zur Realisierung der Vorstellungen einer Bauplanung nicht ein Baugebot erlassen werden kann. Es muß ein besonderer öffentlicher $Z_{\text {weck }}$ hinzutreten. Selbstverständlich kann dies bei einer sogenannten Problemzone der Fall sein. Wir haben also zum Beispiel in Österreich eine Ermächtigung an den Bund zur Gesetzgebung betreffend die Stadterneuerung (Assanierung). Das ist ein Bereich, in dem im Hinblick auf Problemzonen ein öffentlicher Zweck verfolgt wird, der über die Planungsinteressen bei der Flächenwidmung hinausgeht. Baugebote und Positivplanung sind hier zulässig.

Zu Herrn Häberle würde ich sagen, ich sehe nicht ganz ein, warum wir den Eigentumsbegriff differenzieren müssen. Ich meine, daß man im Einzelfall Differenzierungen bei der Frage der Zulässigkeit des Eingriffes vorzunehmen hat, etwa dergestalt, daß man für das Eigentum, das das Existenzminimum sichert, einen größeren Schutz fordert als für anderes Eigentum. Aber ich glaube nicht, daß man von vornherein generalisierend oder in abstrakten Kategorien Abgrenzungen einführen sollte. 
Herr Stolzlechner hat meine Position zum Ausschluß des Schutzes „Öffentliche Rechte aus der Eigentumsgarantie“ kritisiert. Dazu muß ich sagen, bitte, wenn Sie glauben, daß öffentlich-rechtliche Nachbaransprüche wirklich öffentlich-rechtliche Nachbaransprüche gegenüber dem Nachbarn sind, dann sind wir einfach unterschiedlicher Meinung. Ich bin der Auffassung, daß das privatrechtliche Ansprüche sind und nicht öffentlich-rechtliche. Es ist eine unreflektierte Meinung in Judikatur und Lehre, die in Rede stehenden Nachbarrechte per se in allen Aspekten als öffentlich-rechtliche Ansprüche zu qualifizieren, weil sie vor den Verwaltungsbehörden geltendzumachen sind. Wenn Sie die These 10 kritisieren, so muß ich sagen, daß Sie selber in Ihrem Buch über das Betriebsanlagenrecht beifällig die jüngere Judikatur des Verfassungsgerichtshofs zitieren, der sagt, daß die Ablehnung einer Betriebsanlagenbewilligung sehr wohl ins Eigentum eingreift, weil der Eigentümer mit seinem Eigentum nicht alles machen darf, was er will, sondern erst eine Bewilligung braucht. Er darf die Maschine eben erst aufstellen, wenn er eine Bewilligung dafür hat. Was die Rechtsprechung der Straßburger Instanzen anbelangt, so ist es sicherlich möglich, daß die Rechtsprechung in Richtung der Öffnung für den Schutz öffentlich-rechtlicher Ansprüche geht. Die Ansätze, die es bisher gibt, sind äußerst bescheiden, und historisch war es sicher nicht so gemeint, denn es ist eben die Menschenrechtskonvention und nicht die europäische Sozialcharta, die es ja auch noch gibt. Auch bei grundverkehrsbehördlichen Eingriffen habe ich mit der Beschränkung auf das vermögenswerte Privatrecht überhaupt kein Problem. Denn das Grundverkehrsrecht beschränkt die rechtsgeschäftliche Verfügungsmacht. Wenn Sie sagen, daß ich beim Wasserrecht selber die öffentlichrechtlichen Ansprüche unter den Schutz stelle, so haben Sie mich mißverstanden. Ich folge hier der in der Bundesrepublik Deutschland meines Wissens herrschenden Auffassung, daß diese Ansprüche erst geschützt sind, wenn man Investitionen getätigt hat, also die Sache, wie hier gerne gesagt wird, ins Werk gesetzt hat.

Zuletzt zum gemeinnützigen Verein, zum Golfverein. Das ist ein völliges Mißverständnis. Wenn ich sage, es könne für einen gemeinnützigen Verein enteignet werden, so ist selbstverständlich gemeint, $\mathrm{da} ß$ der $Z$ weck des gemeinnützigen Vereins im öffentlichen Interesse liegen muß und daher die Enteignung rechtfertigen kann.

Was die Frage des Telos der Eigentumsgarantie anbelangt, Herr Lange, so muß ich sagen, daß ich nicht der Meinung bin, Eigentum schützt Freiheit, nicht Reichtum, wie das Herr Leisner zur Charakterisierung der Verfassungsgerichtsrechtsprechung formuliert hat. Ich meine, daß das Eigentum neben anderen Grundrechten des Wirt- 
schaftslebens eine grundsätzlich marktwirtschaftliche Ordnung garantiert. Ich will also dieses Telos nicht nur an der Eigentumsgarantie, sondern an allen Grundrechten des Wirtschaftslebens festmachen. Und daher komme ich nicht zur Anerkennung sozialversicherungsrechtlicher Ansprüche als Schutzobjekt der Eigentumsgarantie. Herr Fleiner hat gefragt, ob aus der Eigentumsgarantie nicht auch verfahrensrechtliche Sicherungen abzuleiten sind, damit nicht zu lang dauernde Verfahren die Durchsetzung von Eigentumsansprüchen behindern. Das ist sicherlich grundsätzlich richtig. Ich meine, daß die Ausgestaltungspflicht des Gesetzgebers dahin geht, das Eigentumsrecht in sinnvoller Weise durchsetzbar zu gestalten. Nur glaube ich, daß die Hauptprobleme nicht beim Gesetzgeber liegen, sondern bei der Verwaltung, die einfach die Dinge nicht bewältigt und insbesondere auch bei der politischen Spitze bei der Verwaltung, die aus Rücksichtnahme auf hunderterlei Bürgerinitiativen die Verfahren eben schleppend behandelt.

Ehlers: Es sind zu diesem Zeitpunkt bereits so viele und so gewichtige Fragen aufgeworfen worden, daß ich weder auf alles eingehen noch auch nur den einzelnen Diskussionsbeiträgen in der Kürze der Zeit wirklich gerecht werden kann. Ich bitte um Verständnis, wenn ich mich auf diejenigen Punkte konzentriere, von denen ich den Eindruck habe, daß sie mein Referat zentral berühren.

$\mathrm{Zu}$ Beginn sind Herr Ossenbübl und Her Badura auf die Rechtsprechung des Bundesverfassungsgerichts eingegangen. Bei aller Kritik, die man im einzelnen üben kann, sollten wir die Leistungen dieses Gerichts sehr hoch einschätzen. Zwar hat das Bundesverfassungsgericht viele Fragen offengelassen bzw. offenlassen müssen. Das gilt etwa für die Probleme der Eigentumsunrechtshaftung oder der salvatorischen Klauseln. Auch ist manches unklar geblieben - so etwa der Enteignungsbegriff. Jedoch hat das Bundesverfassungsgericht von Anfang an - nämlich bereits im Jahre 1955 - mit der Weimarer Tradition gebrochen und die Eigentumsgarantie als Grundrecht und nicht nur als Entschädigungsgarantie ernst genommen. Herr Zacher hat darauf hingewiesen, daß diese Sichtweise die richtige ist, und ich möchte dem gerne zustimmen. In der Folgezeit hat das Bundesverfassungsgericht seine Konzeption mehrfach bekräftigt - grundsätzlich vor allem in der Deichordnungs-Entscheidung im Jahre 1968. Es ist deshalb aus heutiger Sicht für mich schwer nachvollziehbar, warum diese Rechtsprechung von der Fachgerichtsbarkeit und der Literatur nicht bzw. nicht hinreichend zur Kenntnis genommen worden ist, so daß es erst des Paukenschlages der Naßauskiesungs-Entscheidung 
bedurfte, um Bewegung in die versteinerte Eigentumsdogmatik zu bringen.

Mit Herrn Häberle bin ich der Meinung, daß es das Eigentum nicht gibt, sondern eine Vielzahl von Eigentumspositionen. Wenn es richtig ist, daß Art. 14 Abs. 1 GG das Recht schützt, auf der Grundlage und im Rahmen der Gesetze Vermögensgegenstände behalten und nutzen zu dürfen, ändert sich das Eigentumsrecht mit jeder Gesetzesänderung, und das bedeutet $z$. B. auch mit jedem Bebauungsplan oder mit jedem Landschaftsplan in Form einer Satzung. Zutreffend hat deshalb Herr Badura darauf hingewiesen, daß man Art. 14 Abs. 1 GG nicht in dem Sinne funktionalisieren darf, daß man die Eigentumspositionen in feste Schubkästen einteilt.

Was das von Herrn Roellecke angesprochene Problem der Verfügungsbefugnis über die Eigentumsgegenstände angeht, liegt vermutlich ein Mißverständnis vor. Ich möchte die Verfügungsbefugnis nicht aus dem Schutz des Eigentums ausklammern, sondern betrachte die Verfügungsbefugnis nur als Unterfall der Nutzungsbefugnis.

Eine Reihe von Beiträgen hat sich mit dem Verhältnis von Eigentums- und Umweltschutz beschäftigt. Soweit es um das „Ob“ des Umweltschutzes geht, möchte ich noch einmal deutlich machen, daß in Art. 14 Abs. 2 GG bereits eine Staatszielbestimmung „Umweltschutz" enthalten ist, weil der Gesetzgeber durch den Sozialauftrag des Art. 14 Abs. 2 GG in Pflicht genommen wird. Im übrigen entspricht der Satz „Im Zweifel für den Umweltschutz“ $\mathrm{m}$. E. ebensowenig dem Art.14 GG wie seine Umkehrung „Im Zweifel für die Freiheit“. Es kommt eben alles auf eine verhältnismäßige Zuordnung an. Überhaupt gibt es im Verfassungsrecht keine festen Formeln, die uns der Notwendigkeit des immer neu ansetzenden Abwägungsbemühens enthöben. Deshalb habe ich auch Zweifel, Herr Ossenbübl, ob man von einem Rechtsbegriff "Marktwirtschaft" sprechen kann. Solche Großformeln sind nicht ungefährlich.

Einige Äußerungen haben das Stichwort „Untermaßverbot“ aufgegriffen. Der Terminus, der zwar selten verwendet wird, aber nicht von mir stammt, soll zum Ausdruck bringen, daß der Gesetzgeber zur Sicherstellung eines Mindeststandards rechtlicher Grundrechtsverwirklichung verpflichtet ist. Für die Eigentumsgewährleistung ergibt sich dies aus der Institutsgarantie. Der Mindeststandard läßt sich nicht absolut, sondern nur relativ in Abwägung mit dem Gebot des Art. 14 Abs. 2 GG festlegen. Die Gegenüberstellung von Unter- und Übermaßverbot ist natürlich nicht zufällig, sondern gewollt, weil sie m.E. plastisch und präzise den Spielraum des Gesetzgebers bestimmt. 
Nun hat Herr Wabl die Frage aufgeworfen, ob der Gesetzgeber durch die Begrenzung von beiden Seiten her nicht einer Art Doppelzange ausgeliefert wird. Es könnte die Gefahr bestehen, daß die gesetzgeberischen Gestaltungsmöglichkeiten zu sehr eingeschränkt werden. Jedoch gewährleistet das Untermaßverbot nur Mindestgarantien. Umgekehrt meine ich, daß auch das Übermaßverbot durchaus flexibel und elastisch wirkt und erst ab einer gewissen Schmerzgrenze den Gesetzgeber wirklich einengt. Ob man von einer Überforderung des Gesetzgebers sprechen kann, wie dies in einigen Diskussionsbeiträgen angeklungen ist, möchte ich zunächst dahingestellt sein lassen, weil wir vermutlich im Zusammenhang mit der Erörterung der Ausgleichs- und Enteignungsregelungen noch auf dieses Problem zu sprechen kommen werden.

Wenn ich Herrn Badura richtig verstanden habe, hatte er Zweifel, ob man beim Nachbarschutz nicht doch unmittelbar auf Art. 14 GG rekurrieren müsse. Dies ist die alte Konzeption des Bundesverwaltungsgerichts. Das Gericht stellt in bestimmten Fällen - nämlich bei schweren und unerträglichen Belastungen - nicht auf das einfache Gesetz, sondern direkt auf Art.14 GG ab. Von dieser Auffassung habe ich mich aber gerade distanzieren wollen. Im Unterschied zu den sonstigen Freiheitsrechten, bei denen wir es immer mit einem natürlichen Substrat zu tun haben, vermag Art. 14 GG ohne gesetzliche Ausgestaltung keine Wirkungen zu entfalten. Vielfach wird aber eine verfassungskonforme Auslegung des einfachen Rechts in Betracht kommen. Das viel gescholtene Gebot der Rücksichtnahme - das nicht nur im Baurecht, sondern auch in anderen Rechtsgebieten zur Anwendung gebracht wird - ist in meinen Augen ein Beispiel hierfür. Allerdings siedelt das Bundesverwaltungsgericht dieses Gebot nur auf der Ebene des einfachen Gesetzesrechts an, während ich meine, daß die Wurzeln in Art.14 GG zu suchen sind. Ausgelegt wird dann allerdings das einfache Recht.

Sehr schwierige Fragen hat Herr Schmidt-Aßmann angesprochen. Ich möchte einen Aspekt herausgreifen, nämlich die mögliche Interessenparallelität von Eigentums- und Umweltschutz. Soweit eine derartige Parallelität besteht, muß der Staat daran anknüpfen, also Umweltschutz nicht gegen, sondern mit dem Eigentümer durchsetzen. Die Steuerungsprobleme im einzelnen lassen sich nicht leugnen. Immerhin haben sich im Umweltrecht gewisse Prinzipien herausgebildet, an denen sich der Gesetzgeber orientieren kann. Neben den genannten Gesichtspunkten lassen sich vielleicht noch das Verursacher- und das Kooperationsprinzip nennen. 
Der letzte Punkt, auf den ich eingehen möchte, betrifft die von Herrn Lange angesprochene Frage eines Eigentumsschutzes rechtswidriger Baugenehmigungen. Daß sich der Gesetzgeber unsicher war, wie dieser Fall zu behandeln ist, zeigt die im letzten Absatz des $₫ 48$ VwVfG enthaltene subsidiäre Rechtswegklausel für den enteignungsgleichen Eingriff. Wenn ich der Auffassung bin, daß wegen der Gesetzesabhängigkeit des Art. 14 GG rechtswidrige Genehmigungen nicht dem Schutz dieser Vorschrift unterfallen, heißt dies natürlich nicht, daß dem Genehmigungsadressaten überhaupt kein Verfassungsschutz zukommt. Einen verfassungsrechtlich abgesicherten Vertrauensschutz gibt es sicher. Nur würde ich diesen Schutz in Art. 2 Abs. 1 GG i.V.m. dem Rechtsstaatsprinzip verorten wollen. So viel zunächst.

Hänni: Ich darf mich hier aus schweizerischer Sicht kurz fassen. Zunächst zu der Bemerkung von Herrn Zacher: Ich stimme ihm voll bei, daß die Unvermehrbarkeit des Bodens tatsächlich ein zentrales Problem darstellt. Und ich möchte beifügen, daß dieser Umstand nicht nur mit Blick auf die Lösungen zu berücksichtigen ist, sondern schon bei der Entstehung der damit zusammenhängenden Probleme, wenn Sie nur schon an die verstärkte, vielleicht sachfremde Funktion des Bodens als Vermögensanlage denken. Das kann eine Reihe von Problemen überhaupt erst verursachen, die dann später unter Umständen nur sehr mühsam gelöst werden können. So haben wir in der Schweiz beispielsweise vor zwei Jahren eine auf fünf Jahre befristete Veräußerungssperre eingeführt. Sie wird jetzt zurückgenommen auf drei Jahre, möglicherweise wird sie auch vollständig aufgehoben, sie ist aber eine typische Folge der Entfremdung des Bodeneigentums als Vermögensanlage, die ihrerseits mit der Unvermehrbarkeit des Bodens zusammenhängt.

Sodann hat Herr Fleiner die Frage aufgeworfen, ob der Schutz der Eigentumsgarantie in Wirklichkeit nicht auch und gerade durch die demokratische Partizipation am Planungsverfahren gewährleistet werden kann. Ich bin der Auffassung - und ich habe das auch schon im Referat so ausgeführt - , daß die demokratische Mitwirkung im Planungsverfahren tatsächlich einer der Eckpfeiler beim Schutz des Eigentums ist, weil eben - auch dies habe ich darzustellen versucht - die dem Gesetzgeber auferlegten Schranken bei der Konkretisierung der Eigentumsgarantie doch sehr weit gezogen sind. Herr Fleiner hat alsdann die weitere Überlegung ins Spiel gebracht, ob nicht die Schranke "Zeit", bzw. die Zeit überhaupt, eine bedeutendere Rolle spielen müsse bei der Bestimmung des Eigentumsbegriffs. Diesem 
Umstand ist zweifellos vermehrt Rechnung zu tragen. Ich darf Sie in diesem Zusammenhang nur an die neueste Rechtsprechung des schweizerischen Bundesgerichtes zur Koordinationspflicht der Behörden im Rahmen von Bewilligungsverfahren erinnern. Wenn nämlich mehrere Bewilligungsverfahren völlig unkoordiniert nebeneinander abgewickelt werden, führt dies dazu, daß die ersten Bewilligungen schon wieder erlöschen, wenn die letzten erst rechtskräftig werden. Dies führt zu einer erheblichen Schwächung der Eigentümerposition, weshalb das Bundesgericht klargemacht hat, daß hier eine Verpflichtung der Behörden zur Koordination der Verfahren besteht. Das kann ein möglicher Ausweg sein. $\mathrm{Ob}$ es der einzige ist, oder ob allenfalls aus der Eigentumsgarantie eine Entschädigungspflicht bei extremen Verzögerungen abgeleitet werden kann, das wird die Zukunft weisen müssen. Im Moment allerdings scheint die Rechtsprechung das Schwergewicht auf die Koordinierungspflicht zu legen.

Bei der Frage des differenzierten Eigentumsbegriffes schließlich, die Herr Häberle aufgegriffen hat, läßt sich aus schweizerischer Sicht sagen, daß die Rechtsprechung diesen Weg mindestens seit dem leading case Zizers (BGE 105 Ia 330) ausdrücklich durch die Feststellung geöffnet hat, daß die verschiedenen Ziele und Wertungen, die in der Bundesverfassung im Rahmen von Kompetenznormen einen Ausdruck gefunden haben, gleichrangig neben der Eigentumsgarantie stehen, was natürlich die Herausbildung eines differenzierten Eigentumsbegriffs stark begünstigt. Im übrigen dürfen wir nicht vergessen, daß wir die Gleichrangigkeit des Umweltschutzgedankens nicht aus der Sozialbindung herleiten müssen, sondern daß die Existenz eines eigentlichen Umweltschutzartikels in der Bundesverfassung möglicherweise eine sachgerechtere und ungezwungenere Abwägung der verschiedenen Interessen erlaubt, als dies beim Umweg über die Sozialbindung von Art. 14 GG der Fall ist.

Frotscher: Ich möchte zwei eher grundsätzliche Anmerkungen zu den Referaten machen und im Anschluß daran noch eine Detailfrage aufwerfen. Zunächst zu dem Referat von Herrn Rill. Hier scheint es mir erforderlich, Ihr kritisches Augenmerk noch einmal auf die Thesen 3 und 4 zu lenken. Der Begriff der „präkonstitutionellen Eigentumsordnung", wie er hier verwendet wird, scheint mir ein gefährlicher Maßstab für die Auslegung der Eigentumsgarantie in der Gegenwart. Die "präkonstitutionelle Eigentumsordnung “ verweist in diesem Zusammenhang auf die Regelung des Eigentums im Jahre 1867. Wenn man sich aber vor Augen führt, daß gerade im 19. Jahrhundert und speziell in der angesprochenen Epoche ein besonders individuali- 
stischer Eigentumsbegriff ausgeprägt war und die soziale Komponente des Eigentums zu verschwinden drohte, dann ist es, wie ich meine, heute an der Zeit, von einem solchen individualistischen Eigentumsbegriff endgültig Abschied zu nehmen und statt dessen wie für einen Sozialstaat angemessen - die soziale Komponente oder Sozialpflichtigkeit des Eigentums, wie sie in Art. 14 Abs. 2 GG normiert ist, wieder stärker zu betonen.

Die Leitsätze 3 und 4 von Herrn Rill stehen in enger Verbindung. Die These 4 ist ja auch in der Diskussion schon mehrfach angesprochen worden, u. a. von Herrn Ossenbübl, der noch einmal unterstrichen hat, daß es richtig sei, die Gewährleistung der marktwirtschaftlichen Ordnung als Telos der Eigentumsgarantie anzusehen. Ich möchte dagegen ausdrücklich den Vertretern der Gegenmeinung beispringen und die Auffassung des BVerfG verteidigen, wonach das Grundgesetz trotz der bestehenden Freiheitsgarantien sich nicht auf eine bestimmte wirtschaftspolitische Ordnung festgelegt hat. Das ist verfassungsrechtlich gut so, auch wenn ich persönlich durchaus von der politischen Richtigkeit der sozialen Marktwirtschaft überzeugt bin. Schließlich erscheint es mir zu kurz gegriffen, wenn Herr Ossenbübl in der juristischen Auseinandersetzung den Zusammenbruch des kommunistischen Regimes in Osteuropa als Argument für eine Neuinterpretation des Grundgesetzes verwenden will.

Ich komme dann zu dem Referat von Herrn Ehlers, dessen Konzept mich in allen Teilen überzeugt hat. In einem Punkt möchte ich allerdings eine Ergänzung vorschlagen und noch einmal unterstreichen, was in der Diskussion bereits von Herrn Badura, Herrn Ossenbübl und anderen gesagt worden ist. Es geht dabei um den Leitsatz 15, also um die Sozialbindung des Eigentums, die ja auch ausdrücklicher Bestandteil unseres Tagungsthemas ist. Herr Ehlers nimmt hier eine Abwägung vor zwischen den Privatnützigkeitsinteressen auf der einen und den Allgemeinwohlbelangen auf der anderen Seite. Dabei darf man m. E. jedoch nicht stehenbleiben und die rechtssystematischen Bemühungen sozusagen beim Verhältnismäßigkeitsprinzip als einem doch sehr unbestimmten Maßstab abbrechen und alles Weitere dem Richter im Rahmen der Einzelfallentscheidung überlassen. Statt dessen müssen wir die vorhandenen Differenzierungsansätze weiterentwickeln, um auf diese Weise zu einer Theorie der abgestuften Sozialbindung, wie ich es nennen möchte, zu kommen. Die Elemente einer solche Theorie kann man bisher nur andeuten; zu Recht ist jedoch in der Diskussion bereits auf die Entscheidung des BVerfG hingewiesen worden, in der das Gericht jedenfalls ansatzweise eine solche Abstufung in der Sozialbindung vorgenommen und deutlich ausgesprochen 
hat, daß Grund und Boden nicht wie eine mobile Ware behandelt werden können. Das Gericht hat diesen Ansatz in dem sog. Mitbestimmungsurteil wieder aufgenommen und hat differenziert zwischen dem (stärker sozial verpflichteten) Anteilseigentum und dem sonstigen Eigentum, das in unserer Diskussion z. T. auch als „kleines“ Eigentum bezeichnet worden ist. Ich glaube, Herr Häberle, man kann Ihrem Anliegen im Ergebnis gerecht werden, wenn man zwar einerseits daran festhält, daß alle Arten von Eigentum in den Schutzbereich des Art. 14 GG fallen, also das "große“ Eigentum ebenso wie das persönliche "kleine“ (Die von Rittstieg in seiner Monographie „Eigentum als Verfassungsproblem" versuchte Aufspaltung und Einschränkung der Eigentumsgarantie ist nach meiner Meinung verfassungsrechtlich nicht haltbar.), wenn man jedoch auf der anderen Seite im Rahmen der Sozialbindung gem. Art. 14 Abs. 2 GG nach verschiedenen Eigentumsarten differenziert und auf diese Weise die soziale Funktion des Eigentums, gerade beim Grund und Boden und gerade im Hinblick auf den Umweltschutz, besonders zur Geltung bringt. Herr Ehlers hat bereits, zwar nicht in seinen Leitsätzen, wohl aber im Vortrag, auf die notwendige Unterscheidung nach dem Eigentumsobjekt hingewiesen. Dem Privatnützigkeitsinteresse des einzelnen an diesem Objekt sind dann die öffentlichen Belange gegenüberzustellen, wobei man hinsichtlich der Vielzahl der Eigentumsobjekte doch über die bisher genannten entweder sehr weiten oder sehr vagen Einteilungen hinaus zu einer stärkeren Typisierung und einer Art Rangfolge kommen müßte. Diese „Skala" würde vor dem ganz persönlichen Eigentum, wie es beispielsweise unser Tagungsanzug darstellt, bei dem zunächst niemand irgendeine Form der Sozialbindung für zulässig erachten wird, über das Auto, wo die Abwägung schon komplizierter wird, bis hin zu dem unvermehrbaren und deshalb so „kostbaren“ Grund und Boden reichen. Bereits das Auto wird man heute mit Blick auf die Umwelt nicht mehr zu den Eigentumsobjekten rechnen können, bei denen die Bedeutung für die Freiheitsentfaltung des einzelnen den unbedingten Vorrang vor den Interessen der Allgemeinheit erhalten müßte. Hinsichtlich des Grund und Bodens ist anzumerken, daß es in früherer Zeit sehr wohl als „frei“ zu bezeichnende Gesellschaften gegeben hat, die kein Privateigentum an Grund und Boden, sondern nur ein Gemeineigentum, eine Allmende oder ähnliche Formen des Gemeinschaftsbesitzes gekannt haben. Zusammenfassend möchte ich meinen, daß es richtiger ist, den Schutz der Eigentumsgarantie nicht von Anfang an auf bestimmte Eigentumsobjekte einzuengen, sondern vielmehr den Weg über Art. 14 Abs. 2 GG und eine darauf basierende Theorie der abgestuften Sozialbindung zu gehen. 
Damit komme ich zu dem Detailproblem, das ich noch ansprechen wollte. In Ihrem Leitsatz 10, Herr Eblers, behandeln Sie den Luftraum über einem Grundstück, den Sie im Unterschied zur Gewässernutzung dem privatnützigen Eigentum zurechnen wollen. Hier muß man m. E. Zweifel anmelden, weil völlig unberücksichtigt bleibt, daß der Luftraum nach allgemeiner verwaltungsrechtlicher Auffassung als eine öffentliche Sache im Gemeingebrauch einzustufen ist. Wenn Sie die Privatnützigkeit des Luftraumes dann auf „eine gewisse Höhe“ über dem Grundstück begrenzen wollen, so erscheint diese vage Grenzziehung problematisch. In einem beschaulichen Ort wie Marburg würde vielleicht eine Luftsäule von $20 \mathrm{~m}$ Höhe ausreichen, während in Frankfurt oder Manhattan ganz andere Dimensionen eine Rolle spielen.

Abschließend möchte ich doch betonen, daß ich Herrn Hännis Referat mit Interesse entnommen habe, wie offen die Verfassungsordnung eines allgemein als konservativ gekennzeichneten Landes die Eigentumsfrage angeht. Insbesondere die von Herrn Hänni in Leitsatz 15 angesprochenen "demokratischen Mitwirkungsrechte" bei der Grenzziehung zwischen Eigentumsschutz und Umweltgestaltung erscheinen mir bedenkenswert.

Oldiges: Aus der Fülle der hier angesprochenen Probleme greife ich nur den Einzelaspekt der Baufreiheit heraus. Obwohl die damit verbundene Problematik seit den siebziger Jahren an rechtspolitischer Brisanz verloren hat, besitzt sie durchaus auch weiterhin noch paradigmatische Bedeutung für das Eigentumsverständnis insgesamt und zugleich auch für das Verhältnis von Eigentumsrecht und Umweltschutz. Dem Referat von Herrn Rill haben wir entnehmen können, daß aus österreichischer Sicht die Baufreiheit aus dem Eigentumsrecht fließt; das besagt seine These 5 e ohne jedes Wenn und Aber. Herr Hänni ist für die Schweiz schon etwas zurückhaltender, wenn er in These 6 darauf hinweist, daß das Problem der Baufreiheit angesichts der Abhängigkeit des Bauens vom Staat keine wirklich maßgebliche Rolle spiele. Herr Eblers schließlich geht in seinen Thesen 8 und 21 noch darüber hinaus. Seiner These 8 zufolge ist die Baufreiheit nur institutionell durch Art. 14 GG gewährleistet und im wesentlichen nur gesetzlich konstituiert. In These 21 werden die Konsequenzen aus diesem Ansatz gezogen; hiernach bedeuten Nutzungsbeschränkungen bei Grund und Boden keine Enteignung. Dem stelle ich die keineswegs neue, sondern von Rudolf Reinhardt entwickelte und vom Bundesverfassungsgericht übernommene - These entgegen, daß die Eigentumsgewährleistung der Privatnützigkeit des Eigentums dient. 
Zur Privatnützigkeit gehört nun aber neben dem „Haben-dürfen“ auch das "Gebrauchen-können“, also die Nutzungsbefugnis. Ich nehme an, dem würden auch Sie, Herr Ehlers, noch zustimmen können; das meine ich jedenfalls anderen Ihrer Bemerkungen entnehmen zu können. Sie vermeiden es aber, hieraus für die Baufreiheit Konsequenzen zu ziehen. Was ist Baufreiheit denn anderes als ein Ausdruck der Nutzungsbefugnis, des "Gebrauchen-könnens“? Damit erweist sie sich aber wie das "Gebrauchen-können" selbst als ein Bestandteil des Eigentumsrechts und nimmt an dessen verfassungsrechtlicher Gewährleistung teil. Baufreiheit ist darum ein unmittelbar aus der Verfassung ableitbares Recht.

Nun wird dem bekanntlich entgegengehalten, Baufreiheit sei lediglich verwaltungsrechtlich, nämlich durch die kommunale Bauleitplanung, vermittelt und genieße damit keinen Verfassungsschutz als ein Individualgrundrecht des Grundstückseigentümers. Gewiß unterliegt die Baufreiheit einem Planungsvorbehalt - aber auch das gilt nicht einmal uneingeschränkt, denn das Prinzip der Planmäßigkeit der Bebauung ist auf breiter Front der Bebauung nach den Planersatznormen 34 und 35 BauGB gewichen. Letztlich geht es hierbei insgesamt um einen städtebaulichen Ordnungsvorbehalt der Baufreiheit. Dieser Ordnungsvorbehalt konstituiert nicht die Baufreiheit - und schon gar nicht im Sinne einer Gewährung durch die Verwaltung -, sondern setzt ihr eine gesetzliche Schranke.

Auch Sie, Herr Ehlers, sprechen nicht von einer verwaltungsrechtlichen Vermittlung der Baufreiheit, meinen aber doch wohl, daß sie erst durch das Gesetz konstituiert werde. Wenn dem so wäre, könnte der Gesetzgeber die Baufreiheit, so wie er sie selbst erst bewirkt hat, nahezu beliebig auch wieder einschränken. Das ließe sich aber, wie mir scheint, mit der Privatnützigkeit des Eigentums an Grund und Boden nicht vereinbaren.

Nun noch ein Wort zur These 21 von Herrn Eblers. Wenn die Nutzungsmöglichkeit des Eigentums an Grund und Boden, wie es mir richtig erscheint, als Baufreiheit unmittelbar durch Art.14 GG geschützt wird, dann ist auch der Bodenwert eine Komponente des Eigentumsrechts. Denn der Bodenwert bringt die städtebauliche Nutzbarkeit eines Grundstücks zum Ausdruck; er ist ihr Indikator. Eine planerische Herabzonung mindert regelmäßig die Nutzbarkeit eines Grundstücks und ist insoweit verfassungsrechtlich relevant. Auch hier liegt ein Eigentumsentzug vor, wenn auch nicht in der Form des Substanzentzuges, sondern als Entzug der Nutzungsmöglichkeit. Das wird dort am deutlichsten, wo planerische Festsetzungen wie etwa bei der Festlegung von öffentlichen Verkehrs- oder Grünflä- 
chen eine privatnützige Verwendung der betroffenen Grundstücke gänzlich ausschließen. In diesem Zusammenhang gehen Sie, Herr Eblers, auf die Entschädigungsregel des $\$ 42 \mathrm{BauGB}$ und die dort geregelte Sieben-Jahres-Frist ein. In These 16 haben Sie die SiebenJahres-Frist damit gerechtfertigt, daß das genutzte Grundeigentum eine verfassungsrechtlich stärkere Position besitze als das ungenutzte. Ich erkläre mir diese Regelung jedoch anders. Grundsätzlich genießen, wie ich meine, genutztes und ungenutztes Grundeigentum verfassungsrechtlich den gleichen Schutz. Allerdings läßt $\ 42$ Abs. 3 BauGB planerische Herabzonungen ohne volle entschädigungsrechtliche Kompensation des Bodenwertverlustes zu, wenn und soweit von einer bestehenden planerischen Bebaubarkeit über mehr als sieben Jahre hinweg nicht Gebrauch gemacht worden ist. Diese Regelung ist indes nicht Ausdruck einer geringeren eigentumsrechtlichen Schutzmöglichkeit, sondern begründet lediglich eine Obliegenheit des Eigentümers zu plankonformer Nutzung seines Eigentums. Das Gesetz hat mit dieser Obliegenheit eine neuartige Eigentumsschranke im Sinne des Art. 14 Abs.1 S. 2 GG entwickelt, die sich aus der besonderen Sozialpflichtigkeit des Eigentums an Grund und Boden rechtfertigt. Versteht man $\$ 42$ Abs. 3 BauGB in dieser Weise, dann fügt er sich lückenlos in das Gebäude des verfassungsrechtlichen Eigentumsschutzes ein, das auch die Baufreiheit umfaßt.

Breuer: Ich möchte noch einmal zu einer Reihe von grundsätzlichen Punkten Stellung nehmen und versuchen, aus dem Rechtsvergleich etwas herzuleiten; denn ein Rechtsvergleich dient ja in erster Linie dazu, daß man eigene Ansätze kritisch überdenkt und prüft, was man eigentlich aus den anderen Rechtsordnungen lernen kann.

Erstens: Ein rechtstatsächlicher Befund verdient hervorgehoben zu weden. Er ist in allen drei Staaten, die wir betrachtet haben, gleich und wahrscheinlich ein gemeinsames Phänomen aller Industriestaaten. Die Situation ist antithetisch. Auf der einen Seite ist das Eigentum Teil der privatnützigen Ordnung und der Freiheit. Persönliche Freiheit und vermögensrechtliche Freiheit sind nicht teilbar. Das ist sicherlich richtig. Aber auf der anderen Seite ist ebenso richtig, was Herr Zacher nachdrücklich betont hat und was man nur unterstreichen kann. Unter den heutigen Verhältnissen ist die Bodennutzung ebenso wie das umweltrelevante Handeln immer durch einen Bezug zur Gemeinnützigkeit gebunden. Der Grund und Boden ist Bestandteil eines Umweltmediums. Die Bodennutzung hat Ausstrahlungswirkungen. Es kommt ein historisches Moment hinzu, und zu dieser Bemerkung gibt das Referat von Herrn Rill Anlaß. Im 19. Jahrhundert ist die 
Eigentumsfreiheit zum Kern der grundrechtlichen, liberal-rechtsstaatlichen Ordnung gemacht worden. Wir sind dabei nicht stehengeblieben. Die neuzeitlichen Entwicklungen sind vorangeschritten, und immer drängender und immer bedrohlicher wird uns bewußt, daß der Grund und Boden eigentlich nur Teil eines Mediums und Teil sozialer Gesamtzusammenhänge ist. Mir scheint es nun der richtige Ansatz zu sein, daß diese Kollisionslage in die Inhalts- und Schrankenbestimmung des Eigentums einbezogen wird. Dies ist der maßgebende Ansatz in der Bundesrepublik Deutschland und auch, wenn ich es recht verstanden habe, der Ansatz der Schweizerischen Bundesverfassung, seit der Art. 22ter eingefügt ist. Hier frage ich Sie, Herr Rill, kritisch, ob Sie nicht in gewissem Maße an einer archaischen Idylle des 19. Jahrhunderts festhalten, wenn Sie das privatnützige, individuelle Eigentum so sehr in den Vordergrund rücken und seine zivilrechtliche Unterfütterung zum Maß des Verfassungsrechts machen wollen.

Erfordert nicht eine sinngerechte Auslegung auf der Höhe der Zeit, daß man die ganzen Sozialbezüge und die Entwicklung der industriestaatlichen Gesellschaft als Problem der Inhalts- und Schrankenbestimmung des Eigentums verinnerlicht? Ich meine, daß in Ihren weiteren Ausführungen dieser Gedanke durchaus zum Tragen kommt. In Österreich geht man ja nicht davon aus, daß die öffentlichrechtliche Gesetzgebung und die Berücksichtigung der Gemeinwohlbelange im Widerspruch zur verfassungsrechtlichen Eigentumsgarantie stünden. Interessant und im Rahmen des Rechtsvergleichs spannend ist, daß man in Österreich die moderne öffentlich-rechtliche Gesetzgebung der Bodennutzung und des Umweltschutzes gar nicht an der Verfassungsgarantie und der archaischen Uridee des privatnützigen, individuellen Eigentums mißt, sondern insoweit dem Gesetzgeber weitgehende Gestaltungsspielräume zuerkennt, wobei es auf die Verhältnismäßigkeit und die Abwägung ankommt. Meine kritische Frage ist also, ob hier nicht das österreichische Modell nur scheinbar von dem deutschen und dem schweizerischen Modell abweicht.

Zweitens: In allen drei Rechtsordnungen ist die spezifische Gesetzesabhängigkeit des Eigentums sehr deutlich zum Ausdruck gekommen. Was das Bundesverfassungsgericht in der Bundesrepublik Deutschland dem parlamentarischen Gesetzgeber an spezifischer Verantwortung zugestanden hat, nämlich Inhalt und Schranken des Eigentums zu bestimmen, und zwar durch zivilrechtliche wie durch öffentlich-rechtliche Gesetze, scheint ein allgemeiner Grundzug der drei Rechtsordnungen zu sein. Ich verweise hier auf die Thesen 4, 6 und 7 von Herrn Eblers und kann auch auf die Thesen 4 und 5 von Herrn Hänni verweisen und bei Ihnen, Herr Rill, auf die Thesen ab 
Nr. 20, wo die Gestaltungsfreiheit des Gesetzgebers zum Ausdruck kommt. Deshalb scheint mir in der Tat, daß es nicht möglich ist, ein abstraktes Eigentum der verfassungsrechtlichen Betrachtung voranzustellen. Eigentum ist gesetzesabhängig, es ist gesetzesgestaltet. Dabei ist auch typisch, daß der Art.14 des Grundgesetzes ebenso wie die Verfassungsbestimmung der Schweiz die Institutsgarantie des Eigentums an den Anfang stellt. Die Institutsgarantie bedeutet, daß der Gesetzgeber die subjektiven Eigentumsrechte zu konstituieren hat. Er muß bestimmen, welche Rechte der Eigentümer gegenüber der öffentlichen Hand hat und welche interprivaten Rechte es gibt. Nur in zweiter Linie bezieht sich dann das Eigentumsrecht auf die Rechtspositionen, die gesetzlich gestaltetes Eigentum sind. An diesem Punkt bin ich bei der Baufreiheit angelangt. Vor 15 Jahren konnte man vielleicht noch einen Sturm der Entrüstung hervorrufen, indem man die These vertrat, daß die Befugnis zur baulichen Nutzung offentlichrechtlich vermittelt sei, und zwar durch öffentlich-rechtliche Gesetze, Planung und sonstige Verwaltungsentscheidungen. Nach dem heutigen Tage scheint mir, daß diese These nicht mehr ganz so revolutionär ist. Herr Ehlers hat zwar, sozusagen um sich selbst zu schützen, zunächst gesagt, er vertrete weder die Auffassung der öffentlichrechtlichen Fundierung der Baufreiheit noch die Gegenthese der natürlichen, vorstaatlichen und privatrechtlichen Freiheit zu bauen. Aber was dann bei Ihnen, Herr Eblers, in der These 8 zum Ausdruck gekommen ist, kommt zumindest dem sehr nahe, was unter der öffentlich-rechtlichen Baufreiheit, jedenfalls von meiner Seite aus, verstanden worden ist.

Es entspricht nicht nur dem Blick auf das einfache Gesetz, daß die Befugnis zu bauen durch öffentlich-rechtliche Gesetze normiert ist, daß danach in erster Linie der kommunale Plangeber die Nutzungsbefugnisse durch öffentlich-rechtliche Disposition bestimmt und daß dann noch die Verwaltung bei der Einzelfallentscheidung unbestimmte Rechtsbegriffe anwendet. Es fügt sich vielmehr dieses Bild auch in das Konzept der Institutsgarantie ein, die dem Eigentumsrecht vorangeht. Von Ihnen, Herr Hänni, ist, wenn ich es so sagen darf, aus der typisch pragmatischen Sicht der schweizerischen Rechtsordnung der Blick auch auf die einfachgesetzliche Gestaltung gerichtet worden, und Sie haben gesagt, es spiele dann keine sehr große Rolle mehr, ob die Baufreiheit rechtstheoretisch auf eine vorstaatliche, privatrechtlich gestaltete Befugnis gegründet wird oder auf eine öffentlich-rechtliche Verleihung. Man sollte auch einmal kritisch nachfragen, ob es denkbar ist, daß eine sonstige Bodennutzung mit dem gleichen Impetus zum Inhalt einer vorstaatlichen Freiheit gemacht wird, etwa die Nutzung 
des Landwirts unter den modernen Verhältnissen oder die Nutzung durch umweltrelevante Anlagen mit erheblichen Luftverschmutzungen. Hier ist man allgemein sehr viel vorsichtiger mit der These, es werde eine vorstaatliche Freiheit ausgeübt. Vielmehr waltet hier stärker das Bewußtsein, daß durch öffentliches Recht Lebensbereiche geordnet, Befugnisse des einzelnen und Gemeinwohlbelange zu einem Ausgleich gebracht und so Chancen der individuellen Lebensgestaltung und Risiken gegeneinander austariert werden.

Drittens: Die Crux liegt nun in der Tat bei der Abgrenzung der parlamentarisch-gesetzlichen Gestaltungsfreiheit. Hierüber müssen wir weiter nachdenken. Ansätze dazu sind geboten worden, aber an diesem Punkt sind wir mit unseren Erkenntnissen noch nicht fertig. Es ist nicht nur nach verschiedenen Schutzgütern des Eigentumsrechtes zu fragen, sondern eine vielfältige weitere Differenzierung geboten. Herr Ossenbiubl und andere haben dies angedeutet, ich will es nicht noch einmal im einzelnen wiederholen. Es kommt auch auf die Art der gesetzlichen Beschränkung sowie auf die Art der begrenzten Befugnisse des Eigentümers an, nämlich Nutzungsbefugnisse, Verfügungsbefugnisse und die Privatnützigkeit im Sinne einer Mindestrentabilität. Insofern glaube ich, daß man einem interessanten Begriff von Herrn Ehlers, nämlich dem Begriff des Untermaßverbotes, durchaus einen Sinn abgewinnen kann. Der Rekurs auf das Prinzip der Verhältnismäßigkeit ist meines Erachtens unzulänglich. Hieraus droht in der Tat eine Eigentumsgefährdung unter den Gesichtspunkten, die ich erwähnt habe. Das Verhältnismäßigkeitsprinzip ist der Ausdruck einer verfassungsrechtlichen Schaukelphilosophie. Wenn die Belange des Gemeinwohls besonders wichtig sind, liegt es nahe, daß das Eigentum zurücktreten muß und die Eigentümerrechte eingeschränkt, wenn nicht sogar aufgehoben werden können. Der Gedanke des Untermaßverbotes lenkt den Blick auf den entscheidenden Punkt, daß zumindest ein Grundbestand von Nutzungsbefugnissen, Verfügungsbefugnissen und privatnütziger Verwendung erhalten bleiben muß. Hier muß die zukünftige Überlegung zur typologischen Herausarbeitung von Eigentümerpositionen ansetzen. Sehr wichtig ist der Gesichtspunkt, daß Eigentum in der Zeit gedacht werden muß. Herr Fleiner hat darauf hingewiesen. Mir scheint indessen, daß der Gedanke der Eigentumsnutzung in der Zeit nicht nur dazu geführt hat, daß die öffentliche Verwaltung eigentumsrelevante Verfahren nicht beliebig hinauszögern darf. Vielmehr führt dieser Gedanke auch dazu, daß ein Eigentumsrecht in der Zeit begrenzt oder auch durch Umplanung oder Gesetzesänderung aufgehoben werden kann. Im Gegensatz zu Herrn Oldiges bin ich der Meinung, daß das Muster- 
beispiel für den Gedanken des Eigentums und der Eigentumsnutzung in der Zeit in der 7-Jahres-Frist des $\$ 44$ BauGB zu finden ist.

Viertens: Ein ganz wichtiger Punkt ist von Herrn Eblers in These 18 angesprochen worden. Hier haben Sie, Herr Eblers, sinngemäß ausgeführt, Eigentumsbeschränkungen könnten unzulässig werden, wenn die Summe der gesetzlichen oder administrativen Maßnahmen unverhältnismäßig wird. Ich bin nicht ganz sicher, ob die Tragweite dieses Gedankens auf Anhieb erkennbar wird. Paradigmatisch will ich an den Fall der landwirtschaftlichen Bodennutzung erinnern. Daß hier aus gut verstandenen Gründen des Umweltschutzes öffentlich-rechtlich die Eigentumsnutzung in einer Weise beschränkt werden kann, die über traditionelle Vorstellungen weit hinausgeht, ist heute schon Konsens geworden. Aber eigentumsrechtlich liegt das große Problem darin, daß einerseits die umweltrechtlichen Beschränkungen und andererseits die wirtschaftsrechtlichen $Z$ wänge, die zum großen Teil vom EG-Recht herkommen, die landwirtschaftliche Bodennutzung in die Enge treiben. Von der einen Seite her werden wirtschaftliche Zwänge gesetzt, die es dem Landwirt, der seinen Boden nutzt, außerordentlich schwer machen, am Ende noch privatnützig zu wirtschaften. Ich darf nur die Frage stellen, ob Sie hier Lösungsansätze aufgrund Ihrer These 18 sehen. Auch die Umweltabgaben, die heute diskutiert werden, müssen vor dem Hintergrund betrachtet werden, daß ein neues Instrument zusätzlich zu den alten ordnungsrechtlichen Instrumenten geschaffen werden soll. Auch hierdurch droht eine Kumulation von Instrumenten, die durchaus die Privatnützigkeit des Eigentums aus den Angeln heben könnte.

Herr Vorsitzender, ich bin bereit, an dieser Stelle Schluß zu machen, weil ich zu den Ausgleichspflichten noch eine Frage habe. Wenn Sie mir konzedieren würden, daß ich zu den Ausgleichspflichten nachher noch ein paar Worte sagen dürfte, wäre ich...

Vorsitzender: Wenn wir es zeitlich hinbekommen, sehr gerne. Ich bitte um Verständnis. Wir kommen so langsam in das Problem der angemessenen Verteilung der Redechancen. Ich versuche es. Schönen Dank, Herr Breuer.

Wieland: Mir geht es um das Verhältnis zwischen Grundeigentum und Umweltschutz. Der Schutz des Grundeigentums und die Anforderungen des Umweltschutzes müssen zu einem Ausgleich gebracht werden. Das ist nicht nur in allen drei Referaten - mit unterschiedlichen Akzenten - deutlich geworden, sondern wurde auch in der Diskussion schon mehrfach betont. Ich möchte von der Möglichkeit 
der Rechtsvergleichung, die uns die drei Referenten bieten, mit der Bitte Gebrauch machen, am Beispiel der Nutzung der Luft näher zu erläutern, wie weit die dem Gesetzgeber eingeräumten Gestaltungsbefugnisse reichen. Herren Rill und Eblers habe ich so verstanden, daß sie es dem Gesetzgeber verwehren würden, in einem Lufthaushaltsgesetz eine $\$ 1$ a Abs. 3 Wasserhaushaltsgesetz entsprechende Regelung zu treffen. Demnach dürfte die Nutzung der Luft über einem Grundstück nicht aus dem Schutzbereich der Eigentumsgarantie herausgenommen werden. Herr Hänni hielte eine derartige Bestimmung auf der Grundlage des eher pragmatischen schweizerischen Ansatzes möglicherweise für zulässig.

Meiner Ansicht nach erlaubt die Eigentumsgarantie des Art. 14 GG, die Luft ebenso wie das Wasser einem öffentlich-rechtlichen Regime zu unterstellen. Wie das Bundesverfassungsgericht in seiner Naßauskiesungsentscheidung eine Bewirtschaftung des Wassers mittels Ermessensentscheidungen der zuständigen Behörde für verfassungsgemäß erklärt hat, so wäre auch eine vergleichbare Bewirtschaftung der Nutzung der Luft zulässig, sofern alltägliche, die Umwelt nur unwesentlich belastende Nutzungen ebenso erlaubnisfrei blieben wie die Entnahme kleinerer Wassermengen. Zu denken wäre keineswegs nur an das Atmen, sondern etwa auch an das Heizen einer Wohnung. Die Bewilligung von über einen solchen Gemeingebrauch hinausgehenden Sondernutzungen könnte einem Bewirtschaftungsermessen unterstellt werden. Löst nicht eine Bewirtschaftung auf angemessene Weise den Interessenkonflikt zwischen der Freiheit des Eigentümers, der die Luft mit Schadstoffen belasten will, und der Freiheit seiner Mitmenschen, die eine möglichst saubere Luft atmen wollen? Muß man nicht die Eigentumsgarantie so verstehen, daß sie dem Gesetzgeber die Aufgabe zuweist, über die Einführung eines Bewirtschaftungsermessens zu entscheiden? Art.14 GG enthält nicht nur die rechtsstaatliche Eigentumsgarantie, sondern auch die demokratisch fundierte Zuweisung der Inhalts- und Schrankenbestimmung an den Gesetzgeber. Die Verfassung hat darauf vertraut, daß der Gesetzgeber in rechtsstaatlich vertretbarer Weise festlegt, wie weit die Rechte des Eigentümers reichen.

Hoffmann-Riem: Der Vorstand hat uns das spannende Thema des Wechselverhältnisses von „Eigentum“ und „Umweltschutz“ vorgegeben. Durch die Themenformulierung und die ergänzenden Fragen hat er gleichzeitig einen inhaltsschweren Akzent gesetzt: Er hat nämlich stets das Eigentum als Ausgangspunkt gewählt. Alle Referenten und die Diskussionsredner haben sich an diese Akzentsetzung gehalten. 
Ich möchte gleichwohl einmal das Thema von seinem eigentumsrechtlichen Kopf auf die umweltrechtlichen Füße stellen. Wenn man das Thema so umformuliert, ergeben sich nämlich für manche Fragen andere Akzente auch in den Antworten. Das Thema müßte dann heißen: „Umweltschutz bei der Nutzung des Eigentums“. Die damit verbundenen Akzentveränderungen möchte ich an drei Beispielen verdeutlichen.

Als erstes greife ich das von Herrn Wieland soeben analysierte Beispiel der Luftnutzung auf. Herr Ehlers und Herr Rill haben beide gesagt (Thesen 10 bzw. 5 e), daß die Nutzung der Luft zum Eigentum dazugehört. Herr Eblers hat eine Begründung gegeben: Die Luftsäule müsse mitgeschützt sein, weil ohne deren Nutzung das Eigentum funktionslos werde. Nun glaube ich nicht, daß irgend jemand eine Luftsäule nutzt. Ich denke, man nutzt Luft, und Luft ist extrem flüchtig. Die von mir angesprochene Akzentänderung ergibt sich bei der Überlegung, daß nicht nur das Eigentum funktionslos werden kann; vielmehr kann die Nutzung der Luft durch den Eigentümer des Grundstücks dazu führen, daß die Luft funktionslos wird, und zwar nicht nur für ihn. Also müssen die Antworten andere sein, als die Referenten sie gegeben haben. Sie können in der Richtung gefunden werden, die Herr Wieland eben angedeutet hat. Ich würde die Konstruktion nur dogmatisch etwas anders ausrichten. Dabei knüpfe ich einerseits an die Thesen z. B. von Herrn Ossenbiubl und Herrn Frotscher an, die auf die gebotene Differenzierung der Eigentumsrechte verwiesen haben; andererseits an die von Herrn Ehlers angesprochene Idee, daß es einen persönlichen Mindeststandard gibt, den er das Untermaßverbot genannt hat. Dieser Mindeststandard muß sicherlich die existentielle, persönliche Nutzung des persönlichen Eigentums betreffen. Nicht aber kann ich mir vorstellen, daß es einen verfassungsrechtlich zwingenden Mindeststandard auch im Hinblick auf die Luftnutzung gibt, soweit die unternehmerische Nutzung von Grundeigentum betroffen ist. Vielmehr muß es möglich sein, etwa wenn die vorhandene Luftbelastung die weitere Luftnutzung nicht ohne Schaden für alle zuläßt, jegliche unternehmerische Nutzung der Luft auszuschließen. Ein solcher Nutzungsausschluß wäre keine Enteignung des Eigentümers.

Mein zweites Beispiel führt zum Thema des Bestandsschutzes. Bestandsschutz taucht bei Herrn Eblers z. B. in These 16 oder bei Herrn Rill in These 11 auf. Wenn man nicht vorrangig nach dem Bestand des Eigentums fragt, sondern nach dem Bestand der Luftqualität - also wieder die erwähnte Akzentveränderung vornimmt dann ergeben sich erhebliche Rangordnungsverschiebungen. Ich will 
das nicht umfassend ausführen, sondern nur beispielhaft ein Unterthema ansprechen. Man sagt immer, der Bestandsschutz beim Eigentum sei besonders stark, wenn es um den Schutz von getätigten Dispositionen gehe. Wie ist es aber, wenn die von dem Unternehmer getroffenen Dispositionen auf Erträgen aufbauen, die nur dank der übermäßigen Ausnutzung der Umwelt erwirtschaftet werden konnten? Kann die frühere Ausbeutung gewissermaßen zur rechtlichen Barriere für den Schutz der Allgemeinheit in der Zukunft werden? Doch wohl kaum. Also ist auch das Thema "Dispositionsschutz" sehr viel differenzierter zu betrachten, wenn es gleichzeitig unter Berücksichtigung des "Bestandsschutzes“ für das Medium Luft behandelt wird.

Meine dritte Anmerkung ist grundsätzlicher Art. Bei der Beschäftigung mit Eigentumsrechten und -beschränkungen pflegt man in Kategorien von Gefahren und Schutz zu sprechen. Die von der Rechtsordnung bereitgestellten Institutionen der Gefahrenabwehr und der Schutzvorsorge bauen dabei auf einem bestimmten Kausalitätsverständnis auf, nämlich dem der linearen Kausalität. Dieses Kausalitätsmodell ist in dem üblichen Schrankendenken immanent, es wird bei Eignungsprüfungen zugrunde gelegt und es wirkt auf unsere Wahrscheinlichkeitsüberlegungen, Bewreislastverteilregeln usw. ein. Wenn ich mir nun die von Herrn Eblers an den Anfang seiner Ausführungen gestellten Bedrohungen der Umwelt ansehe, also etwa das Waldsterben oder das Ozonloch, dann frage ich mich und Sie, ist es eigentlich Zufall, daß Herr Eblers am Ende keine Antwort gegeben hat, wie seine dogmatischen Figuren zur Bekämpfung dieser Bedrohungen einsetzbar sind? Ich habe den Verdacht, dies könne daran liegen, daß die Rechtsfiguren, mit denen wir uns üblicherweise beschäftigen, z.T. gar nicht dazu taugen, den hochkomplexen Umweltgefährdungen beikommen zu können, die die Risikogesellschaft prägen. So habe ich in den Referaten keine Auseinandersetzung mit dem Problem der summierten Gefahren oder der Synergieeffekte gehört. Es fehlte eine Befassung mit latenten Risikolagen. Könnte es nicht sein, daß man bei der Lösung all dieser Probleme nicht mehr weiterkommt, wenn man wie bisher in linearen Kausalkategorien denkt? Muß man dieses nicht durch ein Denken in dynamischen Kausalitäten ersetzen und dabei etwa aus der Chaostheorie lernen, sich mit den im Umweltbereich möglichen - Katastrophen auslösenden - „Schmetterlingseffekten“ befassen und Fertigkeiten im Umgang mit "Turbulenzen“ entwikkeln? Das aber würde etwas erfordern, das auch ich hier natürlich nicht leisten kann, das aber - wie ich glaube - eine Aufgabe der Zukunft sein muß. Es wird nämlich darum gehen, die Dogmatik 
wirklich neu zu konzipieren, und zwar viel radikaler, als Sie, Herr Ehlers, das am Ende gefordert haben. Die Dogmatik des Eigentums in der vernetzten Risikogesellschaft kann nicht mehr die der bilateral gedachten Eigentümergesellschaft sein. Die Rechtsdogmatik und die rechtlichen Argumentationen müssen auf Formen komplexer Gefährdungen, auf Vernetzungen und eben auf den Umgang mit Turbulenzen umgerüstet werden, die nicht zuletzt aus der Nutzung des Eigentums und der Gefährdung des Guts „Umwelt“ entstehen können.

Murswiek: Ich spreche zum Thema „Eigentum und Umweltnutzung", und zwar greife ich einen speziellen Aspekt heraus, die Umweltnutzung, die die Grenzen des privaten Grundeigentums überschreitet. Im Ergebnis möchte ich hierbei Herrn Wieland und Herrn Hoffmann-Riem unterstützen. Die Eigentumsgarantie als Institutsgarantie umfaßt auch das Recht des Eigentümers, sein Sacheigentum zu benutzen. Das ist unstreitig. Im Prinzip dürfte auch unstreitig sein, daß der Eigentumsgebrauch nur insoweit unter dem Schutz der Eigentumsgarantie steht, als er nicht in Rechte Dritter eingreift. Der Eigentümer eines Messers hat kraft dieses Eigentums nicht das Recht, fremde Kehlen durchzuschneiden. Ein Gesetz, das solche Handlungen verbietet, schränkt nicht das Eigentum ein, sondern die allgemeine oder spezielle Handlungsfreiheit. Das Recht, auf öffentlichen Straßen mit dem Auto zu fahren, um ein anderes Beispiel zu nennen, folgt nicht aus dem Eigentum am Auto, sondern aus dem Gemeingebrauch. Ich behaupte, daß entgegen verbreiteter Meinung in bezug auf die Nutzung öffentlicher Umweltgüter nichts anderes gelten kann, und möchte meinen Standpunkt in Auseinandersetzung mit These 10 von Herrn Eblers verdeutlichen. Herr Eblers, wenn Sie mit der Luftsäule über dem Grundstück den geometrischen Raum über der Grundfläche meinen und nichts weiter, dann haben Sie mit dieser These völlig recht. Ihr argumentum ad absurdum, daß man andernfalls auf dem Grundstück nicht bauen, ja nicht einmal ein Blümchen wachsen lassen könnte, würde nichts als eine Selbstverständlichkeit untermauern. Um einen völlig anderen Sachverhalt geht es dagegen bei der Nutzung des Umweltmediums "Luft“. Hier haben wir es nicht mit einer, wie Sie es nennen, „Luftsäule“ zu tun, die fest und unerschütterlich auf dem Grundstück steht. Die Winde wehen, wie sie wollen, und sie ignorieren die Grundstücksgrenzen nicht einmal. Wer die Luft mit Schadstoffen in nicht völlig unerheblicher Quantität befrachtet, der nutzt nicht lediglich die von Ihnen dem Eigentum zugeordnete „Luftsäule“ über seinem Grundstück, sondern der greift mit seinen Immissionen über die Grundstücksgrenzen hinaus, belastet die Luft auch 
anderswo, oft in großen Entfernungen. Hierzu gibt die Eigentumsgarantie keinen Rechtstitel. Insoweit muß exakt dasselbe für die Luft gelten, was das Bundesverfassungsgericht für das Grundwasser gesagt hat. Eigentumsrechtlich geschützte Befugnisse, die Ressource Luft zur Befrachtung mit Schadstoffen zu nutzen, gibt es daher nur insoweit, als das geltende Recht entsprechende Luftnutzungsbefugnisse als subjektive Rechte ausgestaltet, zum Beispiel über den begrenzten Bestandsschutz für genehmigungsbedürftige Anlagen, unter Umständen auch sonst unter Vertrauensschutzaspekten. Ich nehme an, daß sich Entsprechendes generell für die Nutzung öffentlicher Umweltgüter sagen ließe.

Püttner: Der fortgeschrittenen Zeit wegen nur einige Fragen. Die Referenten und Herr Häberle sprachen von "kleinem Eigentum“ und von „großem Eigentum“. Meine Frage: Gibt es insoweit einen unterschiedlichen Schutz? Sehen Sie Ansatzpunkte dafür in Ihren Ländern? Die Weimarer Reichsverfassung kannte ja einen gewissen Vorzug für selbsterarbeitetes Eigentum oder Vermögen; könnte es so etwas auch heute geben? Zweitens: Das Stichwort Eigentumsstruktur ist nur bei Herrn Hänni etwas deutlicher angeklungen (in der Frage "Monopol der öffentlichen Hand"). Aber das Thema wird uns sicherlich bald wieder beschäftigen, wie weit die öffentliche Hand Eigentum aus dem Verkehr ziehen darf, vielleicht auch entwerten darf, so daß gar keine Möglichkeiten für die Privaten mehr bestehen, interessantes Eigentum zu haben, zu erwerben, zu pflegen. Meine Frage: Bietet dagegen die Verfassung Schutz, ist also eine bestimmte Eigentumsstruktur vorgegeben, die der Staat notfalls durch entsprechende Regelungen schützen und wahren muß? Das würde mich aus allen drei Ländern interessieren. Aber Herr Ehlers, wenn Sie antworten, dann bitte ich zu berücksichtigen, daß außer des von Ihnen genannten Art. 14 auch noch der Art. 15 im Grundgesetz steht, der gewöhnlich überlesen wird, aber zum Text der Verfassung gehört.

Ein weiterer Punkt: Erwähnt wurde die Unterscheidung zwischen Eigentum und verliehenen Rechten oder wohlerworbenen Rechten. Ich plädiere mit Herrn Rill gegen Herrn Stolzlechner nachhaltig dafür, daß wir nicht den Eigentumsbegriff endlos ausweiten und auch auf gewöhnliche Gewerbegenehmigungen oder Ausnahmegenehmigungen erstrecken. Dann wird das Eigentum konturenlos, und dann wird der Eigentumsschutz konturenlos. Damit haben wir im Grunde nichts gewonnen, sondern möglicherweise eher eine Einbuße zu verzeichnen. Ich darf also auch Herrn Ehlers, Herrn Hänni fragen, wie Sie es eigentlich damit halten wollen. 
Zum Schluß: Herr Ossenbübl (nicht mehr im Saal) hat behauptet, das Bundesverfassungsgericht habe fehlgegriffen, als es die wirtschaftspolitische Neutralität des Grundgesetzes postulierte. Ich möchte nur daran erinnern, daß das Gericht damals hinzugefügt hat: In den Grenzen der Festlegungen der Verfassung. Und wir haben nun bemerkt, daß diese Festlegungen offenbar etwas stringenter sind, als wir das damals vermutet haben. Aber das wesentliche Anliegen des Verfassungsgerichts war damals darauf hinzuweisen, daß wirtschaftspolitischer Gestaltungsspielraum für den Gesetzgeber verbleiben und nicht alles aus der Verfassung herausgelesen werden soll; und das können wir heute auf Art.14 GG mit dem gleichen Recht nach wie vor anwenden. Ich lese Art. 14 Abs. 1 so, daß da drin steht: Inhalt und Schranken des Eigentums werden vom Gesetzgeber bestimmt und nicht vom Bundesverfassungsgericht, schon gar nicht per Güterabwägung.

Steinberg: Herr Ehlers hat sehr eindrucksvoll für uns die Konturen eines neuen Systems der Eigentumsgarantie auf der Basis der Rechtsprechung des Bundesverfassungsgerichts entworfen. Das Bundesverfassungsgericht hat, Herr Ehlers hat es in seinem Zwischenbeitrag sehr deutlich gesagt, diese Rechtsprechung nicht erst vor zehn Jahren entwickelt, sondern in einer Fülle von vorangegangenen Entscheidungen, die allerdings erst seit 1981 auch in die Rechtsprechung der Fachgerichte Eingang gefunden haben. Mit dieser Rezeption haben wir ein großes Maß an Rechtssicherheit wiedergewonnen, auch wenn natürlich viele Fragen offenbleiben und immer offenbleiben werden. Im übrigen schreibt das Bundesverfassungsgericht keine Lehrbücher. Das ist wohl eher unsere Aufgabe.

Ich möchte zu der Frage Stellung nehmen, was diese neue Rechtsprechung unter dem Gesichtspunkt des Umweltschutzes bringt. Hier gibt es, wie ich denke, eine Reihe von wichtigen Gesichtspunkten. Erstens: Die bisherige Konzentration der Diskussion auf Art. 14 Abs. 3 GG wurde abgeschwächt. Wesentliche Probleme sind in den Bereich des Art. 14 Abs. 1 GG verlagert worden, und das lenkt, wie Herr Eblers völlig richtig ausgeführt hat, den Blick auf die Gestaltungsspielräume des Gesetzgebers. Ich glaube also, die Perspektive hat sich völlig verwandelt, und die alte, teilweise auch fruchtlose Kontroverse „Eigentum/Enteignung hier - Umweltschutz dort“ ist abgemildert.

Der zweite Punkt ist bereits mehrfach betont worden: die Stärkung der Rolle des Gesetzgebers durch die Anerkennung der Befugnisse zur Inhaltsbestimmung. Wir haben eben nicht mehr das Eigentum, 
sondern wir haben einen sehr differenzierten, flexiblen, situativen Eigentumsbegriff. Ich kann hier keine Kriterien zulässiger Differenzierungen bei der Inhaltsbestimmung liefern, das würde zu weit führen, aber ich denke, daß manches, was die Fachgerichte in den vergangenen Jahren zur Abgrenzung von Inhaltsbestimmung und entschädigungspflichtiger Enteignung entwickelt haben, hier bei der Inhaltsbestimmung im Rahmen des Art. 14 Abs. 1 GG eine Rolle spielen wird. Die Gestaltungsspielräume des Gesetzgebers sind nicht nur, und das ist für den Umweltschutz natürlich von großer Bedeutung, anzuerkennen bei der Frage der Inhaltsbestimmung als solcher, sondern auch bei Härteregelungen in Fällen unzumutbarer Belastungen, von denen die Festsetzung von Entschädigungen in Form der ausgleichspflichtigen Inhaltsbestimmung nur eine Möglichkeit darstellt.

Dritter Punkt: Diese neue Rechtsprechung führt zu einer Stärkung der Rolle des Bundesverfassungsgerichts, und viertens, das ist sozusagen die Kehrseite, es führt zu einer Schwächung der Bedeutung des Richterrechts. Und das ist sicherlich nicht ganz ohne Auswirkungen für die in Betracht kommenden Wertungsgesichtspunkte, die bei der Ausgestaltung des Eigentums eine Rolle spielen.

Auch nach der Neu-Orientierung der eigentumsrechtlichen Dogmatik bleiben zweifellos viele Fragen offen, und sie müssen auch deshalb offenbleiben, weil letztendlich durch keine noch so neue Formel, etwa des formalisierten Enteignungsbegriffs, die wesentliche Aufgabe der Bewertung der staatlichen Inpflichtnahme von Eigentum in der konkreten Situation entbehrlich wird. Allerdings ist die Bewertung grundsätzlich heute vom Gesetzgeber vorzunehmen und nicht mehr von den Gerichten. Das erscheint unter Umweltschutzgesichtspunkten von weitreichender Bedeutung.

So sehr ich im Grundsatz mit dem Referat von Herrn Eblers übereinstimme, so bin ich in einem Punkte dezidiert anderer Ansicht, und zwar zu These 5, der Anerkennung des sog. eingerichteten und ausgeübten Gewerbebetriebs als Eigentum. Bemerkenswert erscheint, daß dieses Recht als Eigentumsrecht weder in der schweizerischen noch in der österreichischen Rechtsordnung anerkannt ist, wie der schweizerische und der österreichische Landesbericht gezeigt haben. Nach meiner Ansicht ist auch die deutsche Rechtslage nicht anders. Hierzu nun einige Hinweise:

Erstens: Das Bundesverfassungsgericht ist offensichtlich dabei, diesen Topos aufzugeben. Der Befund der neueren Rechtsprechung erscheint mir insoweit eindeutig. Zweitens: Ich halte es für sehr problematisch, Herr Ehlers, wenn Sie, wenn ich Sie richtig verstanden 
habe, formulieren, solange dieses Recht ein sonstiges Recht im Sinne von $\$ 823$ Abs. $1 \mathrm{BGB}$ sei, müsse es auch ein Eigentumsrecht i.S. des Art. 14 GG sein. Das halte ich für einen sehr problematischen Ansatz, und ich denke, daß selbst der Bundesgerichtshof, der ja im Anschluß an das Reichsgericht diese Formel entwickelt hat, davon abgerückt ist, und zwar in der Puffreisentscheidung (BGH, DÖV 1990, 1065). Drittens: Ich glaube, daß die Notwendigkeit der Betonung des Eigentumcharakters des eingerichteten und ausgeübten Gewerbebetriebs, modern wird dies im Zivilrecht zu $\$ 823$ Abs. 1 BGB als Unternehmensrecht oder das Recht der gewerblichen Betätigung bezeichnet, überschätzt wird. Diese Position ist selbstverständlich ein Recht, und auch eine verfassungsrechtlich geschützte Rechtsposition. Nur, die gewerbliche Betätigung fällt in den Schutzbereich des Art. 12 Abs. 1 GG, und ist eben dort zu bearbeiten und unterliegt möglicherweise dort dann ähnlichen Regeln wie das Eigentum des Art. 14 Abs. 1 GG, also vor allen Dingen der Ausgestaltungsmöglichkeit des Gesetzgebers. Dort im Rahmen von Art. 12 Abs. 1 GG ist auch die Möglichkeit der Zubilligung von Entschädigung anzuerkennen, die man da natürlich nicht ausgleichspflichtige Inhaltsbestimmung nennen kann, sondern für die ich die Bezeichnung „Verhältnismäßigkeitsausgleich“ vorgeschlagen habe und für die es Hinweise in der Rechtsprechung des Bundesverfassungsgerichts gibt. Damit würde einem wesentlichen Anliegen der Rechtsprechung des Bundesgerichtshofs Rechnung getragen, einen finanziellen Ausgleich bei unzumutbaren Belastungen der gewerblichen Betätigung zu gewähren. Ähnlich lassen sich die Probleme des eingerichteten und ausgeübten Gewerbebetriebs im Bereich des Staatshaftungsrechts lösen. Wenn man sich von dem Gedanken löst, und auch dafür gibt es zahlreiche Ansätze, daß der sog. enteignungsgleiche Eingriff nur bei der Verletzung von Eigentumsrechten Entschädigungsansprüche einräumt, und statt dessen anerkennt, daß alle rechtswidrig verletzten Rechte nach Staatshaftungsrecht ausgleichspflichtig sind, dann ergibt sich zwangsläufig auch bei rechtswidrig verletzten Unternehmerrechten eine Ersatzpflicht. Dies ist $\mathrm{m}$. A. nach der systematisch richtige Ort für einen Ausgleich in diesen Fällen.

$\mathrm{Zu}$ einem weiteren Punkt kann ich mich sehr kurz fassen, weil darauf einige Vorredner bereits eingegangen sind. Das ist die Bestandsschutzdiskussion, hier vor allen Dingen mein Zweifel an der These 10 von Herrn Ehlers. Es erscheint zunächst sehr einprägsam, wenn gesagt wird, es gäbe kein zweidimensionales Eigentum. Nur, die Frage ist doch, gehört zum Eigentumsrecht auch die Befugnis, umweltschädigende Substanzen zu emittieren und damit möglicher- 
weise Schäden, Verletzungen der Grundrechte Dritter oder von Umweltschutzgütern herbeizuführen. Für die Beantwortung dieser Frage halte ich das Luftsäulenbild für nicht sehr überzeugend. Vor allem scheint diese These dem Grundkonzept des Referates zu widersprechen, in dem der Ausgestaltungsspielraum des Gesetzgebers betont wird. Es gibt doch - auch nach Auffassung von Herrn Ehlers - keine abstrakte Eigentumsposition mehr. Warum soll nicht, wie beim Grundwasser ( $\$ 1$ a WHG), der Gesetzgeber etwa eine ähnliche Regelung in $\$ 1$ a BImSchG aufnehmen. Auf die Zulässigkeit einer derartigen Regelung deutet auch der Klammerzusatz des Bundesverfassungsgerichts in seinem Naßauskiesungsbeschluß hin, wo Ausführungen zum Grundwasser gemacht werden und in Klammern hinzugefügt ist „und die Luft“ (BVerfGE 58, 300, 339). Die Probleme sind offensichtlich austauschbar, und das muß auch ähnliche Problembewältigungen erlauben. Und damit sehe ich eigentumsrechtlich keine Bedenken, daß etwa der Gesetzgeber diese Luftverschmutzungsrechte aus dem Begriff des Eigentums ausschließt, und konsequenterweise nicht länger einen Rechtsanspruch auf die immissionsschutzrechtliche Genehmigung einräumt. Ich will nicht sagen, daß dies rechtspolitisch erwünscht sein muß. Darüber kann man diskutieren. Aber die jetzige Ausgestaltung des $\$ 6 \mathrm{BImSchG}$ wird nicht durch Art.14 GG geboten.

Zum Schluß eine ganz kurze letzte Bemerkung, Herr Häberle hat aus Verfassungsmaterialien die Staatszielbestimmung Umweltschutz in einer Reihe von Ländern, auch von neuen Bundesländern, erwähnt. Ich möchte darauf hinweisen, daß wir in Hessen seit Anfang d.J. eine Staatszielbestimmung Umweltschutz in unserer Landesverfassung haben, die im Januar in einer Volksabstimmung von über $80 \%$ der Bevölkerung beschlossen wurde. Vielleicht könnte dies ein Vorbild für den Bundesgesetzgeber, aber auch die neuen Länder sein.

Pitschas: Wir sind ja nun fast in einem Seminar, da darf man doch noch einmal manche Fragen an die Herren Referenten etwas einfacher stellen. Die erste Frage, die ich aufwerfen möchte, bezieht sich auf die konzeptionelle Gedankenführung. Ich schlage in die gleiche Kerbe wie Herr Steinberg, etwas tiefer vielleicht. Die Vorredner häufen Gedankenbausteine auf Bausteine und stützen das alles auf Art. 14 GG, doch ist denn das überhaupt das ganze Fundament, um das Thema so recht zu bearbeiten? Ich möchte vielmehr als ersten Punkt anregen, daß man über die Querbeziehung zur Berufsfreiheitsgarantie nachdenkt. So ist das Recht am eingerichteten und ausgeübten Gewerbebetrieb beispielhaft genannt worden. Das ist ja in der Tat in einer 
These von Ihnen, Herr Eblers, aufgetaucht, wo es um den Krabbenfischerfall geht. Mich hat doch sehr verblüfft, daß Sie im Rahmen des „Untermaßes“ plötzlich dazu kamen, der Krabbenfischer könne sich dann mit seinem Gewerbebetrieb gegen die Einleitung von Dünnsäure nicht mehr zur Wehr setzen. Ich finde, wir müßten gerade in diesem Punkt die Synergieeffekte, bevor wir ins Chaos kommen, von Art. 12 und Art. 14 GG zusammenführen; und dann bestimmt Art. 12 Abs. 1 GG die eigentumsrechtliche Untermaßgarantie.

Der zweite Punkt. Sie hatten, sehr geehrter Herr Ehlers, dankenswerterweise in Ihrer Zwischenbemerkung hervorgehoben, Art. 14 Abs. 2 GG vermittele uns so etwas wie einen sozioökologischen Minimalstandard. „Sozio" deshalb, weil es ja ein Aspekt der Sozialstaatsgarantie ist, die nicht weiter explizit hier genannt worden ist. Wenn man sie aber als Ordnungsprinzip des Miteinanderlebens im Sozialstaat versteht, dann hat Art.14 Abs.2 GG daran teil und vermittelt auch in diesem Miteinanderleben umweltschutzrechtliche Standards. Dies war wohl auch Ihre Auffassung. Ich will sie an dieser Stelle noch einmal klarstellen mit zwei Konsequenzen. Die erste Konsequenz daraus ist für mich, daß sich die Staatszieldiskussion um den Umweltschutz relativiert. Zweitens, und mir wichtiger, ist der Gedanke: Es ergibt sich eine Lastenperspektive im Umweltschutzrecht für den Bürger, vor allem aber auch für die Unternehmen, und zwar direkt aus Art. 14 Abs. 2 GG, Art.12 Abs.1 GG sowie dem Sozialstaatsprinzip.

Ich möchte noch ein Kompetenzproblem hinzufügen, das sich aus dem Verständnis der Grundrechtsdimensionen überhaupt ergibt. Herr Rill führt in den Thesen 19 und 20 aus, daß bei der Atomenergiediskussion gar nicht die Grundrechte maßgebend wirken würden und schon gar nicht das Eigentumsrecht. Ihr Stichwort war „Neutralität“. Was ist das für ein Verständnis der Grundrechte? Ich setze dagegen die soziale Steuerungsdimension des Eigentumsgrundrechts. Art.14 GG kann doch nicht ohne diese sozialstaatliche Dimension bleiben - und dann Neutralität! Das schmeckt mir nicht ganz, sondern ich würde eher sagen, keine Neutralität, sondern dynamischer Grundrechtsschutz. Das ist die deutsche Lösung und d.h., Vertrauen in den Gesetzgeber zu setzen. Im Gegensatz zu manchem meiner Vorredner möchte ich hierzu doch noch einmal das von Herrn Ehlers hergenommene Boxberg-Urteil ins Feld führen. Auf der einen Seite fordert es höchst differenzierte Verfahrensgarantien, auf der anderen Seite die Pflicht zur öffentlichen Diskussion - und das ist ein ziemliches inhaltliches Kriterium bei der Verfolgung umweltpolitischer Ziele. 
Und ein letzter Punkt, bitte schön. Wenn wir so Sozialstaatsgarantie, Berufsfreiheitsgarantie, Kompetenzunterfütterung zur Diskussion des Eigentumsgrundrechtsschutzes hinzunehmen, dann gewinnen wir doch ein breiteres Fundament der Steuerung von Umwelt- und Bodenordnung durch Eigentumspolitik. Einen so vernetzten Verbund könnte man Systemsteuerung durch „Umweltverfassung“ nennen. Ich wollte dies noch einmal in einer konzeptionellen Anmerkung vortragen. Leider etwas spät, Herr Vorsitzender.

Huber: Ich möchte es ganz kurz machen und Herrn Ehlers, dessen Konzeption ich insgesamt sehr klar und einleuchtend gefunden habe, nur in zwei Detailpunkten widersprechen. Er hat unter der These 9 u. a. den Fall behandelt, daß Erlaubnisse und Bewilligungen nach dem Wasserhaushaltsgesetz eigentumsrechtlich verankert seien. Dem möchte ich widersprechen. Wenn nämlich die Eigentumsgarantie des Art. 14 selbst keine Rechtsposition ist, wie Herr Ehlers dies jenseits des "Untermaßverbotes" in der These 4 festgestellt hat, was ja auch richtig ist, dann steht es in der Gestaltungsfreiheit des Gesetzgebers, bestimmten Rechtspositionen den Charakter vermögenswerter Rechte zu verleihen. Der Gedanke der Kompensation, aus dem heraus er jedoch die Verankerung der Erlaubnisse und Bewilligungen in Art. 14 GG hergeleitet hat, setzt hingegen einen Eingriff in ein vorgefundenes Rechtsgut voraus, also einen vorverfassungsrechtlichen Eigentumsbegriff. Das widerspricht $\mathrm{m}$. E. der unter These 4 angeführten Ausgangsposition.

Zum zweiten möchte ich auch auf den gerade von Herrn Pitschas angeführten Fall des Krabbenfischers eingehen. Herr Eblers hat hier in der These 12 gesagt, daß bei mittelbaren Einwirkungen besonders strenge Anforderungen an die Zurechenbarkeit zu stellen seien. Ich glaube, diese Formulierung ist mißverständlich, da die Zurechenbarkeit der Einwirkung bei jeder Belastung Voraussetzung für die Eröffnung grundrechtlicher Schutzbereiche ist. Ich meine, es wäre besser, wenn man sagen würde, es seien besonders strenge Anforderungen an die Intensität der Grundrechtsbeeinträchtigung zu stellen. Im Fall des Krabbenfischers kann man so dann durchaus zu einer Beeinträchtigung des eingerichteten und ausgeübten Gewerbebetriebs kommen wenn man dieses Recht akzeptiert —, falls die Überdüngung der Nordsee, die ja in diesem konkreten Fall eine Rolle gespielt hat, dazu führen würde, daß der Gewerbebetrieb des Krabbenfischers zum Erliegen käme.

Friauf: Mit dem Blick auf die Uhr des Herrn Vorsitzenden muß ich mich auf einige Stichworte beschränken: Die Eigentumsgarantie 
gehört zu den zentralen verfassungsrechtlichen Faktoren, die die Wiedergeburt absolutistischer Bestrebungen, in welchem Gewande auch immer, verhindern sollen. Sie wirkt, unter dem Blickwinkel unseres heutigen Themas, auch als Verbot eines „Umweltabsolutismus“. Die jeweils in Frage stehenden Ziele des Umweltschutzes dürfen, so legitim und bedeutsam sie an sich erscheinen mögen, in keinem Fall absolut gesetzt und einseitig realisiert werden. Die Eigentumsgarantie erzwingt vielmehr in jedem Fall einen angemessenen und gerechten Ausgleich mit den Belangen der betroffenen Eigentümer. Das muß auch bei dem im Prinzip berechtigten Hinweis auf die Gesetzesabhängigkeit des Eigentums (Thesen 2 und 4 von Herrn Eblers) bedacht werden. Der den Inhalt des Eigentums gestaltende Gesetzgeber ist seinerseits, auch soweit er Belange des Umweltschutzes verfolgt, nicht im Sinne eines absolutistischen „sic volo, sic jubeo..." frei, sondern unterliegt wesentlichen grundrechtlichen Vorgaben.

Der These 10 von Herrn Ehlers pflichte ich, entgegen der durch die Herren Frotscher und Steinberg geäußerten Kritik, nachdrücklich bei. Das Recht zur Nutzung der Luftsäule über einem Grundstück wird, als notwendige Voraussetzung jedweder überhaupt denkbaren Grundstücksnutzung, vom Eigentum am Grundstück umfaßt. Es kann, anders als das Recht zur Gewässerbenutzung, nicht vom Grundstück getrennt und von einer besonderen staatlichen Verleihung abhängig gemacht werden. Überspitzt gesagt: Ein Grundstück, auf dem ich nicht ohne besondere Erlaubnis atmen darf, mag auch das von mir ausgeatmete Kohlendioxyd zur Umweltbelastung beitragen, das gehört mir nicht. Freilich müssen, was Art und Intensität der Luftbenutzung angeht, die berechtigten Belange des Umweltschutzes beachtet werden. Dabei handelt es sich dann aber um eine (sekundäre) Problematik der gesetzlichen Schrankenziehung, nicht um die (primäre) Frage des Schutzbereiches der Eigentumsgarantie als solcher. Problematisch erscheint mir in diesem Zusammenhang auch Herrn Häberles These von der abgestuften Intensität des Eigentumsschutzes. Sicher kann die Rechtsordnung das Eigentum an einem Grundstück nicht in jeder Hinsicht ebenso behandeln wie das Eigentum, das einem Staatsrechtslehrer an seiner Privatbibliothek zusteht. Auch hier handelt es sich aber wiederum nicht um die Frage der Gewährleistung als solcher, sondern lediglich um die Schrankenziehung, in deren Rahmen bei den verschiedenen Eigentumsobjekten naturgemäß unterschiedliche Konfliktlagen mit öffentlichen Belangen bewältigt werden müssen. Ginge man demgegenüber bereits auf der Stufe der Gewährleistung von einer unterschiedlichen Schutzintensität (oder auch 
„Schutzwürdigkeit“) verschiedener Eigentumsobjekte aus, dann würde auf den folgenden Stufen der Schrankenziehung bis hin zur Bemessung der Enteignungsentschädigung leicht eine Spirale nach unten in Gang gesetzt, an deren Ende der Eigentumsschutz in manchen Fällen praktisch gegen Null tendieren müßte. Das aber kann schwerlich im Sinne des Art. 14 I GG liegen.

$\mathrm{Zu}$ der von den Referenten befürworteten Ausdehnung der Gewährleistungsbreite des Eigentums auf „alle vermögenswerten Rechte des öffentlichen Rechts, die nicht ausschließlich auf staatlicher Gewährung beruhen" (These 5 von Herrn Eblers), erscheint eine skeptische Bemerkung angezeigt. Die meisten von uns - ich schließe mich selbst ausdrücklich ein - sind im Anschluß an die schon vom Reichsgericht eingeleitete Entwicklung über Jahrzehnte hinweg für eine Ausweitung des Schutzbereichs des Art.14 I GG eingetreten. Heute, nachdem auch das BVerfG diese Konzeption übernommen hat, müssen wir uns aber fragen, ob wir hier keinen Irrweg beschritten haben. Wir können die Augen nicht mehr davor verschließen, daß die Extensivierung des Eigentumsschutzes mit innerer Zwangsläufigkeit zu einer weitgehenden Reduktion der Schutzdichte geführt hat, die schwerlich dem ursprünglichen Sinne der Eigentumsgarantie entspricht. In dem Maße, in dem das verfassungsgeschützte Eigentum verbreitert worden ist, hat es sich immer stärker ausgedünnt. Die Inhaber von Rentenanwartschaften aus der gesetzlichen Rentenversicherung haben praktisch nichts dadurch gewonnen, daß ihre Anwartschaften dem Schutz des Art.14 I GG unterstellt worden sind. Andererseits deutet sich an, daß die Formeln, mit denen diese Einbeziehung begründet zu werden pflegt, zu relativierenden Sprengsätzen für den Kernschutz des Eigentums werden könnten. -

Schließlich möchte ich mich, abweichend von der Äußerung des Herrn Vorsitzenden, auch aus deutscher Sicht ausdrücklich der These 12 von Herrn Hänni anschließen, die sich für die prinzipielle Einbeziehung des Vermögens in den Schutz der Eigentumsgarantie ausspricht. Ohne auf die dogmatischen Aspekte im einzelnen einzugehen, bleibt festzuhalten, daß es nicht richtig sein kann, den Eigentumswert dort schutzfrei zu lassen, wo das Eigentum als solches, das ja für den einzelnen in den meisten Fällen entscheidend erst durch seinen Wert Bedeutung besitzt, unter dem Schutz der Garantie steht. Herr Ossenbïhl hat in seinem Diskussionsbeitrag mit Recht auf die Umweltabgabenproblematik hingewiesen. Die Eigentumsgewährleistung in umweltrelevanten Bereichen müßte praktisch gegen Null tendieren, wenn es wirklich zulässig sein sollte, durch die - in der Phantasie mancher Politiker unbegrenzte - Erfindung von immer neuen Auf- 
gabenarten die betroffenen Eigentumsobjekte für die Inhaber zu entwerten.

Meyer: Herr Friauf, glauben Sie ernsthaft, daß das Recht zu atmen zu einem Eigentumsgrundrecht deshalb wird, weil Sie es auf dem Grundstück veranstalten?

Friauf: Der Einwand sticht nicht, Herr Meyer. Das individuelle Recht zu atmen hat als solches natürlich nichts mit dem Eigentum zu tun. Hier geht es aber um die spezifische Frage, wo, wie und zu welchem Zweck ich „atmen“, d.h. die Luft benutzen darf. Da ein Grundstück schlechterdings nicht ohne Inanspruchnahme seiner Luftsäule genutzt werden kann, läßt sich die Befugnis zur Nutzung der Luft nicht vom Bodeneigentum trennen, ohne dieses selbst in seiner Substanz zu zerstören. Wenn und soweit der Staat über die Inanspruchnahme der Luft verfügt, verfügt er zwangsläufig über die Nutzung des Eigentums an den betroffenen Grundstücken. In jedem Fall ist der Schutzbereich des Art. 14 I GG tangiert.

Schachtschneider: Eine gesicherte grundrechtliche Dogmatik der Eigentumsgarantie kann nur die materiale Offenheit des Eigentumsbegriffs dogmatisieren, wie das auch fast allgemein vertreten worden ist. Also ist der Eigentumsbegriff der Lage gemäß dynamisch zu entfalten. Das muß der Gesetzgeber tun. Aber das Bundesverfassungsgericht hat wegen Art. 1 Abs. 3 und Art. 19 Abs. 2, der Wesensgehaltsgarantie, die Kompetenz, stellvertretend für das Volk das letzte ordentliche Wort darüber zu sprechen, welches die jeweils richtige Eigentumsregelung ist. Die Eigentumsordnung muß sich in der Wirtschaftsordnung bewähren, also empirisch, und gegebenenfalls neuen Lagen oder besseren Erkenntnissen richtigen Rechts angepaßt werden. Auf diese Weise ist die jeweilige Eigentumsordnung Verwirklichung der allgemeinen Freiheit, wie Gesetze überhaupt die Freiheit verwirklichen und nicht beschränken. Herr Ehlers hat die Eigentumsgarantie als Freiheitsrecht vorgestellt. Was heißt das? Er hat das näher mit dem Schlagwort gekennzeichnet: Ohne Eigentum keine Freiheit. Ich befürchte, das bedeutet, daß manche viel und viele wenig Freiheit haben. Die Freiheit aber soll allgemein sein. Das müßte auch für das Eigentum gelten, das ganz unterschiedlich zugeteilt ist und wohl immer unterschiedlich zugeteilt sein wird. Ein Lösungsversuch anderer Art war der Sozialismus, der nicht erfolgreich war. Die Formel von Herrn Eblers bringt die Gefahr der Umdrehung mit sich, daß nämlich die Freiheit wie das Eigentum konzipiert wird. Das Eigentum 
wird meist als Herrschaftsrecht vorgestellt, das würde bedeuten, daß auch die Freiheit Herrschaft vermittelt, eine liberalistische, konstitutionalistische Position, die im Widerspruch zum Freiheitsbegriff steht. Die Freiheit ist Autonomie, und auch die Eigentumsgarantie ist als Autonomiekompetenz zu konzipieren, nicht als Herrschaftsrecht, als die Kompetenz also zur Nutzung von Sachen und anderen Lebensmöglichkeiten. Nicht zum Eigentum gehören die Nutzungsmöglichkeiten der Luft. Wenn die Luftsäule zum grundrechtlich geschützten Eigentum gehört, dann auch und insbesondere die Luft. Ich möchte aber meine Luft atmen können und nicht darauf angewiesen sein, das Eigentum anderer zu nutzen, wenn ich atmen, also leben will.

Nun zwei Nebenbemerkungen: Es besteht kein Bedarf für ein Recht am Unternehmen. Die Unabhängigkeit der Unternehmen wird durch die unternehmerische Effizienz gesichert. Gerade durch die Institution der Unabhängigkeit sind die Unternehmen wirtschaftlich erfolgreich. Das wollen wir, das bedarf keines Grundrechtsschutzes. Ein Grundrechtsschutz würde nicht mehr bedeuten als die Pflicht des Gesetzgebers, das Unternehmensrecht praktisch vernünftig zu regeln. Unterschiede zum geltenden Recht würde ein Grundrechtsschutz der Unternehmen kaum ergeben. Ähnliches ist zum Eigentumsschutz öffentlich-rechtlicher Rechte zu sagen. Ich folge insofern dem, was Herr Rill für Österreich ausgeführt hat. Die Regelungen vor allem der Sozialleistungen sind nach dem Rechtsstaats- und dem Sozialprinzip zu beurteilen. Die Eigentumsgarantie hilft insofern nicht weiter.

Sachs: Die Luftsäule muß ich natürlich dann auch jetzt kurz kommentieren, nachdem sie so in den Mittelpunkt gerückt ist. Ich hatte mir eben gedacht, der Unterschied zwischen dem Raum über dem Grundstück und dem Stoff „Luft“, den man ja auch in Flaschen packen kann, sei schon sehr wichtig, und ich wollte in Richtung von Herrn Murswiek sprechen. Die zwischenzeitlichen Beiträge haben mich dann doch in Überlegungen gestürzt, ob das richtig ist. Denn wenn wir das so sehen, diesen Unterschied wirklich konsequent machen, dann müssen wir ihn auch machen bei der Grundstücksfläche und dem Boden. Denn auch dieser Raum auf dem Erdboden ist etwas anderes als die Erde, die ich in Säcke packen kann. Und dann ist in der Tat von dieser Fläche nur noch ein abstraktes geometrisches Gebilde übrig, das Art. 14 sicherlich nicht alleine meint. Das soll nicht bedeuten, daß keine Unterschiede in der Behandlung des Verfahrens mit dem Grundstück mit seiner Oberfläche, mit der Luft über der Oberfläche angebracht wären. Denn mit Herrn Eblers Gegenkritik meine ich, daß auch dann, wenn der Gesetzgeber über völlige inhalt- 
liche Gestaltungsfreiheit verfügen würde bei der Inhaltsbestimmung des Eigentums, dies dennoch einen wesentlichen Grundrechtsschutz bedeuten würde, denn die so konstituierten beliebigen Inhalte würden immerhin gegen Änderungen geschützt sein, und das wäre doch schon etwas.

Dann vielleicht einige Unklarheiten, wenn Herr Eblers Zeit nachher hat, kann er sie möglicherweise aufklären. Bei These 13 finde ich den Begriff der imperativen Abgabenerhebung. Er wirft die Frage auf nach den nichtimperativen Abgabenerhebungen. $\mathrm{Da}$ fehlt mir momentan die Phantasie; vielleicht war es nur eine pleonastische Formulierung? Aber das wäre vielleicht klarzustellen.

Bei der Systematik der Eigentumsbeeinträchtigungen, Herr Ehlers, wollte ich nachfragen. Zwei Bereiche kann ich klar trennen. Einmal die deliktischen rechtswidrigen Beeinträchtigungen, die im Haftungsrecht behandelt sind, da habe ich keine Probleme. Die anderen sind die Beeinträchtigungen, die potentiell rechtmäßig sein könnten. Da unterscheiden Sie ja wohl die Schrankenbestimmungen einerseits, dann die Enteignungen andererseits, Enteignungen als näher qualifizierte Entziehungen. Da ist die Frge: Wenn es eine Entziehung gibt, die nicht alle diese Qualifikationen aufweist, ist das dann etwas drittes, oder würde das möglicherweise noch unter die Schrankenbestimmung fallen? Da hatte ich bei Ihrem Beispielsfall, daß bei Rechtsänderungen Positionen wegfallen, das Gefühl, daß Sie das wohl unter Enteignungen fassen würden. Da würde aber dann die Zuordnung für öffentliche Zwecke fehlen.

Dann bei These 26 ist es vielleicht nur ein Mißverständnis, wenn Sie mit dem Klammerdefinitionszusatz Erfolgsunrecht hier Fälle von rechtmäßigen Handlungen mit rechtswidrigen Folgen bezeichnen. Wenn ich richtig sehe, ist die Lehre vom Erfolgsunrecht so $\mathrm{zu}$ verstehen, daß durch den rechtswidrigen Erfolg auch die Handlung eben rechtswidrig wird und nicht rechtmäßig bleibt. Aber das ist vielleicht auch nur mißverständlich. Sie haben eben „an sich“ rechtmäBig, glaube ich, mündlich formuliert und gehen vielleicht mit mir konform, und dann ist die Zeit um, ich höre auf.

Maurer: Es ist mehrfach darauf hingewiesen worden, daß die Eigentumsgarantie eine Konkretisierung der Freiheitsrechte darstelle, Eigentumsschutz also Freiheitsschutz sei. Das ist sicher richtig. Nur darf der Blick auf den Gleichheitssatz nicht verlorengehen. Es ist daher sehr positiv zu werten, daß Herr Rill und Herr Hänni die Gleichheitsproblematik in ihre Referate einbezogen haben. Herr Zacher hat sie zu Recht ebenfalls wieder in seinem Diskussionsbeitrag erwähnt. 
Sodann möchte ich noch einige Bemerkungen zum Enteignungsbegriff von Herrn Eblers machen. Erstens: Herr Eblers weist zu Recht darauf hin, daß Enteignung die Entziehung des Eigentums „im Wege der Durchbrechung der Eigentumsordnung", d.h. der fortbestehenden Eigentumsordnung, ist. Das ist ein wesentliches Moment. Wäre dies gestern beachtet worden, dann wären die „Enteignungsmaßnahmen “, die früher in der sowjetischen Besatzungszone und in der DDR durchgeführt wurden, nicht als Enteignungen bezeichnet worden, sondern als das, was sie wirklich waren, nämlich als Sozialisierungen und Konfiskationen. Zweitens: Sie sprechen, Herr Eblers, in ihrem Enteignungsbegriff von "Staatsaufgaben“, von der Eigentumsentziehung zur Erledigung von Staatsaufgaben. Üblicherweise wird in diesem Zusammenhang von öffentlichen Aufgaben gesprochen. Es stellt sich daher die Frage, ob Sie mit den "Staatsaufgaben“ etwas anderes, etwas engeres meinen, als üblicherweise unter „offentlichen Aufgaben" verstanden wird. Drittens: Zur sog. Legalenteignung. Man müßte hier unterscheiden. Die Enteignung ist eine Exekutivmaßnahme. Deswegen erfolgt sie auch in der Regel durch Verwaltungsakt aufgrund eines Gesetzes. Ausnahmsweise kann aber anstelle der Verwaltung der Gesetzgeber eine Enteignung durchführen. Als Beispiel ist auf die Enteignung der Deichgrundstücke in Hamburg hinzuweisen, mit der sich auch das Bundesverfassungsgericht zu befassen hatte. Davon zu unterscheiden ist die Eigentumsneuregelung, durch die auch in bestehende Rechtspositionen eingegriffen wird. Nach der überwiegenden Meinung können solche Eingriffe eine Enteignung sein, müssen es aber nicht, so daß sich die weitere Frage nach der Abgrenzung stellt. In Wirklichkeit handelt es sich jedoch in diesen Fällen überhaupt nicht um eine echte Enteignung, sondern um ein Übergangsproblem. Das zeigt sich auch daran, daß die Voraussetzungen und die Folgen dieser Eingriffe anders sind. So trifft das, was Herr Ehlers über die Entschädigung sagte, durchaus auf die echte Enteignung zu, keineswegs aber auf diese zweite Gruppe von „Legalenteignungen“. Viertens: Ein wesentliches Problem des Enteignungsbegriffes und möglicherweise der ganzen Enteignungsdogmatik ist die Frage der teilweisen Enteignung. Die Enteignung erfaßt nach der neueren Definition nicht nur die vollständige, sondern auch die teilweise Entziehung des Eigentums. Sie haben, Herr Ehlers, eine Formel vorgeschlagen, die ich auch schon verwendet habe, mit der ich aber selbst nicht recht zufrieden bin, nämlich die Formel, daß sich die Enteignung auf die Entziehung von rechtlich verselbständigbaren oder verselbständigungsfähigen Eigentumspositionen beschränkt. Damit wollen Sie wahrscheinlich die teilweise Entziehung von den 
Nutzungs- und Verfügungsbeschränkungen abgrenzen. Die Frage ist jedoch, ob sich damit eine klare Grenze finden läßt, ferner ob es nicht doch auch Nutzungs- und Verfügungsbeschränkungen gibt, die bereits einen Eingriff in eine verselbständigungsfähige Eigentumsposition bilden und daher unter dem Begriff der Enteignung fallen. Das ist eines der Probleme, die noch geklärt werden müßten, was aber wohl nur aufgrund von Einzelfällen möglich ist, die einfach einmal durchdekliniert werden müßten, um dann vielleicht zu einem tragfähigen Ergebnis zu kommen.

Vorsitzender: Vielen Dank, Herr Maurer. Ich schließe jetzt die Diskussion und erteile unseren Referenten das Schlußwort. Zunächst Herr Hänni bitte.

Hänni: Ich werde mich angesichts der vorgerückten Zeit darum bemühen, meine Ausführungen so kurz und knapp wie möglich zu halten. Ich möchte zunächst eingehen auf das Verhältnis zwischen Umweltschutz und Eigentumsgarantie, das insbesondere von den Herren Wieland, Hoffmann-Riem und Murswiek angesprochen worden ist. Es stellte sich dabei die Frage, ob es sozusagen ein Recht auf Luftverschmutzung gebe. Mit Bezug auf das schweizerische Recht kann ich dazu sagen, daß es so etwas nicht gibt: Die im Umweltschutzrecht verbindlich festgesetzten Immissionsgrenzwerte, die Emissionsbegrenzungen und die Sanierungspflichten stellen Maßnahmen dar, die als Inhaltsbestimmungen des Grundeigentums prinzipiell entschädigungslos zu dulden sind. Auch wenn höchstrichterliche Entscheidungen dazu noch ausstehen, ist nicht daran zu zweifeln, daß solche Eingriffe in das Grundeigentum - insbesondere aufgrund der dogmatischen Konzeption der Zizers-Entscheidung - nicht als materielle Enteignungen zu qualifizieren sind. Insofern beinhaltet die Eigentumsgarantie keinen Anspruch auf Luftverschmutzung.

Herr Püttner hat sich sodann gefragt, ob durch die Eigentumsgarantie wohl eine bestimmte Eigentumsstruktur geschützt sei. Das würde ich bejahen, es ist eine bestimmte Eigentumsstruktur geschützt, aber diese ist natürlich im Rahmen einer offenen Verfassung änderbar. Es besteht kein Schutz gegen die Änderung der Verfassung, und wie das Beispiel der Annahme des Rothenturm-Artikels gezeigt hat, können damit ziemlich einschneidende Konsequenzen verbunden sein.

Herr Brener hat nochmals den Faktor "Zeit" ins Spiel gebracht. Tatsächlich handelt es sich hier um ein sehr wichtiges Element. Ich darf in diesem Zusammenhang darauf hinweisen, daß das schweizerische Raumplanungsgesetz eine Anpassung der eigentümerverbind- 
lichen Nutzungspläne dann verlangt, wenn sich die Verhältnisse erheblich geändert haben oder nach Ablauf des auf 10 bis maximal 15 Jahre festgesetzten Planungshorizontes. Zum Zeitpunkt des Erlasses des eidgenössischen Raumplanungsgesetzes im Jahre 1979 ging man sozusagen davon aus, daß wir alle 15 Jahre wieder neu über unseren Boden verfügen können. Die Tatsache der Unvermehrbarkeit des Bodens wurde bei dieser Konzeption verdrängt, denn es ist offensichtlich, daß damit die fatale Konsequenz verbunden wäre, immer wieder neu Bauland einzonen zu müssen. Dieses Vorgehen kann jedoch nur in eine Sackgasse münden, denn die Vorstellung einer in 15-Jahres-Rhythmen ablaufenden Bauzonenplanung ist mit der Unvermehrbarkeit des Bodens nicht zu vereinbaren.

Gestatten Sie mir noch zwei Schlußbemerkungen. Wir haben heute nicht über das Thema des Vollzugs gesprochen. Aus den vorgetragenen Überlegungen zur Situation in der Schweiz haben Sie vielleicht den Eindruck gewonnen, mit Bezug auf die Nutzung von Boden und Umwelt sei alles bestens geregelt. Das ist aber in Tat und Wahrheit nicht der Fall, vielmehr gibt es erhebliche Vollzugsprobleme. Diese Problematik haben wir heute ausgeblendet. Es scheint mir aber sehr wichtig zu sein, daß wir uns bewußt werden, daß es nicht genügt, einfach eine rechtstheoretisch befriedigende Antwort zu finden auf die Fragen, die die Nutzung von Boden und Umwelt im Zusammenhang mit der Eigentumsgarantie aufwerfen, sondern wir müssen uns auch um den Vollzug kümmern. Also: Rechtstheorie ja, aber gleichzeitig ist das Augenmerk auf etwas banalere Dinge, wie eben den Vollzug, zu richten. Diese Ergänzung schien mir notwendig, weil der Vollzugsaspekt nach meiner Auffassung heute - auch in der Diskussion - zu kurz gekommen ist.

Die zweite Bemerkung betrifft die Entschädigungsproblematik. Ich habe im Rahmen des Referates aufzuzeigen versucht, daß der im schweizerischen Recht geltende Grundsatz der vollen Entschädigung zu gewissen Härten führen kann. Dabei gilt es zu beachten, daß eben nicht der Gesetzgeber, sondern der Richter feststellt, wann eine sog. materielle Enteignung vorliegt (Die Probleme der formellen Enteignung sind in diesem Zusammenhang von weit geringerer Bedeutung). Nun sind aber die Voraussetzungen, die zur Annahme des Vorliegens einer materiellen Enteignung erfüllt sein müssen, durch das Bundesgericht immer weiter verschärft worden. Das ist an sich aus einer bestimmten Optik verständlich und auch zu begrüßen, nur hat dies umgekehrt gewisse Rückauswirkungen auf den Gestaltungsspielraum der Planungsbehörden: Weil die Grundeigentümer wissen, daß die Hürden für eine Entschädigung aus materieller Enteignung derart 
hoch sind, setzen sie alles daran, ihre privatnützigen Eigentümerinteressen im Rahmen der Nutzungsplanung zu maximieren. Dies führt aber dazu, daß nicht immer das Optimale oder auch nur das Zweckmäßige erreicht werden kann. Es ist deshalb zu fragen, ob nicht allenfalls vermehrt über die Abschöpfung von Planungsmehrwerten ein Ausgleich der Interessen erzielt werden könnte. Ein tieferes Ansetzen der Hürden bei der materiellen Enteignung bei gleichzeitiger Koppelung mit der Abschöpfung von Planungsmehrwerten könnte Spielräume eröffnen für eine optimalere Raumplanung, für eine sozialverträglichere Nutzung der Umweltmedien und ganz allgemein die Herstellung einer optimalen Konkordanz zwischen den verschiedenen angesprochenen Interessen bei der Nutzung von Grund und Boden erleichtern. Vielen Dank.

Ehlers: Meine Damen und Herren, ich habe aus der Diskussion viel gelernt und bin insbesondere auch für Kritik und Ergänzungen dankbar. Ich denke, Sie haben Verständnis dafür, daß ich nicht auf alles eingehen kann.

Zunächst sei kurz aufgegriffen, daß sich aus der Sozialbindungsklausel selbstverständlich abgestufte Bindungswirkungen ergeben. Es macht einen Unterschied, ob das "kleine" oder das "große" Eigentum betroffen ist. In Naturschutzgebieten gelten strengere Regeln als in Landschaftsschutzgebieten, in Kernzonen härtere Maßstäbe als in Pufferzonen usw.

Herr Steinberg hat nochmals die Rolle des Gesetzgebers und die besondere Bedeutung des Gesetzes herausgestellt. Dies gibt mir Gelegenheit, darauf hinzuweisen, daß es durchaus einen inhaltlichen Unterschied ausmacht, ob wir eine Problemstellung unter der Überschrift des Art. 14 Abs. 1 und 2 oder des Abs. 3 GG diskutieren. Geht man von der Ebene der Absätze 1 und 2 aus, wird der Blick von vornherein auf die vielfältigen Gestaltungsmöglichkeiten des Gesetzgebers gelenkt. Die Leistung eines finanziellen Ausgleichs ist nur eine denkbare Variante unter mehreren anderen. Bei der Enteignung kommt nur die Entschädigung als Rechtsfolge in Betracht. Nun darf zwar auch die Enteignung nur ultima ratio sein. Hinzu kommt aber, $\mathrm{da} ß$ an die Enteignung strengere Anforderungen als an die Beschränkung von Eigentumspositionen zu stellen sind, weil die Enteignung die Eigentumsordnung durchbricht, d.h. Ausnahmecharakter haben muß. Der Begriff „Wohl der Allgemeinheit“ i.S.d. Art. 14 Abs. 2 GG ist daher nicht identisch mit dem Begriff "Wohl der Allgemeinheit" i.S.d. Art. 14 Abs. 3 GG. 
An Herrn Sachs gewendet: Es gibt Entziehungsakte, welche die weiteren Voraussetzungen der Enteignung nicht erfüllen. Bei der gesetzlichen Regelung solcher Entziehungsakte handelt es sich um Schrankenregelungen. Herrn Hoffmann-Riem kann ich nur zustimmen. Die potenzierten und summierten Gefährdungen bzw. Synergieeffekte sehe ich auch. Der Gesetzgeber ist aufgerufen, dem Rechnung zu tragen.

Wie nicht anders zu erwarten war, wurde die Frage der Baufreiheit kontrovers behandelt. Herr Oldiges und Herr Breuer haben sich hierzu unterschiedlich geäußert. Herr Oldiges will ein Grundrecht auf Baufreiheit anerkennen, während ich nur die Institutsgarantie des Eigentums bemüht habe. Dahinter verbirgt sich ein schwieriges Problem, das sich in der Kürze der Zeit nur schwer darstellen läßt: nämlich die Frage, ob sich Inhalt und Schranken des Eigentums materiell unterscheiden lassen. Ich habe dazu bereits einiges in meinem Referat gesagt. Geht man davon aus, daß es keine unbegrenzte Freiheit gibt und Art. 14 GG von vornherein nur das schützt, was die Gesamtheit der Gesetze hergibt, muß man m. E. ein Grundrecht auf Baufreiheit ablehnen. Das heißt natürlich nicht, daß der Gesetzgeber nach Belieben verfahren darf. Er bleibt an die Vorgaben des Art. 14 Abs. 1 GG gebunden. Damit bin ich keineswegs bei der Konzeption von Herrn Breuer. Ich habe nicht nur, um mich abzusichern, anders formuliert, Herr Breuer, sondern glaube, daß uns einiges in diesem Punkt trennt. Konstruiert man die Bebauungsbefugnis rein öffentlichrechtlich, läßt sich nur schwer begründen, warum sie dem Schutz des Art.14 GG unterfallen soll. Üblicherweise werden vermögenswerte Positionen des öffentlichen Rechts ja nur als Eigentum i.S.d. Art. 14 GG angesehen, wenn sie im Zusammenhang mit einer Leistung stehen. Eine Leistung des Bauherrn ist bei dem Erlaß von Bebauungsplänen und Baugenehmigungen aber nicht ersichtlich. Stellt man auf die Ausnutzung der Baugenehmigung ab, überzeugt das nicht, weil ein einträgliches tatsächliches Handeln der Bürger nicht dazu führen kann, daß eine Position in den Schutz des Art. 14 GG einrückt. Im übrigen müßten bei einem Abstellen auf das Ausnutzen auch alle anderen ins Werk gesetzten öffentlich-rechtlichen Gewährungen wie z. B. die Subventionen - dem Schutz des Art. 14 GG unterfallen. Mit Herrn Friauf möchte ich aber davor warnen, den Kreis der von Art. 14 GG erfaßten Rechte des öffentlichen Rechts beliebig zu erweitern. Andererseits meine ich aber zugleich, daß wir hinter den Schritt, den wir insoweit erreicht haben, nicht zurückgehen sollten.

Wenn ich Herrn Oldiges richtig verstanden habe - ich bin nicht sicher, ob dies der Fall ist -, vertritt er die Auffassung, daß es sich bei 
den planerischen Herabzonungen gem. $\$ 42$ BauGB nicht um einen Fall der Inhalts- und Schrankenbestimmung, sondern der Enteignung handelt. Dann müßte man m. E. aber auch die Konsequenz der Verfassungswidrigkeit ziehen, weil die $\$ \$ 39 \mathrm{ff}$. BauGB nicht die Zulässigkeit, sondern nur die Rechtsfolge regeln.

Große Probleme wirft die von Herrn Breuer angesprochene Kumulation von Belastungen auf. Die Landwirtschaft sieht sich heute zahlreichen umwelt- und wirtschaftsrechtlichen Regelungen ausgesetzt. $\mathrm{Zu}$ Recht ist auf das EG-Recht hingewiesen worden - genannt seien nur die Quotenregelungen. Dementsprechend wird dem Gesetzgeber eine schwierige Prüfung abverlangt. Er muß vor dem Hintergrund der bereits bestehenden Belastungen jede neue Inpflichtnahme auf ihre Verhältnismäßigkeit hin überprüfen. Was von der Freiheit insgesamt übrigbleibt, muß den Namen Eigentum noch verdienen.

Sehr viele Beiträge haben sich mit der Nutzung der Luft beschäftigt. Ich bin zunächst vom geltenden Recht ausgegangen und habe mit Bedacht von einer Nutzung der Luftsäule über dem Grundstück des Eigentümers und nicht der Nutzung der Luft schlechthin gesprochen. Das Recht zur Nutzung der Luftsäule ist nach $\$ 905$ BGB und den Vorschriften des Bundesimmissionsschutzgesetzes nicht aus dem Schutz des Grundeigentums herausgenommen worden. Eine andere Frage ist natürlich, ob der Gesetzgeber dies anders regeln könnte. Die Herren Steinberg, Murswiek, Wieland und Hoffmann-Riem haben dies bejaht und die Meinung vertreten, der Gesetzgeber sei nicht gehindert, die Nutzung der Luft allein einem Bewirtschaftungsermessen der Verwaltung zu unterstellen. Mit Herrn Friauf bin ich skeptisch. Man könnte die vorgebrachte Argumentation dann unter Umständen auch auf die Nutzung des Bodens übertragen, weil - wie Herr Zacher zu Recht bemerkt hat - ja auch der Boden ein knappes, nicht vermehrbares Gut ist. Ich möchte aber daran erinnern, daß bei Zugrundelegung meiner Ausführungen dem Grundeigentümer die Nutzung der Luftsäule nur bis zu einer gewissen Höhe verfassungsrechtlich garantiert wird. Was Herr Wieland und Herr Murswiek vor Augen hatten, ist die Luftverschmutzung durch die Industrie. Das ist eine Frage, ab welcher Höhe die Nutzung der Luftsäule gekappt werden darf. Das Bewirtschaftungsermessen darf jedenfalls nicht sozusagen bei Null einsetzen.

Anders als Herr Frotscher meine ich, daß die Luft nicht schlechthin als öffentliche Sache angesehen werden kann. Partiell mag etwas anderes gelten - etwa soweit es um die Nutzung der Luftsäule über öffentlichen Straßen und Wegen oder eine Nutzung im Sinne des Luftverkehrsgesetzes geht. 
Ich wollte an sich noch auf weitere Diskussionsbeiträge eingehen, höre aber, daß die Zeit zu knapp geworden ist, und möchte daher zum Schluß kommen. Art. 14 GG gilt allgemein als schwieriges Grundrecht. Die Beschäftigung mit dem Thema hat mir gezeigt, daß dieser Ruf zu Recht besteht. Dennoch hoffe ich, daß es Ihnen heute nicht so ergangen ist wie jenem berühmten amerikanischen Studenten, der gesagt haben soll: „Als ich nach Harvard kam, war ich sehr verwirrt. Als ich Harvard verließ, war ich immer noch sehr verwirrt - aber auf einem viel höheren Level.“ Vielmehr würde ich mir wünschen, daß Diskussion und Vorträge dazu beigetragen haben, mehr Klarheit in dem einen oder anderen Punkt zu erzielen. Vielen Dank.

Rill: Zuerst eine Klarstellung. Herr Pitschas hat mich mißverstanden. Ich habe nicht behauptet, daß das Grundrecht auf Leben wie auf Unverletzlichkeit des Eigentums mit der Atomstromerzeugung überhaupt nichts zu tun haben. Ich habe nur behauptet, daß die Grundrechte auf Leben und Unverletzlichkeit des Eigentums in der Frage, ob überhaupt Atomstrom erzeugt werden darf, neutral sind. Wir hatten ursprünglich eine Rechtslage in Österreich, die die Erzeugung von Strom aus Atomkraft nicht verbot. Kein Mensch hat moniert, daß das dem Grundrecht auf Leben widerspricht. Jetzt haben wir ein Atomsperrgesetz, ohne daß deshalb die Eigentumsgarantie verletzt wäre. Im übrigen sind die Grundrechte selbstverständlich nicht neutral. Erwarteterweise ist meine Position, Art. 5 entstehungszeitlich zu interpretieren, angegriffen worden. Eine archaische Idylle habe ich deshalb aber nicht gezeichnet. Zur Orientierung an der Entstehungszeit muß ich folgende grundsätzliche Bemerkung machen. Ich meine, Rechtsvorschriften werden durch die Änderung von gesellschaftlichen Verhältnissen und Wertungen in ihren Sinngehalten nur dann verändert, wenn diese gesellschaftlichen Wertungen in neuen Rechtsvorschriften einen Ausdruck gefunden haben, die eben den älteren Rechtsvorschriften, sei es auch nur teilweise, derogieren, oder wenn diese Rechtsvorschriften auf solche Entwicklungen in der Gesellschaft verweisen. Das Grundrecht aus 1867 ist trotz mehrfacher Verfassungsübergänge auch heute geltendes Verfassungsrecht, weil es bei keinem Übergang eine Verfassungsmehrheit für ein neues Eigentumsgrundrecht gegeben hat. Insbesondere die ideologischen Gegensätze unter den politischen Kräften haben das verhindert. Ich frage mich, nach welchen Gesichtspunkten soll ich heute den Art. 5 oder sonst eine Bestimmung der Verfassung modern auslegen. So wie es die Grünen mit großer Überzeugung meinen oder wie es die Vertreter des Arbeitgeberverbandes mit Emphase vortragen? Im übrigen habe ich 
ausdrücklich gesagt, daß der Gesetzesvorbehalt des Grundrechts aus 1867 ein offener Gesetzesvorbehalt ist und für viele mögliche Auffassungen von dem, was das öffentliche Wohl ist, Platz läßt. Ich sehe denn auch in der bisherigen österreichischen Umweltgesetzgebung kein grundlegendes eigentumsgrundrechtliches Problem. Auf Einzelfragen will ich nicht eingehen. Was die Nutzung der Luft oder die Nutzung des Grundwassers anbelangt, sehe ich keinen Grund, diese aus der Eigentumsordnung auszunehmen. Ich meine, daß die Beschränkungen der Nutzung dieser Medien abgewogen werden müssen mit den individuellen Interessen der Eigentümer, das ist eben Eigentumsgarantie. Ich glaube allerdings, daß die Möglichkeiten, den Wünschen des Umweltschutzes Rechnung zu tragen, nach österreichischem Verständnis hinreichend groß sind. Außerdem müssen Sie die unterschiedliche Ausgangslage bedenken. In der Bundesrepublik Deutschland ist die Eigentumsgarantie sehr lange von Art. 14 Abs. 3 GG her aufgezogen worden. Daher steht die Entschädigungsproblematik stark im Vordergrund. In Österreich ist das nicht der Fall und wird es - so glaube ich - auch nicht sein, wenn der Verfassungsgerichtshof, was ich ja hoffe, der richtigen Auffassung der Lehre folgt und die These aufgibt, daß Enteignungen nicht zu entschädigen sind. Damit schließe ich. Ich danke für das Interesse, das Sie meinen Ausführungen entgegengebracht haben.

Vorsitzender: Meine Damen und meine Herren, es ist ausgiebig, substantiell und sehr gehaltvoll diskutiert worden, wie das der Problematik dieses Themas m. E. auch angemessen war. Es war nicht leicht, lassen Sie mich diesen einen Satz noch sagen, die vielen Diskussionsbeiträge am heutigen Nachmittag angemessen unterzubringen. Ich bitte um Nachsicht, wenn der eine oder andere in eine für ihn lästige "Warteschlange" geraten ist, aber ich meine, der Umstand, daß Sie fast alle bis zum Schluß hier im Saal geblieben sind, hat es leichter gemacht, diese Last des Wartens zu ertragen. Meine Damen und Herren, die Beiträge, die hier vorgetragen wurden, waren aus meiner Sicht alle sehr wertvoll, sehr substantiell, egal an welcher zeitlichen Stelle sie hier plaziert werden konnten. Im Druck wird dieser zeitliche Umstand dann auch nicht in dieser Gewichtung zum Ausdruck kommen. Ich darf mich nun zum Abschluß bei den Referenten ganz herzlich bedanken, auch dafür, daß Sie sich in der Diskussion so zurückgehalten haben, was die Inanspruchnahme der zeitlichen Ressourcen anbelangt. Ich bedanke mich aber auch bei Ihnen für die Diskussionsbeiträge und für die Teilnahme an der Diskussion. Ich darf nunmehr den fachlichen Teil schließen. 
Bachof: Meine Damen und Herren Kollegen, es ist üblich, daß dem Vorstand am Ende der zweiten von ihm gestalteten Jahrestagung der Dank für seine Tätigkeit ausgesprochen wird, und als das älteste anwesende Mitglied fühle ich mich dazu berufen. Zwar hat Herr Denninger dem Vorstand schon in der Mitgliederversammlung gedankt; aber erstens waren damals viele Mitglieder noch nicht anwesend, und zweitens gibt es ein Sprichwort „Man soll den Tag nicht vor dem Abend loben“. Ich meine freilich, auch nach dem heutigen Tag haben wir keinen Grund, das Lob irgendwie einzuschränken, ganz im Gegenteil! Was die Tagung selbst betrifft, so hat Herr Ossenbiuhl schon alles Notwendige gesagt, ich will es nicht wiederholen. Er hat festgestellt, diese Tagung sei nicht nur eine gute gewesen, sondern eine ganz besonders hervorragende. Ich kann das im Vergleich von nunmehr 40 unserer Tagungen, an denen ich teilgenommen habe, nur unterstreichen. Dem Dank habe ich nur eines noch hinzuzufügen, was noch nicht gesagt worden ist: Es ist mit Recht bedauert worden, daß angesichts der wachsenden Zahl unserer Mitglieder die Chance jedes einzelnen, um ein Referat gebeten zu werden, immer geringer wird. In dieser Hinsicht hat der scheidende Vorstand, im Rahmen der durch die derzeitige Gestalt unserer Tagungen beschränkten Möglichkeiten, doch einiges bewirkt. Es war das erste Mal, daß an den beiden Haupttagungen - also ohne Berlin - zusammen nicht nur 8 oder 9 , sondern 11 Referate gehalten werden konnten. Und zwar, was ich bewundert habe, ohne daß wir dadurch in Zeitnot geraten wären. Das war also hervorragend organisiert. Zu loben ist auch die Zeitdisziplin, welche die Referenten eingehalten haben; darauf hatte der Vorstand vermutlich vorbeugend hingewirkt. Nicht so gut stand es freilich mit der Zeitdisziplin vieler Diskussionsteilnehmer. Der neue Vorstand möchte, wie seine zwei heute anwesenden Mitglieder mir gesagt haben, insoweit für eine Änderung sorgen. Ich kann nur hoffen, daß ihm das gelingt und daß er im übrigen unsere Vereinigung mit dem gleichen Erfolg leiten möge wie der scheidende Vorstand. Diesem nochmals herzlichen Dank, und dem neuen Vorstand viel Glück! 
